\title{
The Burrowing Barnacles (Cirripedia: Order Acrothoracica)
}

\section{History}

The study of the order Acrothoracica began in 1849, when Hancock discovered in shells of the gastropod Fusus and Buccinum a highly modified barnacle which he named Alcippe lampas. Darwin placed Alcippe in the Lepadidae very close to Alepas and Anelasma, although he recognized the great similarity to his Cryptophialus. For the latter he established a new order, the Abdominalia (1854). Noll (1872b) placed Alcippe with Cryptophialus in the Abdominalia. In 1905 Gruvel noticed the misconception upon which the name of Abdominalia was based, i.e., the cirri on the terminal segments of the body being of a thoracic nature rather than abdominal appendages, as Darwin had erroneously assumed. Gruvel changed the name Abdominalia to Acrothoracica and placed within this new order the genera Alcippe, Cryptophialus, Kochlorine Noll (1872a), and Lithoglyptes Aurivillius (1892). Norman (1903) noticed the synonymy of Alcippe with Blyth's genus of birds and changed the name to Trypetesa, although many subsequent workers failed to notice this. Berndt (1903a, 1903b, 1907b) and Kuhnert (1934) have reported on the anatomy and development of these animals. Additional genera have been described and named Weltneria Berndt $1907 \mathrm{~b}$, Berndtia Utinomi 1950a, Balanodytes Utinomi 1950b, Chytraea Utinomi 1950c, Rogerella Saint-Seine 1951, Zapfella Saint-Seine 1954, Simonizapfes Codez 1957, and Brachyzapfes Codez 1957. The fossil form-genus Nygmites Mägdefrau (1937) includes at least one species (N. sacculus) which is considered to be an acrothoracican, anticipating Zapfella. 


\section{Specimen Deposition}

The following museums have been chosen as major depositories of acrothoracican material. Under each species description the depositories for that species will be abbreviated as indicated in the following schedule. The name of the individual most instrumental in assisting me at each institution and the one to whom the material was sent also is included.

In addition to these major depositories, about one hundred institutions were sent a standard set of three species of acrothoracican cirripeds: Weltneria spinosa, Kochlorine floridana, and "Cryptophialus" melampygos (see page 118). These institutions are too numerous to mention individually. The sets were bulk-labeled, so local fractioning into five sets and redistributing is expected.

Aust Australian Museum, College Street, Sydney, N.S.W., Australia; Elizabeth C. Pope.

BA Museo Argentino de Ciencias Naturales "Bernardino Rivadavia", Avda. Angel Gallardo 470, Buenos Aires, Argentina; Elena Martinez Fontes.

Belg Institut Royal des Sciences Naturelles de Belgique, Rue Vautier, 31, Brussels 4, Belgium; W. Adam.

BPB Bernice P. Bishop Museum, 1355 Kalihi St., Honolulu, Hawaii 96819; Yoshio Kondo. Accession number 7246, and catalog numbers B460 to B465.

Brit British Museum (Natural History), Cromwell Road, London, S.W. 7, England; J. P. Harding, Keeper of Zoology.

CA California Academy of Sciences, Golden Gate Park, San Francisco, California 94118; Department of Invertebrate Zoology; Allyn G. Smith.

Dublin National Museum of Ireland, Kildare Street, Dublin, 2, Ireland; Colm O'Riordan, Natural History Division. Catalog numbers NMI.11.1967/ 1 to 17 .

Mex National University of Mexico, Cuidad Universitaria, Mexico City, Mexico; Instituto de Biologia; Llamas Flores. Catalog numbers: IBUNAM $022468-1$ to 20 ; $090468-1$ to 6 .

Paris Museum National d'Histoire Naturelle, 61, rue de Buffon, Paris Ve, France; Laboratoire de Zoologie; J. Forest.

Seto Seto Marine Biological Laboratories (of the University of Kyoto), Sirahama, Wakayama-ken, Japan; Huzio Utinomi.

SFSC San Francisco State College, San Francisco, California 94132; Department of Marine Biology.

SIO Scripps Institution of Oceanography, University of California, La Jolla, California 92038; William A. Newman.

UCT University of Cape Town, Cape Town, Cape Province, South Africa; Zoology Department; John Field.

USNM United States National Museum, Washington 25, D.C.; Marine Invertebrates; Fenner A. Chace, Jr. Catalog numbers: 122603 to 122629 and 123331 to 123334 . 
Vict

National Museum of Victoria, 284-321 Russell Street, Melbourne, Victoria, Australia; Edmund D. Gill. Catalog numbers: J-186 to J-192.

\section{Acknowledgments}

It is a pleasure to acknowledge the kind consideration and assistance offered to me by the institutions and individuals listed above under the subject of Specimen Distribution. In addition, the following individuals and institutions have been most helpful:

Australia: John Yaldwyn and Donald McMichael, Australian Museum; Robert Endean and the Great Barrier Reef Committee.

France: Dr. B. Salvat and Dr. F. Salvat, Muséum National d'Histoire Naturelle, Paris.

Great Britain: R. Bassindale of Bristol; D. J. Crisp of Menai Bridge Laboratories; H. Barnes of Millport, Scotland.

Hong Kong: Dennis Hill, University of Hong Kong.

ItALY: Stazione Zoologica di Napoli (NSF Table Award).

JAPan: Tadeshige Habe, National Science Museum, Tokyo; S. M. Shiino, Mie Prefectural University, Tsu.

LiBeria: Frank Tichy and Dr. Joshna of the University; Dr. and Mrs. William Winnett; Russell Riley.

New Zealand: Elizabeth Batham, and the staff of the Universities of Canterbury, Otago, and Auckland.

Nigeria: Alice O'Grady.

Panama: Stewart and Claire Jadis, Canal Zone Police; Joe Becker, U.S. Army.

Philippines: The National Museum.

Singapore: D. S. Johnson of the University, and Eric Alfred of the National Museum.

South Africa: Mr. and Mrs. Lawrence Meiring of Cape Town; Mrs. C. M. Connolly of Fishoek.

Trust Territories of the Pacific Islands: The Commissioners and their staffs; Peter and Ann Wilson; the Robert Owens, George Hagiwaras, and Peter Hills.

United States: Ensign and Mrs. Gaylord Galiher, USN; Mr. and Mrs. Henry Scott at Addis Ababa, Ethiopia; Leo Hertlein at the California Academy of Sciences; C. G. Bookhout and Lawrence McCloskey of Duke University Marine Laboratories; Tom Hopkins of New College and Cape Haze Marine Laboratories, Sarasota, Florida; University of California at Santa Barbara; University of Hawaii Marine Laboratories; Dr. Willard D. Hartman of the Peabody Museum, Yale University.

This work was begun as a thesis for the degree of Doctor of Philosophy in Zoology at the University of California at Berkeley under the supervision of Dr. Cadet Hand. Substantially furthered by a sabbatical leave for one year from San Francisco State College, it was completed under a five-year grant for a study on the reproduction 
of barnacles from the National Institutes of Health, United States Public Health Service, number GM-09953.

Special thanks are due my wife, Jean, who typed the manuscript and was helpful in many other ways, and to William A. Newman who gave suggestions on the manuscript.

\section{Abbreviations Used in the Figures}

\begin{tabular}{|c|c|c|c|}
\hline $\mathrm{AN}$ & Anus & MAN & Mandible \\
\hline ANT & Antennule & MAN.P & Mandibular palp \\
\hline $\mathrm{AP}$ & Aperture in the shell & $\mathrm{MAX}_{1,2}$ & Maxilla (first and \\
\hline APO & Apodeme & & second) \\
\hline ATR & Atrium of oviduct & $\mathrm{MC}$ & Mouth cirrus \\
\hline BP & Body process & MP & Mouthparts \\
\hline $\mathrm{CA}$ & Caudal appendage & $\mathrm{NE}$ & Naupliar eye \\
\hline $\mathrm{CC}$ & Comb collar & $\mathrm{O}$ & Ovary \\
\hline $\mathrm{CE}$ & Cyprid eye & $\mathrm{OK}$ & Orificial knob \\
\hline $\mathrm{CF}$ & Caudal furca & $\mathrm{OP}$ & Operculum \\
\hline $\mathrm{CM}$ & Mantle cavity & PB & Protuberant button \\
\hline EMF & External mantle flap & $\mathrm{PE}$ & Penis \\
\hline $\mathrm{ESO}$ & Esophagus & $\mathrm{PO}$ & Orificial palp \\
\hline $\mathrm{G}$ & Gizzard & $\mathrm{RC}$ & Retractor corporis \\
\hline $\mathrm{H}$ & Head & & muscle \\
\hline HD & Horny disk & RO & Retractor orificii \\
\hline HK & Horny knob & & muscle \\
\hline 1 & Intestine & $\mathrm{S}$ & Sperm \\
\hline IG & $\begin{array}{l}\text { Infra-esophageal } \\
\text { ganglion }\end{array}$ & SG & $\begin{array}{l}\text { Supra-esophageal } \\
\text { ganglion }\end{array}$ \\
\hline A & Labrum & STO & Stomach \\
\hline LAR & Larva & SV & Seminal vesicle \\
\hline $\mathrm{LB}$ & Lateral bar & $\mathrm{TC}$ & Thoracic cirri \\
\hline LBT & Lateral bar termina- & TE & Testis \\
\hline & tion & YO & Yellow organ \\
\hline
\end{tabular}

Detailed labels on figures 1 and 23 .

\section{Methods}

When a specimen of the order Acrothoracica is found, it has to be removed from the shelly matrix into which it has burrowed before it can be studied in detail. Often the specimen itself will not be seen from the surface of the shell. The females can pull into the burrow for 
a considerable distance, especially upon drying, and empty-appearing tapered slits in all shelly material should be examined, using the following procedures. Note is made of the shape of the burrow in the shell before all cirripeds are removed. Individual identification is indicated as more than one species of cirripeds can occupy a single shell or coral fragment. It is standard practice to photograph the slit with the photographic axis perpendicular to the surface of the shell, and with a small piece of graph paper as a scale in the field of focus, for later reference if the specimen contained within the slit is a new species or is otherwise of special interest. If enough specimens are available, study should be made of the internal shape and size of the burrow, the presence of males on the wall of the burrow, and the extent of the cemented attachment area of the female. This is best done by chipping away one wall of the burrow and removing the female without the aid of acid, although many useful observations can be made after the shell has been decalcified.

It will be noted under the section on the Burrow (page 9) that the shape and size of most species varies more within some species than between several genera, so at present the burrow shape is a useful taxonomic char cteristic only in distinguishing between families.

Most of the shelly material should be decalcified in a weak acid solution to aid in the removal of the specimens. If the specimens are obtained alive, they can be nicely fixed and the shell decalcified at the same time by placing them in a large quantity of Bouin's fluid. If the specimens are processed in formalin or alcohol, additicnal acid can be added at intervals to decalcify the shells. If the specimens are dried, they can be placed in 70-percent ethyl alcohol with 2-percent $\mathrm{HCl}$. The alcohol preserves the specimens when they are decalcified; but 10-percent formalin is satisfactory, and even water can be used if the barnacles are removed quickly.

There is no special concentration of acid to use. Specimens have been placed in grossly different concentrations of hydrochloric acid for days without ill effects, and other acids work with similar ease. Carbon dioxide bubbles form below the specimen and lift the specimen from the burrow when the shelly matrix is sufficiently decalcified. These bubbles could perhaps damage the specimen if they are formed too violently. It has been found that an initial concentration of 1 - to 2-percent $\mathrm{HCl}$ is most effective, with $\mathrm{HCl}$ added at intervals to keep the bubbling action at about the initial level.

Most specimens will not be completely freed from the shelly matrix, and must be hunted out and removed by gently pulling or tearing apart the decalcified matrix. The dark red coloration on the barnacles, which is retained in most species through the above treatment, aids in locating them; dental tools or watchmaker's forceps aid in their 
removal. The specimens are transferred to a neutral solution similar to their decalcification solution, and then transferred to a preserving solution.

Most of the taxonomic characteristics of the burrowing barnacles are associated with chitinous structures. These chitinous structures are seen most clearly by removing the soft parts with $\mathrm{KOH}$; this can best be done by treating the specimen in a solution of about 10-percent $\mathrm{KOH}$ in a very small beaker set within a larger beaker holding a shallow layer of boiling tap water. Such a double boiler will prevent the boiling of the $\mathrm{KOH}$ and the violent bubbling action which might force the specimen out of the beaker and onto the hot plate. It is especially useful when dealing with dried specimens, which cannot be effectively treated in any other way. A disadvantage of this treatment is that the soft ventral body processes become obscured as deflated wrinkled areas. Thus, the utility of the ventral body processes for taxonomic purposes is reduced by treatment with $\mathrm{KOH}$. Since most of my descriptions are based on $\mathrm{KOH}$-treated material, I am specifically warning against drawing any conclusions about the presence or absence of these structures, or their detailed anatomy.

Once the heating in the $\mathrm{KOH}$ has progressed to the point where the cirriped is almost transparent and can hardly be seen, it should be removed from the $\mathrm{KOH}$ with a large-bore tube or medicine dropper, and transferred to clear, cool, tap water. From the tap water it can be transferred to alcohol for dehydration if desired, or directly to glycerin for clearing.

Since the specimens are mere "ghosts" of their former selves and are extremely delicate, they should not be handled with pins or forceps, but only with pipetted fluids. It is desirable to transfer the specimen with a quantity of glycerin onto a depression slide, where the cover slip will not depress and distort it. After drawings or photographs are made in this nearly original inflated condition, the specimen can again be transferred to a plain microscope slide. The cover slip can be supported by fragments of cover slips to allow it to settle gently on the specimen, flattening it by stages, to give a clear view of the details of the anatomy without excessive distortion. Finally, the glass fragments can be removed and the cover slips placed on the specimen itself.

Dissection of such minute specimens is largely a matter of the separation and realignment of rather large parts of the specimen. Routine procedure includes the placing of a pin in the sharp bend of the thorax and with a posterior traction drawing the thorax out through the dorsoposterior wall of the mantle cavity. This frees the thoracic cirri for more detailed study, and also draws them away from the mouthparts which remain in the head region. After examination 
the apertural lips or opercula are separated from the head and flattened separately if possible. The mouth field should be examined from several angles, which sometimes can be accomplished by rolling the head area by moving the cover slip, or by carefully lifting and redepositing the head several times.

If fresh or living material is available, studies of the musculature and other organ systems can be undertaken by staining, clearing, and mounting in balsam, and by making serial sections which are stained and examined.

Any males found associated with the females should be examined in situ, before heating in $\mathrm{KOH}$ if possible, and notes should be taken on their position and penetration of the female. They should then be removed and studied separately in glycerin, or stained and mounted in balsam.

Larvae usually are treated along with the female, using the female as a transfer vessel.

Trypetesa lateralis has been kept alive in shallow dishes of sea water in a refrigerator for over a year. Although no noticeable growth occurred under these conditions, the females reacted quickly to a touch by withdrawing deeply into the burrow.

The first few attempts at keeping the barnacles alive in the laboratory involved leaving them with their commensal hermit crabs. It soon became apparent that the barnacles were hardier than the hermit crabs, and did not require hermit crabs in order to survive. Separate vessels were allowed to evaporate to two-thirds volume, before distilled water was added to the original level, without killing the barnacles. Temperature fluctuations did not seem as deleterious to the barnacles as to the crabs. Yet the crabs can be found in protected littoral zones where the barnacles are not found.

\section{Orientation}

Orientation in barnacles is made difficult by their curled adult configuration. It has been said that they stand on their heads and kick food into their mouths with their feet. This is figuratively true with both the orders Thoracica and Acrothoracica. From evidence of comparative anatomy and embryology, the following orientation terms can be designated, as they pertain to the order Acrothoracica. All descriptive matter pertains to the female unless otherwise stated. The area where the mantle is cemented to the burrow is dorsal, except in Trypetesa lateralis which is cemented on the right side. The ventral surface of the body extends from above the mouthparts onto the inner curvature of the thoracic cirri. The caudal appendages, 
if present, are on the posterodorsal end of the thorax. Anterior is toward the head, posterior toward the terminal cirri.

\section{Segmentation}

Segmentation in the Acrothoracica has been thoroughly covered by Darwin (1854), Berndt (1903a), Gruvel (1905), and Utinomi (1957).

The only information that should be added here is that the occurrence of six pairs of cirri plus caudal appendage in Weltneria has eliminated all doubt as to the homology of cirri between the Acrothoracica and the Thoracica. The Acrothoracica can possess the same cirral complement as the Thoracica. The loss of cirri is probably at the anterior end of the terminal set of cirri, as evidenced by the retention of a caudal appendage in Lithoglyptes and Kochlorine, with four and three pairs of terminal cirri, respectively, and the tendency for the first pair of terminal cirri to be reduced.

\section{Common Names}

There are two words in common English usage which I would like to review at this time. The first word is the common name contraction of the subclass Cirripedia-should it be CIRRIPED or CIRRIPEDE? I will use the former, and urge its general adoption. Dr. James A. H. Murray (1893) lists the following:

CIRRIPED-PEDE. 1828 Stark Elem. Nat. Hist. II. 121 Class IV Cirripeda (Mollusca Cirrhopoda, Cuv.) 1832 Lyell Princ. Geol. II. 108. So loaded with cirrhipeds, and with numerous ova, that all the upper part of its shell is invisible. 1855 Gosse Marine Zool. 1. 168. The bivalve shell is thrown off, and the little cirriped is seen in its true form. 1859 Darwin Orig. Spec. IV (1873) 79. Cirripedes long appeared to me to present ... a case of great difficulty.

Note that Darwin is the first authority listed using the spelling CIRRIPEDE. Even his geological mentor Lyell used the -PED ending! Nevertheless, the spelling has changed over the years. The Shorter Oxford English Dictionary on Historical Principles, edited by C. T. Onions in 1933 (Oxford) also lists the word CIRRIPED -PEDE.

I cannot cite recent references completely because of copyright requirements, but Funk and Wagnalls' Britannica World Language Edition for the Encylopedia Britannica (1956) cites only one spellingCIRRIPED. To compound the confusion, Webster's Third New International Dictionary unabridged (1961) cites it CIRRIPEDE, CIRRIPED, 
while Webster's Collegiate Dictionary (1947, fifth edition) cites only CIRRIPED!

The Latin "pes, pedis," foot, would seem to require a "CIRRIPED" form, but it also could be derived from the French, where the cirripede form would be permissible. A final argument is that, of the dictionaries cited, CIRRIPED was the only form accepted in two, while none cited only CIRRIPEDE.

The next common name to be considered is Barnacle. Dictionaries usually state that this term pertains to members of the order Thoracica only, leaving members of the other orders deprived of common names except those derived from the scientific ones. Yet common usage among the cirripedologists seems to allow such terms as "parasitic barnacles" for the Ascothoracica and Rhizocephala, and "burrowing barnacles" for the Acrothoracica.

Again, let us look at the history of this word. Murray (op. cit., vol. 1888) cites the origin as the goose, not the shell it mythically comes from. Then the term was applied to the pedunculate thoracicans, finally also to the balanoids. Webster's (op . cit., 1961) definition is as follows (brackets mine):

BARNACLE: Any of numerous marine crustaceans constituting the Order [!] Cirripedia, being free-swimming in the larval state but permanently fixed as adults and protected by a calcified shell of several pieces [not good, even for thoracicans], and having usually six pairs of biramous feathery cirri that are modified limbs and are protruded and drawn back with a grasping motion serving to catch the food that floats within reach.

If the use of "barnacle" conjures up images of rough-shelled fouling organisms, what do we do with Alepas? Since this common name has no direct association with the order Thoracica anyway, couldn't we stretch it to include the Cirripedia in general? One advantage of this position is that the use of the common name of "cirriped" would be reduced, if the spelling of this form happens to cause any discomfort.

\section{The Burrow}

The burrow of acrothoracican barnacles provides protection for the soft-bodied animals, which lack shelly plates of their own. These burrows are formed in almost anything calcareous in the sea. The shape of the aperture is typically a tapered slit a few millimeters long and less than a millimeter wide, as viewed from the outside.

The families can be separated by burrow shape. The Lithoglyptidae have burrow apertures in the shape of tapered slits several times longer than wide (fig. 12o, p). The Cryptophialidae have short, almost 
round slits (fig. 33i), while the Trypetesidae have long slits usually bent at the finely pointed end (fig. 34c).

The interior of the burrow generally extends nearly straight down into the shelly material, the exception being the members of the Family Trypetesidae; these are large species in which lateral flattening has taken place. All species are able to extend their cirri from the burrow aperture, but the trypetesids tend to make most of their cirral strokes within the mantle cavity.

The method of forming the burrow is largely by abrasion. This is accomplished by chitinous teeth extending outward from the surface of the mantle more or less distributed over the entire surface, but particularly concentrated in some areas in some species. That abrasion accounts for most of the burrowing is attested by the piles of shell powder lying along the aperture on the surface of the host shell in undisturbed specimens. The mantle teeth are renewed with each molt, providing a fresh set to abrade the calcareous substratum.

The fact that when the larva initially settles it does not bear mantle teeth, together with the lack of production of powdered shell material during initial burrowing, suggests that the initial penetration into the substratum is accomplished by chemical dissolution (cf. Berndt, 1903a, p. 405). Furthermore, the cemented attachment area, needed for a good purchase on the shell to provide a base for moving the mantle and needed for abrasion to be successful, is missing from these first larval penetration stages. The first antennae, with which the cyprid attaches to the shell, are withered and exposed externally, and could not support abrasive movement. No acid or other solvent has been isolated or identified, however.

A pending issue of the American Zoologist is expected to contain the papers presented at a symposium on the penetration of calcareous substrates by invertebrates. Of direct interest will be the papers of Seilacher, and Tomlinson. A recent paper by Turquier (1968) describes the use of carbonic anhydrase in burrowing by Trypetesa nassarioides.

Burrows normally are made in dead shelly material. In mollusks the exterior of the shell is available, especially if the periostracum has been eroded off. The interior of dead shells is also available, although silting and burying of the shell is a problem to the barnacle. This silting problem is solved sometimes by the services of a hermit crab (especially in Trypetesa) which carries the shell around, circulates sea water, and eats a variety of food close to the barnacle. Echinoids are presumed to be dead when burrowed. Corals usually are attacked at the dead bases and wherever the skeleton is exposed, although Berndtia purpurea has been described in living coral (Utinomi, 1950a). 
The cirriped can, at most, be considered a modest shell-weakening pest, and in general does little if any harm to the host. All species of the order collect food without taking from or giving anything of value to the host.

The excavation of the burrow is allometric, with an initial elongation of the slit preceding a deepening and widening. This provides an initial access to the outside with room to manipulate the cirri before the extensive brood pouch and ovarian area are developed. The growth rate is difficult to estimate, and is apparently typical of invertebrates in being largely dependent on temperature and food availability. I have kept Trypetesa lateralis alive in shallow dishes in a cold box for over a year, with no perceptible increase in burrow size.

A major structural element within the burrow is the attachment area, which provides the fulcrum for mantle movement already mentioned. The cement affording the attachment apparently is provided by glands on the dorsal mantle area (cf. Lithoglyptes spinatus Tomlinson and Newman, 1961). The cemented area may be small if the mantle has a conspicuous horny "knob," or large if a horny "disk" is on the mantle. Acid will release the mantle at the point of attachment, but it is not certain whether this involves releasing the cement or destroying the shell surface to which the cement is applied.

It is clear that all species examined are cemented into the burrow, and no species hangs in the burrow by hooks or spines as suggested by some early workers.

\section{The Mantle}

The conspicuous features of the exterior of the mantle include the apertural armament, the teeth, the lateral bars if present, and the cemented horny disk or knob.

The cemented area was just discussed under the subject of the burrow. The mantle, being cemented firmly to the burrow wall, cannot molt in this area. As a consequence, many layers of exuviae build up, becoming "horny" in appearance. Since this cemented area often expands with the growth of the female, the consecutive layers usually are not deposited directly on top of each other, but in eccentric rings with the wider gaps between rings posteriorly. Males often are attached to the margins of this horny disk.

The flattening of this attachment area is, perhaps, a consequence of the inability of the center of the area to continue to abrade the shell, while the edges do continue to abrade. Hence, the otherwise rounded mantle sack usually is flattened in the attachment area. 
The most obvious features of any acrothoracican body, when viewed alive, are the lips of the mantle aperture. The thickened plates are probably homologous and certainly analogous to the occludent margin of the mantle of the thoracicans and can be termed an "operculum." They often are armed with a variety of teeth, spines, hooks, and hairs or bristles. These major structures often are compounded in turn with their own serrations, hairs, teeth, and spines.

In general, a hair or bristle can be defined as a more or less flexible, pointed process ten or more times as long as wide, without additional ornamentation unless it is plumose, when it will have extremely fine hairs along its length. A spine is stouter, with a single major point, but may bear several types of ornamented features, including smaller spines, teeth, or hairs. Teeth usually terminate in more than one point, although the tiny processes scattered around the general mantle surface are called teeth even if some have only one point. Hooks are spines with the distal end curved at least 90 degrees, although the actual curvature often is difficult to estimate.

Some spines (e.g., Lithoglyptes spinatus, L. bicornis?) can be articulated, and fold down into the mantle aperture or outward to project beyond the surface of the shelly host material.

It has already been noted that no acrothoracican hangs in its burrow by the use of these hooks or spines. They are apparently for defense against invasion into the mantle cavity or into the burrow. No foreign animal species has ever been reported with a living female in either the mantle cavity or the burrow. Those species without major hooks and spines on their mantle have opercula which fit tightly into the burrow aperture, closing the connection of the burrow to the outside.

An orificial knob is seen in some species as a raised hillock, often bearing additional spines, just dorsal to the aperture. The function of this armed knob apparently is to close the area of the burrow aperture not directly occluded by the opercular lips. This arrangement is necessary where the attachment area begins near the surface of the shell and extends posteriorly along the horny knob or disk, for the operculum, to have any flexibility in opening, must be removed from this fixed cemented area by at least a little distance. The orificial knob fills the unprotected gap between cemented attachment area and flexible operculum. The calcareous residue from the abrading process often forms an aggregated mass at the attachment end of the aperture that seems to replace the need for an armed orificial knob, and serves as a mechanical barrier against ingress in this critical nonflexible area. In the Cryptophialidae, where the attachment area has been moved down and away from the burrow aperture as the animal matures and where the very small burrow aperture is filled with the 
operculum, there is no trace of an orificial knob or of the aggregated calcified layer.

Fossil acrothoracicans are separated on the presence or absence of a so-called peduncular slit (see section, Fossils, page 134). It is possible that the presence of an orificial knob or of such an aggregated calcified layer would allow a more extensive peduncular slit, more extensive growth away from the attachment area, and hence more flexibility of movement. Rogerella, with an extensive peduncular slit, also has ridges of aggregated shell material still remaining along the edges of the burrow (see fig. 39).

The length of the aperture, used by Aurivillius $(1892,1894)$ as an important diagnostic characteristic, is not readily measured precisely. The opercular plates do not extend for the entire length of the aperture. The ventral end of the aperture is lined internally with the comb collar and ends ventrally perhaps in an orificial velum, or a few small teeth. The dorsal end of the opercular plates are fused together for a short distance, and hence measurements to the dorsal end of the opercular plate are not strictly equivalent to the true apertural length. Nevertheless, since the female usually lies on its side when being observed free of the burrow, and the exact dorsal termination of the aperture is not discernible, and since moving the female into a position where this termination would be visible could cause more distortion, the figures in this work for apertural length are for the straight-line distance from the ventral end of the aperture to the dorsal end of the base of the opercular plates. This will be longer than the true length of the aperture as measured within the animal.

Another striking feature of the mantle exterior is the lateral bars. These are variously developed in different families, reaching their maximum development in the Cryptophialidae.

The more primitive families have lateral, rod-shaped areas reinforced with scale-like chitinous thickenings of the mantle wall, perhaps with associated hairs (fig. 3a). The cryptophialids have well-developed, rolled, chitinous, rod-like bars, with associated ranks of teeth along one or both sides of the bar, and terminating posteriorly in an array of teeth often set on a raised area (fig. 28a).

The major lateral bars are approximately in the middle of each side of the mantle, extending from the aperture about half the distance to the posterior margin. In addition, secondary reinforcing bars of ten are found dorsally, from the apertural area into the cemented disk area.

The reinforcing bars appear to give support to the abrasive teeth studding the mantle surface. If the abrasion of the shell by teeth on a mantle surface is effected by muscles which only can contract, it would be difficult to push outward against the shell. No major muscle masses are associated with these lateral bars, and this supports the 
view that they are involved primarily in holding the mantle outward against the shell.

The inner surface of the mantle generally is smooth, except for the area surrounding the mantle aperture, where hairs and the comb collar usually are found.

The principal structure in this area is the comb collar, which consists of a thin membrane lining the inner surface of the mantle near the aperture, and extending into the aperture itself. The membrane is minutely folded with the anterior or apertural ends dissociated into an extremely delicate row of fringed hairs (fig. 2c). The comb collar extends from one side of the aperture to the other. It may extend along most of the aperture, or be confined to the ventral end away from the attachment end. Often it is folded inward between the paired thoracic cirri, or outward from the aperture as a separate velum, e.g., as described in Berndtia purpurea by Utinomi (1957, p. 7).

In addition to the comb collar, the mantle aperture frequently is guarded by an array of hairs distributed in patches. An internal lateral bar has been described for Balanodytes taiwanus (Utinomi $1950 \mathrm{~b})$.

Another special feature of the mantle interior includes fleshy projections in the genus Trypetesa. Utinomi (1964) describes a series of finger-like processes in T. habei, while Darwin's description (1854) of $T$. lampas, and my description (Tomlinson 1953) of $T$. lateralis describes two internal mantle flaps. These are probably respiratory in nature, and may have something to do with a brood function in the latter two species.

The mantle itself is laced with muscle strands, and contains the ovary in the dorsal portion. These are discussed under the separate headings, Muscular System (page 22) and Reproductive System (page 24).

\section{External Mantle Flap in Trypetesa lateralis}

\section{Penetration and Male Incidence}

An external mantle flap, strongly equipped with boring teeth, appears on mature females of $T$. lateralis. It burrows away from the female in an arc, and finally perforates to the outside of the shell with a very small, slit-shaped opening.

That the perforations are necessary for some process is supported by the great lengths to which the animal will go to establish this perforation to the outside. Flaps two-thirds as long as the entire barnacle are not uncommon for barnacles in some positions within the shell (e.g., within the columella). 
Evidence allying this organ to the sexual process is indicated by the fact that this perforation is not established until full maturity is reached. If it were a vital necessity, one would think that it would be established earlier in development.

It was considered that this flap was associated with the barnacle's lateral orientation, and the presence of large numbers of males under the female. The males line the region of the burrow close to the proximal end of the flap. This would explain the necessity of eventually establishing the opening at the distal end of the flap to provide a flow of fresh water for the males, yet this opening is not required until after the developmental period of the young female. A current of water is maintained through this slit by movements of the mantle within the burrow; this action can be seen readily in living material.

The function of this external mantle flap, a structure unique in Trypetesa lateralis females, has been a subject for investigation since the discovery of the species.

Methods: Many barnacles were collected and measured in the living state (686 Specimens, 250 exceeding $0.3 \mathrm{~mm}$ aperture length). A record was made of the length of the apertural slit of the female barnacle in the shell, the number of barnacles in the shell, and whether an external mantle flap had penetrated to the outer surface of the shell under the barnacle. The shells containing these barnacles were then decalcified in a sufficient quantity of Bouin's fluid to weaken the shell but not to free the barnacle completely. Then the shells were washed with water and again evaluated for length of the slit and presence of the external mantle flap penetration.

The female barnacles were removed carefully and the males attached to the females or to the burrow walls were counted. Frequently the penetration of the flap could best be determined after the female had been removed from the shell.

Inasmuch as the flap would open frequently among bryozoan colonies or serpulid worm cases, the presence of an opening could not always be positively established. Uncertain specimens were not considered in the data.

Results: The results are shown graphically in figure $36 \mathrm{c}$. The numbers of specimens and the relative percentages are given. It can be seen that most of the females whose external mantle flap do not penetrate have no males, and those whose flap penetrates have males.

A few females who have a penetrating flap and do not have a male would be expected, even if a penetrance were required for males to be present, inasmuch as the males may not settle on the female as soon as space is available. The few specimens (four) with males and without a penetrating flap seem unexplainable, but could be temporary or misguided individuals, inasmuch as two of those four males were 
larval forms, and perhaps would not have become permanently established. Of the remaining two males, perhaps tiny worm borings or the odd shape of the burrow could have been responsible for a water passage.

In three instances the external mantle flap hole was sealed by balanoid barnacles or the cases of serpulid worms. In each circumstance there were no males associated with the females, although the females were large and would definitely be expected to possess males.

\section{Water Transport by the External Mantle Flap}

Water is pumped through the hole formed by the penetrance of the external mantle flap to the outside of the shell. It is pumped by the movements of the mantle against the burrow wall. These movements are produced by the stroking of the thorax in the feeding process, corresponding to the beating of the cirri of the thoracicans.

The water is pumped from the outside of the shell in toward the female, and out the main aperture around the lips of the mantle sack. When carmine particles are added to the water they can be seen to move in jerky beats into this hole. When the hole is plugged with excessive carmine particles a cleaning action is employed by forcing water back out through the hole, forcing particles about one-fourth millimeter away from the shell.

With nineteen measurements on three animals at $17^{\circ} \mathrm{C}$, the pumping beats occur $31.2 \pm .2$ times a minute, and pull carmine particles for a distance of $0.25 \mathrm{~mm}$. Between beats the particles are motionless. The average opening to the external mantle flap was $0.44 \times 0.10 \mathrm{~mm}$, giving a minimum volume pumped of $0.011 \mathrm{~mm}^{3}$ per stroke. This is a minimum figure, because the carmine particles are pulled from all directions from $0.25 \mathrm{~mm}$, and travel a greater distance within the hole itself, although this distance would be impossible to determine precisely. With 31.2 strokes per minute, there would be $0.343 \mathrm{~mm}^{3}$ of water per minute passing through the hole.

If there were six males (a high number) with the female, each of $0.008 \mathrm{~mm}^{3}$ volume, in each minute about 7.2 times as much water goes by as their combined volume. The average number of males per female with males, of 305 barnacles, is 1.96 males per accompanied female. This volume of water should be quite sufficient to supply the males with ample fresh sea water. Of course, the female probably uses some of the oxygen for her external mantle flap and the left side of the mantle. 
The beating rates seem to be the result of a feeding action, which can beat at any given rate, or cease completely. It is not a matter of irritation of the animal. The barnacles have been seen stroking after being completely untouched for hours, even days; yet they also have been completely quiescent after equivalent periods of time.

\section{Digestive System and Feeding Mechanisms}

All acrothoracicans collect food in a manner similar to the thoracicans, that is, with a sweeping of a cirral net. Generally the cirral net extends out through the mantle aperture and beyond the burrow, sweeping in a rhythmical manner, in much the same way as thoracican barnacles sweep the water with their cirri. These species are aligned vertically to the surface of the shell, and are equipped with long biramous cirri-much like those of thoracican barnacles. I have observed the following species behave in this manner: Weltneria spinosa, W. hirsuta, Lithoglyptes spinatus, Kochlorine floridana, and Cryptophialus melampygos.

An interesting comparison of the feeding mechanism of these species with the species of the genus Trypetesa can be made. Trypetesa lateralis feeds with regular sweeps inside the mantle cavity and the water currents set up by the sweeping bring food material into the sac and within the area covered by their rather reduced terminal cirri (see Tomlinson, 1955). The shortness of the thoracic cirri makes the formation of a fan-like net of cirri impossible in the genus Trypetesa.

This leads us to the speculation that the shortening of the thoracic cirri is perhaps a modification due to the occasional, somewhat horizontal orientation of most trypetesids in the thin regions of the shell, and to the completely horizontal orientation of $T$. lateralis. A horizontal canting, even though slight, would greatly impair the activity of the rapidly sweeping fan seen in the vertically aligned forms.

Many specimens of some trypetesids ( $T$. lampas, $T$. habei) are oriented in a completely vertical fashion, so the modification of the cirri would be adaptive only to those specimens occupying thinner regions of the shell. Once the feeding mechanism was perfected in primitive trypetesids, the more horizontal orientation of the specialized $T$. lateralis required only the adaptation of a separate water circulation for the males, via the external mantle flap.

Since the terminal cirri are clustered at the posterior end of the thorax (hence the name "acrothoracica") they do not move in relation 
to each other to any appreciable degree, and hence cannot move the food progressively toward the mouth as is done in the thoracicans. Probably for this reason one pair of cirri is isolated near the mouth (hence the name "mouth cirri") and almost certainly serves to remove the food from the terminal cirri by wiping action. Perhaps the comb collar also serves as cirral combs or wipers when it is pressed against the cirri by the mantle operculum. This latter action would not seem to aid in feeding other than to keep the cirri clean. The exception to the function of the mouth cirri described is to be found in the members of the family Cryptophialidae, where those mouth cirri present are reduced to mere stumps with a few hairs. They have instead a well-developed labrum, which extends in a long tongue up to and even beyond the mantle aperture. The labrum is hairy on the ventral surface and lateral margins, and could serve to direct food material to the mouth, once it has been brushed from the terminal cirri.

The mouthparts consist of a pair each of mandibles and first and second maxillae. The former are strongest, with heavy teeth along the cutting edge, and they usually possess fine hairs along the ventral and posterior surfaces and angles. The first maxillae typically have two (or three) strong spines at the anterolateral angle, a pronounced gap or diastema, and an array of finer spines and hairs on the posteromedial angle. A long apodeme connects the first maxilla to a more medial fulcrum.

The second maxillae, placed close together at the posterior end of the mouth field, are soft and rounded with a dense coat of hairs. Haired "keels" often extend from the medial edge of the second maxillae dorsally between the bases of the first maxillae.

The mouth itself is immediately below the chitinized posterior curvature of the labrum, and leads to a dorsally directed muscular esophagus.

The esophagus makes a dorsal bend around a heavy transverse adductor muscle, and then it leads directly into the stomach of all acrothoracicans except the cryptophialids. In the latter a heavy triturating mill, called a "gizzard," directly precedes the stomach.

The stomach is large, glandular, and relatively nonmuscular. It may have one or more digestive glands extending from it.

In the suborder Pygophora a simple tube-like intestine leads to an anus between the terminal cirri on the dorsal side. The suborder Apygophora, represented by the unique family Trypetesidae, does not possess an intestine or anus.

In those acrothoracicans having a pair of caudal appendages, they are uniramous, short, and flank the anus. They were once called anal appendages, and perhaps serve the function of clearing the anal area of debris. Many species are without them, however. 


\section{The Cirri}

The number of cirri is the most important single characteristic in the order Acrothoracica. The new genera and families have not always been established primarily with the number of cirri in mind, but it happens that this is the single most discrete differentiating characteristic of such groupings. Although it may prove that the separation of genera by the number of cirri is not well founded, I have retained it as the most successful method. I would caution the reader to make certain of the number of cirri very carefully, as it is easy to miss a pair when they are only about a millimeter long, usually less than 40 micra wide, and are bunched together in a tight mass. I have erred twice in this myself, and I urge workers in this group to make cirral segment counts, not so much for the segment count itself, but to better insure an accurate cirral count.

Referring again to the segment count, it seems that knowledge of the number of segments is of little value in the identification of the Acrothoracica. Not only are the numbers difficult to ascertain, but are highly variable between the two sides of one animal, and between different animals in the same host. A count, nevertheless, will be given for one side of one animal where possible.

The setation, or the size and distribution of bristles on the cirri, is very characteristic. The setae themselves may be faintly haired, or "plumose." This characteristic is less useful than the size and distribution of the setae on the cirrus, inasmuch as we are now at the limits of resolution of a light microscope.

\section{Feeding Habits of Trypetesa lateralis Females}

The females of the genus Trypetesa have no anus. This deficiency is amplified by the complete absence of an intestine, as well. The digestive tract of these barnacles is composed of a mouth, a short, highly muscular esophagus, and a large sack-like stomach with weak musculature.

In studying the feeding habits of the female $T$. lateralis, the question arose that if she took indigestible items into her stomach, how did she get rid of them? There are several possibilities: First, she need not take indigestible items into her stomach. As a second hypothesis, if she does ingest these items, perhaps she does not get rid of them, but accumulates them until she dies. Thirdly, she may actually void the contents through the body wall by some method of phagocytosis. Or, fourthly, she could regurgitate these items back through 
the esophagus and mouth, either by violent contractions of the entire body and mantle to put pressure on the stomach; or by reverse peristalsis in the esophageal region, "milking," as it were, the contents back out at intervals.

To solve the first question as to whether ingestion of indigestible items occurs I tried feeding the barnacles various substances by saturating anything they might ingest with these substances. Carmine, bone charcoal, "Aquadag," and "Higgins Eternal Ink" carbon particles were tried. It was found that the latter was the most effective when allowed to stand long enough to allow the ammonia in this product to escape.

The barnacle would ingest sizable quantities of the ink particles when immersed in a 10- to 30-percent solution of ink in sea water for periods of several hours to four days. Of course at this concentration they had little choice of ingesting anything without taking in carbon particles, but at least under these conditions indigestible particles were ingested, rejecting the first hypothesis.

Investigation of serial sections of normal females of different sizes not subjected to any artificial particles did not reveal any gradation of accumulation of debris in the gut, as would be expected if the females retained indigestible material until death. The second hypothesis, therefore, is rejected.

Similarly, voiding of discreet particles such as carbon particles by phagocytosis, or other means through the mantle wall, should be evident in the serial sections of those ingesting ink particles, but no evidence of this was seen in a total of 56 animals. Hence, the third hypothesis seems to be rejected.

The most probable answer occurring to me is that the contents are regurgitated back through the esophagus and mouth. As has been indicated, this could be brought about by violent contractions of the entire mantle, or by reverse peristalsis in the esophagus. The latter process was investigated without success by trying to observe the action of the esophagus in living specimens with a portion of the shell removed. Vital dyes were introduced to aid in this study with no success. Animals were placed back into fresh sea water after a period of time in ink solution, and then killed and sectioned at intervals (see table 1) to see if the emptying of the ink was a gradual or spasmodic occurrence. The results inconclusively pointed toward a gradual elimination of the carbon, but inasmuch as discharged carbon could still be in the mantle cavity and could be reingested, and in view of the fact that more carbon was invariably found in the mantle cavity than in the stomach, no decisive conclusion can be drawn.

Methods: Thirty-two adult (over $0.5 \mathrm{~mm}$ aperture) living Trypetesa lateralis females were placed in 1 inch of sea water to which 10 -percent 
aged "Higgins Eternal Ink" or bone charcoal powder had been added, at $13^{\circ} \mathrm{C}$ in semidarkness. On day three, four females were removed from the ink-water, killed, and sectioned. On day four, sixteen of the remaining animals were placed in $1 \frac{1}{2}$ inches of clear sea water at $13^{\circ} \mathrm{C}$, and samples were removed, killed, and sectioned at intervals stated in the table below. On day seven, the barnacles from the bone charcoal were killed. All barnacles were living upon removal from the test conditions.

The sectioned barnacles were grouped rather subjectively into five classes, numbered 0-4, but judged on the following basis: $0-$ no carbon; 1-a trace of carbon; 2-a little carbon; 3-some carbon; 4 - considerable carbon. The slides were judged by serial number only, without the bias of knowing how long the animal had been in the solutions. The largest portion of the stomach was used as a standard point of judgment.

TABLE 1.-Results from the ingestion and egestion of carbon particles in Trypetesa lateralis.

\begin{tabular}{cccccccc} 
& & \multicolumn{4}{c}{ Number in classes } \\
Number of females & Days in ink & Days in clear water & 0 & 1 & 2 & 3 & 4 \\
\hline 4 & 3 & 0 & 3 & 0 & 0 & 0 & 1 \\
10 & 4 & 5 & 3 & 0 & 2 & 4 & 1 \\
6 & 4 & 9 & 3 & 0 & 1 & 1 & 1 \\
12 & $7 *$ & 102 & 10 & 2 & 0 & 0 & 0
\end{tabular}

* Bone charcoal carbon.

Conclusions: Under ideal conditions for a complete elimination at one time, one would expect all specimens to be in grades " 0 " and "4." The difficulties of this statement have already been stated: the carbon can be reingested after elimination into the mantle cavity and still not reach stages 3 or 4 , or the female may not have reached stages 3 or 4 in the first place. A complete spasmodic elimination would fit the data as well as a gradual elimination.

The only statement that can be made is that apparently there is regurgitation, but whether it is spasmodic or gradual cannot be determined from this type of data. The regurgitated material is not compacted into pellets or ribbons.

\section{Excretory System}

The excretory system of the acrothoracicans, as maxillary glands, does not differ in essential features from that of the thoracicans. The system has been reviewed by Utinomi (1960) and Nilsson-Cantell (1921). Four species from different families have been investigated in 
detail: Trypetesa lampas, Cryptophialus minutus, Lithoglyptes indicus, and Berndtia purpurea. The maxillary glands are located on both sides just posterior to the mouth, with portions extending anteriorly into the second maxillae and posteriorly along the ventral thorax. Three paired parts have been described: the endosac, urinary bladder, and urinary duct. The endosacs lie immediately posterior to the second maxillae, are slightly swollen, and contain a large and usually darkcolored globular mass. It is generally assumed that this portion serves the main excretory function. The paired urinary bladders are situated anteromedially from the endosacs, to which they are connected by a narrow funnel, and are often triangular in shape. The urinary ducts are small and thin-walled, and are difficult to follow in serial sections. They open on the second maxillae.

Utinomi (1960, p. 21) refers to cephalic nephrocytes in Berndtia purpurea. These are extremely large and round cells in numerous masses scattered through the cephalic region. He proposes that these may be another sort of excretory organ. Other similar cells are found scattered throughout most of the rest of the body. All resemble the cells containing carmine following injection experiments conducted on other crustacea. No injection experiments are known for acrothoracicans, however. Feeding fine carbon particles to Trypetesa lateralis (see page 20) gave no indication of phagocytosis of ingested particles.

The function of the maxillary glands probably is to remove cellular wastes flowing through the blood lacunae scattered throughout the body and mantle, and may be supplemented by the nephrocytes and digestive glands.

\section{Muscular System}

The muscular system of the acrothoracicans has been studied in detail and in a comparative manner by Utinomi (1960). Much of the summary below will be following the terminology of Utinomi, who in turn follows Nussbaum's (1890) work on thoracicans.

The mantle contains two layers of muscle, one longitudinal and one radiating from the attachment area in a generally circular manner. Typically the longitudinal strands are external, but these may interlace in a complex manner. These discreet longitudinal muscle bands terminate somewhat short of the mantle aperture - the only mantle area lacking two sets of muscle strands. Additional muscle bundles of special function may radiate from the area of the horny knob or upper end of the attachment disk, especially in species bearing lateral bars, to reinforce the support of the mantle during body movement and abrasive mantle activity. 
A heavy set of muscle bands typically extends from the body near the upper attachment disk to the dorsal end of the orifice. This retractor orificii would have the function of pulling the body down into the mantle sac.

The muscles of the body proper are numerous and complicated. Utinomi (1960) separates them into three groups: the longitudinal or extensors, the oblique or flexors, and the transverse set. The first two groups are paired. The most obvious and typical sets of muscles include the retractor corporis which originates in the dorsal opercular muscle mass and inserts along the anterior dorsal thorax, more or less continuous with the longitudinal or longissimus corporis along the dorsal thorax to terminal cirri. The adductor capitis and protractor corporis arise in the muscle mass of the dorsal opercular area, the former inserting on the head and mouthparts and the latter on the sides of the thorax.

A variable number of transverse muscles connect the body walls of both sides of the thorax, especially anteriorly. One lies just ventroposteriorly to the curvature of the esophagus. This transverse muscle is of particular interest, in that a similar muscle is found in thoracicans on the dorsoanterior side of the esophagus curve, except in the genus Ibla. This is discussed in the genus Cryptophialus by Berndt (1907a) and by Batham and Tomlinson (1965).

The muscles of the mouthparts are complex, but in general are similar to those of the thoracicans.

The muscles of the cirri are not as well developed as in the thoracicans, and Utinomi (1960) suggests that they therefore cannot flex their cirri as far as can the thoracicans. This is substantiated by my own field observations on several species of both orders.

Before the muscles can become useful characteristics in understanding the systematics of the order Acrothoracica, they will have to be thoroughly examined in many species, ideally by one worker. The present study is not adequate for this comparison, inasmuch as most of the material was recovered dried. The musculature cannot be carefully considered in dried material. The designation of specific muscles is extremely tenuous, inasmuch as small strands of muscle are scattered about the body and mantle, and the designation of particular strands as major muscles is often arbitrary. The presence of an orificial knob in some species makes the designation of these muscle masses associated with the orifice and attachment processes and disks quite difficult.

The muscles are in no way as definitive a characteristic as a cirral count. Whether the muscles become useful in designating natural groups remains to be seen, but at present I am doubtful. 


\section{Circulatory and Respiratory Systems}

Cirripedia in general have a lacunar circulatory system, with the blood moving through lacunae or hollows within the body and mantle. These lacunae have no real walls, and no heart has been described. It appears that body movements cause the blood to circulate.

Respiration is by diffusion through the body and mantle surfaces, and extensions of these surfaces. No specific respiratory structures such as gills can be found. The extensions include the conical ventral body processes, of which Lithoglyptes indicus and Berndtia purpurea have two pair and Kochlorinopsis discoporellae has one pair; the dorsal filamentary body processes in the family Cryptophialidae; and the internal and external mantle flap-like processes in Trypetesa.

\section{Reproductive System}

The ovaries lie on the dorsal side of females of most species (except $T$. lateralis, see section on the Mantle, page 14). They lie in the mantle spaces also occupied by blood sinuses and lacunae, immediately under the horny disk of the mantle. Many fibers traverse the ovary, connecting the inner and outer cuticles.

Oviducts generally arise near the anterior end of the ovaries and open into the mantle cavity on both sides of the ventral thorax between the point where the thorax meets the mantle posteriorly, and the mouth cirri. The oviducts open into the more or less expanded atrium, which in turn opens as a slit into the mantle cavity.

The site of fertilization is not known, but the fertilized eggs are retained in the mantle cavity until hatched, and usually until freed into the sea as cyprid larvae. The nauplius and metanauplius stages are passed in the egg within the mantle cavity in most species.

\section{The Male}

The acrothoracican male is of reduced size, in total mass being smaller than the cyprid larvae. The complete lack of a digestive tract and feeding appendages precludes the intake of food, and the maturation process is at the expense of larval food reserves.

The features typically present in the male include a well-developed single testis and a simple seminal vesicle, a naupliar eye, and paired first antennae. In addition an extensible penis is present in most species in very mature males. Various reflecting, opaque, reddish- 
purple granules are scattered through the body of some species. Yellow organs, representing perhaps stored food droplets or glands, are often present. The integument is not pigmented, but may be variously equipped with clear teeth on the end opposite the first antennae, rectangular or polygonal plates often bearing a number of spots appearing to be pegs or other rugose elevations (see fig. 43, electron micrograph), and hairs, generally around the end opposite the first antennae.

The presence of a penis in some species has been a big question, yet unresolved. Most species have a definite penis which can be pulled out to many times the body length. That this is a feature which matures late in the life of the transient and expendable male is evident in $K$. floridana, where a routine examination of many males by Wells and myself netted each of us only one specimen with a penis. I studied fifteen mature males carefully before I found another one.

\section{Ultrastructure of the Male and Its Sperm}

Gluteraldehyde-osmium treated males of Trypetesa lateralis were sectioned, and examined with an electron microscope for details of the structure of the male and its sperm.

The gross structure of the male seems somewhat acellular. The cell boundaries appear to have broken down and the developing spermatozoa appear to be dispersed in the central region of the organism. The exterior cuticle appears to be laminar and composed of six or twelve layers, depending upon interpretation. The surface of the cuticle exhibits a grooved or pegged effect (fig. 43).

In the region of the developing spermatozoan, many transverse and partial longitudinal sections could be observed in the electron photomicrograph. The head region could not be definitely discerned. The sperm axoneme (flagella or tail) appears to be composed of the typical nine plus two arrangement of microtubules (fig. 44). There appears to be two accessory structures. One is a dense body which is probably analogous to the "outer fibers" of classical spermatozoa structure. The other appears to be an accumulation of granular material. Both do not appear to travel the entire length of the tail, since transverse sections can be observed which show the dense body only (fig. 44a), a granular region only (fig. 44c), and both the dense and granular regions (fig. 44b). Thus there appears to be a region where the two overlap. It was not possible to determine the anterior end. Figure 44d shows a longitudinal section through the granular region only, and figure $44 \mathrm{e}$ shows a longitudinal section through the dense region and a small portion of the granular region at one end. 
Refer to the diagram (fig. 45) for a partial reconstruction of the spermatozoan tail region. The electron microscopist was Fred D. Warner, who also reconstructed the figure of sperm anatomy. The magnification is $20,800 \times$.

The Lack of a Penis in Trypetesa lateralis

InTRODUCTION: The purpose of this project is to clarify whether or not the male of $T$. lateralis has a penis. Hundreds of males had been cursorily examined in the course of sixteen years of study on this species, without a penis being seen. A specific study for this purpose was undertaken by Richard Taverna, one of my assistants.

Methods AND MATERIALS: $T$. lateralis specimens were collected in Tegula shells occupied by hermit crabs at Moss Beach, San Mateo County, California, during October and November 1966, and in the spring of 1967. After the barnacles were found, they were placed, while remaining in the shell, in sea water in a 4 -inch finger bowl at $20^{\circ} \mathrm{C}$. Ascorbic acid was added to the sea water to some specimens $(0.5 \mathrm{~g} / 150 \mathrm{ml})$ for different lengths of time. Such stimulation has been demonstrated to stimulate sexual activity in the Thoracica (Collier, Ray, and Wilson, 1956).

Removal of the barnacle was accomplished by decalcification of the shell in 10-percent HCL and 10-percent formalin. Final removal of the barnacle was accomplished with the use of fine forceps. The male and female then were placed in glycerin as a means of partial clearing. After penetration of the glycerin, the male was removed from the female with ultra-fine forceps and placed on a slide. The male was mounted in glycerine with a raised cover-slip to prevent distortion.

RESULTS AND OBSERVATIONS: The observation of 121 isolated males was not successful in finding a trace of a penis.

The male barnacle of $T$. lateralis did not show any signs of penis formation, either in the ascorbic acid or in ordinary sea water. The failure in either case not to form a penis suggests that either no penis is formed by this organism or that other environmental factors not present at this time of year have yet to be explored.

Conclusion: According to the present findings, there is no evidence for the existence of a penis or other sex organ in $T$. lateralis.

\section{Activation of Acrothoracican Sperm}

The sperm of Trypetesa lateralis can be activated by rupturing mature males in sea water. The length of time it takes for the sperm 
to begin moving depends to some degree on the salinity of the water. Deviations slightly above or below normal salinity appear to hasten the action.

The sperm move in a typical thrashing manner. The nearly uniform diameter of the sperm makes it difficult to determine a head end. The movement is distributed along the length of the sperm.

\section{Embryology and Mating Behavior}

The embryology of members of the order Acrothoracica has been the subject of several papers, especially Trypetesa lampas by Kühnert (1934), Berndtia purpurea by Utinomi (1961), and Cryptophialus melampygos by Batham and Tomlinson (1965).

The major embryonic sequence of egg, nauplius, metanauplius, cyprid, and young barnacle is found in the Acrothoracica as it is in the entire subclass. A striking feature of the Acrothoracica, however, is that most species retain their larva to the cyprid stage within the mantle cavity of the female, before they are released into the sea. In some species, notably Cryptophialus melampygos, the larvae have no swimming appendages, and hence must crawl and be splashed from place to place. These species have extremely dense infestations (over 3,350 individuals in a 5 -inch Haliotis iris).

Motile animals have a capacity for a complex courtship behavior, which informs the partner of mating readiness. The immobile barnacles not only cannot develop such a complex courtship, they are further handicapped by being more or less permanently within a hard capsule. The automatic response of closing the opercula on any intruding object would seem to discourage random search behavior by a neighbor's penis. The Thoracica have remained very fertile, however, with the aid of a chemical messenger. Collier, Ray, and Wilson (1956) have shown that as little as $14 \mu \mathrm{gms} / 1$ of ascorbic acid (vitamin $\mathrm{C}$ ) will cause one species of Balanus to initiate mating behavior. Barnes (1962) showed that the seminal plasma of $B$. balanus contains 21 $\mu \mathrm{gms}$ of vitamin $\mathrm{C}$ per $\mathrm{ml}$. of semen deposit. Thus, the first mature balanoid initiates a chain reaction.

The Acrothoracica have a great advantage in having a motile male, yet he must synchronize with the female if fertilization is to be effective, and he is cemented down, so apparently does not move around to give or receive behavioral clues. It is my opinion that the partial burial of the male within a pocket of the female's mantle tissue in the immediate area of the ovary is a means for the synchronization of sexual development, perhaps on the part of the maturation of the male under some chemical mediation of the female. 
I have seen this embedding of the male in Cryptophialus melampygos, Lithoglyptes indicus (see fig. 5a), Trypetesa lateralis, and T. lampas (see Berndt, 1903a, for a figure of the latter), and I have little doubt that it is a general characteristic.

I have tried ascorbic acid mixtures on males of Trypetesa lateralis for an extended time, and this does not seem to be a stimulant for either the development of a penis or for the discharge of sperm.

\section{Sexuality in the Cirripedia}

In the Crustacea, except for a few hermaphroditic forms (most thoracican barnacles, a few notostracans, isopods, tanaids, penaeids, cephalocarids, and probably Emerita), the dioecious condition is the rule, although the condition is not as simple as implied by recent authors. Green (1961, p. 68) does not recognize the many completely dioecious barnacles, while Charniaux-Cotton (1960, p. 412) does not recognize that self-fertilization does occur in the common barnacles, and perhaps does not occur in the parasitic barnacles. Smith (1960) commented on the latter by pointing out that the unisexual condition is not necessarily a reversion, but occurs in primitive forms.

A wide spectrum of sexuality is found in the Cirripedia. One finds pure hermaphrodites in some species, and hermaphrodites with dwarf complemental males in others. In still others dioecious females are inseminated by miniature males resembling females or cyprid larvae in varying degrees of reduction. The details of the mechanism of fertilization and the sexual cycle of some Rhizocephala have recently been worked out by Yanagimachi (1961a, b), and Yanagimachi and Fujimaki (1967). The sexual mechanisms, however, of the Acrothoracica and those Thoracica with separate sexes or complemental males are not known.

In the Rhizocephala the male is no more than a cyprid which lacks the penis entirely. Yanagimachi $(1961 \mathrm{a}, \mathrm{b})$ has shown that male and female cyprids are morphologically distinct in the rhizocephalan Peltogasterella socialis Krüger. The male, as a cyprid, injects its entire contents through the antennules into the female mantle cavity. The male cells migrate into a special sac in the female and differentiate into spermatozoa.

In both the Thoracica and the Acrothoracica the species with separate sexes show a reduction or loss of the penis (cf. Henry and McLaughlin, 1965).

Dwarf males, whose reproductive system is the only organ system well developed, assure availability and close proximity to females, 
while eliminating direct competition between them. This touches on the general problem of Gauss' Competitive Exclusion Principle (cf. Hardin, 1960).

\section{Conjectures on Sexuality}

An important aspect of the study of the Cirripedia is the spectrum of sexual types displayed. The Thoracica are hermaphroditic with few exceptions, while the Acrothoracica are gonochoristic (dioecious). A mathematical analysis of the advantages of hermaphroditism and parthenogenesis was conducted as a concommitant to research on acrothoracicans (Tomlinson, 1966).

It is generally agreed that sexuality is an advantage because it results in recombination. Because the gametes have to get together, it is obvious that one or both must be motile, or at least mobile. It is also obvious that a reserve food supply must be available to one or both gametes to support the zygote until it can get its own food. These latter two features are to a degree incompatible, inasmuch as stored food reduces motility. It follows logically, therefore, that the optimum adaptation would be to have all of the reserve food not needed for the sustenance of the gamete itself in one gamete, and have the other gamete motile, i.e., an egg and sperm.

In the production of eggs and sperm, the efficiency of specialization and division of labor would evolutionarily tend toward organisms with a separation of gonads. If hormonal control is used in gamete production, efficiency of production would favor a single sex per organism, or at least a single sex at a time (e.g., protandric hermaphroditism). It is of interest to observe that plants, with their local hormones (auxins, etc.), tend to be hermaphroditic (monoecious), while animals, with their systemic hormones, tend to be gonochoristic (dioecious).

The presence of males and females in a population poses potential problems. If there are any differences in their morphology or physiology, the sexes will tend to compete with one another, following the Competitive Exclusion Principle mentioned above. Of course, species usually cannot tolerate the complete exclusion of a sex, and adaptive mechanisms exist to correct this in at least two ways: the sexes may converge back to nearly identical configurations, or they may change their morphology and/or physiology drastically and also change their environmental niche. This latter requires a compensating adaptation to enable the two sexes to assure contact at the breeding season. The reader can provide many examples in the vertebrate groups, but since we are discussing acrothoracicans I will simply state that they 
have utilized the latter course to the extent that the males are strikingly reduced, attached to the female through most of their lives, and do not compete with the female except for a very small amount of burrow space.

In discussing the conversion of the "primitive" sexual form from hermaphroditism to gonochorism or vice versa, I tend to consider either direction as quite possible, and it probably has occurred many times in the history of the animal kingdom. Both sexual types are frequently found in many species of animals and if a strong advantage were to be gained these species could go in either direction (Tomlinson, 1966).

I am inclined to think that the occupation of small shells and small-diameter corals put such a limitation on the density of acrothoracicans, as opposed to thoracicans occupying flat rocks, that the probability of encounter with another organism is small enough to greatly favor a motile member of the species, namely a motile male, rather than to rely on self-fertilization and chance contact. The great densities of the cryptophialids are not to be considered here, inasmuch as they are highly evolved acrothoracicans. Thus, even though lack of motility favors the hermaphrodite, when the chance of encounter reaches a very small level, owing not to the small numbers of individuals but to their being sessile, then self-fertilization or motility of males or gametes becomes the only means for egg and sperm encounter.

\section{Systematics and Characteristics}

It should be noted that in the following figures all scales are $0.1 \mathrm{~mm}$; all specimens have been treated in $\mathrm{KOH}$ except the burrows; all figures were made with a camera lucida except burrows and those labeled "sketch." Abbreviations are on page 4. The species are organized in an order reflecting natural relationships, with the typespecies first. Unless otherwise stated all descriptions pertain to the female.

\section{Order ACROTHORACICA Gruvel, 1905, page 310}

[Cryptosomata Hancock, 1849, page 313; Abdominalia Darwin, 1854, page 563; Gerstaecker, 1866, page 572].

Burrowing cirripeds with soft carapace, without calcareous plates; cirri usually reduced, three to five pairs concentrated toward posterior 
end of body; one pair of cirri usually present in vicinity of mouth; with or without caudal appendages. Three pairs of mouth appendages: mandible with palp, first and second maxillae. Abdomen lacking in adult. Males dwarf and much reduced in structure; ovaries contained in a more or less flattened part of mantle, the same forming at least in part the cemented point of attachment to the burrow wall. Development always includes a cyprid stage, free nauplii frequently deleted. Live buried in barnacle, chiton, gastropod, and pelecypod shells, and in corals, bryozoans, and limestone. Fossil forms in limestone, corals, echinoids, and many mollusk shells; Carboniferous to Recent.

\section{Suborder PYGOPHORA Berndt, 1907b, page 288}

Acrothoracica with terminal cirri biramous; brain with two ventral ganglia; alimentary canal complete; caudal appendage may be present or absent.

Family LITHOGLYPTIDAE AURIVILLIUS, 1892, page 133

Kochlorinidae Gruvel, 1905, pages 328, 335; Berndt, 1907b, page 287.

Balanodytidae Utinomi, 1950b, page 5; 1950c, page 458 .

Berndtiidae Utinomi, $1950 \mathrm{c}$, page 457.

Chytraeidae Utinomi, 1950c, page 457.

Zapfellidae Codez and Saint-Seine, 1957, page 704.

Rogerellidae Codez and Saint-Seine, 1957, page 709.

Utinomiidae Tomlinson, 1963, page 264.

Diagnosis: Pygophora with alimentary canal without gut teeth (gizzard); mouth cirrus well developed; labrum of same relative size as rest of well-developed mouthparts; burrow aperture a tapered slit; caudal appendage may be present.

\section{Weltneria Berndt, 1907b, page 289}

Utinomia Tomlinson, 1963c, page 264.

TyPe-sPeCies: Weltneria spinosa Berndt, $1907 \mathrm{~b}$.

Diagnosis: Lithoglyptidae with five pairs of biramous terminal cirri; caudal appendages present. Heavily chitinized operculum with numerous small marginal teeth; lateral bar of weak granulations or absent; males with blunt posterior projection.

In view of the fact that Weltneria spinosa had been placed incertae sedis by several workers, and type-specimens were not available (in 
fact no specimen was available), no real consideration was given to Weltneria when the new species was described Utinomia newmani by me in 1963. Now that I have been to South Africa and collected numerous specimens from the type-host and locality, I have little doubt that Utinomia is really Weltneria. The generic and specific description of Weltneria spinosa by Berndt (1907b) consists of a total of twenty-one words or their equivalent numbers and abbreviations. Krüger (1940, p. 146) questioned the presence of a caudal appendage.

\section{Weltneria spinosa Berndt, 1907b, page 289}

Figure 1

Diagnosis: Weltneria with a pair of strong hooks at the apex of the operculum; inner and outer margins of operculum armed with strong teeth which may be entire or bifid. A pair of weak and irregular lateral bars are present.

Distribution: From Haliotis midae from Hermanus, near Cape Town, South Africa (thanks to L. S. Meiring), Turbo sarmaticus in association with Cryptophialus turbonis, and Argobuccinum argus from Miller Point, False Bay, South Africa (latter two collected by Mrs. C. M. Connolly). Hundreds of specimens were obtained, and dozens examined.

Material: USNM, Aust, BPB, Brit, Belg, BA, CA, Dublin, Mex, Paris, Seto, SFSC, UCT, Vict.

Size of female $3.89 \mathrm{~mm} \times 2.10 \mathrm{~mm}$ in length and width, and an estimated $1.65 \mathrm{~mm}$ thick (average of 29 specimens). The neotype is $4.7 \times 2.5 \mathrm{~mm}$ (USNM 122606).

The burrow aperture appears like a typed apostrophe, that is, a tapered slit more pointed on one end.

The lips of the mantle aperture are bright red in life, a dull reddish brown when dried, and a light brown when preserved in 70-percent alcohol. They are well developed, bearing heavy single and bifid teeth along the inner and outer margins of both lip plates. A pair of large hooks arm the apex of the curved aperture, between the heavy chitinous plates just mentioned and the portion bearing the infolded velum which terminates in the typical comb collar. The hooks are curved dorsally, toward the attachment side of the mantle. The velum tucks inward from the ventral end of the aperture, and is continuous with a very delicate membrane arising on each side inside the mantle. The assumed function of this velum is to bear the comb collar, with its numerous uniform and fine fibrils which are composed of the convolutions of the membrane, against the cirri to serve a cleaning or protective service. 


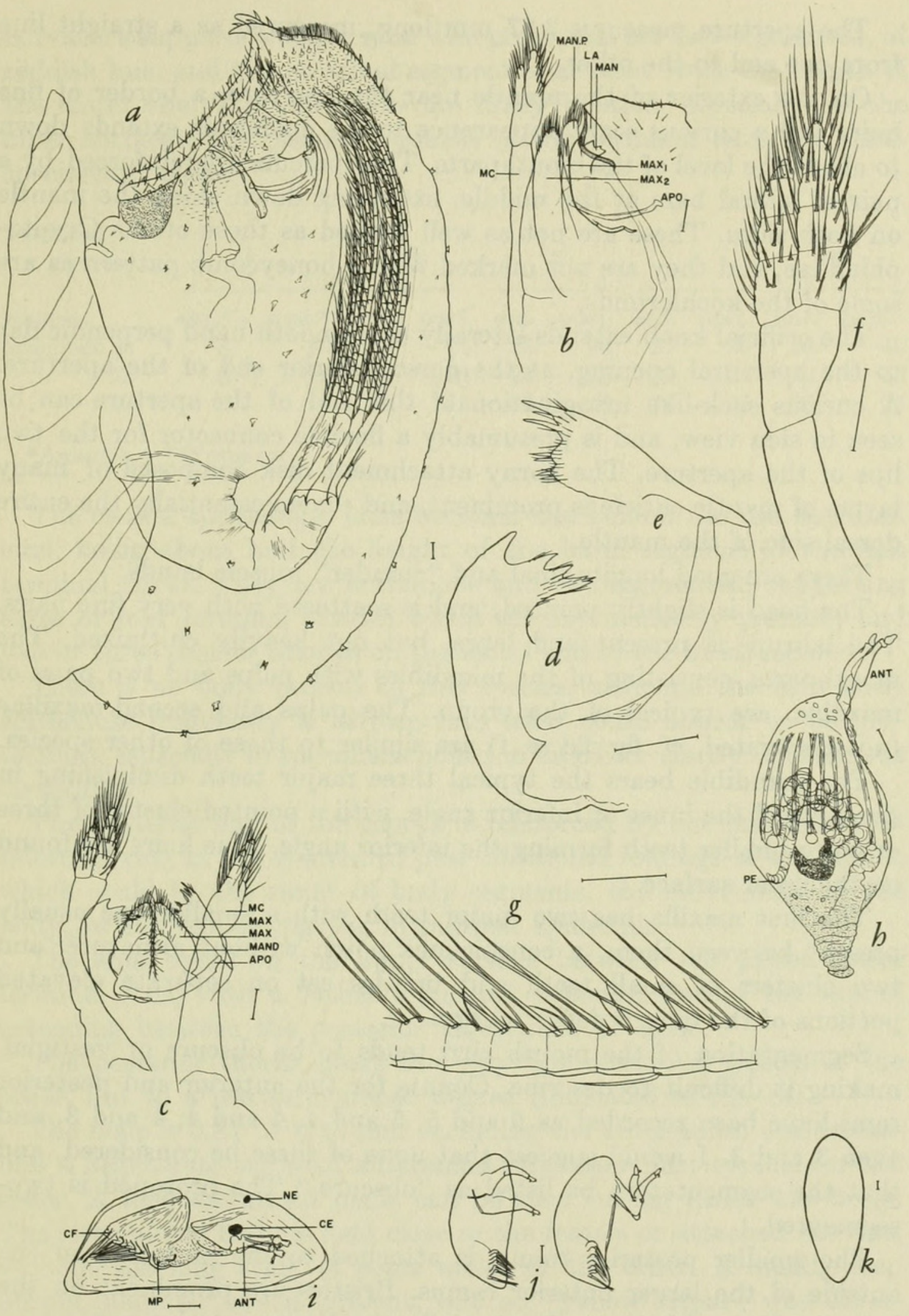

Figure 1.-Weltneria spinosa Berndt, 1907a, from Haliotis midae from Cape Province, South Africa: $a$, female side view; $b$, mouth field, side view; $c$, mouth field, front view; $d$, mandible; $e$, fist maxilla; $f$, detail of distal end of first, or mouth cirrus; $g$, detail of portion of terminal cirrus; $h$, mature male; $i$, cyprid larva from female; $j$, cyprid larvae showing extensibility of antennules; $k$, burrow aperture. 
The aperture measures $3.37 \mathrm{~mm}$ long, measured as a straight line from one end to the other.

On the exterior of the mantle near the aperture, a border of fine hairs and a curious scaly appearance to the epidermis extends down to about the level of the mouthparts. The opercula are reinforced by a pair of lateral bars at the middle, extending down along the mantle on both sides. These are not as well formed as those of the Cryptophialidae, and they are not marked with a honeycomb pattern as are some of the kochlorinids.

The orificial knob extends laterally as a smooth band perpendicular to the apertural opening, at the dorsoposterior end of the aperture. A curious sack-like invagination of this end of the aperture can be seen in side view, and is presumably a flexible connector for the two lips of the aperture. The horny attachment disk composed of many layers of mantle cuticle is prominent, and covers essentially the entire dorsal side of the mantle.

There are good longitudinal and "circular" muscle bands.

The head is slightly pointed, and is scattered with very fine hairs. The labrum is present and large, but not heavily chitinized. The mouthparts, consisting of the mandibles with palps and two pairs of maxillae, are typical of the group. The palps and second maxillae (not illustrated, cf. fig. 2d, e, f) are similar to those of other species.

The mandible bears the typical three major teeth diminishing in size toward the inner or inferior angle, with a pointed cluster of three or more smaller teeth forming the inferior angle. Fine hairs are found on the inner surface.

The first maxilla has two major teeth with a smaller one usually present between them, a conspicuous notch without armature, and two clusters of small teeth and bristles set on separate elevated portions of the inner inferior margin.

Segmentation of the mouth cirri tends to be obscure or vestigial, making it difficult to describe. Counts for the anterior and posterior rami have been recorded as 5 and 5,5 and 4,4 and 4,4 and 3 , and even 3 and 3 . I would suggest that none of these be considered, and that the segmentation be listed as "obscure." The protopod is twosegmented.

The smaller posterior ramus is attached to the protopod on the outside of the larger anterior ramus. Bristles are prominent on the inner surfaces of both rami, especially the larger anterior one.

There are five pairs of biramous, multisegmented terminal cirri. The setation is typical for the suborder. The lesser curvature of each segment supports a distal pair of long setae and a central, shorter pair. There is a much shorter single seta lying between the distal pair. The distal end of every second to fifth segment along the greater 
curvature supports a single seta. The protopods are two-segmented, of reddish hue, and the proximal segment is at least twice the length of the distal one. The protopods are finely bristled, especially on the inner surfaces. The segment counts of the terminal cirri, for three specimens, follow:

Terminal

cirrus:

1

2

3

Ramus:

$\overline{\text { ant.* post.** ant. post. }}$

Specimen 1:

$\begin{array}{lrrrrrrrrrr} & \text { ant.* } & \text { post. } * & \text { ant. } & \text { post. } & \text { ant. } & \text { post. } & \text { ant. } & \text { post. } & \text { ant. } & \text { post. } \\ \text { 1: } & 8 & 10 & 15 & 20 & 21 & 24 & 27 & 28 & 28 & 30 \\ \text { 3: } & 8 & 12 & 17 & 21 & 26 & 28 & 29 & 31 & 32 & 33 \\ & 7 & 9 & 11 & 15 & 19 & 24 & 23 & 25 & 25 & 26\end{array}$

$\begin{array}{lrrrrrrrrrr}\text { 1: } & 8 & 10 & 15 & 20 & 21 & 24 & 27 & 28 & 28 & 30 \\ \text { 2: } & 8 & 12 & 17 & 21 & 26 & 28 & 29 & 31 & 32 & 33 \\ \text { 3: } & 7 & 9 & 11 & 15 & 19 & 24 & 23 & 25 & 25 & 26\end{array}$

ant.

(2)

$\frac{4}{\operatorname{sint} 40 s t}$

5

*Anterior. **Posterior.

The caudal appendages arise between and behind the last terminal cirri, being about half the height of the basal segment of the last terminal cirrus. They are uniramous and two-segmented, supporting three or four terminal bristles which are not markedly pinnate, and two or three shorter bristles on the distal end of the basal segment.

There is no body process in this species, although the thin body epithelium frequently is thrown into what could appear to be projections, especially in specimens boiled in $\mathrm{KOH}$ for clarity of chitinous structures.

The posterior end of the thorax is reinforced by one prominent reinforcing ring in the epidermis, plus additional foldings of the cuticle which could be the result of body segments, the movements of the body, or for reinforcing the cylindrical epidermis.

The anus opens on the upper surface between the paired latter terminal cirri, with a rather truncated posterior end of the thorax extending between the posterior three pairs of cirri.

The posterior thorax bears the very fine striations typical of the order, but to a less pronounced degree (indicated in fig. 1a).

The male is $0.87 \times 0.43 \mathrm{~mm}$ excluding the antennules, and resembles a degenerate sac with antennules for attachment typical for the order. A long annulated penis can be seen curling inside the body. The streamlined body is held close to the female or attached exuviae, without the long stalk of some males of the order. A small, deep purple, naupliar eye is present, but no "yellow organ" was differentiated from the cellular mass.

The embryology seems typical for the order. Eggs are retained in the brood chamber behind the thorax. The naupliar stages are undergone within the egg membrane, and the larvae are retained until the cyprid stage. The cyprids appear typical, with well-developed swimming appendages. 
The CYPRID: The cyprids collected within a gravid female were mature enough to warrant a description. The shape and size $(0.87$ $\mathrm{mm}$ long $\times 0.365 \mathrm{~mm}$ wide $\times 0.15 \mathrm{~mm}$ thick) are typical for the Subclass Cirripedia. The strongly developed antennules were retracted, but were typical, with the "goat's foot" terminal processes. The most noteworthy feature is the very long, two-segmented caudal furca tipped distally with bristles, which represent the caudal appendages. The six pairs of bristled appendages are presumably natatory, and represent the cirri of the adult. No gap or hiatus is seen between the presumptive mouth cirrus and the five pairs of presumptive terminal cirri. A prominent mouth field is visible, with the rudiments of the mouth appendages clearly seen. The carapace is hyaline and smooth, without hairs, teeth, or peg plates found in some other members of the order. Paired cyprid compound eyes and a single dorsal naupliar eye are present.

\section{Weltneria hirsuta (Tomlinson)}

Figure 2

Lithoglyptes hirsutus Tomlinson, 1963 b, page 299.

Utinomia newmani Tomlinson, 1963c, page 265.

Diagnosis: Weltneria with operculum armed with numerous short, simple, and compound teeth and long hairs; operculum terminates in a tapered spine.

Distribution: In Psammocora verrilli from a depth of 3 to 6 feet on Sand Bar Reef and in Porites compressa, from NE. side Checker Reef, Kaneohe Bay, Oahu, Hawaii, and in Bursa bufo (Röding) from the area of Seto, Wakayama-ken, Japan.

The original Hawaiian material was given to me by Charles Stasek and Stephen Wainwright. Additional material was collected by me on Coconut Island, courtesy of the University of Hawaii Marine Laboratory.

Type-Material: Holotype USNM 107544. Paratype material: SFSC; CA; Plymouth Laboratory, England; Seto; Portobello Marine Station, New Zealand. Additional material: Aust, BPB, Brit. Belg, BA, Dublin, Mex, Paris, UCT, Vict.

All descriptions are based on females from Hawaii unless otherwise stated. The mantles of sixteen adults averaged $1.95 \mathrm{~mm}$ in height $\times 1.18 \mathrm{~mm}$ in width (maximum $2.1 \mathrm{~mm}$ and $1.6 \mathrm{~mm}$ ), and are flattened laterally. The mantle is studded with numerous small T-shaped teeth, short spinules, and three- or four-pointed star-shaped teeth, all scattered about on the surface, but particularly near the aperture. The 

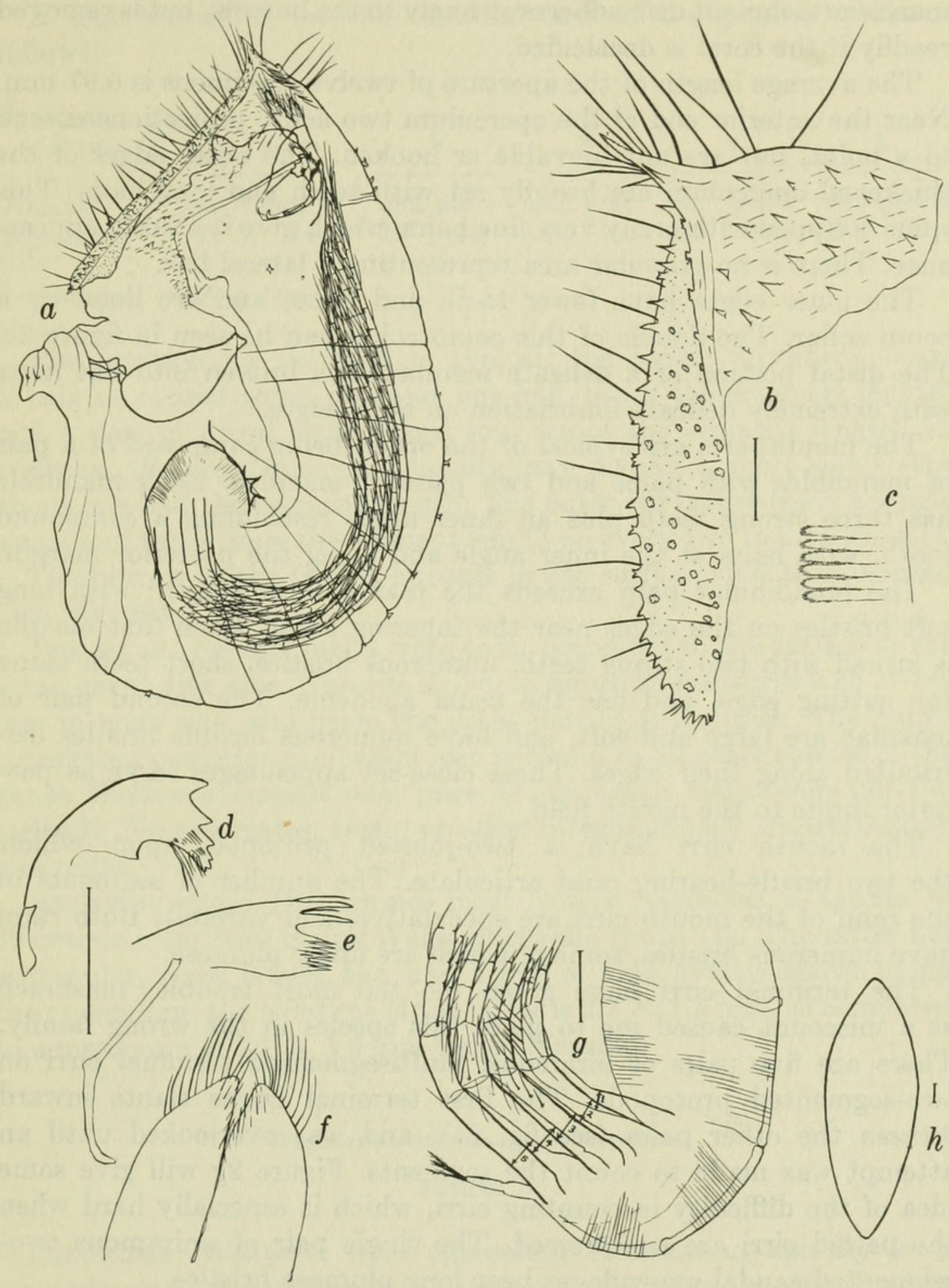

Figure 2.-Weltneria hirsuta (Tomlinson, 1963b) from Coconut Island, Oahu, Hawaii: $a$, female with male, side view; $b$, detail of operculum twisted flat on left end; $c$, detail sketch of portion of comb collar showing fringed outer edge; def: mouthparts dissected out and viewed from outside surface; $d$, mandible; $e$, first maxilla; $f$, second maxillae $g$, detail of basal portions of terminal cirri, the posterior end of the thorax, and the caudal appendage, numbers designate terminal cirri, only one of paired cirri shown; $h$, burrow aperture as viewed from above coral surface. 
mantle attachment disk adheres strongly to the burrow, but is removed readily if the coral is decalcified.

The average length of the aperture of twelve specimens is $0.97 \mathrm{~mm}$. Near the anterior end of the operculum two acute projections extend to a point, but are not movable or hooked. The outer edges of the thickened operculum are heavily set with teeth and long hairs. This spine is tipped with many very fine hairs, which give it a fuzzy appearance. There is no granular area representing a lateral bar.

The inner edges have fewer teeth and hairs, and are lined by a comb collar. The details of this comb collar can be seen in figure 2c. The distal portion of a delicate membrane is broken into flat hairs with extremely delicate fimbriation on both edges.

The mouthparts are typical of the order, being composed of a pair of mandibles with palps and two pairs of maxillae. Each mandible has three strong teeth plus an inner angle resembling a compound tooth, with hairs at the inner angle and along the posterior margin.

The mandibular palp exceeds the mandible in length; with long soft bristles on the edges near the tapering point. Each first maxilla is armed with two strong teeth, numerous bristles, short teeth along the cutting edge, and has the usual apodeme. The second pair of maxillae are large and soft, and have numerous flexible bristles distributed along their edges. These close-set appendages serve as posterior limits to the mouth field.

The mouth cirri have a two-jointed protopod upon which the two bristle-bearing rami articulate. The number of segments in the rami of the mouth cirri are speculative, and variable. Both rami have numerous bristles, some of which are finely plumose.

The terminal cirri have given me the most trouble, inasmuch as a miscount caused me to place this species in the wrong family. There are five pairs of biramous, multisegmented terminal cirri on two-segmented protopods. The first terminal cirrus slants inward between the other pairs (see fig. 2a), and was overlooked until an attempt was made to count the segments. Figure $2 \mathrm{~g}$ will give some idea of the difficulty in counting cirri, which is especially hard when the paired cirri are compressed. The single pair of uniramous twosegmented caudal appendages bear long plumose bristles.

The segment count for the terminal cirri follows:

Terminal cirrus:

$$
1
$$

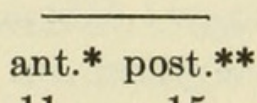

11

15
2

Ramus:

Segments:

*Anterior. **Posterior. 
A segment count for the terminal cirri of a Japanese specimen follows:

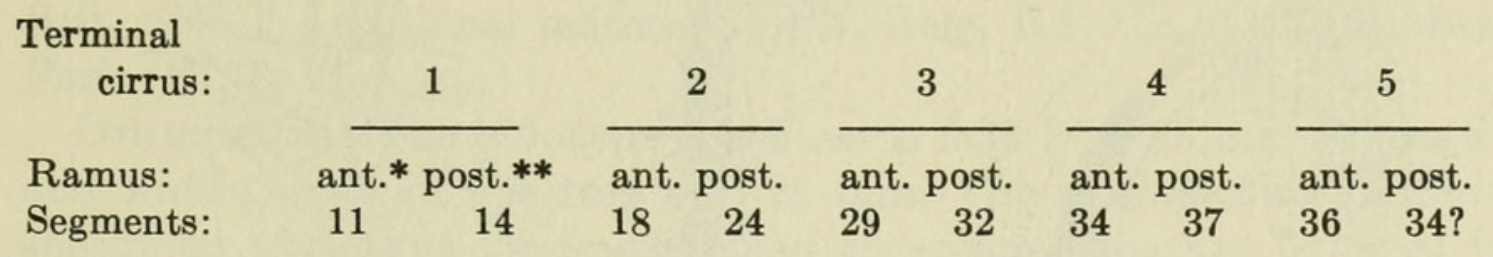

*Anterior. **Posterior.

The setation on the cirri is typical: the inner curvature bears a pair of medial setae one and one-half times the segment length, and a pair of distal setae about four times the segment length. In addition, the distal pair occasionally may possess a short single seta about one-half the segment length. The outer curvature bears a single seta about three times the segment length on every two to six segments.

The burrow of the female appears in the surface view as a pointed oval (fig. $2 \mathrm{~h}$ ).

The male: Several males were seen, cemented to the female in the attachment disk area. The one shown in figure $2 \mathrm{a}$ measures $0.35 \times 0.2$ $\mathrm{mm}$ in body size, and bears the usual pair of antennules. The blunt, corrugated posterior projection also is found in all other species of the genus Weltneria (except one, page 44, in which males were not described). No peg plates, teeth, or other integumentary ornamentation was noted.

Relationships: This species most closely resembles a species of Weltneria from New South Wales, Australia (page 44). The latter has a granular, weak lateral bar, and a row of long hyaline spines along the operculum; the holotype of the latter is $2.7 \times 1.5 \mathrm{~mm}$, as compared to a maximum of $2.1 \times 1.6 \mathrm{~mm}$ for $W$. hirsuta.

\section{Weltneria reticulata, new species}

Figure 3

Diagnosis: Weltneria with operculum terminating apically in a tapered point, set with numerous bifid or multipointed marginal teeth, and ornamented with a reticulated pattern of ridges medially and rows of fine dots laterally.

Eтүмодоgy: reticul- (L.), a net, because of the pattern on the operculum.

Distribution: Approximately fifty specimens from Tridacna maxima Röding, 1798 (T. maxima var. fossor Hedley, 1921) from Heron Island, Queensland, Australia. Two good specimens from Turba 


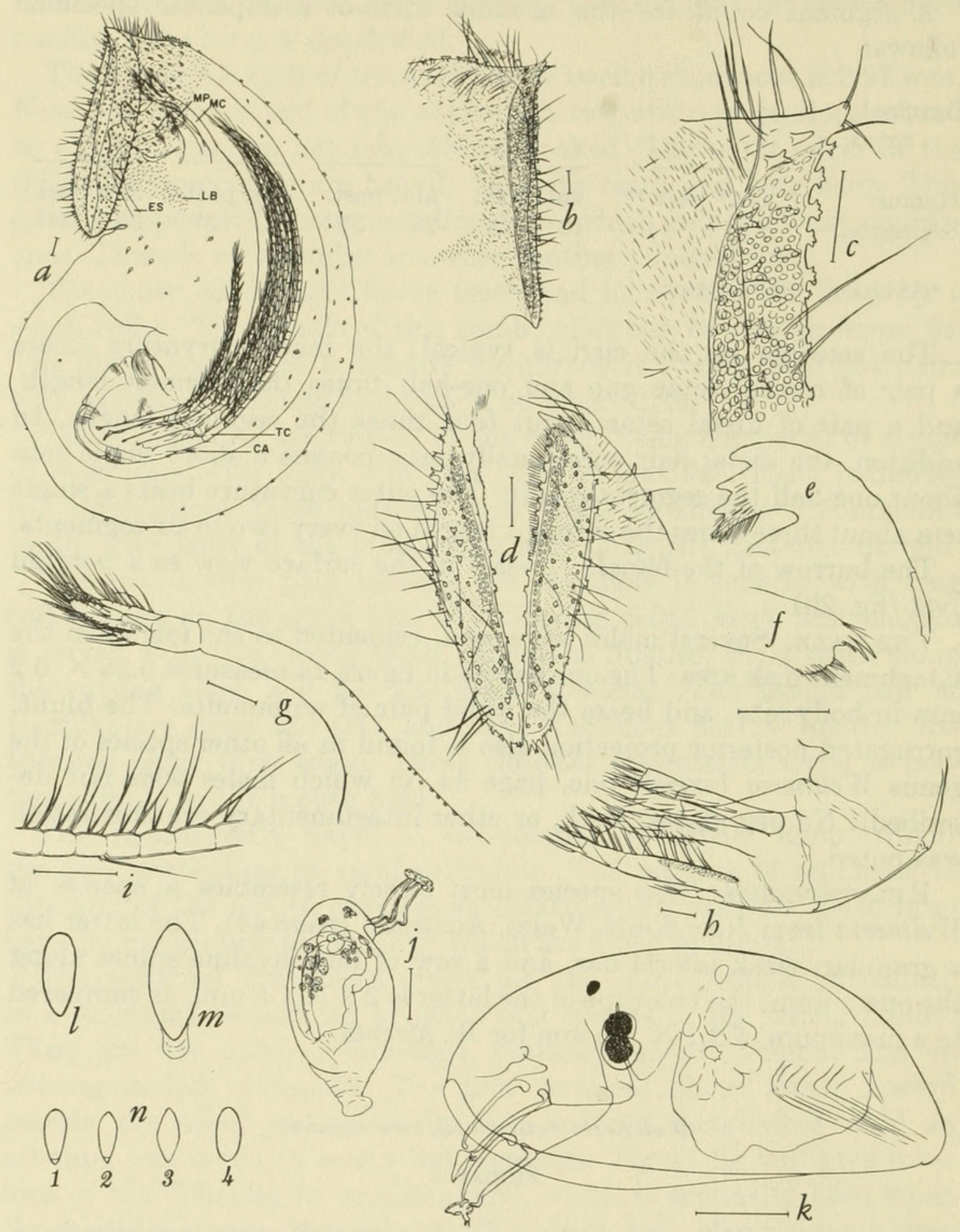

FiguRE 3.-Weltneria reticulata, new species, from Heron Island, Australia, except as noted: $a$, female side view; $b$, opercular area, side view; $c$, detail of operculum, carinal end distal to attachment, side view flattened; $d$, detail of operculum, surface view; $e$, mandible; $f$, first maxilla; $g$, first cirrus (mouth cirrus); $h$, detail of base of terminal cirri, posterior thorax, and caudal appendage, one of paired appendages shown; $i$, detail of terminal cirrus, showing setation; $j$, mature male; $k$, mature cyprid larva taken from female; $l$, burrow aperture in Turbo setosus; $m$, burrow aperture from Turbo chrysostoma from Koror, Palau Islands; $n$, variation in burrow apertures in Tridacna maxima shells. 
chrysostoma L. from Koror Island, collected in 1948 by Daniel B. Langford, from the Bernice P. Bishop Museum shell 204337.

Type-material: Holotype: USNM 122604. Paratypes: Aust, Brit, SFSC. Additional material: BPB, Belg, BA, CA, Dublin, Mex, Paris, UCT, Vict.

Dimensions: The holotype specimen is $2.33 \times 1.33 \mathrm{~mm}$ in length and width, with an aperture of $1.25 \mathrm{~mm}$. The average size of nine specimens (five type-specimens plus four selected mature females) is $2.36 \times 1.46 \mathrm{~mm}$ length and dorsoventral width, with an attachment disk $1.12 \mathrm{~mm}$ wide and an aperture $1.26 \mathrm{~mm}$ long from apex to attachment end, in 70-percent alcohol.

The female: The mantle is equipped with transverse and longitudinal bands of muscle, and armed with numerous small teeth distributed over the surface, especially on the ventral aspect and near the aperture. The teeth may be many-pointed, with two or three points the most common. One tooth with five points was seen, and is included in figure $3 \mathrm{a}$.

The apertural plates, analogous to the operculum, are heavy, broad, and flat, tapering at the apex to curved points, but not bearing major hooks or heavy spines. Both margins of both plates are armed with approximately 20 to 35 fine teeth. The teeth of the outer margin are usually bifid, or two-pointed, although an occasional simple tooth is found. The teeth on the inner margin are more finely divided, with three- and four-pointed teeth common. Across the outer face of the opercular plates are scattered other teeth, which appear to be the culmination of reinforcing ridges laid out in a reticulated pattern. This pattern is seen more clearly on the medial external surfaces of the plates. Rows of fine dots ornament the plates, and long but rather flexible hair-like bristles are scattered along the length of the plates, especially on the outer or lateral edges. The typical comb collar membrane is adherent to the inner surface of the mantle, and projects as convoluted bristle-like extensions between the plates apically.

The color of the mantle in life is a bright brick red, concentrated about the apertural area. A lighter band is found traversing the operculum slightly dorsal (toward the attachment end) of the middle.

On the mantle surrounding the apertural area are fine scale-like markings, scattered with small simple teeth set on heavy, round bases. A few very fine hair-like bristles are scattered about in this area. The scaly portion of the mantle extends posteriorly on both sides in the region where the lateral bar is found in those species bearing this structure, and perhaps this scaly material is an evolutionary beginning of the lateral bar.

The head is rounded, backed on the dorsal side by a pointed crest, and the whole is set with irregularly arranged small hairs. 
The mouthparts are quite typical. An unpaired rounded labrum is situated anteriorly to paired mandibles with palps, and two pairs of maxillae. The mandibles bear three heavy teeth and a cluster of three or four small teeth along the cutting edge from anterolateral to posteromedial. The lateral flat surfaces are equipped with bristles, as is the medial edge posterior to the cutting edge (fig. $3 \mathrm{e}$ ).

The first maxilla bears two strong curved teeth and a few fine bristles anteriorly, a clean notch, and a broad edge bearing numerous bristles in two sets (fig. 3f). The usual long, curved apodeme extends from the base of the first maxilla (fig. 3a).

The second maxilla is broad, heavily bristled, and closes the posterior of the mouth field.

The first pair of cirri, located close to the mouthparts and hence called the mouth cirri, are biramous and appear to possess four and three segments in the anterior and posterior rami, respectively. These segments are difficult to count because of the numerous heavy bristles, and the questionable presence of a tiny segment at the extreme tip of each ramus. The rami are set on a two-segmented protopod. The larger proximal segment is ornamented posteroventrally with a row of fine nodules which appear to be invaginations of the chitinous integument. The bristles on the rami are in distinct tracts, primarily on the margins and along the inner surface of the larger anterior ramus, the latter bristles being somewhat plumose. The smaller posterior ramus overlaps on the outside of the larger anterior ramus near the base.

The other five pairs of cirri are crowded together at the tip of the thorax, hence the name "acrothoracica." These are designated the terminal cirri, and are numbered cirrus two to six, or terminal cirrus one to five. The first terminal cirrus (cirrus 2) is shorter and weaker than the others, which are quite similar to each other in size and shape. All are biramous on two-segmented protopods, with all segments bearing multiple sets of bristles. The last cirrus (6) bears extremely fine bristles anteroventrally. The bristles are primarily on the medial surfaces of the protopod. The basal segment of the protopod is about three times as long as the distal segment.

A detail of the setation of a midportion of the last (6th) cirrus can be seen in figure $3 \mathrm{i}$. The alternation of a pair of long distal setae and a pair of short central setae along the inner curvature of the cirrus is typical, as is the unpaired seta on every second to fifth segment along the greater curvature. There is no small unpaired seta between the longer pairs on the inner curvature, as is found in some species, but there is a small bristle in front of the unpaired seta on the outer curvature. 
The segment count for the cirri follows:

\section{Terminal}

cirrus:

Ramus:

Segments:

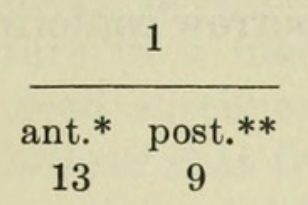

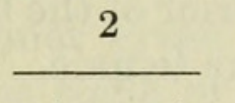

$\begin{array}{cc}\text { ant. } & \text { post. } \\ 18 & 19\end{array}$

$\begin{array}{cc}\frac{3}{\text { ant. }} & \text { post. } \\ 28 & 32\end{array}$

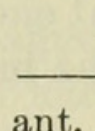

4

ant. post. ant. post $\begin{array}{llll}34 & 38 & 36 & 39\end{array}$

*Anterior. **Posterior.

The thorax is articulated in several places, essentially corresponding to a segment for each cirrus. An incomplete, weak, reinforcing ring is seen just anterior to the entire set of terminal cirri.

The male: The males are rare, attached to the exuviae of the female, and bear the usual paired antennules without long stalks (fig. 3j). A well-developed penis is coiled within the body, but its relationship to the other organs is uncertain. Scattered clusters of cells of apparent glandular function are seen, and there is a curious rounded projection from the end of the body opposite the point of attachment.

The larvae: The larvae are retained to the cyprid stage (fig. $3 \mathrm{k}$ ). The cyprid is typical, with a pair of antennules, a simple naupliar eye and a pair of cyprid eyes, six pairs of bristle-bearing swimming appendages, and a caudal furca probably analogous to the caudal appendage. A small, yellowish sphere with pointed projections was seen in the midst of a glandular mass in the anterior thoracic region. No function is ascribed to this, although it is conceivably analogous to the "yellow organ" of the males. No carapace ornamentation was seen.

RELATIONSHip: The only really effective point of differentiation between the genera has been the number of cirri and the presence or absence of the caudal appendages. Using this criterion, this species is definitely in the genus Weltneria. The appearance of the mantle aperture bears striking resemblance to Berndtia nodosa Tomlinson (1967), however. Berndtia is differentiated from Weltneria by the lack of a caudal appendage in the former. All specimens of this species examined showed clearly a well-developed caudal appendage.

The BURRow: The shape of the burrow aperture, as viewed from the outside, varies with the local conditions, especially the presence of algae and other organisms. The basic shape is that of a typed apostrophe, which is typical of the order.

Figure $3 \mathrm{n}$ shows a set of four burrow apertures averaging $1.15 \times 0.45$ $\mathrm{mm}$ in length and width. The burrow apertures 1 and 2 are in clean shell, while 3 and 4 are overgrown with algae. In the former two the original attachment site can be seen at the pointed end of the slit, which possesses a microscopic shelf of material upon which the larval antennules can be discerned in some specimens. It is difficult to 
detect the attachment end in slits 3 and 4 without recourse to the animal, or by observing the more precipitous slope inside the burrow on the attachment end. The interior of the burrow conforms essentially to the shape of the mantle of the female.

\section{Weltneria aapta, new species}

FIGURE 4

Diagnosis: Weltneria with operculum terminating anteroventrally in a pair of opaque, stout spines, with an array of over twelve hyaline spines along each lip of the mantle aperture. All spines are approximately of the same length. Many hairs and bifid teeth also arm the operculum.

ЕтумоцоGy: aapt- (Gr.), unapproachable, because of the spines.

Distribution: Twelve specimens found associated with Lithoglyptes calcaratus, from Berylsma waitei Hedley, from fish traps off Port MacQuarie, northern New South Wales, Australia, collected by J. Kerslake, from the Australian Museum.

Type-material: Holotype: Australian Museum. Paratypes: CA, SFSC, UCT, USNM. Additional material: Seto, Vict.

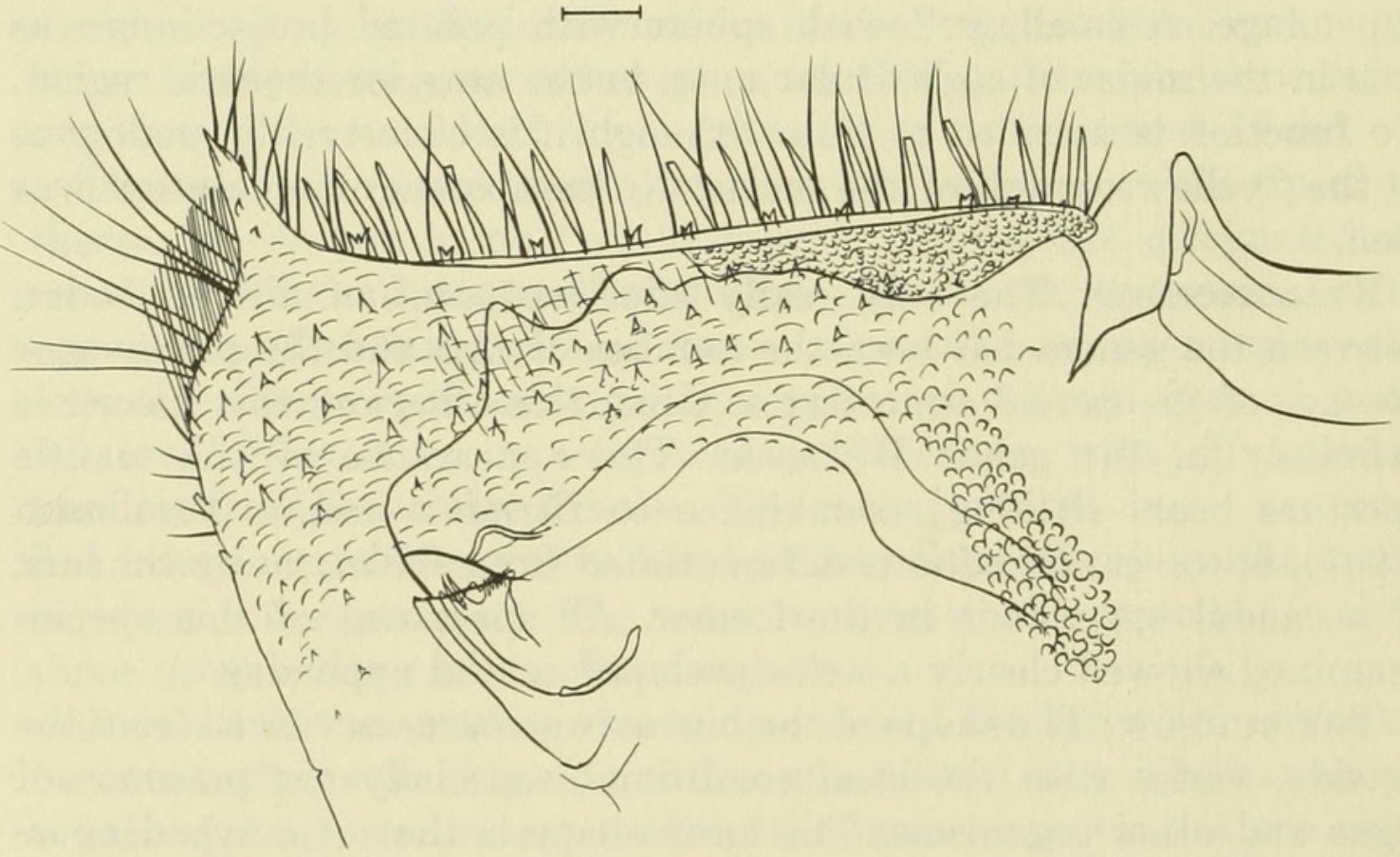

Figure 4.-Weltneria aapta, new species, from Berylsma waitei from Port MacQuarie, New South Wales, Australia. Female opercular area, side view. On mantle margins, the spines and scales are outside, the hairs inside.

Dimensions: Holotype: $2.7 \times 1.5 \mathrm{~mm}$, with aperture of $1.25 \mathrm{~mm}$. Average of eight other specimens, once dried but soaked out in acid alcohol: $2.81 \times 1.38 \mathrm{~mm}$ with aperture of $1.27 \mathrm{~mm}$. 
This species is essentially the same as W. reticulata from Heron Island and other northeastern Australian sites, but differs in the mantle aperture in a manner given in the diagnosis. Although in these dried, dead specimens some of the spines had been broken at their tips, I believe that they were essentially of the same length.

Other lesser points of difference include a shallow depression in this species, caused by the fusion of the two opercula at their dorsal ends, a more pronounced double crest in the head region, and the lack of the pronounced reticulated pattern in the operculum.

The mouth cirri have what appear to be five and four segments in the anterior and posterior rami, respectively. The bristles on the mouth cirri are not plumose.

The segment count for the terminal cirri follows:

Terminal cirrus:

1

2

3

4

5

Ramus:

ant.* post.** ant. post. ant. post. ant. post. ant. post.

Segments: $13^{* * *} 18^{* * *}$ 27 $38 \quad 45$ 53 $51 \quad 57 \quad 53 ?$ 61

*Anterior. $\quad * *$ Posterior.

***From a different specimen than the rest of the count.

\section{Genus Lithoglyptes Aurivillius, 1892, page 133}

Diagnosis: Lithoglyptidae with four pairs of terminal cirri plus a pair of caudal appendages.

TyPe-SPecies: Lithoglyptes indicus Aurivillius, 1892.

Aurivillius erroneously redescribes the family Lithoglyptidae and its genus and species in 1894 as new taxa. These were all first described by Aurivillius in 1892 .

In this genus the mouth cirri are well developed, with a twosegmented protopod and two rami, each subdivided into segments. The thoracic cirri are four multiarticulated, biramous pairs, each pair with numerous bristles and on a two-segmented protopod. A caudal appendage is present in the form of a pair of short, two- or threejointed cirri, not exceeding in length the basal portion of the thoracic cirri. There are also two pairs of conical processes or appendages on the ventral portion of the prosoma (thick body area, attached to the mantle sack). These also are to be found in the presumably closely allied Berndtia, and are perhaps homologous to the two pairs of long, fleshy appendages on the prosoma of Cryptophralus.

Nilsson-Cantell (1921) described a testicular organ in the burrowing form of $L$. indicus, although Aurivillius had described males in his original description. All burrowing forms possess ovaries and, there- 
fore, are considered females, with this possible exception. This has not been confirmed since Nilsson-Cantell's report.

The species of the genus Lithoglyptes are the least understood of the order Acrothoracica. There is no doubt that many intermediate forms are found, which do not lend themselves to accurate placement within the framework of species herein described. As additional work is completed on this genus, probably there will be a number of new species established, and some established species will be placed in synonymy. More work is presently being done on this genus by Utinomi, and by Newman and Tomlinson.

\section{Lithoglyptes indicus Aurivillius, 1892, page 133}

Figure 5

Diagnosis: Lithoglyptes with mantle aperture length equal to the greatest width of mantle, straight, without hooks, processes, or long hairs; oval or elliptical adhesive disk; no external lateral bar; freeswimming nauplius.

Distribution: Aurivillius $(1892,1894)$ has given us a complete description of this species. He characterized it further as follows: Female $6 \times 4 \mathrm{~mm}$, whitish, blue-violet on operculum and near mantle; many specimens found in corals and mollusks from Java Sea, Indian Ocean, and west coast of Sumatra.

Type-material: Unknown. Present material retained at San Francisco State College.

The described female specimen, from the Israel South Red Sea Expedition, Station $149 / \mathrm{E}$ is smaller $(2.84 \times 1.60 \mathrm{~mm}$ with a $1.15 \mathrm{~mm}$ aperture), but otherwise generally fits the description. The aperture is not as long as the mantle is wide. This discrepancy could be due easily to maturational differences. The lack of apertural armament and the details of the cirri and mouthparts concur as to the species. The count of five and three segments for the anterior and posterior rami of the mouth cirrus in this specimen can be considered not of taxonomic importance, as these counts often differ in other populations of acrothoracican species. The body processes are variable in species I have studied, and after $\mathrm{KOH}$ treatment they appear as limp wrinkled papillae. Only one pair of these body processes are figured, but another pair of wrinkles could well have been a second pair of body processes.

The mantle is studded with typically bifid teeth, scattered on the posterior half of the mantle only. The mantle obviously is cemented over a diffuse horny disk area, which forms an inconspicuous knob at the anterior end. 
The mantle is reinforced internally by two thickened rods projecting posteriorly dorsal to the head, between the middle of the aperture and the horny knob area. No separate external lateral bars of scaly appearance were found.

The operculum is armed with many extremely short teeth and very short hairs. Almost all of the teeth have a single point. The ventral (carinal) end of the aperture bears the typical comb collar on a velum which apparently can be moved in and out of the apertural area.

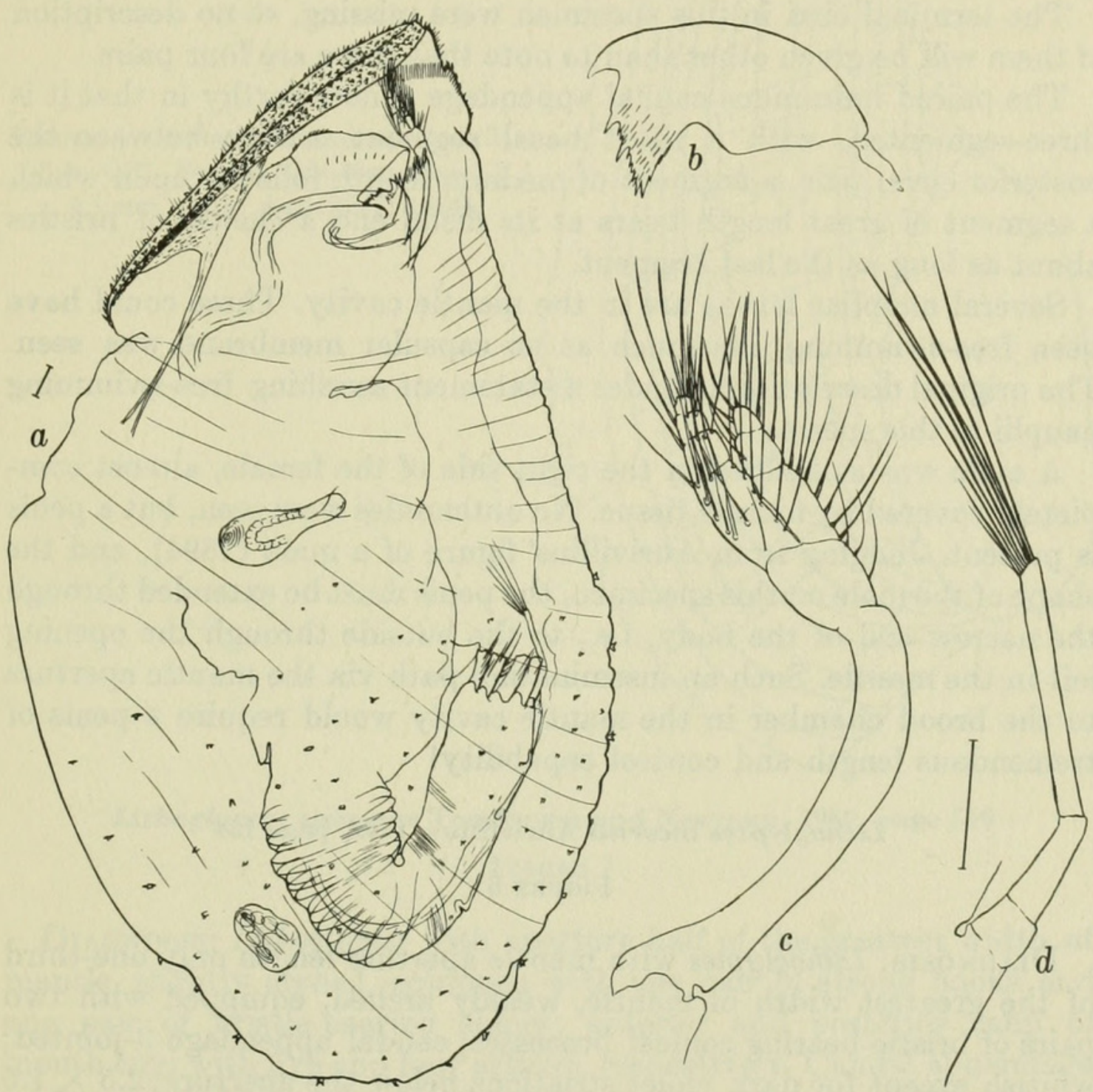

Figure 5.-Lithoglyptes indicus Aurivillius, 1892, from the Red Sea: $a$, female with embedded male, side view, most of terminal cirri missing; $b$, mandible; $c$, mouth (first) cirrus; $d$, caudal appendage.

The head bears a row of short hairs, and has a coating of fine granulations.

The mouthparts are typical of the genus. A shield-like labrum forms the top of the mouth field, followed posteriorly by a pair of 
mandibles with palps, and two pairs of maxillae. The mandibles have three stout teeth and many finer ones on the inner angle, with numerous pairs on the inner edge and lateral surfaces. The maxillae are typical, and have not been figured separately.

The mouth cirrus consists of two multisegmented rami on a twojointed protopod. The number of segments in the rami are difficult to count with confidence, but there are at least five and three in the anterior and posterior rami, respectively, each heavily bristled. The distal shorter segment of the protopod bears bristles.

The terminal cirri in this specimen were missing, so no description of them will be given other than to note that there are four pairs.

The paired uniramous caudal appendage is noteworthy in that it is three-segmented, with a short basal segment arising between the posterior cirral pair, a segment of medium length follows, upon which a segment of great length bears at its distal end a cluster of bristles about as long as the last segment.

Several naupliar larvae are in the mantle cavity. These could have been free-swimming, inasmuch as no capsular membrane was seen. The original description includes a statement ascribing free-swimming nauplii to this species.

A male was embedded in the right side of the female, almost completely covered by mantle tissue. No antennules were seen, but a penis is present. Judging from Aurivillius' figure of a male (1894), and the shape of the male on this specimen, the penis must be extended through the narrow end of the body, i.e., to the outside through the opening left in the mantle. Such an insemination path via the mantle aperture to the brood chamber in the mantle cavity would require a penis of tremendous length and control capability!

\section{Lithoglyptes bicornis Aurivillius, 1892, page 134}

\section{Figure 6}

Diagnosis: Lithoglyptes with mantle aperture length only one-third of the greatest width of mantle, weakly arched, equipped with two pairs of bristle-bearing conical processes; caudal appendage 3-jointed; whitish except for dark violet striations below the aperture; $2.5 \times 1.5$ $\mathrm{mm}$; few specimens found in corals in Java Sea.

I did not see this species, inasmuch as no specimen with these general characteristics had such a short mantle aperture. Otherwise, it very much resembles $L$. spinatus. The above constitutes almost the entire description of this species. See the section on Phylogeny (page 151), and figure 6. 
Figure 6.-Lithoglyptes bicornis Aurivillius, 1892. Female, side view, size 2.5 x $1.5 \mathrm{~mm}$ (after Aurivillius, 1894).

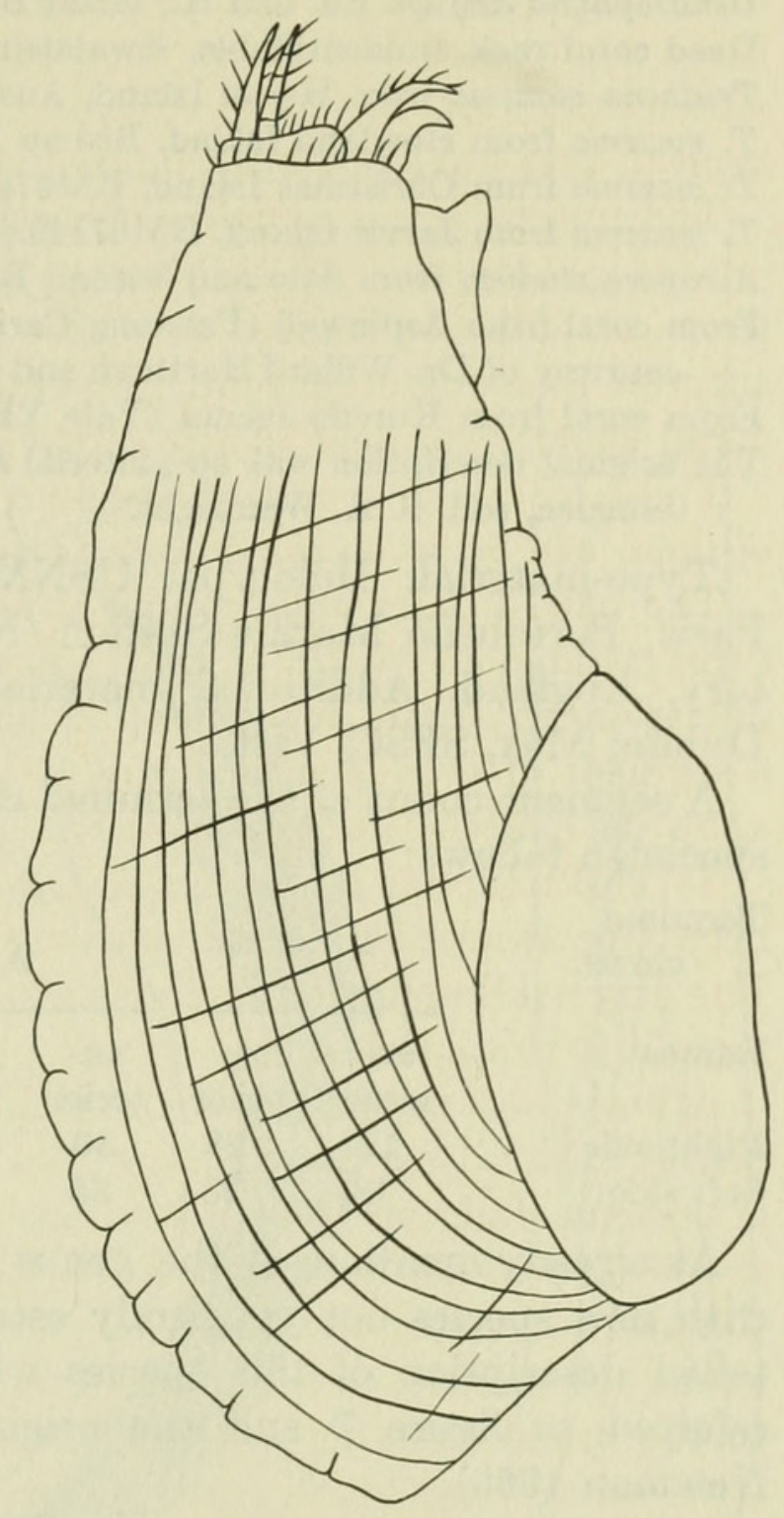

Lithoglyptes spinatus Tomlinson and Newman, 1960, page 519

Figure 7

Diagnosis: Lithoglyptes with aperture half of the greatest width of mantle, slightly arched, equipped with one pair of strong hooks and one pair of bristle-bearing spines; anterior and posterior rami of mouth cirri with five and four articles, respectively. Caudal appendage with two distinct segments; lateral bar weak or absent. Larvae retained until cyprid stage; pink with reddish mantle around aperture.

Distribution: Since its description, L. spinatus has been found to be widely distributed. Identifiable specimens have been found as follows; many incomplete and questionable specimens are not included:

Entedebir Island (Landing Bay) in faviid coral, coll. Stephen Wainwright on Israel South Red Sea Expedition, March-April 1962.

Unident. coral from intertidal rockpools, Minnie Waters, near Grafton, northern N.S.W., Australia, from Australian Museum. 
Dendrophylla axifuga Ed. and H., Great Barrier Reef, Aust. Mus. G6433.

Dead coral rock, unidentifiable, Kwajalein, Marshall Islands (J.T.).

Tridacna maxima from Heron Island, Australia (J.T.).

T. maxima from Howland Island, Bishop Museum BM67357.

T. maxima from Christmas Island, BM67094.

T. maxima from Jarvis Island, BM67149.

Acropora studieri from Seto and Susami Bay, Japan (J.T.).

From coral from Aspinwall (Panama, Caribbean side) and the Maldives Islands, courtesy of Dr. Willard Hartman and the Peabody Museum, Yale University.

From coral from Kuredo Island (Yale YP4179).

The original description was on material from Acropora palmata from Salt Gut, Jamaica, coll. S. A. Wainright.

Type-material: Holotype: USNM 103729. Paratypes: CA; Seto; Paris; Portobello Marine Station, New Zealand; Plymouth Laboratory, England. Additional material: Aust, BPB, Brit, Belg, BA, Dublin, Mex, SFSC, Vict.

A segment count of the terminal cirri of each side of one Kwajalein specimen follows:

Terminal

cirrus:

1

$\begin{array}{cc}\text { an- } & \text { pos- } \\ \text { terior } & \text { terior }\end{array}$

2

3

4

Ramus:

Right side:

19 terior

\begin{tabular}{cc}
\hline an- & pos- \\
terior & terior
\end{tabular}

$\begin{array}{cc}\text { an- } & \text { pos- } \\ \text { terior } & \text { terior }\end{array}$

$30 \quad 34$

18

28

35

40

29

?

36

39

\begin{tabular}{cc} 
& \\
\hline an- & pos- \\
terior & terior \\
$?$ & 44 \\
32 & 38
\end{tabular}

As already mentioned, the genus Lithoglyptes is in a fluid state, with new species not yet firmly established. For this reason, no detailed description of this species will be given here. The reader is referred to figure 7 and the original description (Tomlinson and Newman 1960).

Lithoglyptes ampulla Aurivillius, 1892, page 134

FIgURE 8

Diagnosis: Mantle aperture length one-fourth of the greatest width of mantle, weakly arched, equipped on one side with two anchorhooks, the other side with two feeler-like jointed hooks; caudal appendage four-jointed; whitish; $4.5 \times 2.5 \mathrm{~mm}$; one specimen from coral in Java Sea.

I did not see a specimen of this species. The above diagnosis embodies most of what we know of this species. 

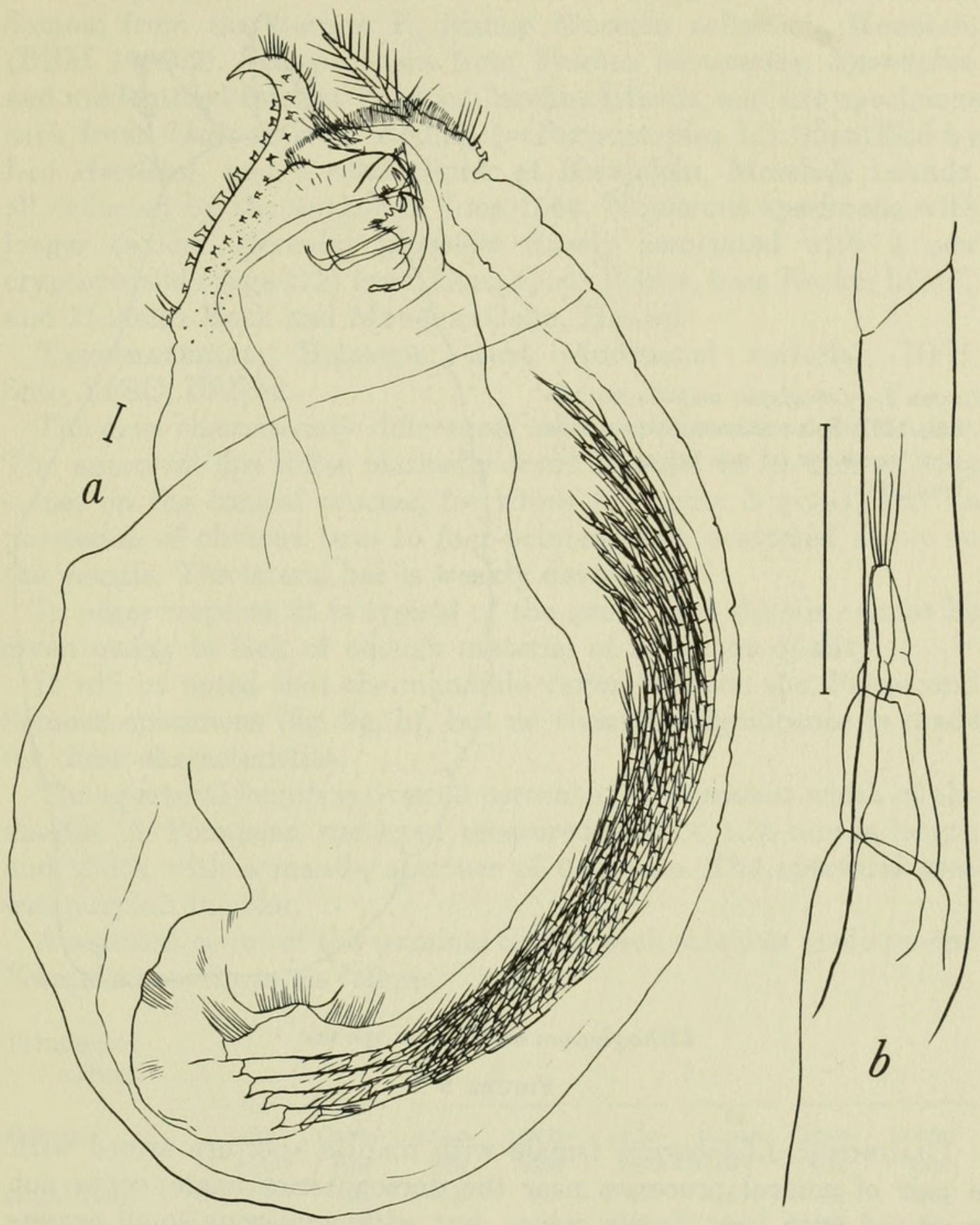

FIGURE 7.-Lithoglyptes spinatus Tomlinson and Newman, 1961 from Tridacna maxima from Heron Island, Australia: $a$, female side view; $b$, detail of caudal appendages showing weak third segment. 
FIgURE 8.-Lithoglyptes ampulla Aurivillius, 1892. Sole specimen, female, side view, size $4.5 \times 2.5 \mathrm{~mm}$ (after Aurivillius, 1894).

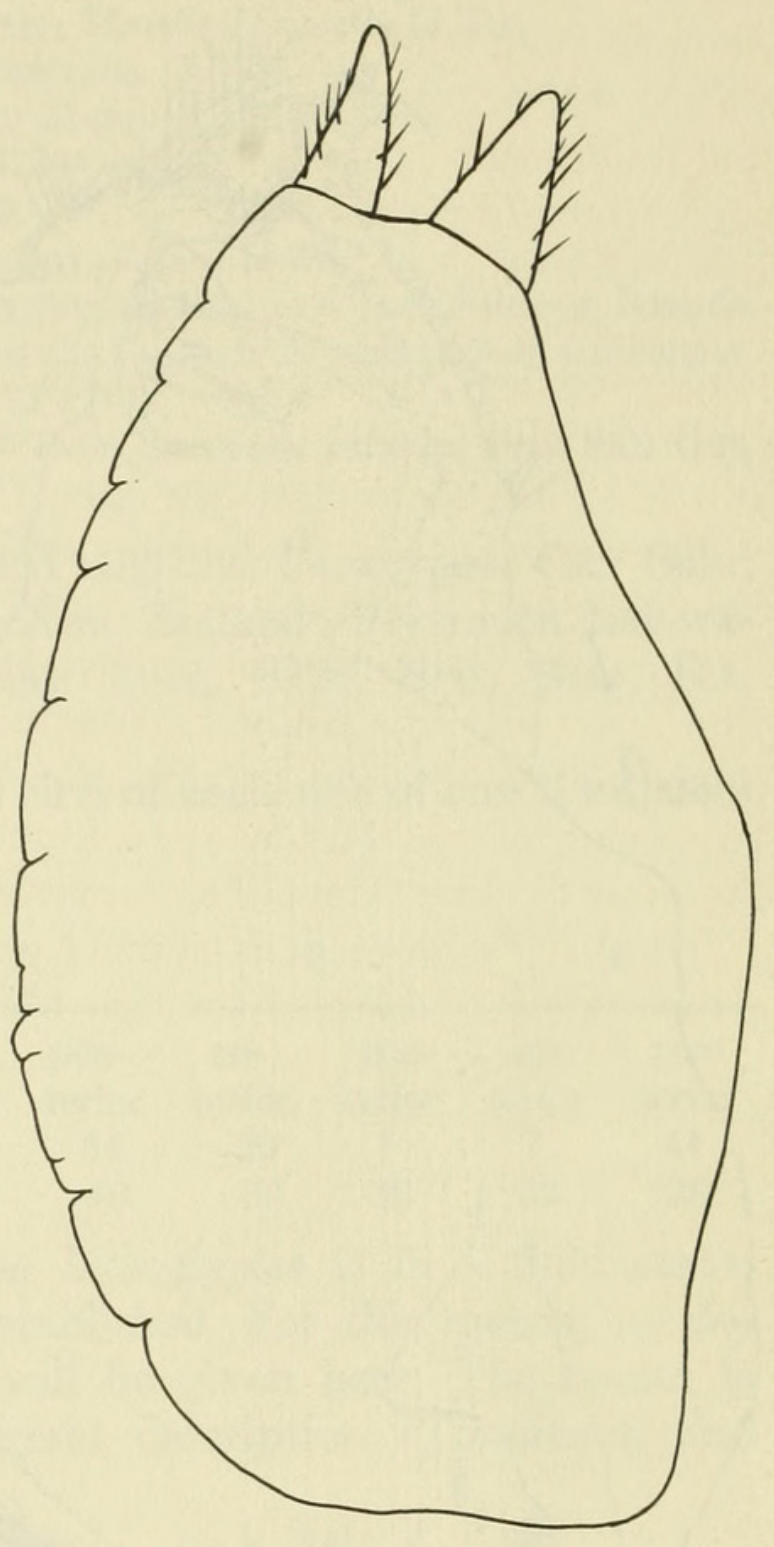

Lithoglyptes mitis, new species

Figure 9

Diagnosis: Lithoglyptes female with mantle aperture armed with a pair of conical processes near the dorsoanterior angle; cones not equipped with long simple spines, but with numerous small granulations and stout simple or bifid teeth. Lateral bar weak. Mantle studded with teeth of appreciable size. Orificial knob present.

ЕтумоLоGy: mitis (L.), mild, without spines, because of the lack of spines on the operculum.

Distribution: Six specimens from Bursa bubo L. from Nadi Bay, Veti Levu, Fiji, from the Australia Museum collection, designated holotype. Two specimens from Ricinula rubicunda from Nadi Bay, Veti Levu, Fiji Islands (Australian Museum specimen). 
Two specimens from Trochus obeliscus Gmelin, Tutuila Nuuuli, Samoa, from the Bernice P. Bishop Museum collection, Honolulu (BBM 198002). Six specimens from Trochus incrassatus, Spondylus, and unidentified coral at Ponape, Caroline Islands, and two specimens each from Thais tuberosa Röding (=Purpura pica L.) (identified by Leo Hertlein), and a coral chunk at Kwajalein, Marshall Islands, all collected by the author in June 1964. Numerous specimens with longer conical opercular processes closely associated with a new cryptophialid (page 112) from Thais aperta Blainv. from Necker Island, and Mokolea Rock and Manana, Oahu, Hawaii.

Type-material: Holotype: Aust. Additional material: BPB, Seto, SFSC, USNM.

The most characteristic differences in this species are on the mantle. The apertural lips differ markedly from $L$. habei in its lack of long spines on the conical process, for which the name is given, and its possession of obvious two- to four-pointed teeth scattered about on the mantle. The lateral bar is weakly developed.

In other respects, it is typical of the genus, and details cannot be given owing to lack of enough material of sufficient quality.

It will be noted that the mandible varies between the Fijian and Somoan specimens (fig. $9 \mathrm{~g}, \mathrm{~h}$ ), but no claim for significance is made for these characteristics.

The apertural length is over 60 percent of the greatest width of the mantle. A Ponapean specimen measured $2.05 \times 1.25 \mathrm{~mm}$ in length and width with a mantle aperture of $0.80 \mathrm{~mm}$. The apertural area was purplish in color.

A segment count of the terminal cirri of each side was made on one Kwajalein specimen, as follows:

Terminal

cirrus:

Ramus:

Right side:

Left side:
1

\begin{tabular}{cc}
\hline $\begin{array}{c}\text { ante- } \\
\text { rior }\end{array}$ & $\begin{array}{c}\text { poste- } \\
\text { rior }\end{array}$ \\
19 & 30 \\
19 & 31
\end{tabular}

2

\begin{tabular}{cc}
\hline $\begin{array}{cc}\text { ante- } \\
\text { rior }\end{array}$ & $\begin{array}{c}\text { poste- } \\
\text { rior }\end{array}$ \\
34 & 37 \\
36 & 41
\end{tabular}

3

$\begin{array}{cc}\begin{array}{c}\text { ante- } \\ \text { rior }\end{array} & \text { poste- } \\ \text { rior }\end{array}$

$43 \quad 46$

$43 \quad 46$
4

\begin{tabular}{cc}
\hline ante- & poste- \\
rior & rior \\
49 & 51 \\
47 & 46
\end{tabular}

The caudal appendage is distinctly two-segmented.

A male was found on one female, measuring $0.36 \times 0.29 \mathrm{~mm}$, with antennules attached to the body and not appreciably stalked. Two other males (fig. 9i) measured about $0.3 \times 0.2 \mathrm{~mm}$, with the younger still in a cyprid carapace $0.42 \times 0.225 \mathrm{~mm}$. A penis may be present. The posterior end is annulated with flanges, but without heavy teeth. The antennules have very short stalks which are typical, and do not bear the internal tubes seen in another species (page 58). 

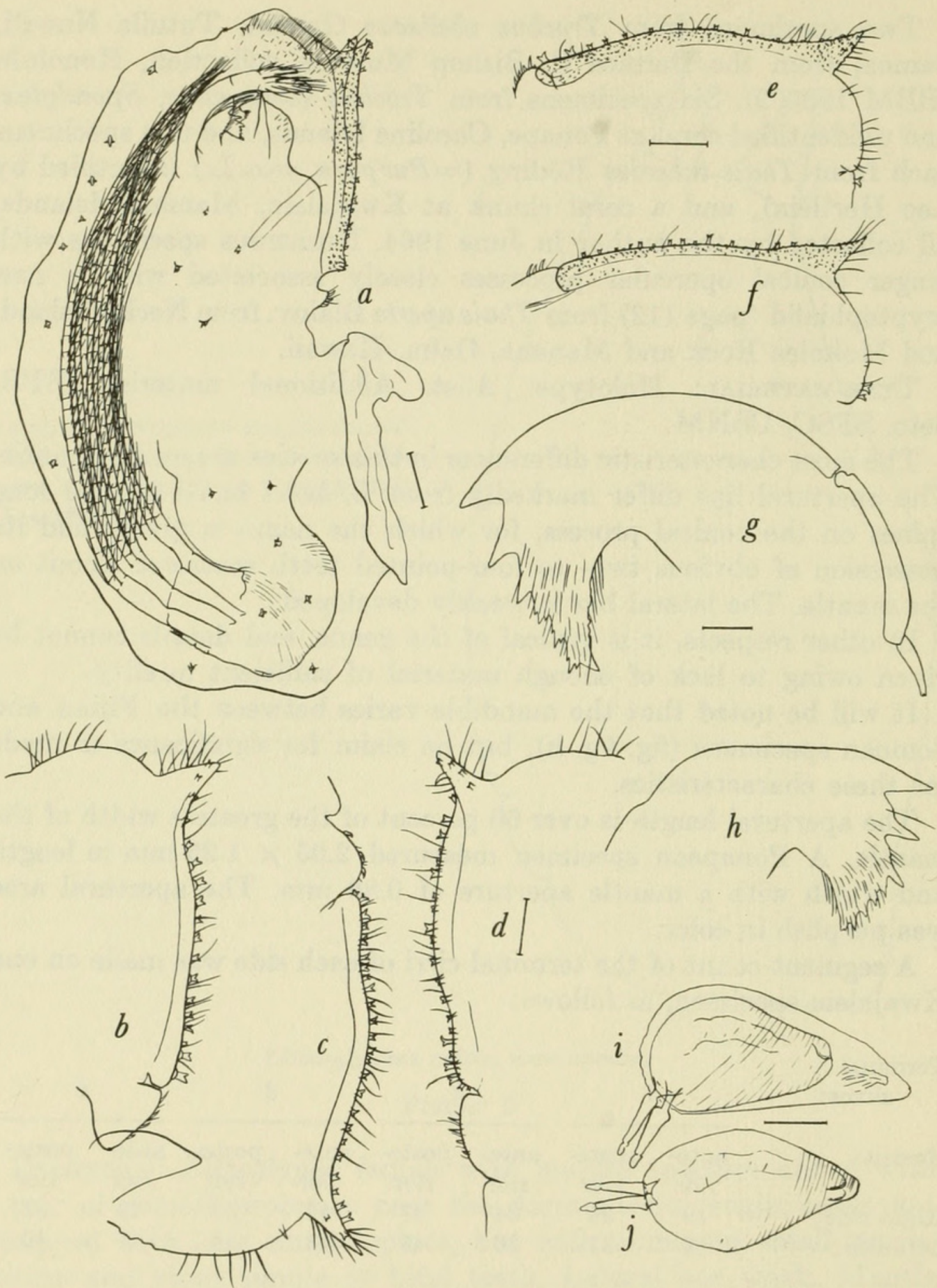

Figure 9.-Lithoglyptes mitis, new species: $a$, female side view; $b$ to $g$ : opercular horizons and details: $b$ to $d$, in coral from Kwajalein, Marshall Islands, scale approximate; $e, f$, in Bursa bubo from Veti Levu, Fiji: e, right operculum, female 1.33 × $0.95 \mathrm{~mm}$; $f$, left operculum, female $1.20 \times 0.86 \mathrm{~mm} ; g, h$, mandibles: $g$, from Fiji, $h$, from Samoa; $i$, young male, in carapace; $j$, mature male.

Lithoglyptes mitis is difficult to separate from L. spinatus. The latter species is abundant throughout the world, and frequently occurs with L. mitis. The presence of several species from several families in one 
shell is no longer surprising, but the distinction of $L$. mitis is clouded by the possibility that it might be an immature form of $L$. spinatus.

The most obvious difference between the two species is in the opercular armament. The pronounced hook and articulated spine in mature $L$. spinatus females is characteristic, but develops rather late in life.

A careful search for intermediate forms was undertaken and in all cases the specimens could clearly be designated $L$. spinatus or mitis in the samples listed above.

Size determinations were made on five $L$. mitis and three $L$. spinatus from the same piece of coral from Ponape. The L. mitis measured an average $2.08 \times 1.15 \mathrm{~mm}$ in length and width, with an aperture of $0.80 \mathrm{~mm}$. The range of each was $1.75-2.38 \times 0.80-1.38$ and $0.63-0.98$. The L. spinatus was $3.75 \times 2.05$ and $1.21 \mathrm{~mm}$, respectively, with a range of $3.0-4.5 \times 1.65-2.50$ and $1.00-1.50 \mathrm{~mm}$. As you can see, there is no overlap in the ranges. That the $L$. mitis was not just young $L$. spinatus is attested by the fact that three of the five specimens of L. mitis were gravid with eggs, and were thus obviously sexually mature. The Kwajalein material gives some overlap. A L. mitis specimen measured $2.84 \times 1.58 \mathrm{~mm}$ with aperture of $0.99 \mathrm{~mm}$, while the measurements of a well-developed $L$. spinatus from the same shell is $2.39 \times 1.31$ and $1.13 \mathrm{~mm}$.

In relationships, I would place $L$. mitis very close to $L$. spinatus, and not quite as close to $L$. habei.

It is noteworthy that there are many collections of $L$. spinatus which are exclusively this species and have no specimens resembling $L$. mitis. L. mitis is not found in association with $L$. habei, which is a western Pacific species. L. mitis is a central Pacific form, from Fiji to the Caroline and Marshall Islands.

\section{Lithoglyptes scamborachis, new species}

Figure 10

Diagnosis: Lithoglyptes with operculum armed with one pair of medial spines bent anteriorly or laterally at the tips, and one stout toothed cone on the left side posteriorly. One pair of weak lateral bars and one prominent posterior apertural bar present. Apertural length 63 percent of greatest width of body. Caudal appendage two-segmented.

EтүмоLоGY: scamb- (Gr.), curved, bent, rachis (Gr., or rhachis), a spine, because of the bent spines on the operculum.

Distribution: Six specimens were found in one valve of Tridacna maxima Röding from Heron Island, Queensland, Australia. Two 

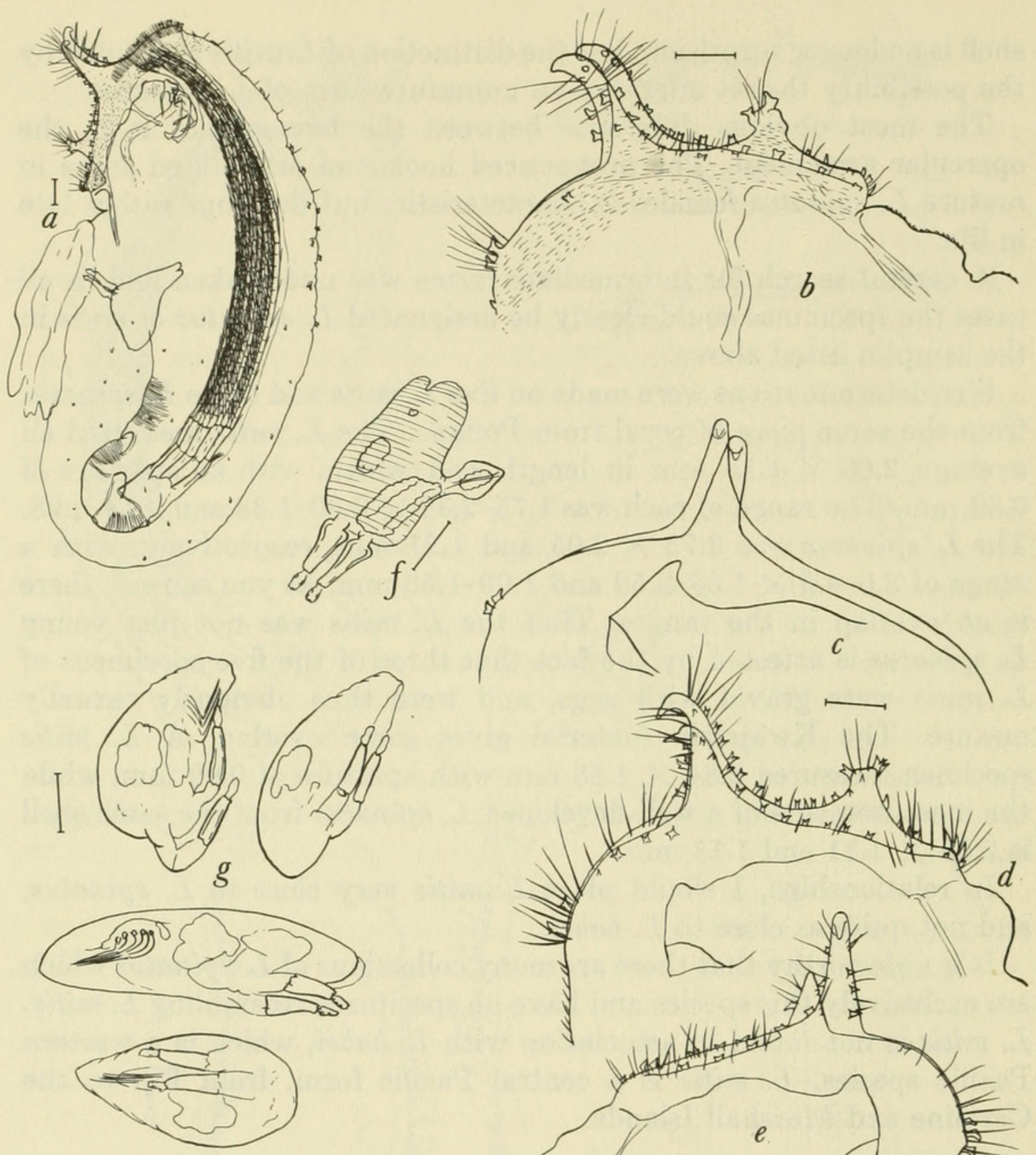
This species is a typical lithoglyptid except for the mantle aperture armature. The genus Lithoglyptes appears to be troublesome in the variability of the mantle armament, but the existing species of the genus are differentiated largely by this characteristic, which is of sufficient complexity and stability to be useful if fully mature specimens are found.

This species was found in association with $L$. spinatus. The latter had unmistakable characteristics precisely as described, and was found in another Tridacna maxima from the same locality. Sufficient variation exists between these two species to establish a new species. The name is derived from the bent spines on the aperture.

The aperture is long, measuring an average of $0.69 \mathrm{~mm}$ from orificial knob to comb collar. This is 63 percent of the greatest mantle width, as compared to $33 \frac{1}{3}$ percent for $L$. bicornis, 25 percent for $L$. ampulla, and 50 percent for $L$. spinatus. Two prominent spines arise in about the middle of the apertural lips and bend anteriorly at their tips. These spines are equipped with bifid teeth and long bristles. On the left lip a strong conical elevation, topped by several strong teeth and many bristles, arises near the posterior end. The remainder of the lips, analogous to the opercula of thoracican cirripeds, are armed with numerous bifid teeth on simple small spines, with scattered bristles at the posterior end and the typical comb collar at the anteroventral end. The sides of the apertural area are scaly, with the scales in places discernable as rows of extremely fine dots. A weak pair of lateral bars arise from the base of the spines and extend posteroventrally along the sides of the mantle.

The rest of the mantle is equipped with small teeth, mostly simple or bifid, but occasionally trifid. The anterior sides of the mantle are almost devoid of these, but bear short bristles along the ventral surface.

The internal structures are typical of the genus. The mouth cirri are faintly segmented into three and one segments for the anterior and posterior rami, respectively. The mouthparts appear very similar to those of $L$. spinatus. The caudal appendage is two-segmented. Larvae are retained in the female mantle cavity until the cyprid stage.

Segment counts are difficult, inasmuch as the distal ends are broken off of some rami of every specimen dissected. A pooled count follows:

\section{Terminal}

cirrus:

Left ramus:

Segments:

$*$ Right ramus. $* *$ Different specimen.

2

ante- poste-
rior rior

$12 \quad 19$

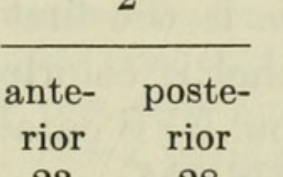

28
3

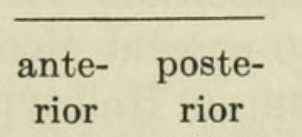

29

(32)*
4

ante- poste-

rior rior

$\left(\begin{array}{ll}28 & 29\end{array}\right)^{* *}$ 
The male appears typical in general aspect. A penis is present. The body bears fine annular striations but no plates or hairs. One male had a peculiar lobe projecting from the body which appeared to be stuck to the body of the female (sketched in fig. 10f). No long stalk was found between the body and antennules in the two males seen, as is found in L. spinatus.

ReLATIONSHiP: L. spinatus, the most cosmopolitan established species, seems the nearest relative to this species. Its relatively wide aperture, paired hooks, and toothy lips are similar. The posterior single cone is in no wise articulated, being, therefore, much different from $L$. spinatus. The unpaired nature of this cone may well not be important, e.g., the other member of the pair may not have developed yet. Kochlorine hamata, however, is very constant in having a single hook on one side only, and therefore this might be a good characteristic.

Aurivillius' two species, described from the southwest Pacific, have a shorter aperture, as already mentioned, and also different apertural armament. $L$. bicornis bears two pairs of bristle-bearing conical processes, while L. ampulla bears two anchor-hooks and two jointed feelers. His notation that the caudal appendage is three- and fourjointed in the two species, respectively, is probably erroneous. His two figures are much different from this species.

\section{Lithoglyptes wilsoni, new species}

Figure 11

Diagnosis: Lithoglyptes without orificial knob; one pair of long, thin, opercular spines curved dorsally; opercular plates with large bifid teeth; no lateral bar. Male antennules with internal tube.

Eтүмодоgy: Named for Peter T. Wilson, Fisheries Biologist of Trust Territory of the Pacific Islands, at Koror, who assisted me in many ways.

Distribution: Fifty-four specimens from Turbo lajonkairi, Wake Island, collected in July-August 1923 by D. Thaanum, from the Bernice P. Bishop Museum shell 66541. In association with about 115 specimens of a new species of Cryptophialus (see page 104). Three specimens from coral from Koror, Palau, Caroline Islands. Sixtyseven specimens from Heliopora sp. from west of Ulul Island, Namonuito Atoll, 15-60 feet deep, collected by William A. Newman on the Carmarsel Expedition. This is the first record in a blue coral. The barnacle in 80-percent alcohol is colorless.

TyPe-MATERIAL: Holotype: BPB catalog number B466, from Wake Island. Paratypes: SFSC, USNM. 

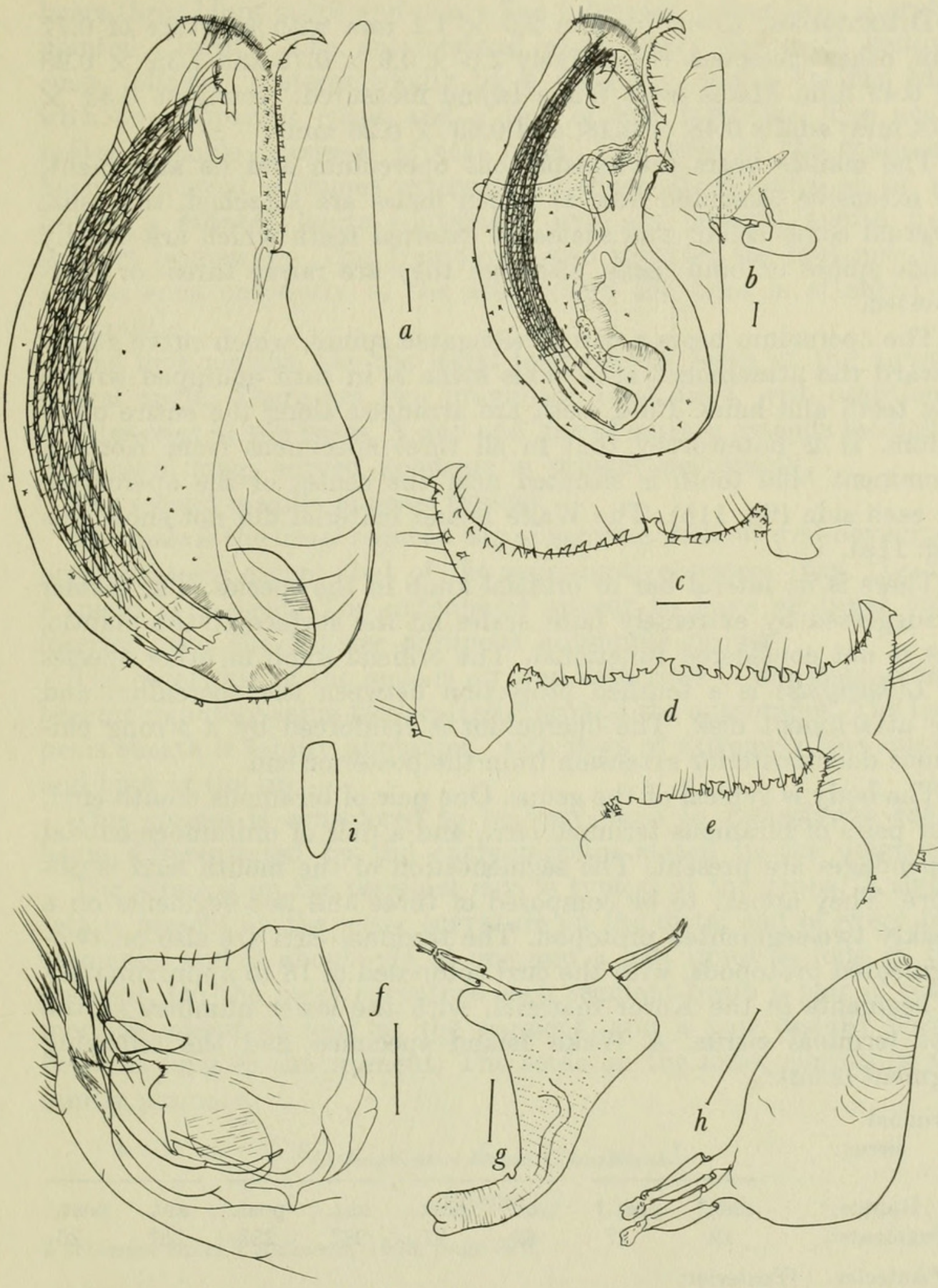

FIGURE 11.-Lithoglyptes wilsoni, new species: $a$, female, side view, from Turbo lajonkairi from Wake Island; $b$, female with males, side view, from coral from Koror, Palau Islands; $c$ to $e$, opercular horizons, three specimens from coral from Koror: $c$, $d$, left operculum; $e$, right operculum; $f$, mouth field, side view, from Koror; $g$, mature male, from Koror; $h$, mature male, from Wake Island; $i$, burrow aperture in Turbo lajonkairi from Wake Island, slight cant on side opposite original attachment probably due to position in shell. 
Dimensions: Koror females $2.0 \times 1.1 \mathrm{~mm}$ with aperture of 0.77 $\mathrm{mm}$, other specimens respectively $2.0 \times 0.9 \times 0.73$ and $1.35 \times 0.95$ $\times 0.49 \mathrm{~mm}$. Males from Wake Island measured: youngest $0.33 \times$ $0.14 \mathrm{~mm}$; adults $0.48 \times 0.18$, and $0.63 \times 0.26 \mathrm{~mm}$.

The mantle bears the conspicuous operculum and its armament, an extensive cemented disk to which males are attached, the usual internal comb collar, and scattered external teeth which are usually single spines or bifid teeth, although they are rarely three- or fourpointed.

The operculum bears a pair of elongated spines, which curve gently toward the attachment area. This spine is in turn equipped with a few teeth and hairs. Bifid teeth are arranged along the entire operculum. It is noteworthy that in all three specimens from Koror a prominent bifid tooth is situated near the center of the operculum on each side (fig. 11b). The Wake Island material did not show this (fig. 11a).

There is no lateral bar or orificial knob in the species. The former is suggested by extremely faint scales on the surface of the mantle, but is not considered functional. The orificial knob in other species of Lithoglyptes is a toothed projection between the operculum and the attachment disk. The operculum is reinforced by a strong chitinous dorsoposterior extension from the posterior end.

The body is typical of the genus. One pair of biramous mouth cirri, four pairs of biramous terminal cirri, and a pair of uniramous caudal appendages are present. The segmentation of the mouth cirri is obscure. They appear to be composed of three and two segments on a weakly two-segmented protopod. The terminal cirri are also on twosegmented protopods, with the cirri composed of 18 to approximately 38 segments in the Koror material, with the lower numbers in the first terminal cirrus. A Wake Island specimen had the following segment count:

Terminal

cirrus:

1

2

Ramus:

Segments:

\begin{tabular}{cc} 
& \\
\hline ant.* & post. $\dagger$ \\
12 & 17
\end{tabular}

\begin{tabular}{rr}
\multicolumn{2}{c}{2} \\
\hline ant. & post. \\
32 & 27
\end{tabular}

\begin{tabular}{cc}
\multicolumn{2}{c}{3} \\
\hline ant. post. \\
$26 ? \quad 28 ?$
\end{tabular}

\begin{tabular}{rr}
\multicolumn{2}{c}{4} \\
\hline ant. & post. \\
$25 ?$ & 26
\end{tabular}

*Anterior. †Posterior.

The caudal appendage is clearly two-segmented.

The mouthparts consist of the usual paired mandible with palps, and two pairs of maxillae (fig. 11f). The labrum serves as an upper lip of the mouth field, and is rounded and heavy. The mandibular palps are simple with several hairs distally, although they appear adherent to the labrum as much as to the mandible. The mandible 
bears three blunt cusps and many fine tubercles, rather than sharplypointed "teeth." The anterolateral angle bears the most distinct cusp, followed posteromedially by a diastema, and a cutting edge with two apparent cusps and a row of fine tubercles. The acute posterior angle possesses typical hairs. The base of the mandible bears the usual chitinous extension to which there seems to be attached a striated fascia continuous with the general mouth field support framework. This framework also involves the first maxillae and extends anteriorly to the area where the head is attached to the mantle.

The first maxilla has the usual long curved teeth at the anterolateral angle. There are two prominent teeth here, with additional smaller ones at the bases. A gap and haired surface extends medially. The usual long, curved apodeme is present posteriorly.

The second maxilla appears typical.

The male is the usual reduced bag of gametes without well-developed organ systems except that of the reproductive system (figs. $11 \mathrm{~g}, \mathrm{~h}$ ). A penis is present. The antennules appear to have an inner tube inserted into the heavier chitinous antennule proper.

The outer skin of the male is arrayed with rows of fine dots, which become minutely spine-like scattered around the antennules. The long penis sheath is faintly annulated, with rows of extremely fine spines, and bifid at the tip.

This species is considered to be very close to Lithoglyptes habei, being differentiated by the characteristics stated in the diagnosis.

The setation on the terminal cirri is typical of the genus. A single seta is present on the outer curvature on the distal end of every few segments, and is about one to one and a half times as long as the segment. On the inner curvature each segment bears a pair of setae medially about as long as the segment, and a pair distally about twice as long as the segment. The setae on the inner curvature are faintly plumose.

\section{Lithoglyptes habei (Tomlinson)}

Figure 12

Kochlorine habei Tomlinson, 1963, page 270.

Diagnosis: Lithoglyptes with mantle aperture armed with a tapered projection usually terminating anteriorly at or near a strong spurlike spine. Strong spines, bifid teeth, and bristles line both granular lips of the aperture, and a granular lateral bar reinforces the sides of the mantle sac. Orificial knob present.

Distribution: Twelve dried specimens in Kelletia lischkei Kuroda from Tomioka, Amakusa, Kyushu, on rock 10 meters below the 


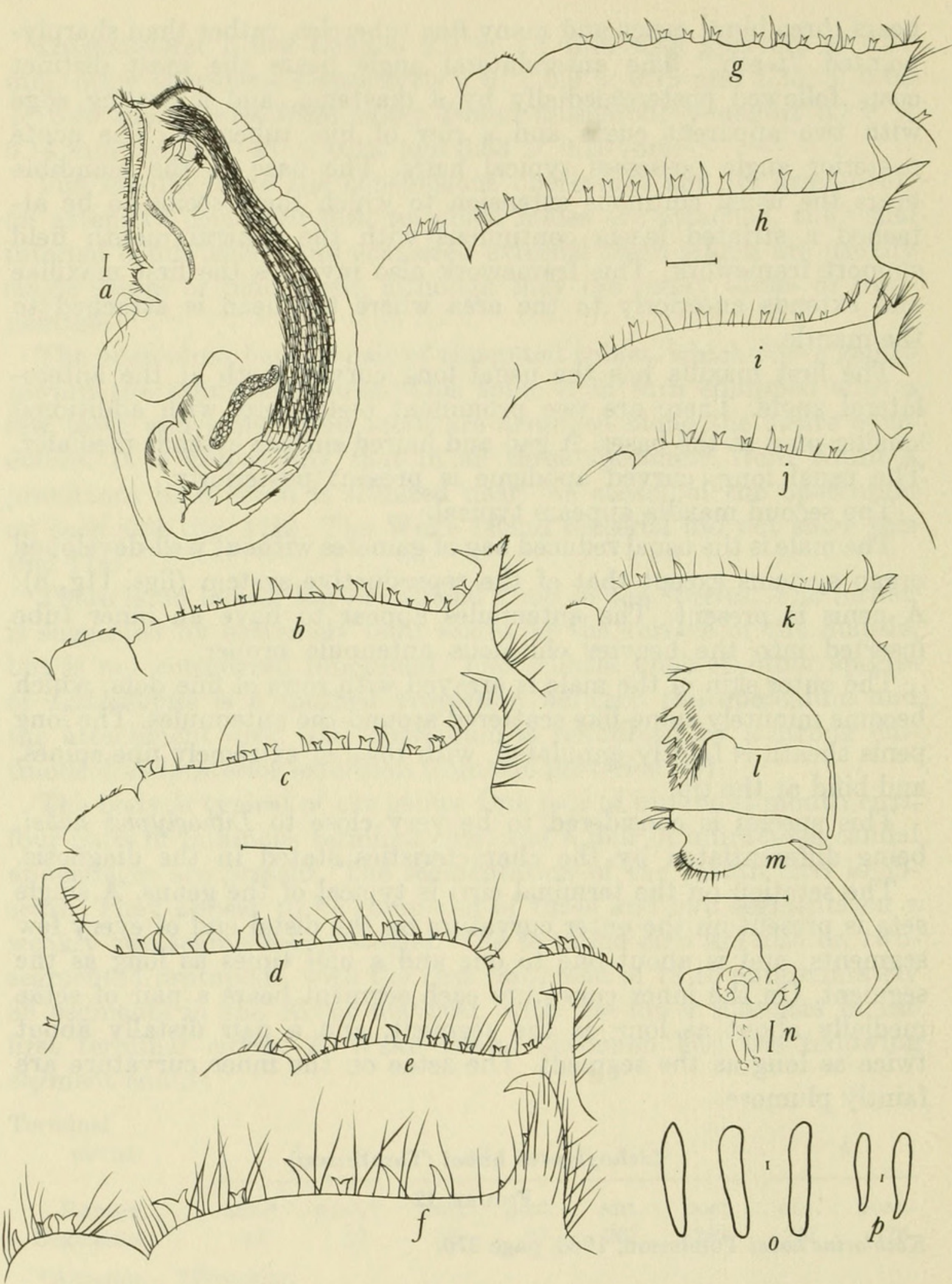

FigUre 12.-Lithoglyptes habei (Tomlinson, 1963c): $a$, female, side view; $b$ to $k$, opercular horizons showing armament, left operculum shown in $b, c, e, f, j$; right operculum shown in $g, h, k ; i$ shows all of the left, a part of the right; $l$, mandible; $m$, first maxilla; $n$, sketch of mature male, obscured; $o$, burrow apertures from Xenogalea stadialis from Forster, N.S.W., Australia, rostral end is down; p, burrow apertures from Cronia pseudomygdala from Port Curtis, Queensland, Australia, through bryozoans, rostral end down. 
surface; three dried specimens in Bursa bufo (Röding) from the area of Seto, Wakayama-ken, Japan (in association with Weltneria hirsuta); three dried specimens in Charonia sauliae (Reeve) from the area of Seto, Wakayama-ken, Japan. Figured specimen from Siphonalia tasmaniensis Ad. and Ang., from Spencer's Gulf, Southern Australia. (C39180 of Australian Museum, Helm's Collection). $2.10 \times 1.20 \mathrm{~mm}$, with aperture of $0.87 \mathrm{~mm}$ after $\mathrm{KOH}$ corrosion. Largest specimen from this locality $2.28 \times 1.20 \mathrm{~mm}$.

Other material, all from the Australian Museum through the courtesy of Drs. Elizabeth Pope and Donald McMichael: from Xenogalea stadialus Hedley, with hermit crab, in lobster pot off Forster, N.S.W. (coll. J. Kerslake); from Berylsma waitei Hedley in fishtraps off Port MacQuarie, northern N.S.W. (coll. J. Kerslake); from Cronia pseudamygdala Hedley, dredged off Port Curtis, Queensland; from Plecuna (Placenta) lobata Sowerby, Port Curtis, Queensland (largest specimen: $3.80 \times 2.28 \mathrm{~mm}$ ); from Dinassovica jourdani (Kiener), locality data: southern to southwestern Australia; from Bursa rubeta L., Darn Ley Is., Torres Str., Australian Museum C51494; Fulgetrum sp. and Ostrea angasi, Victor Harbor, Granite Island, S. Australia (Nat. Mus. Victoria); six specimens distributed to Aust. Mus., NMV, USNM, SFSC, Brit, CA.

Type-Material: Holotype: Seto 197; Paratype: SFSC 630926. Holotype $2.6 \times 1.4 \mathrm{~mm}$ in length and width. Additional material: Aust, BPB, Brit, Belg, BA, CA, Dublin, Mex, Paris, UCT, USNM, Vict.

The female: The mantle is a typical bag of musculature, with an appreciable attachment disk, an orificial knob variously equipped with teeth and hairs, and an aperture with lips considered analogous to the operculum. In addition, a pair of lateral bars arise from near the middle of the dorsal length of the apertural lips, and extend posteroventrally. They are not associated with teeth as in Cryptophialus, and are of a honeycomb or granular appearance. The mantle is almost devoid of teeth around the periphery. Those teeth which are present are extremely small.

The operculum bears a pair of heavy tapered projections near the anterior extremity. The aperture continues ventrally as a relatively soft and unarmed portion, lined with the comb collar, and bearing a few bristles. The tapered projections typically bear a long hyaline spine at or near the tip, giving the general appearance of a spur. On the heavy dorsal limb of the apertural lips, strong hyaline spines and bifid teeth are arrayed, interspersed with bristles. The details of the profile of the armament, and its variation, can be seen in figures $12 \mathrm{~b}$ to $\mathrm{k}$. The six specimens from Dinassovica jourdani from southern or southwestern Australia had very strong spines and teeth which 
were usually bifid, but were often three-pointed, with even fourpointed teeth not uncommon. It is definitely the same species, however.

The internal anatomy is typical of the genus. The pair of mouth cirri each possess two rami on a two-segmented protopod. The rami have weak segmentation, appearing to be five and four segments in the anterior and posterior ramus, respectively. The rami are well equipped with setae which are not plumose. The four pair of terminal cirri are diagnostic of the genus, with typical setation: a pair of long bristles (about four times as long as the segments) on the distal inner curvature, and a pair of short bristles (about as long as the segments) medially, on each segment, plus a single bristle located distally on the outer curvature of fewer segments, up to four segments apart (about 1.8 times as long as the segment). The segmentation of the terminal cirri, for one southern Australia specimen, follows:

Terminal

cirrus:

Ramus:

Segments:

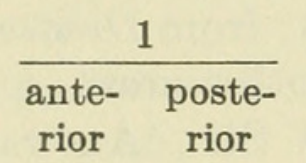

$23 \quad 30$

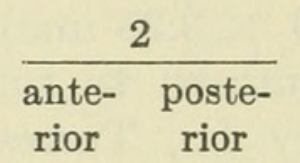

30

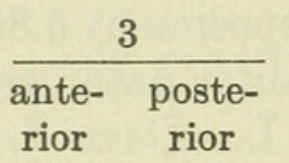

$4144 ?$

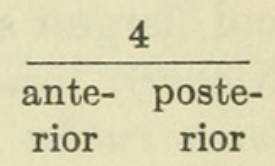

$4938 ?$

That this number is dependent on maturation is indicated by one smaller specimen, in which the anterior ramus of the first terminal cirrus had 15 segments.

A specimen from Kelletia lischkei from Japan had the following segment count:

Terminal

cirrus:

Ramus:

Segments:

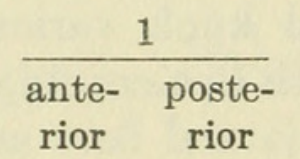

16

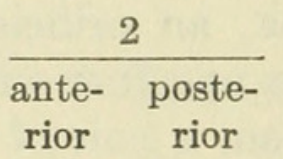

33

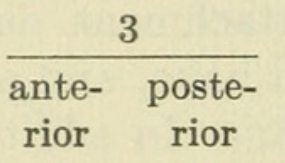

39

41

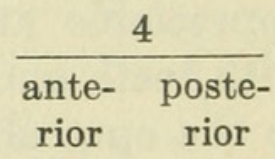

$35 \quad 44$

The one pair of caudal appendages follow the terminal cirri; they are two-segmented, with terminal bristles which do not appear to be plumose.

The mouthparts are typical. The labrum is large and prow-shaped, not unlike a knight's visor. The mandibles have three prominent teeth with about four fine hyaline teeth and many bristles along the cutting edge to a sharp posteromedial angle (fig. 121). The mandibular palp is typical. The first maxillae have the typical few heavy teeth (two prominent ones, plus a variable number of secondary teeth and bristles) separated from a hillock of fine teeth and heavy bristles by a diastema (fig. $12 \mathrm{~m}$ ). The apodeme is typical. The second maxillae are typical.

The esophagus leads dorsally from the mouth field, and bends sharply posteriorly. The posterior part of the digestive tract often bears a dark mass, probably representing indigested material. 
The posterior end of the thorax bears the fine circular striations typical of the order.

The male: The male is not unusual for the order (fig. 12n). Young males are hyaline, without surface ornamentation or armament of any kind. A pair of antennules attach him to the female near the attachment disk, and connect to the male directly without the long stalk seen in some species. A penis is present. As the male matures he appears to elongate, extending from $0.28 \mathrm{~mm}$ to $0.48 \mathrm{~mm}$ in body length.

Kochlorine Noll, 1872a, page 24

Diagnosis: Lithoglyptidae with three pairs of terminal cirri plus one pair of caudal appendages.

TYPE-SPECIES: Kochlorine hamata Noll, 1872b.

\section{Kochlorine hamata Noll, 1872b, page 50}

\section{Figure 13}

Kochlorine haliotidis Noll, 1872a, page 24 nomen nudum.

Kochlorine inermis Stubbings, 1964b, page 343.

Diagnosis: Kochlorine with paired anterior conical processes and one posterior hook on operculum.

Distribution: Noll's material was from Haliotis tuberculata shells from Cadiz, Spain. I have found material in Thais haemastoma L. from the same locality (thanks to the University of Liberia and Frank Tichy), and also from the following localities and hosts:

Accra, Ghana: Cymbium glans, AMNH 101009, Mollusk catalog; courtesy of Arnold Ross and the American Museum of Natural History.

Indian Ocean: Turbo ticaonicus Reeve, 1848. det. Leo Hertlein; courtesy of Dr. Joshna, University of Liberia.

Bône, NE. Algeria: Charonia nodiferus; courtesy of Institute Royal des Sciences Naturelles de Belgique.

Acapulco, Mexico: clam shell fragments; courtesy of Lieutenant and Mrs. Gay Galiher.

Venado and Taboga Islands, Panama (Pacific): many shells; courtesy of Mr. and Mrs. Stewart Jadis, and Joe Becker.

Philippine Islands: Acropora prostrata (Dana); courtesy of National Museum, Manila.

Port Moresby, Papua: Turbo chrysostoma; courtesy of Australian Museum C57952.

Yirrkala, Arnheim Land, Northern Territory, Australia: Tridacna sp.

Hin-Tasin Island, Northern Gulf of Thailand: Unident. shell from California Academy of Sciences, courtesy of Dustin Chivers. 
On the basis of the above material, the species can be considered worldwide in its distribution.

Type-Material: Specimens from Australia have been deposited as follows: Aust, BPB, Brit, BA, CA, Dublin, Mex, Paris, SFSC, UCT, USNM, and Vict.

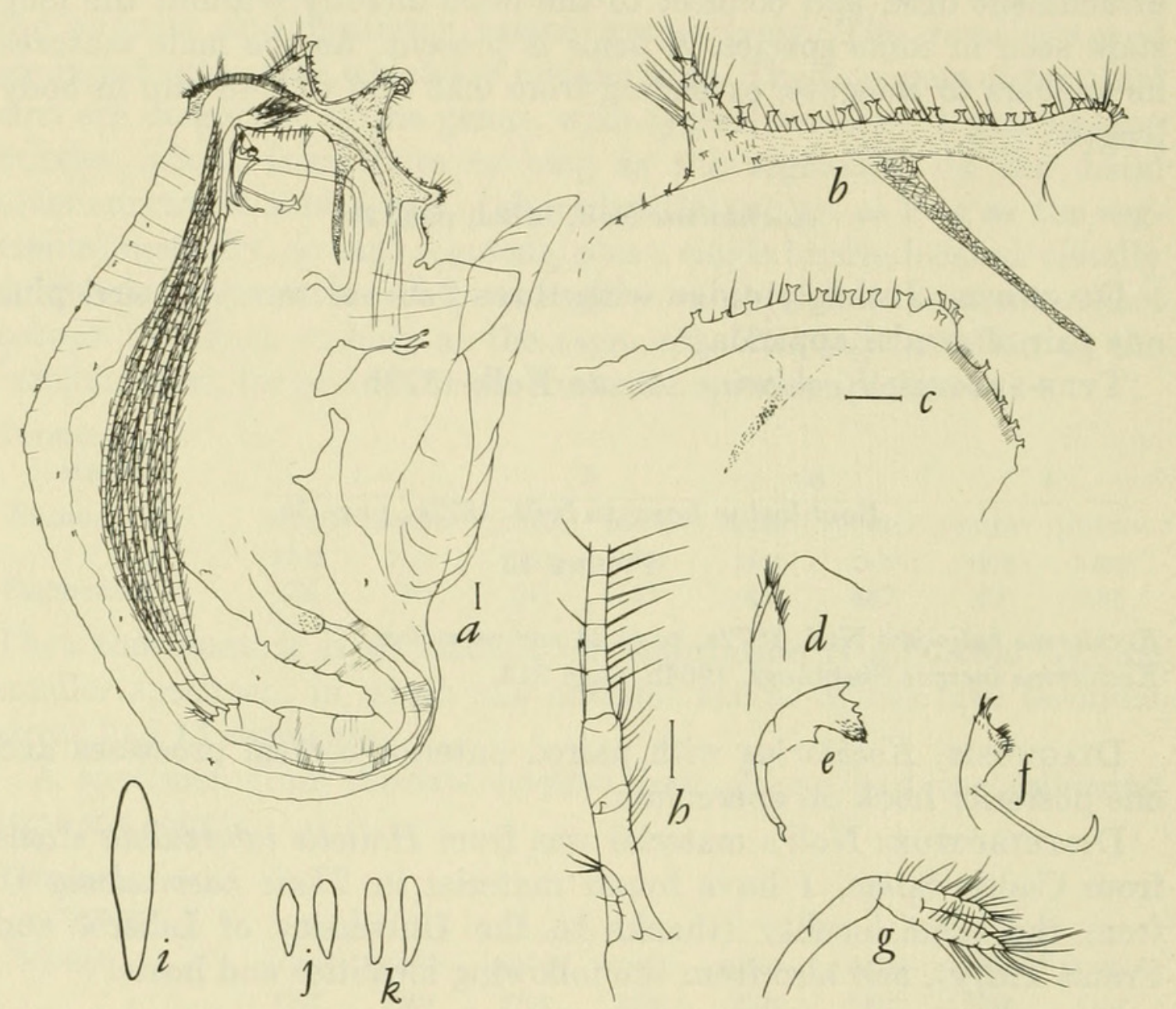

FIGURE 13.-Kochlorine hamata Noll, 1875: a, female with male, side view, from Turbo chrysostoma, Port Moresby, Papua, double hook on left side; $b$, detail of left operculum of specimen in $a$, showing right side without hook $c$, right opercular horizon and weak lateral bar of young specimen from Cadiz; $d$, head and mandibular palp; $e$, mandible; $f$, first maxilla; $g$, mouth (first) cirrus; $h$, detail of basal portion of last terminal cirrus and caudal appendage, same specimen as in $a ; i$, burrow aperture in shell from Gulf of Thailand; $j$, burrow apertures from Acropora prostrata from the Philippines, rostral end down; $k$, burrow apertures from Cymbium glans from Accra, Ghana, rostral end down.

Noll seems to have changed his mind about the designation of this specific name. In 1872 (a) he gave an address in which he stated that he had been working on the description of a new burrowing barnacle in Haliotis tuberculata shells from Cadiz, to be named Kochlorine haliotidis. In another address (1872b) he stated that he was going to change the name owing to the possibility that it might subsequently be found in other hosts. 
Kochlorine was originally described as lacking an adhesive disk, lying free in the cavity, and anchored by the various hooks and spines along the operculum. This is erroneous, although the first discovery of such relatively large hooks could easily lead to such a view. The material I have examined was cemented in the usual acrothoracican manner.

The mantle of the female is typical. The original description stated their size as "3 mm." My illustrated specimen (fig. 13a) from Port Moresby, Papua, is $2.9 \times 1.75 \mathrm{~mm}$. Three specimens from Thais haemastoma L. from Cadiz, Spain (type-locality), from the shell collection of the Institute Royal de Belgique average $2.35 \times 0.925 \mathrm{~mm}$, while specimens from the eastern Pacific (Panama) averaged $0.975 \times$ $0.570 \mathrm{~mm}$ (of 16 specimens), the largest being $1.20 \times 0.83 \mathrm{~mm}$, while three specimens from the eastern Pacific (Acapulco) were much smaller (average $0.733 \times 0.442 \mathrm{~mm}$ ). Three specimens from Ghana average $0.627 \times 0.340 \mathrm{~mm}$, with a cyprid carapace of $0.775 \times 0.036$ $\mathrm{mm}$, but these were in a shell less than $2.1 \mathrm{~mm}$ thick!

The mantle has the usual sprinkling of teeth, most of which are bifid. A pronounced horny adhesive disk and horny knob are present, but there is no separate orificial knob in the attachment area.

The mantle aperture has a well-armed operculum, bearing a pair of toothed cones anteriorly and a single strong hook dorsoposteriorly. The hook has a double termination of sharp, hyaline, dorsally curved points. Scattered bifid teeth and a few relatively short hairs are present on the operculum.

The hook may be on the animal's right or left side, but never on both. Many specimens were carefully examined for this, and the incidence on the right and left sides are approximately equal. A differential count in the various localities may prove interesting with more material, however.

A pair of strong granulated lateral bars is present, plus a single, strong, internal, reinforcing rod extending posteriorly from the dorsal end of the operculum. The retractor pallii rostralis is well developed, as is to a lesser extent the retractor orificii. The retractor corporis is probably present in the form of several rather small strands.

Inside the anteroventral angle of the mantle is the usual comb collar.

The female body is composed of a head region bearing scattered hairs anteriorly, an unpaired labrum, and pairs each of mandibles with palps, first and second maxillae, mouth cirri, three pairs of biramous terminal cirri, and a pair of uniramous caudal appendages.

The mouthparts are typical of the order. The mandible possesses three strong teeth and a haired, fine-toothed, inner cutting angle. The first maxillae bear two major spines with minor spines, teeth, and 
hairs on the inner curve and on the flat external surface, plus the usual long medially curved apodeme.

The segmentation of the mouth cirrus is debatable. Noll ascribed to each ramus of the biramous mouth cirrus the possession of a single segment. I have examined many of these, and confess that in most cases the counting of segments is a very difficult task. I have felt satisfied, however, that in some specimens I have counted five and four segments in the anterior and posterior ramus, respectively (fig. $13 \mathrm{~g})$. The three-segmented protopod described by Noll is also doubtful. The protopods of all species are often wrinkled, giving the appearance of additional segmentation. I feel that it would be safer to consider the long basal portion as being a single segment, with a second segment near the rami shorter than the smaller posterior ramus.

The terminal cirri are not remarkable. Cirral segment counts of a specimen from Papua (not the figured specimen) are as follows:

Terminal

cirrus:

1

2

3

\begin{tabular}{|c|c|c|c|c|c|}
\hline & & & & & \\
\hline & anterior & posterior & anterior & posterior & anterior \\
\hline Segments: & 31 & 39 & 43 & 46 & 51 \\
\hline
\end{tabular}

This count is slightly high for acrothoracicans. The setation of the terminal cirri is typical. A long pair of distal and shorter pair of medial setae are found on the inner curvature of each segment, being about twice as long, and as long as the segment, respectively. A single seta of about twice the segment length is found on the distal end of each two to four or five segments. Occasionally these outer setae are paired (about three times on the cirrus figured).

The caudal appendage was described by Noll as being two-segmented. With this I will not quarrel, inasmuch as it usually appears to me to be two-segmented. The illustration, however, of the last terminal cirrus (fig. 13h) shows what could almost be considered a three-segmented caudal appendage. This ambiguity is seen also in the genus Lithoglyptes, and should not be heavily considered in their classification.

The male: The mature male is approximately $0.1 \times 0.25 \mathrm{~mm}$ in body size, but it is on a stalk which, together with the antennules, may be nearly $0.3 \mathrm{~mm}$ long. The body is distinctly "winged," with two major and lesser pointed protuberances from the stalk.

The typical antennules, naupliar eye, testis, seminal vesicle, and penis is present. The penis extends into one of the "wings," which presumably is elongated into a penis sheath.

I consider Kochlorine inermis Stubbings, 1964, to be a very young $K$. hamata. Only a single specimen was recovered by Stubbings, from 
a tergum of a small Balanus tintinnabulum, from Malembe, Cabinda, Angola (about $5^{\circ} 20^{\prime} \mathrm{S}$ ). In such a restrictive habitat it is not surprizing that a very small animal develops (see above for the small sizes of the Ghana material), and its estimated $0.83 \mathrm{~mm}$ greatest length might reflect a young animal or one which could not develop any larger. The opercular armament resembles that of a young specimen from Thais haemastoma from Cadiz, Spain (the type-locality) (fig. 130). The latter specimen is about $1.6 \mathrm{~mm}$ long (estimated from a flattened state), and believed to be somewhat older than Stubbings' specimen. The similarity in teeth and the apical opercular "mound" is striking.

I have examined Stubbings' specimen of $K$. inermis, through the courtesy of the Musee Royal de l'Afrique Centrale, Tervuren, Belgium. No apparent differences from the description of $K$. hamata were noted, although I did not corrode the specimen to check for a lateral bar. No lateral bar was seen.

The presence of a weak granular lateral bar in my specimen is probably due to its greater maturity, as of course younger ones would not have such obvious structures. I do not consider the variation in the mouthparts significant. The ventral prominences posterior to the mouth region are found in $K$. hamata, also.

The distribution of $K$. hamata, from much of the west coast of Africa, Europe, and the Mediterranean, adds strength to the argument that $K$. inermis is a young $K$. hamata.

\section{Kochlorine anchorella, new species}

\section{Figure 14}

Diagnosis: Kochlorine with pointed mantle aperture armed with three to four pairs of large, anchor-shaped teeth, plus numerous small bifid teeth and many hairs.

Етумодоgт: Named for the anchor-shaped teeth on the operculum.

Distribution: Four specimens from Chama lazarus L. from Heron Island or northern Queensland, Australia, in the collection of the Victoria National Museum. Holotype VNM. Paratypes SFSC, USNM, size $2.35 \times 1.38 \mathrm{~mm}$ in length and width, with aperture $0.85 \mathrm{~mm}$ long. Three fragments from Bursa rubeta gigantea Smith from Woolgoolga, N.S.W., Australia, from the Australian Museum collection. The size of the figured specimen (cleaned in $\mathrm{KOH}$ ) is $3.0 \times 1.6 \mathrm{~mm}$. The holotype and two paratypes average $2.50 \times 1.40$ $\mathrm{mm}$, with an aperture of $0.88 \mathrm{~mm}$.

It has been identified in an unidentifiable piece of coral believed to be from northeast Australia, but with no locality data.

Type-material: Holotype: Vict. J-190. Paratypes: SFSC, USNM. 


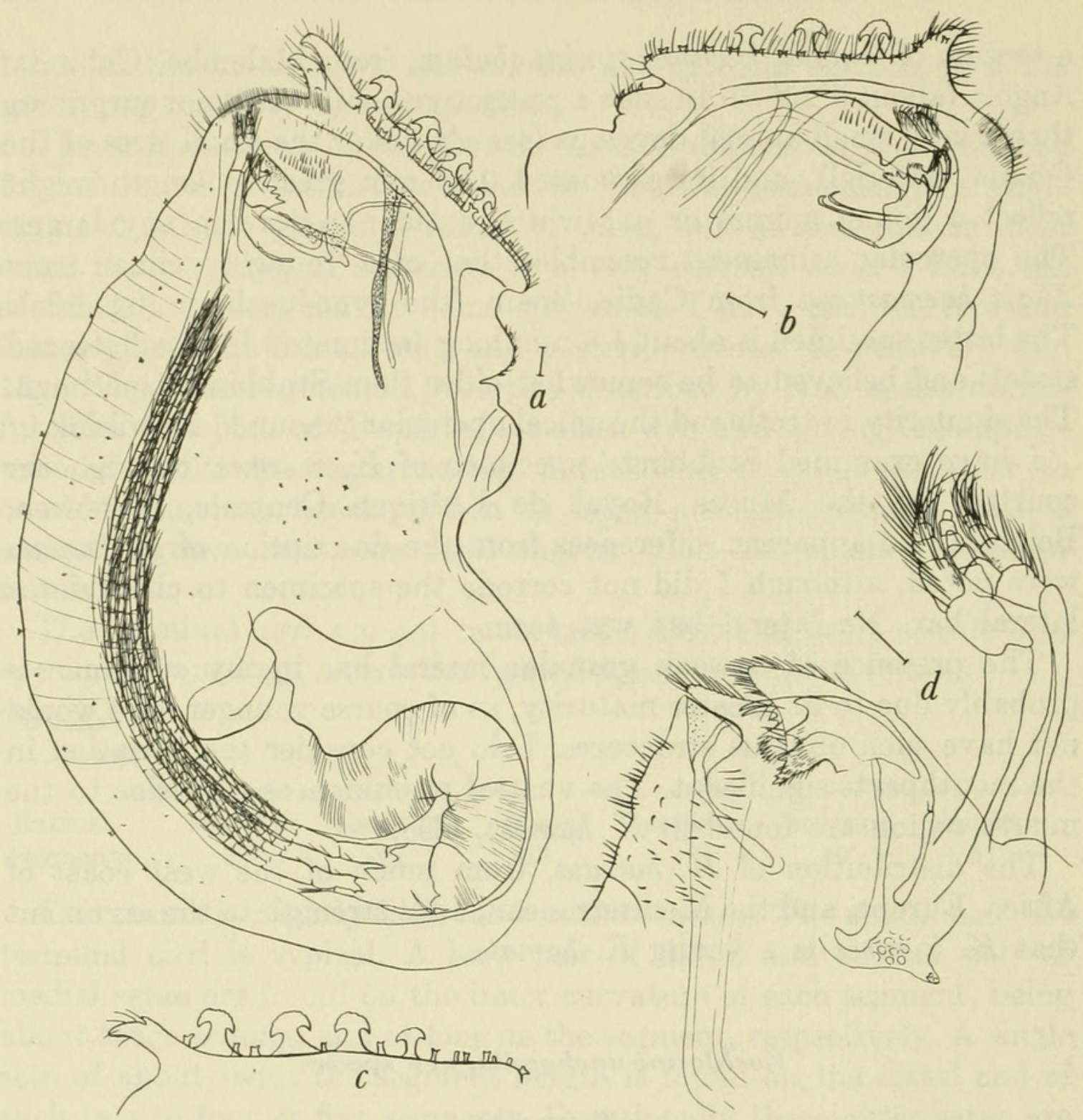

FIGURE 14.-Kochlorine anchorella, new species: $a$, female, side view from Chama from Heron Island, Australia; $b$, detail of operculum of another specimen from Chama from Heron Island, small bifid teeth are on the outer edge of the operculum; $c$, opercular horizon of a specimen from Bursa from Woolgooga, N.S.W., Australia; $d$, mouth field of the specimen in $a$. Setation omitted from one ramus of each cirrus.

This species has the typical kochlorinid three pairs of terminal cirri with caudal appendages, and with strong lateral bars. The main distinguishing features are in the opercula. Each lip of the mantle aperture is armed with an external row of about fourteen bifid teeth, and an inner row of three or four massive anchor-shaped teeth set on tall pillars. The upper surface of these teeth are subdivided. Their resemblance to an anchor suggested the name anchorella. A prowshaped projection elevates the anteroventral end of the armed area. An opercular knob is present, and armed with a few simple spines. Bristles are numerous over the opercular area, and are often fouled with dark material which makes detailed study difficult. 
The mantle is sparsely studded with extremely small teeth, especially in the center of each side and along the ventral margin. These teeth are from two- to four-pointed. An attachment knob is present posterior to the orificial knob.

The mouth cirri are biramous on a two-segmented protopod, with four or five and three segments in the anterior and posterior ramus, respectively.

The mouthparts are typical. The mandible is equipped with three major teeth and a fine-toothed cutting edge.

The first maxilla has two major teeth, a gap broken by a single bristle, and a cutting edge of several fine hyaline teeth.

The second maxillae and mandibular palps -are typical.

The labrum is heavy, with a rounded posterior lip, and scattered dots or bumps over the anterior surface. The lateral wings of the labrum extend into reticulated supporting arms. Behind the apodemes of the first maxillae is another reticulated sheet bearing a pair of projections posteriorly.

The three pairs of terminal cirri have the following segmentation formula for a single specimen counted:

Terminal

cirrus:

1

2

3

\begin{tabular}{|c|c|c|c|c|c|c|}
\hline & & & & & & \\
\hline Ramus: & anterior & posterior & anterior & posterior & anterior & posterior \\
\hline Segments: & 27 & 36 & 42 & 43 & 45 & 46 \\
\hline
\end{tabular}

The setation of the terminal cirri is typical: On the inner curvature there is a pair of long setae on the distal margin at least four times as long as the segments, with a short bristle between the base of each pair about one-third as long as the segment length; also on the inner curvature there is a pair of shorter setae near the middle of the segment, about as long as the segment. On the outer curvature there is a single (occasionally double) seta at the distal margin of a length about one and a half times the segment length, every one to four segments along the length of the cirrus.

The caudal appendage is two-segmented and extends, with the bristles, past the joint of the two-segmented protopod of the terminal cirrus.

The thorax is finely striated on the surface, in a typical manner.

No male was seen.

RELATionships: It is probable that this species is closely related to Kochlorine floridana Wells and Tomlinson. The opercular armament somewhat resembles this species, and the rest of the structures are typical of the genus. The anchor-hooks are considerably larger in $K$. anchorella, however, while they are much less numerous and less ornate. 
The Chama lazarus shell also contained Lithoglyptes spinatus acrothoracicans.

Kochlorine bihamata Noll, 1883, page 472

Diagnosis: Kochlorine with no anterior conical processes; two posterior hooks and spiny teeth on rim of mantle aperture; $5 \mathrm{~mm}$ in size; dried specimens in Haliotis shell from Cape Town, South Africa.

The validity of the species name Kocholorine bihamata is in doubt. Noll (1883) gave a recognizable specific differentiation between the new specimens found at Cape Town, South Africa, and his K. hamata from Cadiz, Spain, yet he did not set it up as a definite species. He stated, as translated from the German, "Should examination of fresh material of Kochlorine from Cape Town demonstrate a new species, one can well label it $K$. bihamata. Meanwhile it is safe to say that the genus Kochlorine lives in the east Atlantic Ocean from Cadiz to Cape Town, bores chambers in shells of Haliotis, and perhaps in other shells also."

I maintain that $K$. bihamata is a recognizable species, although I have not seen it. Even though Noll proposed the name provisionally, he designated a specific name which can be retained without causing undue confusion. Hoek (1883), Weltner (1897), Stebbing (1910), and Barnard (1924) have cited the species as more or less recognizable, although it is probable that none of these writers saw a specimen of this species.

As there are no illustrations of $K$. bihamata, we must rely on Noll's description. A very abundant species in Haliotis midae of South Africa is Weltneria spinosa (q.v.) I would hope that Noll would have noticed the five pairs of terminal cirri on this latter species, had he seen it, and would not have confused it with Kochlorine, although I cannot be too critical of him if he did get confused.

\section{Kochlorine floridana Wells and Tomlinson, 1966, page 27}

Figure 15

Diagnosis: Kochlorine with one pair of short, conical spines and rows of tack-shaped teeth on mantle aperture, and with lateral bar; attachment process moderately developed.

Distribution: From North and South Carolina, Georgia, Florida, and Puerto Rico (see original description). In addition it has been found in the following places and hosts:

Crassostraea virginica, Santa Rosa Sound, Florida (near Pensacola), coll. P. A. Butler; courtesy of Nelson R. Cooley. 
Dredged at the following points by USDI Bureau of Commercial Fisheries-

Pascagoula Fishery Station, courtesy of Harvey R. Bullis, Jr., Murex pomum $07^{\circ} 58^{\prime} \mathrm{N} 58^{\circ} 23^{\prime} \mathrm{W} 10-11$ fathoms; Cymatium parthenopeum $08^{\circ} 06^{\prime} \mathrm{N} 58^{\circ} 20^{\prime} \mathrm{W}$ 23-26 fathoms; Murex fulvescens $31^{\circ} 19^{\prime} \mathrm{N} 80^{\circ} 33^{\prime} \mathrm{W}, 14.5-15.5$ fathoms.

Dredged in many old shell shards off Cape Haze Marine Station, Sarasota, Florida, on "Rhinchodon," with Thomas Hopkins.

Dredged in Bogue Sound, Morehead City, N.C., in many old shell shards; courtesy of C. G. Bookhout and Lawrence McClosky of Duke University Marine Station.

Other material found in Murex microphyllus Lamarck from Tuléar, Madagascar (courtesy of the Institut Royal des Sciences Naturelles de Belgique), is regarded as being identical.

Type-material: Holotype: USNM 113221. Additional material: Aust, BPB, Brit, Belg, BA, CA, Dublin, Mex, Paris, Seto, UCT, Vict.

Size (average of four specimens): $3.33 \times 1.95 \mathrm{~mm}$.

The following description is based on material from Puerto Rico coral.

The operculum is armed with three rows of teeth, some of which are bifid and some rosette shaped. The operculum terminates ventrally (carinally) in a pair of peaks somewhat short of the ventral apertural opening.

The mantle has a reddish band around the aperture, which is common in this order. The two layers of muscle bands arranged more or less perpendicular and parallel to the mantle aperture are also typical for the order. Very small teeth, bifid or single curved spines, stud the external surface of the mantle evenly except for a slight increase in size and number in a patch near the middle of each side. This patch does not seem to be associated with the lateral bar, as it does in Cryptophialus (fig. 15a).

A horny disk for attachment to the shell is a conspicuous feature of the dorsal mantle. Males are found clinging to this disk, which is composed of cemented exuviae.

An orificial knob, bearing short hairs and single teeth curving anteroventrally is prominent at the dorsal end of the mantle aperture or orifice.

The mantle aperture is heavily armed and ornamented in a characteristic manner. The opercular plates fuse to each other and to a heavy supportive bar which extends dorsally and posteriorly toward the attachment disk. These plates terminate about four-fifths of the distance toward the ventral end of the aperture, with the remaining distance filled with light mantle tissue with a few weak teeth and the fringed comb collar which is typical of the order. The plates are pointed into prow-shaped projections pointing ventrally, but no large hooks or articulated spines are present. Studding the apertural plates are num- 

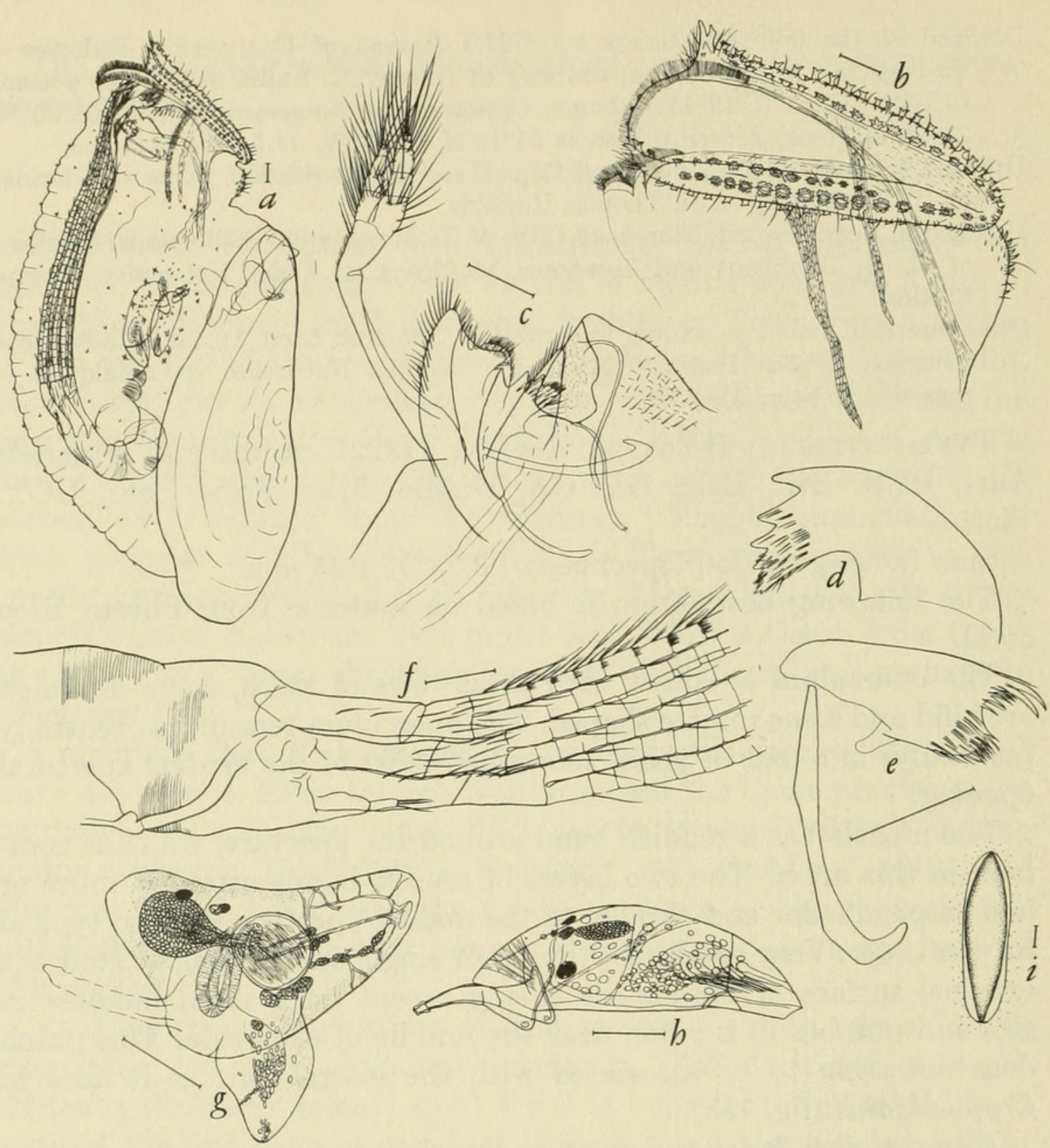

Figure 15.-Kochlorine floridana Wells and Tomlinson, 1966: $a$, female with males, side view, from Puerto Rico; $b$, opercular details of specimen in $a$; $c$, mouth field of specimen $a$, mouth cirrus smaller posterior ramus and lateral bristles on inside of anterior ramus, mouth cirrus bristles faintly plumose; $d$, mandible of a; $e$, first maxilla of $a ; f$, posterior thorax, base of terminal cirri, and caudal appendage of $a ; g$, mature male, with antennules obscured by dirt; $h$, cyprid larva; $i$, burrow aperture in coral "rock" from Puerto Rico.

erous heavy teeth which form three more or less complete rows on each side. The lateral rows are typically bifid, but the two inner or medial rows are characteristically rosette shaped. They have prominent projections from the dorsal and ventral margins of the crowning ring of subteeth, with the rest of the ring notched and subdivided into six to eight additional teeth. The entire tooth looks somewhat like an anemone, or the top of a thistle (fig. 15b). 
Reinforcing these plates are two lateral bars extending posteriorly from about the middle of the apertural plates. These lateral bars are finely reticulated, and are not associated with rows or patches of teeth on the mantle.

The major muscle masses are present to varying degree in the attachment area. I consider two thin and weak-looking muscles from the orificial knob extending toward the attachment disk as the retractor pallii rostralis, although this muscle is considerably weaker than in other members of the genus. The retractor corporis is a large muscle connecting the orificial knob and the dorsal body area, while the retractor orificii extends from the attachment area to the orifice, with slips into the origin of the retractor corporis in the orificial knob.

The head is rounded and studded with one or more rows of fine hairs. Fine scale-like lines are seen between the hairs.

The mouthparts are typical for the order: a pair of mandibles with palps, and two pairs of maxillae (fig. 15c). The unpaired labrum at the anterior mouth field leads into a long tubular esophagus. The labrum is saddle shaped with reinforcing curved rods extending from each side which are perhaps typical of the genus, and fine granulations which often form rows of dots.

The mandible is equipped with two to four major teeth, plus an inner lower angle with numerous fine teeth and bristles. This angle also is bristled on the lateral surface (fig. 15d). The variability in number of major teeth is not common in the order, and does much to destroy the value of the feature as a taxonomic characteristic. Often the left and right mandible of one female will differ in the number of these teeth. A heavy extension of the base of the mandible is apparently an apodeme, but is shorter than the apodeme of the first maxilla, and is not hooked. The mandibu'ar palp is closely adpressed against the labrum. It is edged on the inner margin with a row of hairs.

The first maxilla is typical of the order, bearing two major teeth on the superior outer margin, a gap or diastema usually broken by a couple of bristles, then a rounded margin with numerous very fine teeth and heavy bristles. A long curved or hooked but variable apodeme supports the base of this maxilla in typical fashion (fig. 15e).

The second maxilla forms the typical triangular-shaped, heavily haired bottom of the mouth field.

The first pair of cirri (mouth cirri) are located directly posterior to the mouth field, and curve anteriorly on a long two-segmented protopod. The shorter distal segment is lightly bristled and bears a pair of rami with a variable number of segments. The anterior ramus is longer, and bears four segments, while the posterior ramus has either three or four, although segmentation can be obscure, especially in this genus. Both rami are heavily bristled. The bristles are faintly 
plumose with extremely fine hairs. The smaller posterior ramus is on the inside of the larger anterior ramus in its attachment to the protopod. Both rami are heavily bristled on the margins and on the inside lateral surfaces.

The three pairs of terminal cirri are biramous and multisegmented (fig. 15f). The arrangement of setae is typical for the suborder: a repetition of a distal long pair of setae (two to three and a half times the length of the segments, grading from base to tip of cirrus), and a central shorter pair (about the same length as the segment) along the lesser curvature of each segment, with a single seta (one to two times the length of the segment) on every first to fifth article along the greater curvature. The average numbers of segments per bristle for each cirrus are as follows (one specimen): cirrus 2: 1.69; $3: 2.90 ; 4: 2.97$. The protopods are two-segmented, with the proximal segment much longer than the distal segment. The sutures between segments slant obliquely. The inner surface of each protopod is set with bristles. The average cirral count (of five specimens) with the segments in the anterior (listed first) and posterior ramus of each cirrus, are as follows: $2: 27.0,37.0 ; 3: 40.5,45.6 ; 4: 42.0,44.8$.

The caudal appendages arise between and behind the last pair of terminal cirri. They are uniramous and two-segmented, with usually three terminal setae. The appendage itself is about half the length of the basal segment of the protopod on the last terminal cirrus.

There are no body processes of filamentary appendages. The thorax possesses the usual fine striations.

The male: The dwarf males attach to the female, especially on the exuviae forming the horny disk. Females of adult size have from zero (many females) to five (very few) males each. This is a lower number than is typical for the order.

The young male looks much like a cyprid larva. The swimming appendages, caudal furca, paired cyprid and single naupliar eye, and paired antennules are typical of the entire subclass. The distinct line across the carapace near the posterior end, seemingly articulating a posterior segment of the carapace, is not typical. Glandular cells are found around the cirri and in several masses along the dorsal edge of the carapace. Muscles are attached to the antennule bases. The antennules have a distinct angle near their base, which is clearly dimpled with heavy chitin.

The mature male has an obvious cellular testis and a seminal receptacle full of hair-like sperm, connected in turn to an annulated penis whose termination and method of employment is obscure (fig. $15 \mathrm{~g})$. There seems to be a penis retractor muscle connected to one of three lobes projecting from the main body of the male, with the testis in another lobe; the third lobe bears a few cells which appear glandular. 
Several distinct clumps of cells are distributed around the seminal vesicle and into the various lobes. One such mass is adjacent to a complex yellow body which could be the standard "yellow organ" of acrothoracican males. A naupliar eye is retained. The antennules were obscured with debris in all specimens examined. This could be a result of the secretion of an attachment cement typical of cyprids. It is strange, however, that attached young males had clean antennules while the mature males did not.

The outer surface of the mature male is covered with rows and patterns of extremely fine dots, indicated marginally in the figure.

The size of the mature male figured is $0.34 \times 0.20 \mathrm{~mm}$ in body size (excluding one lateral lobe which was flattened for illustration purposes). This reduction in length is typical of the maturation of males in the order. No trophic structures are possessed, and it is believed that after fertilization the male is expended.

The BURRow: The average dimensions of the aperture of four burrows, which represent all the burrows on a mechanically selected piece of coral from Puerto Rico, is $0.8 \times 0.2 \mathrm{~mm}$. This aperture is slightly below the surface of the coral, however. Figure $16 \mathrm{i}$ shows the apostrophe-shaped aperture proper, heavily stippled, with the surface of the coral lightly stippled. The smoothed bevel between these lines was made by the barnacle extending its mantle outward beyond its normal position below the narrow neck of the aperture. The burrow is slightly larger than the dimensions of the female, and no particular internal undercutting or other special features were noted.

\section{Genus Kochlorinopsis Stubbings, 1967, page 302}

Diagnosis (emend.): Lithoglyptidae without retractor pallii rostralis muscle. Operculum straight, without spines, but with numerous bifid and multipointed teeth, and hairs. No lateral bar.

TyPe-sPecies: Kochlorinopsis discoporellae Stubbings, 1967, page 302.

Kochlorinopsis discoporellae Stubbings, 1967, page 302

Figure 16

Diagnosis: Sole species with the characteristics of the genus.

Distribution: West Africa: Senegal, Guinea, Ivory Coast, Ghana, and Gabon; in the bryozoan Discoporella umbellata and three species of Cupuladria.

The female mantle is extremely flattened, oval, light brown (alcoholic), and about $3 \times 2 \mathrm{~mm}$. It has no flattened attachment pad. 
Retractor corporis and retractor orificii muscles are present, retractor pallii rostralis muscles are absent. A single pair of ventral body processes are found on the thorax. The size of the female figure, calculated from the stated magnification, is $3.48 \times 2.52 \mathrm{~mm}$, with an aperture of $1.14 \mathrm{~mm}$.

The mouth cirri are biramous on a two-segmented protopod. The rami have five and four, or seven and five segments. Three pairs of biramous, multisegmented terminal cirri bear typical setation. A pair of short, two-segmented caudal appendages bear three terminal setae. The mouthparts are the typical mandible with palp and two pairs of maxillae.

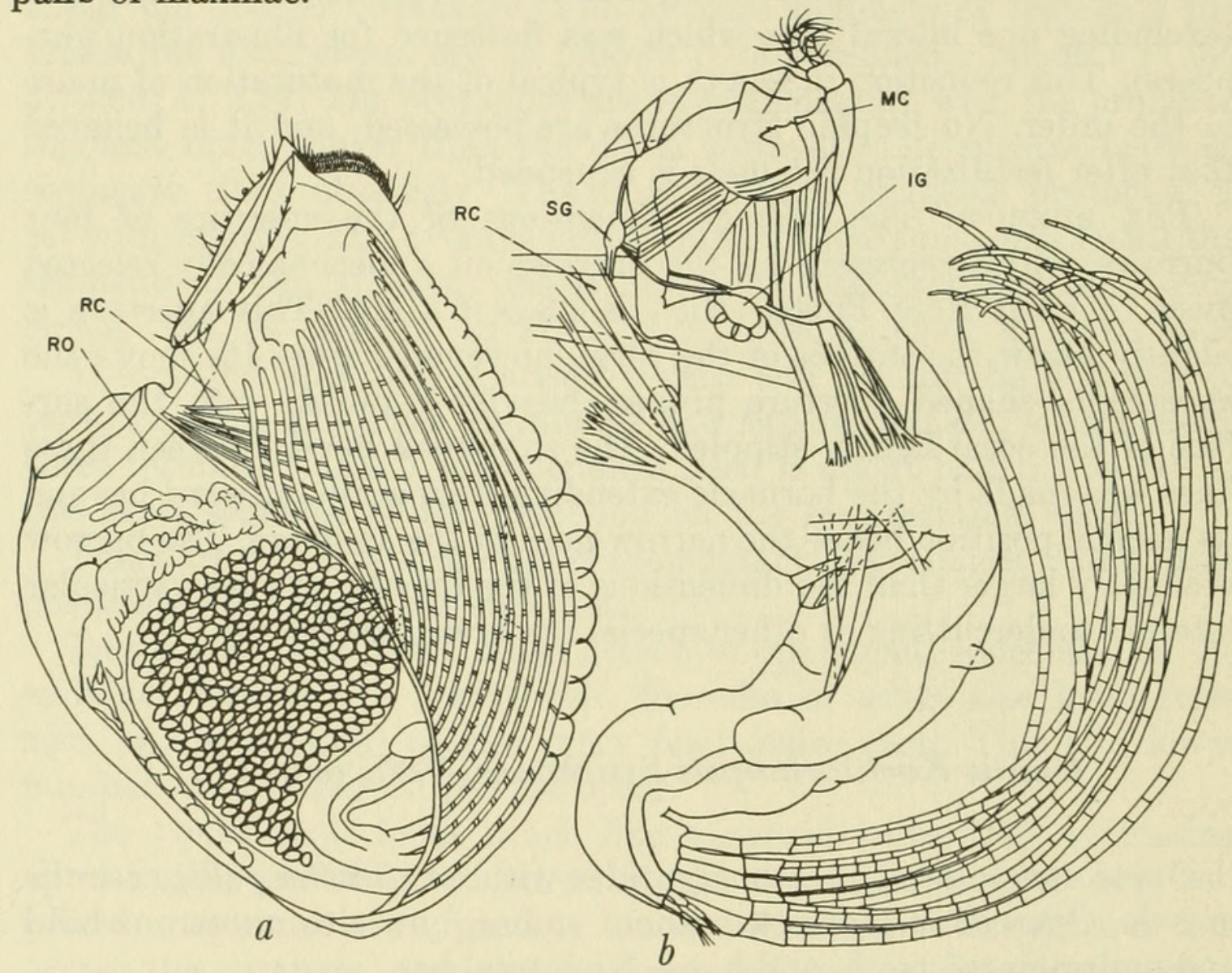

Figure 16.-Kochlorinopsis discoporellae Stubbings, 1967, female, side view: $a$, showing mantle musculature, ovary, and egg mass; $b$, with mantle removed, setae omitted from the terminal cirri (after Stubbings, 1967).

The male is triangular, with a single, remarkable, two-jointed antenna. The posterior is blunted, and a penis is apparently present. It measures $0.33 \times 0.20 \mathrm{~mm}$.

I have not examined a specimen of this species, but rely on Stubbings' description, to which the reader is referred for more details.

Stubbings did not distinguish in his diagnosis of the genus Kochlorinopsis a point which he makes in his description: the lack of a retractor pallii rostralis muscle. I have added this to the diagnosis. 


\section{Genus Berndtia Utinomi, 1950a, page 84}

Berndtia Hiro (Krüger, 1940), not a valid use of name.

Diagnosis: Lithoglyptidae with five pairs of terminal cirri without a pair of caudal appendages.

TyPE-SPECIES: Berndtia purpurea Utinomi, 1950a, page 84.

\section{Berndtia purpurea Utinomi, 1950a, page 84}

\section{Figure 17}

Berndtia purpurea Hiro (Krüger, 1940), not a valid use of name.

Diagnosis: Berndtia with mantle aperture not as long as width of mantle; adhesive disk long and narrow; female 3-5 mm $\times 2-4 \mathrm{~mm}$; violet-blue beneath aperture, rest pinkish yellow; found in living intertidal corals Lepastrea purpurea (Dana) and Psammocora profundacella Gardiner, from the Pacific Coast of southern Japan.

The nature of the symbiotic association with the living coral colony is an interesting problem. There seems to be a competition for space with the barnacle crowding the polyps. The polyps form a partition between themselves and the barnacle (Utinomi, 1957).

Krüger (1940) referred to the name Berndtia purpurea without any descriptive material. He based the name on a letter from Hiro, who published a note on the new barnacle in 1937. Hiro has assumed the name of Utinomi. The complete species description was published by Utinomi in 1950.

Utinomi has made a thorough study of this species, to which the reader is referred $(1950 \mathrm{a}, 1957,1960,1961$, and 1967). He gave me a few specimens, upon which the accompanying figure is based.

\section{Berndtia fossata, new species}

\section{Figure 18}

Diagnosis: Berndtia with opercular lateral margins with fine teeth each serrated into three to five points arranged in an arc.

Етумодоgy: fossa (L.), a ditch, because it lives in a "little ditch" of its own making, in addition to the host name.

Distribution: One almost complete specimen and three partial specimens in Psammocora fossata from Siassi (Low Island), eastern New Guinea. Coral from the Australian Museum G6678, thanks to John Yaldwyn. 


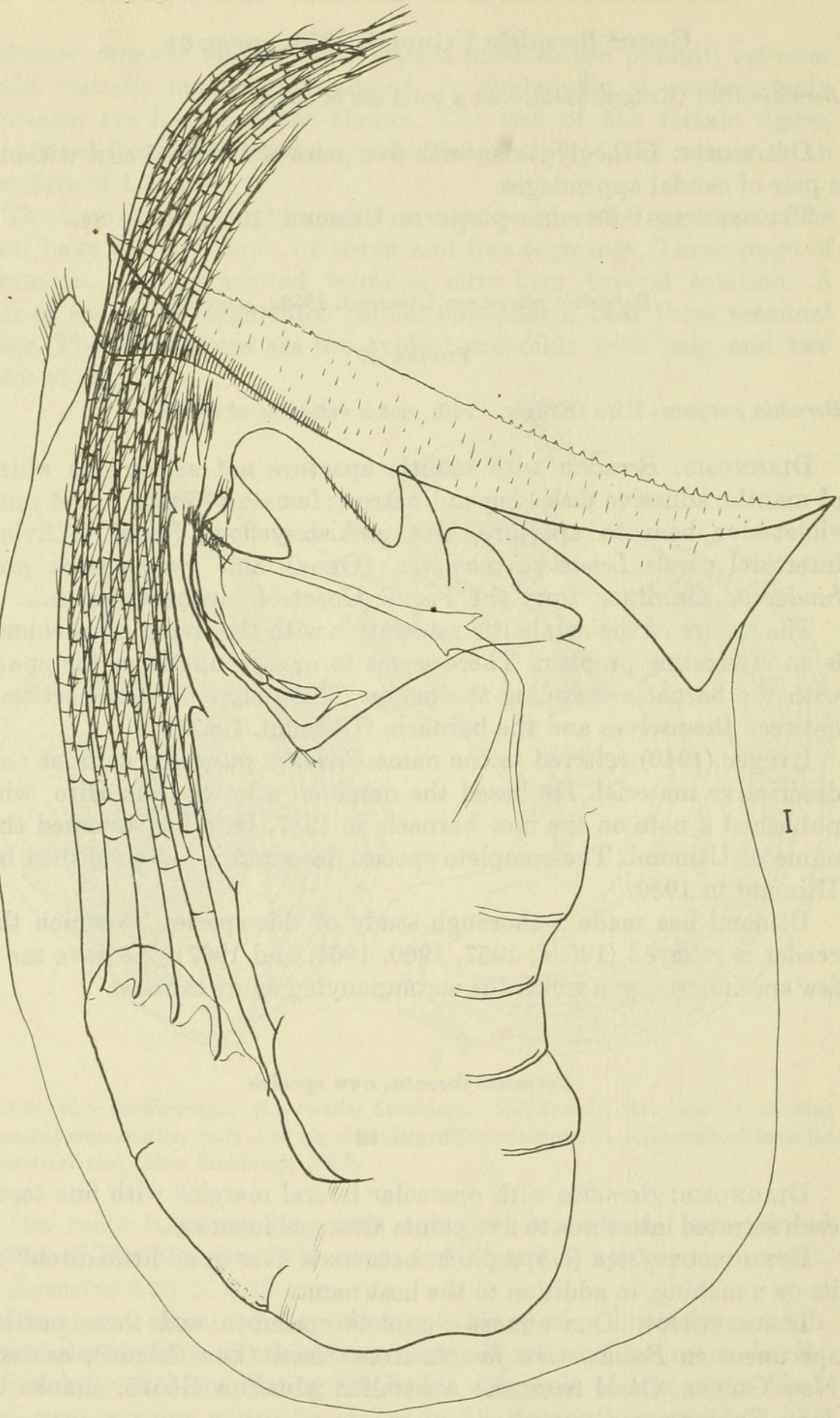

Figure 17.-Berndtia purpurea Utinomi, 1950a, from Tanabe Bay, Japan, female side view. 
TYPE-MATERIAL: All specimens retained at SFSC.

Dimensions: Size of best specimen approximately $4.25 \times 2.0 \mathrm{~mm}$, with aperture of $1.5 \mathrm{~mm}$.

This species is much like the other two species of the genus, except for the margins of the operculum mentioned in the diagnosis. In addition, small teeth and many short hairs are scattered about on the external surface of the operculum (figure 18a).
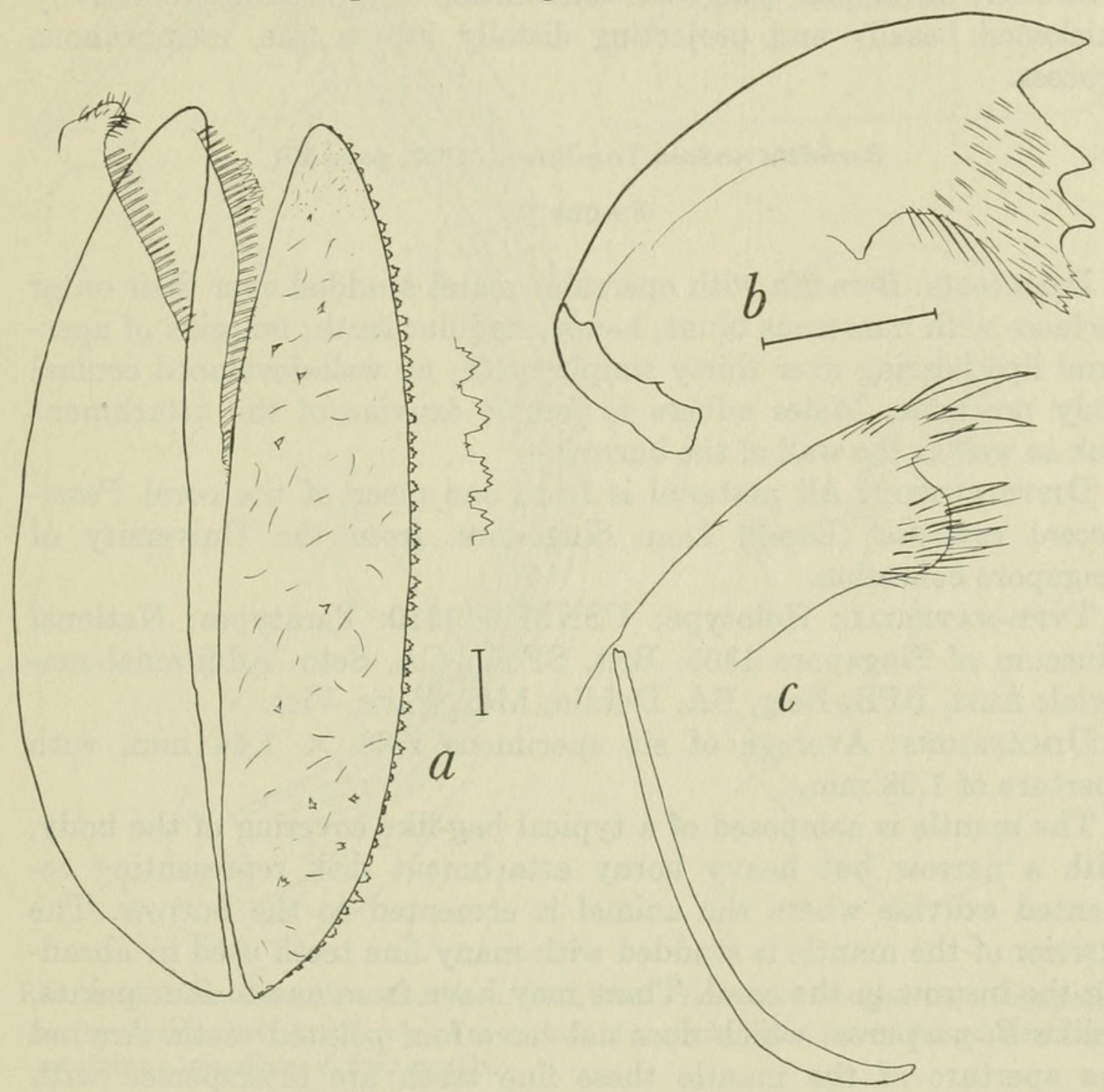

Figure 18.-Berndtia fossata, new species, from Psammocora fossata from eastern New Guinea: $a$, sketch of surface view of opercula, with detail of margin; $b$, mandible; $c$, first maxilla.

The body is almost exactly the same as in the other species of the genus, as far as can be ascertained. There are five pairs of terminal cirri without a caudal appendage, plus a prominent mouth cirrus with six and five segments in the anterior and posterior ramus, respectively, on a two-segmented protopod.

The mouthparts are typical (figure 18b, c). The mandible has three major teeth plus an inner angle with numerous fine teeth and hairs. 
The first maxilla has the usual two strong teeth, a gap, and a bristled margin with thin hyaline teeth. The second maxilla, labrum, and mandibular palps are typical.

No body processes could be seen, but these could be missed in these specimens.

An orificial velum is probably present (figure 18a). The comb collar is strongly developed, with each convolution of the membrane heavily thickened basally and projecting distally into a fine, membranous process.

\section{Berndtia nodosa Tomlinson, 1967, page 101}

Figure 19

Diagnosis: Berndtia with opercular plates studded over their outer surfaces with numerous blunt, heavy, nodular teeth; margins of apertural lips bearing over thirty simple teeth; no well-developed conical body processes. Males adhere to female exuviae of the attachment disk as well as the wall of the burrow.

Distribution: All material is from one piece of the coral Psammocora contigua (Esper) from Singapore, from the University of Singapore collection.

TyPe-Material: Holotype: USNM 113310. Paratypes: National Museum of Singapore 1305, Brit, SFSC, CA, Seto. Additional material: Aust, BPB, Belg, BA, Dublin, Mex, Paris, Vict.

Dimensions: Average of six specimens $2.88 \times 1.44 \mathrm{~mm}$, with aperture of $1.08 \mathrm{~mm}$.

The mantle is composed of a typical bag-like covering of the body, with a narrow but heavy horny attachment disk representing cemented exuviae where the animal is cemented to the burrow. The exterior of the mantle is studded with many fine teeth used in abrading the burrow in the coral. These may have from one to four points, unlike $B$. purpurea, which does not have four-pointed teeth. Around the aperture of the mantle these fine teeth are interspersed with small hairs and scale-like ridges common in the order. Muscle bands are conspicuous, particularly the longitudinal bands on the ventral lateral surface.

The mantle has a heavy attachment disk. The exterior of the mantle has many abrasive teeth with from one to four points.

The operculum is evenly studded over the external surface with heavy teeth which appear superficially blunt, but may have a fine rosette of extremely small nodules around the outer margin. An orificial velum of moderate size extends from the typical comb collar. The ventral apertural interior has a brush of fine hairs. No orificial knob is present. 
The head and mouthparts are not exceptional. Segmentation of the mouth cirri tends to be so obscure or vestigial that no attempt will be made to describe it.

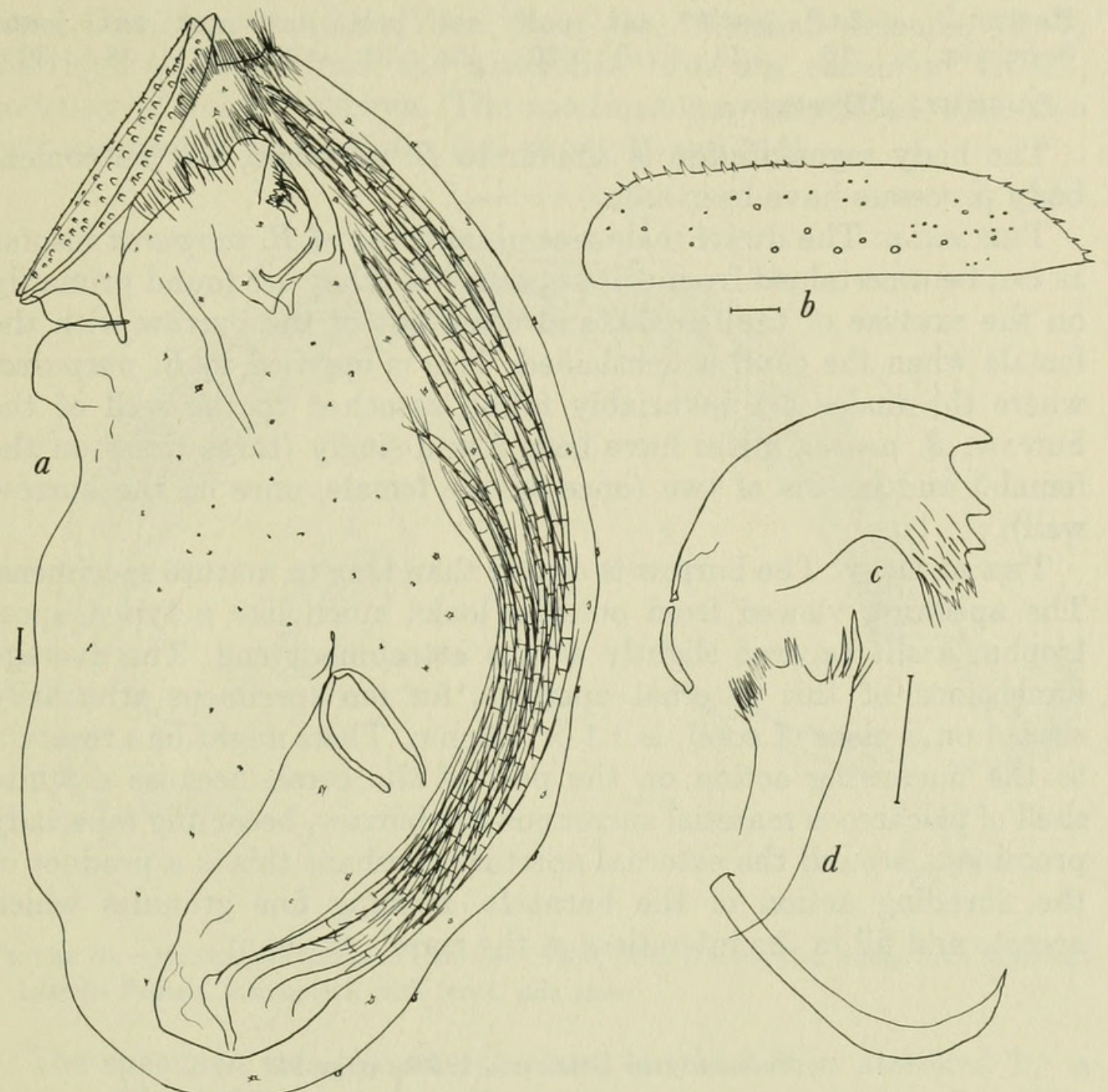

Figure 19.-Berndtia nodosa Tomlinson, 1967, from Psammocora contigua from Singapore: $a$, female side view; $b$, surface view of one side of operculum of $a$, rostral (attachment) end at right; $c$, mandible; $d$, first maxilla.

There are five pairs of biramous, multisegmented terminal cirri. The lesser curvature of each segment supports a distal pair of long setae (two and a half times segment length) and a central, shorter pair (one times segment length). In addition, a short unpaired bristle extends from between the bases of the distal pair. The distal end of every second to sixth segment along the greater curvature supports a single setae (one and a half times segment length). None of these bristles are plumose. The protopods are two-segmented, with the proximal segment not quite three times as long as the distal segment. 
A segment count for the terminal cirri follows:

Terminal

\begin{tabular}{|c|c|c|c|c|c|c|c|c|c|}
\hline cirru & & 1 & & & 3 & & & 4 & 5 \\
\hline & int & $\mathrm{pc}$ & ant. & post. & t. & t. & t. & post. & ant. post. \\
\hline
\end{tabular}

*Anterior. ${ }^{* *}$ Posterior.

The body segmentation is similar to $B$. purpurea, but no conical body processes have been seen.

The Male: The dwarf male resembles those of $B$. purpurea insofar as can be ascertained from dried specimens. They are found primarily on the exuviae of the female, and come out of the burrow with the female when the coral is decalcified. This is opposed to B. purpurea, where the males are invariably found attached to the wall of the burrow. $B$. nodosa males have been found singly (three times on the female) and in sets of two (once on the female, once on the burrow wall).

The BURRow: The burrow is deeper than long in mature specimens. The aperture, viewed from outside, looks much like a typed apostrophe: a slit tapered slightly at the attachment end. The average dimensions of this external aperture, for ten specimens arbitrarily circled on a piece of coral, is $1.1 \times 0.5 \mathrm{~mm}$. There might be a reaction to the burrowing action on the part of the coral, because a white shell of calcareous material surrounds the burrow, becoming especially prominent around the external aperture. Perhaps this is a product of the abrading action of the barnacle, forming fine granules which accrete and fill in the interstices of the coral's skeleton.

\section{Balanodytes Utinomi, 1950b, page 91}

Diagnosis: Lithoglyptidae with four pairs of terminal cirri, without a caudal appendage.

\section{Balanodytes taiwanus Utinomi, 1950b, page 91} Figure 20

Diagnosis: Balanodytes with orifice broadly arched, with a spiniferous projection on each side of its upper edge. Attachment area weakly developed or absent. Fibrous lateral bar present inside of mantle. Retractor orificii absent, but retractor pallii rostralis present. Color uniform yellowish in preserved and dried state.

Distribution: Utinomi's description is based on a complete and an incomplete female, which were lost in dissection. They both occupied 
pits in the basal shells of Balanus tintinnabulum tintinnabulum from the littoral near Takao on the western coast of Formosa.

My material consists of a single dried female specimen from the coral Distichopora nitida Verr. from the Marshall Islands, R. V. Ethridge collector, from the Australian Museum collection G6234, courtesy of John Yaldwyn. The specimen was associated with two new species of Cryptophialus (see pages 90 and 114).

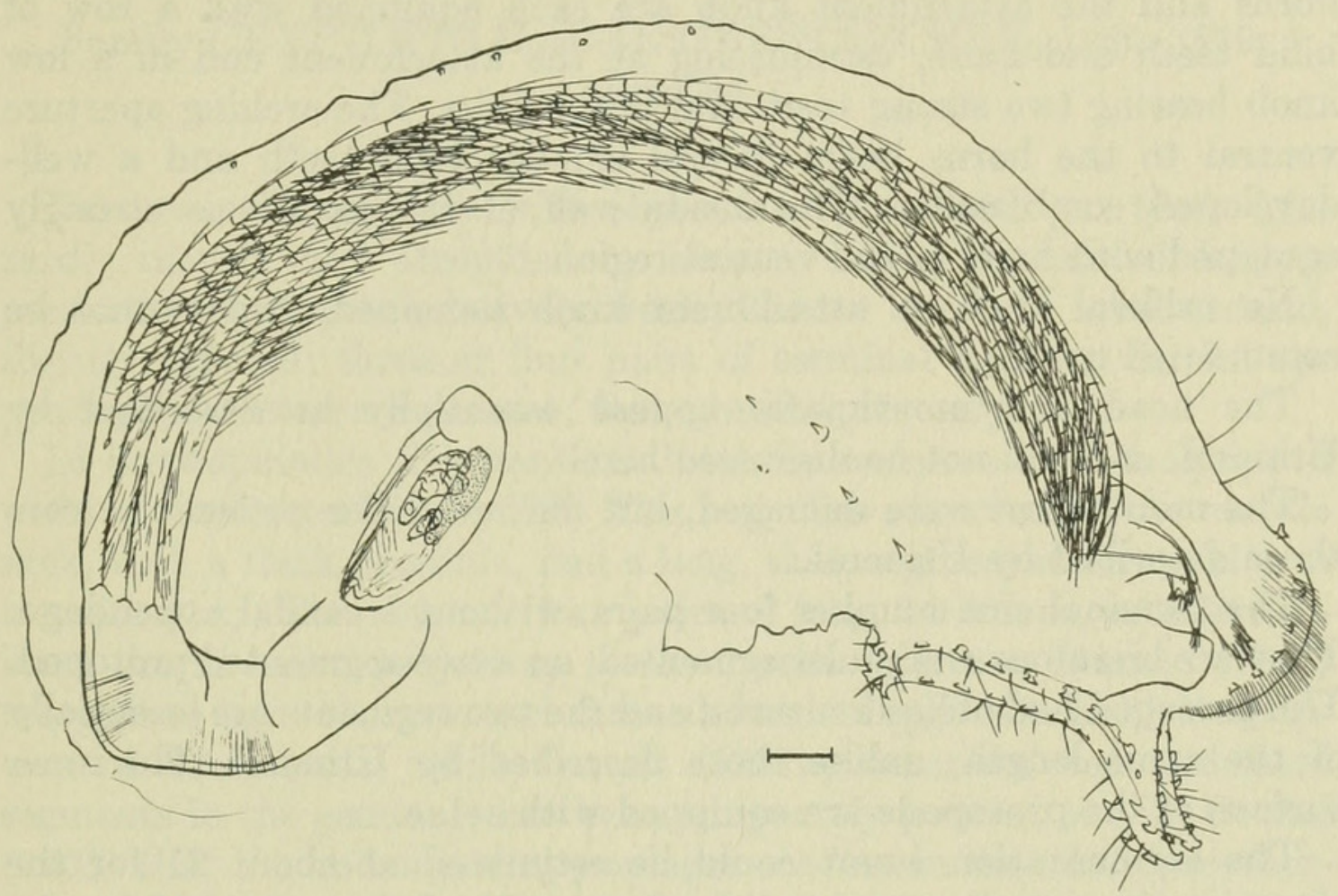

Figure 20.-Balanodytes taiwanus Utinomi, 1950b, from Distichopora nitida from Marshall Islands. Female, incomplete, with larva, side view.

The specimen was almost complete, but had been attacked by a fungus. No male was found. Four cyprid larvae were found in the mantle cavity. Since identification was not possible until the animal was removed, and since three species were found in one hand-sized piece of coral, no detailed description of the burrow is possible. However all burrows in the coral appeared to be either typical tapered slits or the very short slits of the crypotophialids. In general, the slit of acrothoracicans is approximately the same size and shape as the apertural area of the contained barnacle.

The size of the specimen in glycerin is $2.08 \mathrm{~mm}$ long, with an aperture of $0.7 \mathrm{~mm}$ measured straight across. Utinomi gave the size as $2.2 \mathrm{~mm}$ long and $1.2 \mathrm{~mm}$ wide.

The mantle is a clear, uniform, light yellow in the dried condition. There are a few extremely small teeth scattered about on the external surface of the mantle and about five single-toothed spines pointing posteriorly in a crude line starting near the dorsal end of the aperture 
and proceeding posteriorly. Details of the rest of the mantle excepting the aperture are lost (see fig. 20).

The mantle aperture is characteristic of the species. A pair of hornlike projections arise near the middle of the aperture and curve slightly forward near the tips. They are armed on both sides with several strong simple or bifid teeth, and many hairs.

The pair of strongly chitinized opercular plates between these horns and the attachment knob are each equipped with a row of bifid teeth and hairs, terminating at the attachment end in a low knob bearing two strong teeth and many hairs. The arching aperture ventral to the horns bears several smaller bifid teeth and a welldeveloped comb collar. The inside wall of the mantle is strongly equipped with hairs in the ventral region.

No orificial knob or attachment knob remained, and cannot be commented upon.

The head and mouthparts appear essentially as described by Utinomi, and will not be discussed here.

The mouth cirri were damaged, but did not differ noticeably from those described by Utinomi.

The terminal cirri number four pairs, without a caudal appendage. They are biramous and multisegmented, on a two-segmented protopod. The protopod had oblique sutures, and the two segments are essentially of the same length, unlike those described by Utinomi. The inner surface of the protopods are equipped with setae.

The segmentation count could be estimated at about 21 for the shortest, the anterior ramus of the first terminal cirrus, and 45 for the rest, with a little variation. This number is higher than average, but I did not experience as much difficulty as described by Utinomi regarding the obscured segmentation in the central areas of the cirri.

The setation differs from that described by Utinomi. Most rami clearly showed a single seta at the distal angle of every two or three segments on the outer curvature, of about one and a half times the segment length. On the inner curvature each segment bore a pair of setae on the distal angle about three times the segment length and a pair in the middle of the segment about two and a half times the segment length.

THE CYPRID: The presence of cyprid larvae within the mantle cavity indicates that the larvae are retained to this stage in this species. The cyprids had been boiled in $\mathrm{KOH}$ but still differences from other species of the order were noted.

No cyprid or naupliar eyes were distinguished. No detailed ornamentation of the carapace was seen. 
The front of the cyprid is rounded. The entire carapace was streamlined, tapering posteriorly in both side and top view.

Masses of granular and cellular material occupied the anterior half, while the swimming setae occupied the posterior half. The latter appeared typical of the order, and a small caudal furca was noted. Typical antennules were present.

\section{Family CRYPTOPHIALIDAE GERSTAECKER, 1866-1879, page 534}

Diagnosis: Pygophora with alimentary canal with gut teeth (gizzard); mouth cirri atrophied or absent; large, attenuated labrum present; mouthparts relatively weak; burrow aperture nearly round, slightly tapered; three or four pairs of terminal cirri; no caudal appendage; lateral bars present; free cyprid larva only.

In cryptophialids the mantle is laterally compressed and equipped with an oval attachment disk. The body lies recurved in the mantle sack, with a thick prosoma, and a long, thin, segmented terminal portion (thorax). The three or four pairs of long, biramous, multiarticulated thoracic cirri project up to the narrow aperture. Darwin (1854) recognized eight thoracic and three abdominal segments in his description of $C$. minutus, while Berndt (1907a) described ten undefined segments in the genus. It has been adequately pointed out by Gruvel (1905) that the abdominal appendages are lost in the adult acrothoracicans, and hence the designation of abdominal appendages is in error.

The "mouth cirri" (Berndt) are unique among the Acrothoracica in not being biramous. Darwin called these the "first pair of maxillipeds," while Krüger (1940) considers them to be modified, atrophied, first cirri. The latter view I consider to be correct. The three or four pairs of biramous thoracic cirri stand on two-segmented basal portions (protopods).

\section{Genus Cryptophialus Darwin, 1854, page 563}

Diagnosis: Cryptophialidae with three pairs of terminal cirri; two dorsal body processes present; mouth cirri rudimentary or absent.

Type-Species: Cryptophialus minutus Darwin, 1854, page 563. 


\section{Cryptophialus minutus Darwin, 1854, page 563}

Figure 21

[=C. striatus Berndt, 1903b, page 436, =C. minutus striatus Berndt, 1907a, page 167 ; 1907b, page 289].

Diagnosis: Cryptophialus with three pairs of terminal cirri; two dorsal body appendages; mandible with three teeth; lateral bar termination strongly swollen; one to seven males found on female; free cyprid stage only; to $2.5 \mathrm{~mm}$.

This is the second described species in the order acrothoracica. Darwin did a thorough job on it, his first barnacle, and got his start on cirripeds and an effective impetus toward the foundation of his principles of evolution with this species. He placed it in the order Abdominalia, leaving the earlier Trypetesa (=Alcippe) lampas in the Lepadidae. Both are now in the order Acrothoracica.

Distribution: The species was described from Concholepas peruviana from the Chonos Archipelago, southe̊rn Chile. Berndt (1903b) extended the host list to Chiton magnificus, also from Chile. I can now extend the host and distribution list as follows:

Concholepas concholepas Brugiuere, 1789; purchased in Santiago, Chile, from local market as "crazy shell" food, by Blanca Nebenschoss de Kurlat of Buenos Aires, Argentina, who kindly gave it to me. Nine dried specimens were removed in good condition. The figures are from these specimens. The average size of three whole specimens is $2.15 \times 1.11 \mathrm{~mm}$.

Concholepas concholepas, Ushuaia, Tierra del Fuego, Argentina, loaned by the Museo Argentino de Ciencias Naturales, Buenos Aires, through the courtesy of Professora Martinez Fonte (their number 19832). Six dried specimens removed in good condition.

Empty slits without recognizable specimens also were found in: Acanthina (Chorus) gigantea Lesson. Talcahuano, Chile, 13829; C. concholepas. Pucusana, Peru (60 km. south of Lima);

C. concholepas. Puerto San Antonia, Santiago, Chile, 12865;

Fissurella maxima Sow. Valparaiso, Chile, 9027.

Material: The nine specimens are deposited as follows: Aust, BPB, Brit, BA, Mex, Seto, SFSC, USNM, Vict.

When describing his new species of Cryptophialus striatus in 1903, Berndt clearly pointed out that he based his new designation solely on a comparison with Darwin's descriptions and drawings. He stated that the main differences were the regular chitinous striations on the dorsal body surface, and the somewhat heavier thoracic portion of his new species, together with the occurrence of the animal in a chiton, instead of a gastropod. He gave a good description of the 
entire digestive tract and the nervous system, the latter of which was not described by Darwin.
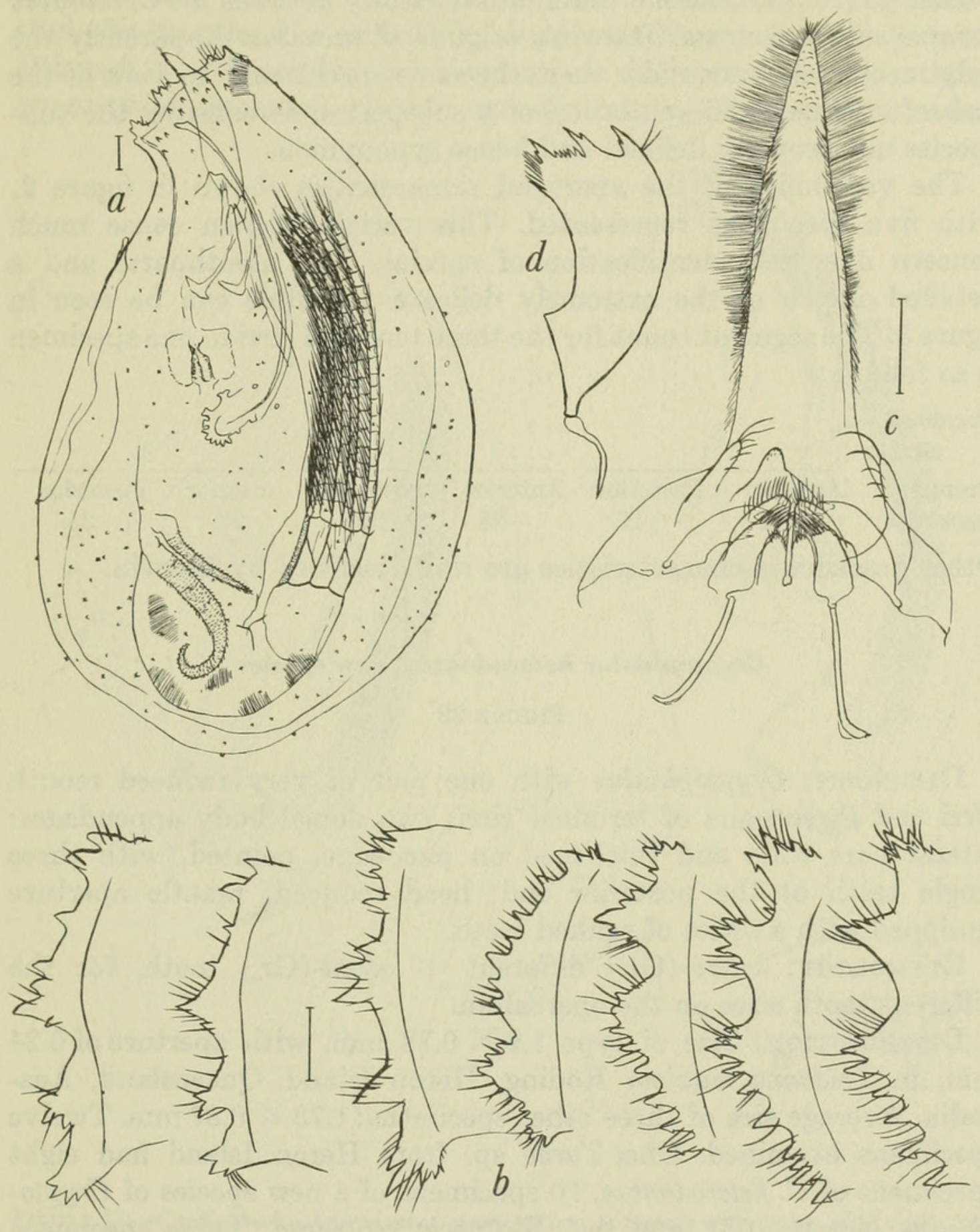

FIgURE 21.-Cryptophialus minutus Darwin, 1854, from Concholepas concholepas from Chile: $a$, female side view; $b$, opercular horizons: left three are separate individuals, right four are paired 1-2 and 3-4, letter $b$ denotes attachment (rostral) end of animal; $c$, mouth field, front view; $d$, mandible.

In 1907(a) Berndt himself states that these differences are not enough to justify a new species, especially in the light of his new species, C. longicollatus, which has the same kind of dorsal body 
striations; and the statement of Darwin that $C$. minutus has "fine, transverse, toothed scales," although he does not picture them.

Berndt (1907a) does not differentiate clearly between his $C$. minutus striatus subspecies, and Darwin's original $C$. minutus. Apparently the only recourse is to consider them the same species and, in view of the lack of adequate differentiation of a subspecies, to consider the subspecies not properly defined and hence synonymous.

The variability of the apertural armament is shown in figure 2, with five specimens represented. This variability can cause much concern over the identification of species. The mouthparts and a detailed sketch of the extremely delicate mandible can be seen in figure 3 . The segment count for the three terminal cirri in one specimen is as follows:

Terminal cirrus:

Ramus:

Segments:

$\frac{1}{\text { Anterior Posterior }}$

$\frac{2}{\text { Anterior }} \begin{gathered}\text { Posterior } \\ 23\end{gathered}$

$\frac{3}{\text { Anterior }}$ Posterior

Other descriptive characteristics are well described by Darwin.

\section{Cryptophialus heterodontus, new species}

Figure 22

Diagnosis: Cryptophialus with one pair of very reduced mouth cirri and three pairs of terminal cirri; two dorsal body appendages; lateral bars wide and thickened on one edge, pointed, with three single teeth at the posterior end; head reduced; mantle aperture equipped with a series of ranked teeth.

Етумоlogy: hetero-(Gr.) different + odont-(Gr.) tooth, for the different tooth sizes on the operculum.

Distribution: Size of type $1.9 \times 0.78 \mathrm{~mm}$, with aperture of 0.24 $\mathrm{mm}$, in Tridacna maxima Röding, Heron Island, Queensland, Australia. Average size of three other specimens: $1.73 \times 0.87 \mathrm{~mm}$. Twelve specimens examined. One Turbo sp. from Heron Island had eight specimens of $C$. heterodontus, 10 specimens of a new species of Cryptophialus (see p. 107), and two Weltneria reticulata. Three specimens also were found in Distichopora nitida Verr. from the Marshall Islands, R. J. Ethridge, collector, Australian Museum G6234.

Type-material: Holotype: USNM 122618. Paratypes: Aust, SFSC, Vict. Additional material: BPB, Brit, CA, Paris, Seto.

The mantle is equipped with two prominent lateral bars, which are significantly heavier on the dorsal side, giving it a doubled appearance. The posterior end of the lateral bar is near several teeth which are not very prominent. A row of bifid teeth are arrayed on the external 
mantle sac immediately posterior to the aperture. A secondary reinforcing bar lines the dorsal interior of the mantle sac. Scattered teeth, usually two- or three-pointed, but occasionally four-pointed, stud the mantle. No orificial knob or attachment knob is present, although a well-developed adhesive area is represented by a large quantity of cemented exuviae, usually bearing two or more males.

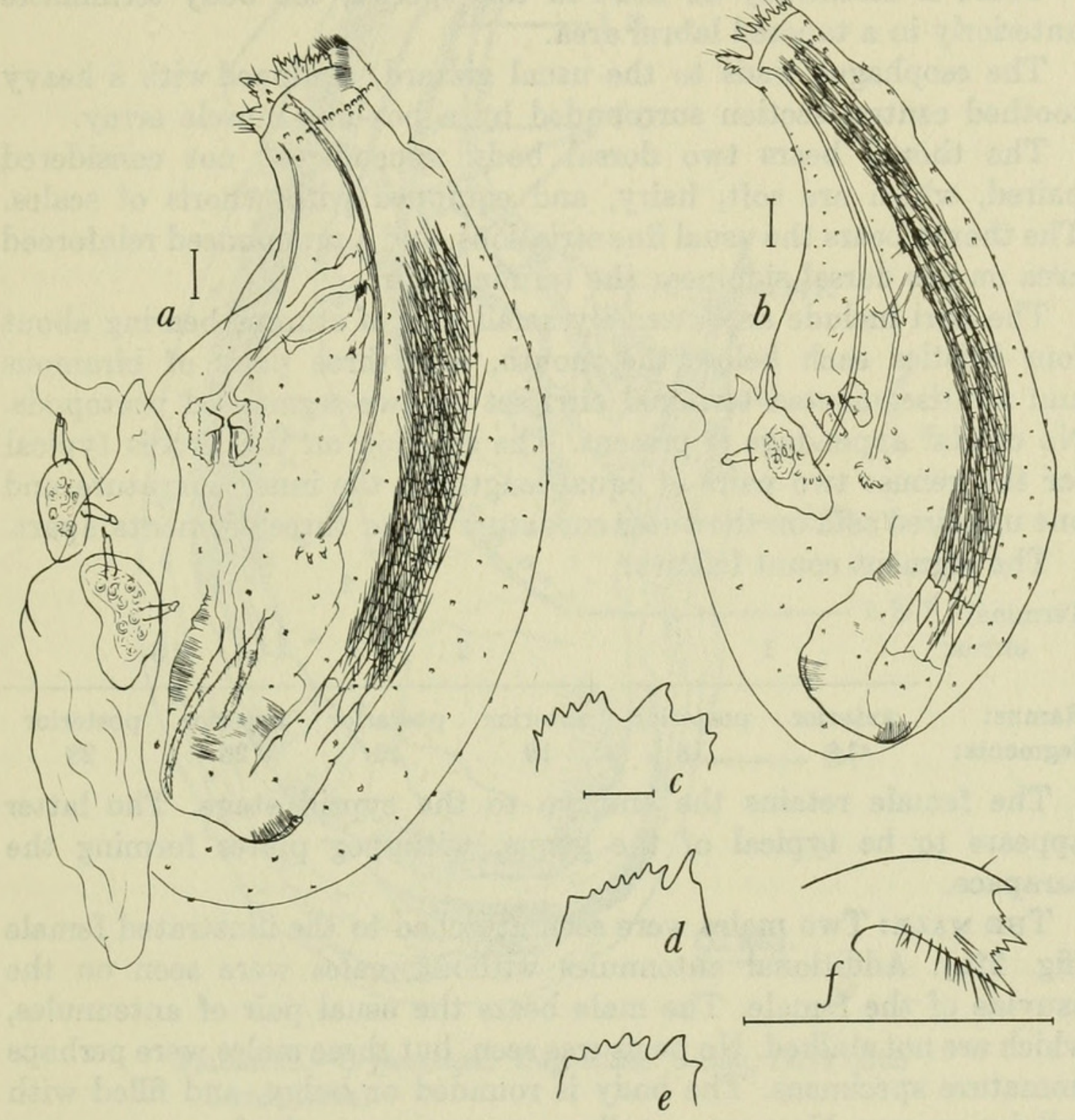

FIGURE 22.-Cryptophialus heterodontus, new species: $a$, female with males, side view, from Tridacna maxima from Heron Island, Australia; $b$, female with male, side view, from Distichopora nitida, from the Marshall Islands; $c, d$, e, opercular horizons of Heron Island specimens, rostral end to right; $f$, mandible, Heron Island specimen.

The mantle aperture is armed on both sides with an array of heavy teeth which become progressively larger dorsally. These teeth bear secondary teeth and hairs. A velum bearing the comb collar is prominent on the ventral side of the aperture. The length of the aperture of the type specimen is $0.3 \mathrm{~mm}$. 
The apertural armature varies, as illustrated in outline in figures 22c-e.

The mouthparts are typical, with a long labrum, a pair each of mandibles with palps, first maxillae, and second maxillae. The mandibles are illustrated from a sketch in figure 22f. They are extremely light and easily broken in this genus.

There is essentially no head in this species, the body terminates anteriorly in a tapered labral area.

The esophagus leads to the usual gizzard, equipped with a heavy toothed central section surrounded by a box-like muscle array.

The thorax bears two dorsal body appendages, not considered paired, which are soft, hairy, and equipped with whorls of scales. The thorax bears the usual fine striations, and a pronounced reinforced area on the dorsal side near the terminal cirri.

The cirri include an extremely small pair of stumps bearing about four bristles each below the mouth, and three pairs of biramous and multisegmented terminal cirri set on two-segmented protopods. No caudal appendage is present. The setation on the cirri is typical for the genus: two pairs of equal length on the inner curvature and one unpaired seta on the outer curvature up to three segments apart.

The segment count follows:

Terminal

cirrus:

1

2

3

\begin{tabular}{lcccccccc}
\cline { 2 - 3 } \cline { 5 - 7 } Ramus: & anterior & posterior & & anterior & posterior & & anterior & posterior \\
Segments: & 14 & 18 & & 19 & 21 & & 20 & 23
\end{tabular}

The female retains the embryo to the cyprid stage. The latter appears to be typical of the genus, with peg plates forming the carapace.

The male: Two males were seen attached to the illustrated female (fig. 22a). Additional antennules without males were seen on the exuviae of the female. The male bears the usual pair of antennules, which are not stalked. No penis was seen, but these males were perhaps immature specimens. The body is rounded or bulgy, and filled with cellular masses. No eyes or yellow organs were noticed.

\section{Cryptophialus longicollatus Berndt, 1907a, page 200}

Figure 23

Diagnosis: Cryptophialus with three pairs of thoracic cirri; two dorsal body appendages; with long neck of mantle to aperture; two long spines on mantle aperture; lateral bar terminations pointed, without swelling; to $1.44 \mathrm{~mm}$; in Haliotis ovina, from Mauritius. 


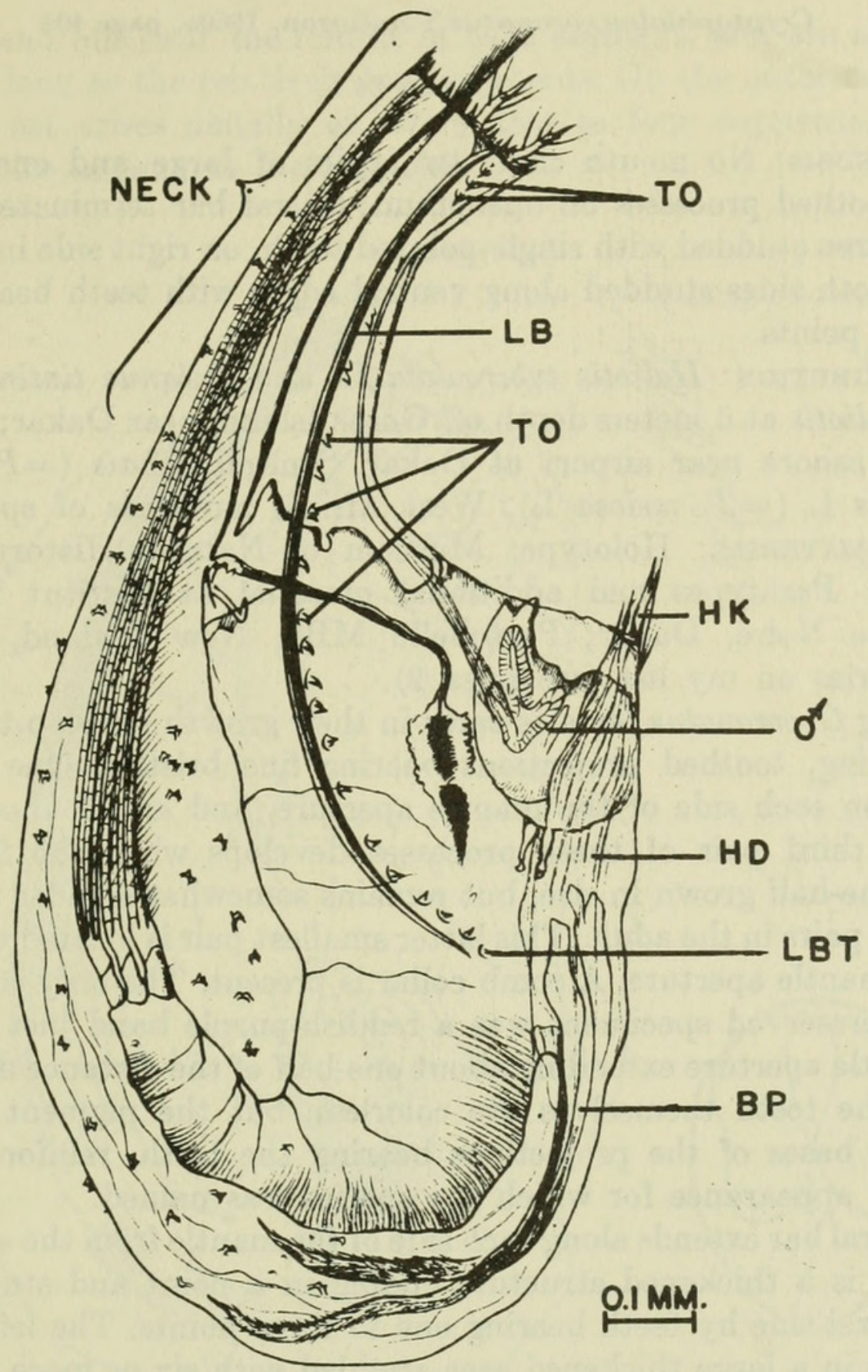

FigURE 23.-Cryptophialus longicollatus Berndt, 1907a (after Berndt 1907a).

Berndt describes this species from 45 to 50 specimens from two shells. The mantle opening lies on a long, attenuated process, which is up to one-third as long as the entire animal. The labrum and cirri are correspondingly longer, extending to the mantle opening. On each side of the mantle openings are two-jointed, especially strong spines, the basal joint being bristled. 
Cryptophialus coronatus Tomlinson, 1960a, page 404

Figure 24

Diagnosis: No mouth cirri; two pairs of large and one pair of small toothed processes on operculum; lateral bar terminates on left side in area studded with single-pointed teeth, on right side in tapered point, both sides studded along ventral edges with teeth bearing one to three points.

Distribution: Haliotis tuberculata L. and Balanus tintinnabulum (L.). Haliotis at 6 meters depth off Goree Island, near Dakar; Balanus washed ashore near airport at Dakar, Senegal; Thais (=Pourpres) neritoides $\mathrm{L}(=T$. nodosa $\mathrm{L})$, West Africa, hundreds of specimens.

Type-material: Holotype: Museum of Natural History, Paris, 1959-10. Paratypes and additional material at Institut Français d'Afrique Noire, Dakar; Portobello MBS, New Zealand, and all depositories on my list (see page 2).

Young $C$. coronatus females early in their growth develop two pairs of tapering, toothed projections bearing fine bristles. One of each pair is on each side of the mantle aperture, and are of about equal size. A third pair of these processes develops when the female is about one-half grown in size, but remains somewhat smaller than the first two pairs in the adult. This latter smallest pair is located ventrally on the mantle aperture. A comb collar is present. The only coloration on the preserved specimens was a reddish-purple band just beneath the mantle aperture extending about one-half of the distance down the neck. The teeth themselves are colorless, but the pigment extends into the bases of the projections bearing the teeth, reinforcing the "crown" appearance for which the species was named.

A lateral bar extends along each side of the mantle from the aperture. The bar is a thickened structure ending in a point and studded on the ventral side by teeth bearing one to three points. The left lateral bar ends in a large thickened area studded with six or more teeth.

THE CIRRI: The mouth cirri are entirely missing in this species. One hundred sixty-seven carefully corroded, dissected, and wholemounted specimens were examined with no trace of mouth cirri.

There are three pairs of biramous, multisegmented terminal cirri in $C$. coronatus. The segmentation count is low, as follows:

Terminal

cirrus:

1

2

3

\begin{tabular}{|c|c|c|c|c|c|c|}
\hline Ramus: & anterior & posterior & anterior & posterior & anterior & posterior \\
\hline Segments: & 11 & 16 & 18 & 19 & 21 & $21 ?$ \\
\hline
\end{tabular}

The setation is typical of the genus. On the inner curvature of each ramus of each cirrus two pairs of setae with very fine hairs arise, one 
distally and one near the middle of each segment, and are all about twice as long as the relatively long segments. On the outer curvature a single set arises distally on every two to four segments, and is about twice as long as the segments.

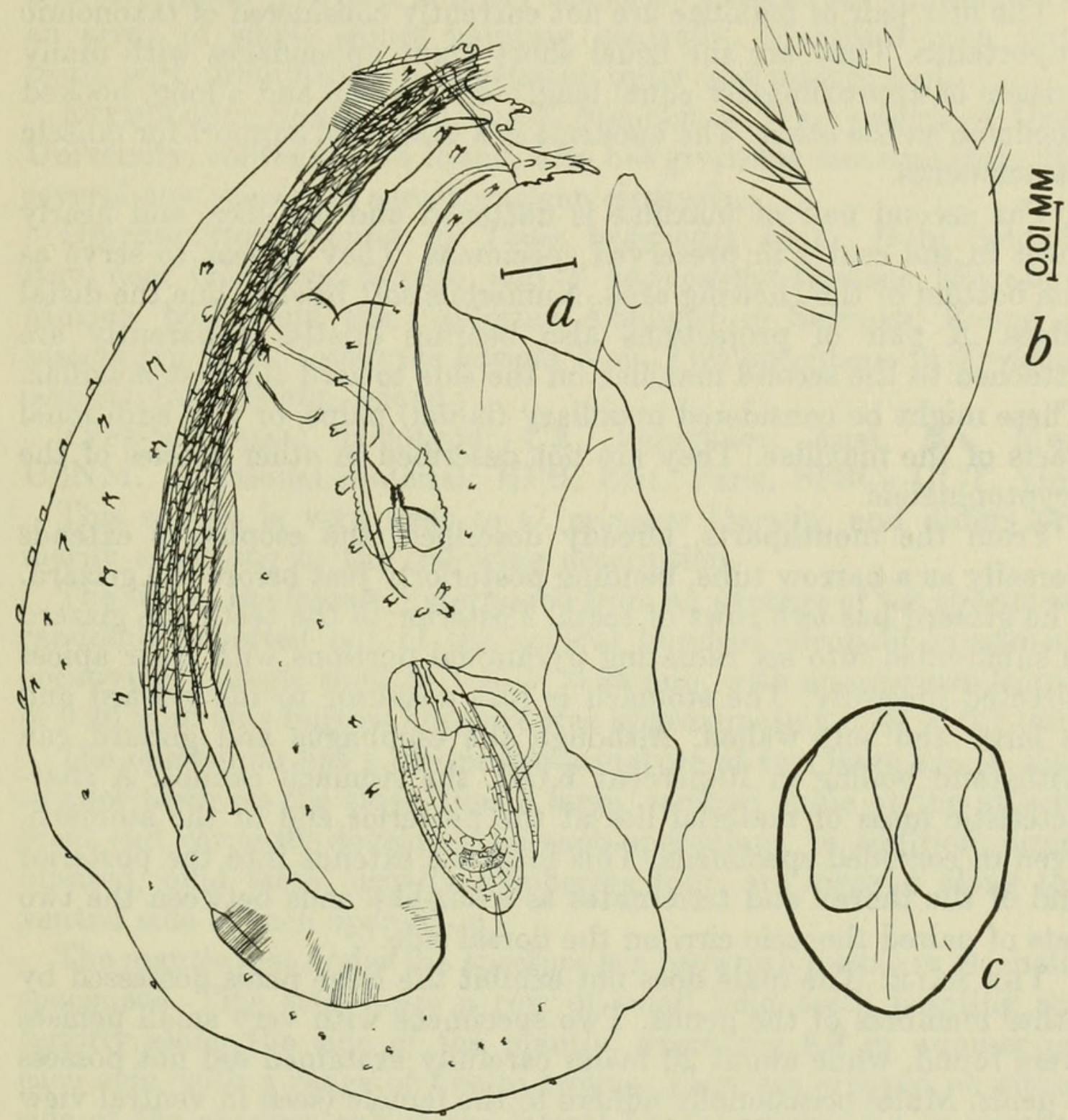

Figure 24.-Cryptophialus coronatus Tomlinson, 1960a: $a$, female, side view, with male larva, ventral view, from Balanus tintinnabulum from Dakar, Senegal; $b$, mandible from specimen from Thais nodosa from West Africa; $c$, burrow aperture with contained operculum of female.

The mouthparts of $C$. coronatus are typical of the genus. A long labrum extends to the mantle aperture and terminates with many fine bristles. The mandibles have three major teeth plus many additional heavy bristles projecting along the chewing edge. Additional lighter bristles are located on the broad face of the mandible. 
The mandibular palps are long, paired appendages lying laterally to the mandibles along the edge of the labrum. They are the longest of the paired mouthparts. They have four strong bristles on their medial edges, and the terminal bristle seems to be articulated on a separate projection.

The first pair of maxillae are not currently considered of taxonomic importance. They are the usual short blunt appendages with many bristles of approximately equal length on one end and a long, hooked apodeme on the other. The apodeme is a thickened support for muscle attachments.

The second pair of maxillae is flattened and leaf-like, and nearly meet in the center in preserved specimens. They appear to serve as the bottom of the chewing area. Numerous soft bristles line the distal edges. A pair of projections also bearing bristles apparently are attached to the second maxillae on the side toward the first maxillae. These might be considered maxillary (labial) palps, or just additional parts of the maxillae. They are not described in other species of the cryptophialids.

From the mouthparts, already described, the esophagus extends dorsally as a narrow tube, bending posteriorly just before the gizzard. The gizzard has two rows of teeth. Posterior to the teeth the gizzard is subdivided into six radiating pyramidal portions with their apices directed inwardly. The stomach is just posterior to the gizzard and is large and soft walled. Although the esophagus and gizzard can withstand boiling in 10-percent $\mathrm{KOH}$, the stomach cannot. A characteristic mass of material lies at the posterior end of the stomach, even in corroded specimens. This intestine extends into the posterior end of the thorax and terminates as a slit-like anus between the two sets of paired thoracic cirri on the dorsal side.

The male: The male does not exhibit the large penis possessed by other members of the genus. Two specimens with very small penises were found, while about 20 males carefully examined did not possess a penis. Males occasionally adhere to the female (seen in ventral view in fig. 24a), but are more abundant in the burrow. The specimen adhering to the type female measures $0.32 \times 0.13 \mathrm{~mm}$. The male integument contains peg plates, obvious polygons bearing numerous dark spots. This is common in the genus.

The Larva: No detailed study of larval development was made on this species. The eggs are deposited in a brood pouch which is dorsal to the posterior part of the thorax. It contains two body appendages which may aid in maintaining the larvae. The eggs are retained until the cyprid stage. 


\section{Cryptophialus wainwrighti, new species}

Figure 25

Diagnosis: Cryptophialus with mouth cirrus, three pairs of terminal cirri, and two dorsal filamentary body processes. With three compound spines and about four large bifid teeth along each mantle aperture, none of which is finely serrated. Lateral bar terminates in an array of single spines pointing ventrally. Mandible with three teeth, with prominent notch between outer and middle tooth.

Eтүмоlogy: Named in honor of Stephen A. Wainwright, of Duke University, colleague and friend, who has given me material including several new species of acrothoracican cirripeds.

Distribution: Found in Thais triseriallis Blain. from Soldado Bay, near Guaymas, Mexico, and T. haemostoma Lomans, Mazatlan, Mexico, both from the California Academy of Sciences. Found in association with Kochlorine hamata Noll. Two specimens in Tridacna maxima from Heron Island.

Type-material: Holotype: CA. Paratypes: Aust, BA, Mex, USNM. Additional material: BPB, Brit, Paris, SFSC, UCT, Vict.

This species is very near to $C$. minutus Darwin, and differs primarily according to the following description.

The size of the female, determined from an average of ten specimens randomly pipetted out of the several hundred alcoholic specimens occupying a single shell, is $1.43 \times 0.84 \mathrm{~mm}$, with an aperture length of $0.26 \mathrm{~mm}$. One burrow aperture was approximately $0.25 \times 0.1 \mathrm{~mm}$.

The operculum has a distinctive armature of two large spines with smaller teeth on the sides, plus a large, toothed spine at the attachment end variously developed on each operculum. In addition, large, blunted, bifid teeth, usually numbering four, are arrayed along the ventral side of each operculum.

The mantle just under the aperture is a brownish purple in alcoholic specimens. This area bears a row of small bifid teeth pointing anteriorly along the side of the mantle, averaging 8.3 in number on each side, with a range of five to twelve. They are arrayed on either side of the anterior end of the lateral bar, averaging 6.1 in number on the ventral side and 2.25 on the dorsal side. This is a low number for the genus.

The lateral bars are simple, pointed, and extend posteriorly along each side of the mantle. They end in an array of single spines, point ventrally, and are often arranged in crude circles. Along the sides of the lateral bars, but especially the ventral side, are characteristic bifid or trifid teeth which project posteroventrally, and are set on bases which taper into thin points anterodorsally. Another single reinforcing bar is seen in the dorsal apertural area, and a row of 
prominent teeth point forward along the ventral margin of the mantle. Other teeth are very small and scattered about on the mantle.
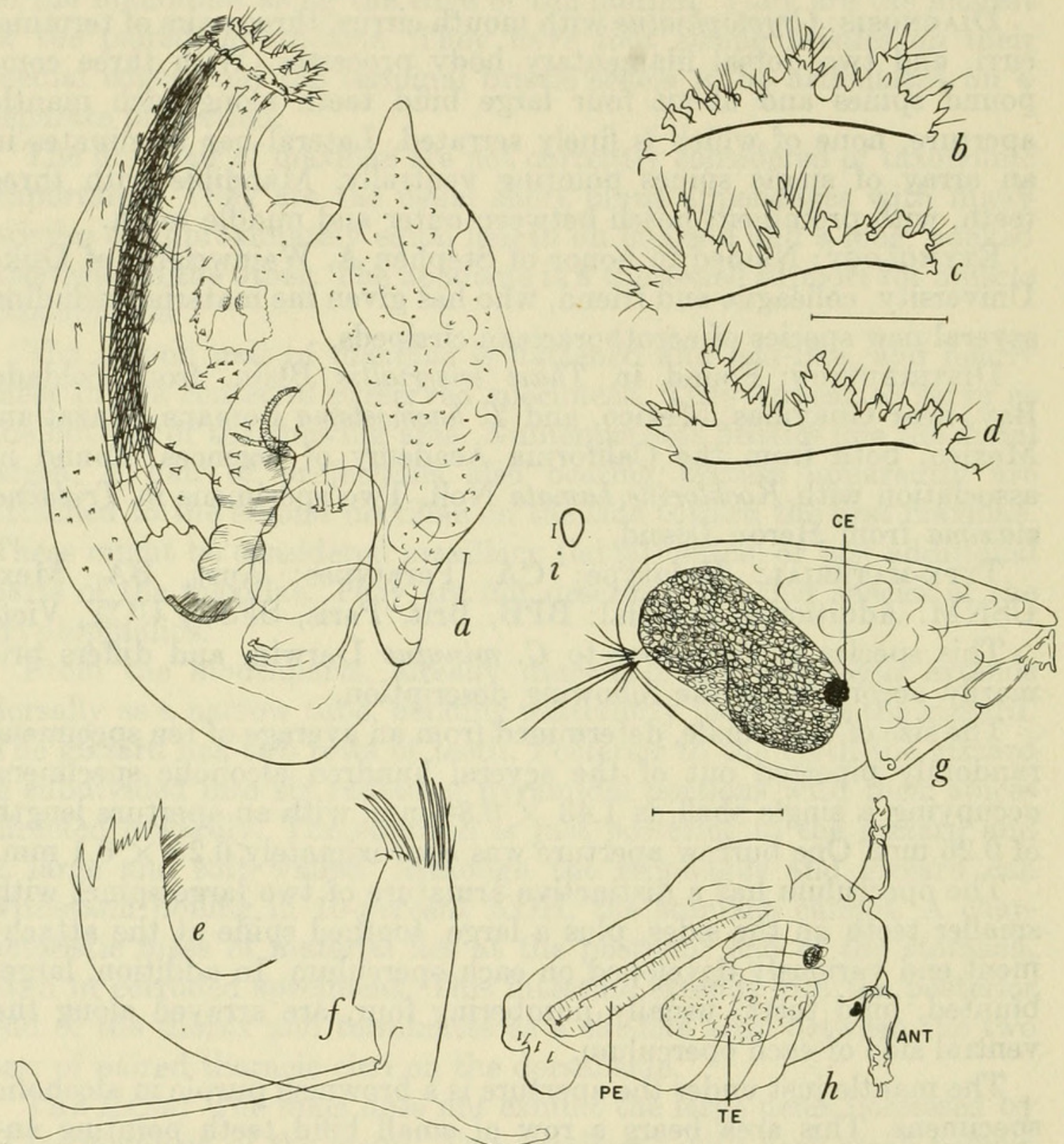

Figure 25.-Cryptophialus wainwrighti, new species, from Thais triseriallis from Soldado Bay, Mexico: $a$, female, side view, with cyprid larvae; $b, c, d$, opercular horizons of different specimens, rostral (attachment) end at right $(b)$ and left $(c, d) ; e$, mandible; $f$, first maxilla; $g$, larval or immature male; $h$, mature male; $i$, burrow aperture, surface view.

There is no orificial knob, but the attachment disk is well developed, and forms a horny disk of cemented exuviae bearing curious whole or partial small disks scattered over its surface.

The usual comb collar on the orificial velum guards the ventral end of the interior of the aperture.

The head is rounded and prominent, although not noticeably hairy. A prominent labrum, which may be creased near the anterior end, 
bears hairy margins. The mouthparts consist of the usual pairs of mandibles with palps, first and second maxilla. The mandibles bear the usual three teeth with finer teeth between. A distinguishing feature is the prominent notch which separates the anterolateral tooth from the others (fig. 25e). The first maxillae are typical, with heavy bristles rather than teeth, and with the usual apodeme. The second maxillae are typical of the order.

The mouth cirri are so small as to be barely noticeable. The few thin bristles on a raised hummock are all that remain, and whether they are functional or vestigial is open to question.

The posterior thorax is finely creased with striations caused by corrugations in the cuticle. The anal region bears a chitinous reinforcing with striations slightly more prominent.

Three pairs of biramous, multisegmented terminal cirri crown the thorax. They are set on a two-segmented protopod, with somewhat fewer hairs on the protopod than seems typical. The segment count for the three terminal cirri are as follows:

Terminal

cirrus:

1

2

3

\begin{tabular}{|c|c|c|c|c|c|c|}
\hline Ramus: & anterior & posterior & anterior & posterior & anterior & posterior \\
\hline Segments: & 9 & 15 & 17 & 18 & 20 & 20 \\
\hline
\end{tabular}

Each segment bears two pairs of bristles on the inner curvature, while each one to four segments along the outer curvature bears a single bristle. All bristles are about of the same length, and slightly plumose. No caudal appendage is present.

The dorsal side of the thorax bears two filamentary body processes, not paired. The anterior process appears to be slightly larger in this species.

The esophagus leads directly dorsal from the mouth, then takes a bend posteriorly to the gizzard. The gizzard is typical for the genusa muscle-supporting framework with two split hemispheres of rounded, tubercle-bearing, grinding plates, followed by what appears to be a finer triturating mill.

The larvae are retained to the cyprid stage. The cyprids are typical of the genus, appearing essentially as that shown for the larval male (fig. $25 \mathrm{~g}$ ), but with many rows of roughly rectangular plates in the carapace, each bearing about 20 projecting pegs arranged in rows and geometrical patterns. The larval male also had these peg plates, but they were much less apparent. The antennules are set on jointed processes, with the "elbow" demonstrating a chitinous curlicue internally.

The males are not unusual. They possess a hyaline mantle without peg plates, with a prominent penis, and a pair of antennules. The posterior end is bifid, with about four small teeth. The presence of 
eyes and yellow organs could not be determined with confidence. The type-specimen has three males attached to the horny disk, but up to six have been found on one female. Spent males are common, as evidenced by the bare antennules attached to the female. The males do not seem to be attached to the wall of the burrow.

RELATIONSHIPS: The nearest relative in space and affinities appears to be Cryptophialus minutus Darwin. The major differences are those noted in the diagnosis: the mantle and lateral bar armament, and the notched mandible. The uniformity of the aperture is demonstrated by three separate and randomly chosen specimens shown in figure $25 \mathrm{~b}-\mathrm{d}$. The lateral bar teeth are very good characteristics, but the mandible is difficult to see clearly.

\section{Cryptophialus variabilis Stubbings, 1961, page 189}

\section{Figure 26}

Diagnosis: Cryptophialus with two pairs of long, slender, hairy spines on operculum, lateral bar without a terminal array of teeth.

Distribution: Calypso Station III, Principe Island, Ilots dos Mosteiros, northeast corner of the island, Gulf of Guinea expedition of 1956. In a conglomerate of molluscan shell, calcareous algae, and the shell of Balanus tintinnabulum tintinnabulum. Thirty-eight specimens recovered. I have dissected one specimen presented by $\mathrm{H}$. G. Stubbings through the courtesy of J. Forest of Museum Nationale d'Histoire Naturelle, of Paris. The largest specimen measured by Stubbings was $1.69 \mathrm{~mm}$.

In addition, five specimens from Acropora digitifera (Dana) from Palawan Island, Philippine Islands, added the following information: Measurements of three specimens which were complete were as follows in length and width in millimeters: $1.35 \times 0.85 ; 1.35 \times 0.70$; and $1.35 \times 0.70$. They clearly had features as described below, including three pairs of terminal cirri, two dorsal body processes, apparently identical mouth parts, and cirral segment count of 14 to 24 segments.

Stubbings describes this species in part as follows:

The mantle aperture bears two pairs of processes of variable length. When fully developed they are long and furnished with a few slender setae, but no teeth [mine did-J. T.]. In undeveloped forms and when damaged they project only slightly above the mantle border. The mantle aperture is armed with stout toothlike spines with serrated edges. The mantle is studded along the ventral margin and the anterior region with trifid, or occasionally more complex teeth. The lateral bar ends abruptly on the left side and here [and] there are a few simple conical teeth in place of the complex spines. On the right side the bar tapers somewhat and there are no conical teeth. There are very minute teeth scattered along both lateral bars. 
Three pairs of terminal cirri are present and also rudimentary mouth cirri. The latter are short and unjointed with two or three terminal setae only. These appendages appear to be attached for much of their length to the ventral body surface and to be free only near the distal extremity. There is a single dorsal body process.

At this point I disagree with Mr. Stubbings. The single specimen that I dissected clearly had two dorsal body processes. The Principe Island specimen that I dissected was a mature female without attached male. She measured (in 70-percent alcohol) $1.50 \times 0.75 \mathrm{~mm}$, with a neck length of $0.338 \mathrm{~mm}$ without spines and $0.489 \mathrm{~mm}$ with spines, and a neck width at the narrowest constriction of $0.226 \mathrm{~mm}$. The aperture was $0.28 \mathrm{~mm}$ long.

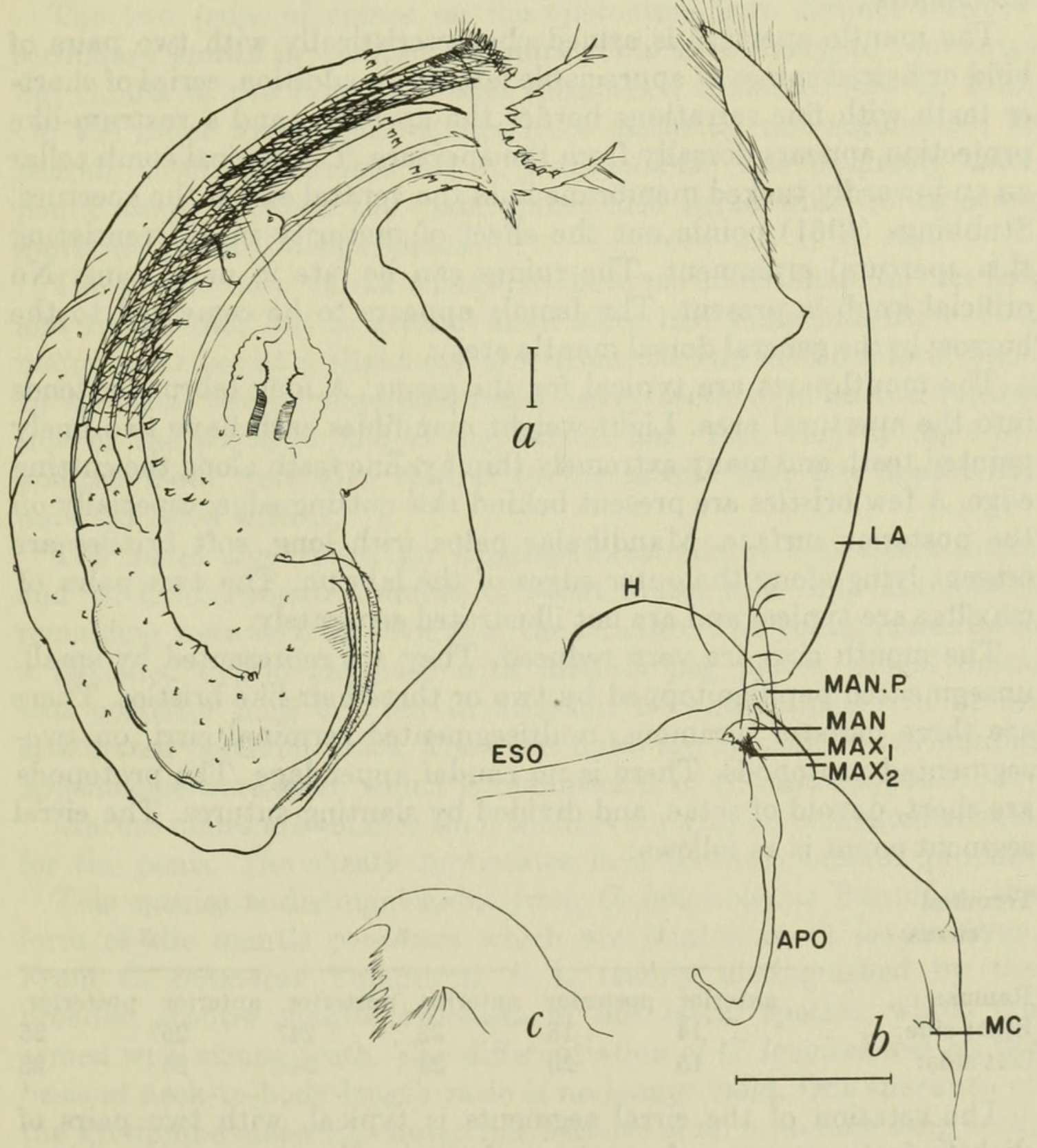

Figure 26.-Cryptophialus variabilis Stubbings, 1961, from a specimen from Stubbings from Balanus tintinnabulum from Principe Island, Guinea: $a$, female, side view; $b$, mouth field with labrum; $c$, mandible. 
The mantle possesses the typical teeth with one to three points scattered about the surface, especially the ventroposterior area. Ventrally pointing heavier teeth are aligned along the ventral side of the lateral bars, and face anteriorly ("upward" in the burrow) just below the aperture in a circle around the mantle.

The lateral bars are typical. They appear to be rolled thickly on the dorsal edge, and possess extremely small granulations scattered about along their length. The left lateral bar (illustrated in fig. 26a) terminates in an area of a circle of three teeth rather less developed than other specimens of the same genus. The right lateral bar does not possess this terminal cluster of teeth. An auxiliary internal strengthening bar appears in the dorsal curve of the neck area of the mantle.

The mantle aperture is armed characteristically with two pairs of bifid or haired spines of appreciable length. In addition, series of shorter teeth with fine serrations border the aperture, and a rostrum-like projection appears dorsally from the aperture. The typical comb collar on an inwardly tucked membrane lines the ventral end of the aperture. Stubbings (1961) points, out the effect of maturity in differentiating this apertural armament. The spines can be late in developing. No orificial knob is present. The female appears to be cemented to the burrow in the general dorsal mantle area.

The mouthparts are typical for the genus. A long labrum extends into the apertural area. Light-weight mandibles each have two finely pointed teeth and many extremely thin hyaline teeth along the cutting edge. A few bristles are present behind this cutting edge, especially on the posterior surface. Mandibular palps with long, soft bristles are present lying along the outer edges of the labrum. The two pairs of maxillae are typical and are not illustrated separately.

The mouth cirri are very reduced. They are represented by small, unsegmented papillae topped by. two or three hair-like bristles. There are three pairs of biramous, multisegmented terminal cirri, on twosegmented protopods. There is no caudal appendage. The protopods are short, devoid of setae, and divided by slanting sutures. The cirral segment count is as follows:

\section{Terminal}

cirrus:

1

Ramus:

Right side:

Left side: anterior posterior

$14 \quad 18$

$15 \quad 20$
2

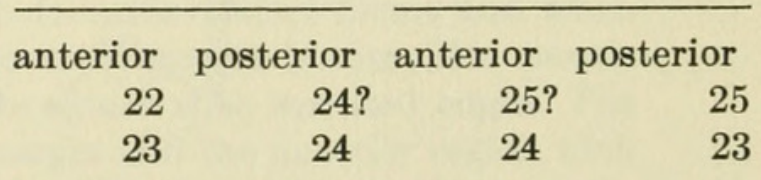

The setation of the cirral segments is typical, with two pairs of slightly feathery setae of equal length (twice the segment length) on 
the inner curvature, one pair arising distally and one pair arising from midsegment; one seta (twice the segment length) arises from the outer curvature at the distal end of approximately every third segment, becoming every segment near the distal end of the cirrus. The first terminal cirrus has short (less than a segment length) additional setae on the sides of the dorsal end of each segment.

The esophagus extends dorsally from the mouth area, and bends posteriorly at the gizzard. The anterior portion of the gizzard bears two patches of about twenty-five nodules for grinding, followed by what appears to be several rows of fine hairs forming a strainer.

Noteworthy additional information from the Palawan material includes the opercular armament, lateral bars, and the male.

The two pairs of spines on the operculum bore distinct teeth or secondary spines in addition to hairs. This is contrary to Stubbings but similar to the Principe Island specimen I examined (see fig. 26a). On the other hand, these spines were distinctly not segmented, as Berndt (1907a) describes for $C$. longicollatus. The pinnately compound teeth between the main spines also agree with $C$. variabilis more than with $C$. longicollatus.

The lateral bars varied somewhat between individuals on the left and right sides, but in general both sides had some indication of a major tooth set at a slight distance from the end of the lateral bars. In addition, two or more additional heavy teeth were on the ventral side of the posterior end of the lateral bar. Two very strong finepointed teeth were also ventral to the lateral bar, but apparently not associated with it.

The males are typical for Cryptophialus. About five intact males and an indeterminate number of spent males with only antennules remaining were seen on several of the females. The young males have a flattened cyprid carapace with distinct peg plates, dorsal hairs, and posterior long bristles, in addition to what appears to be an articulated posterior plate. The antennules are typical. No swimming appendages were seen, which is reminiscent of $C$. melampygos.

Mature males are smaller than the larvae, with an elongated sheath for the penis. The sheath terminates in a toothed, bilobed process.

This species is distinguishable from $C$. longicollatus Berndt in the form of the mantle processes which are jointed in $C$. longicollatus. From $C$. coronatus Tomlinson, it is readily distinguished by the broader, stouter mantle processes in this latter species, which are armed with strong teeth. The differentiation of $C$. longicollatus on the basis of neck-to-body-length ratio is no longer valid. One specimen of the Philippine material, chosen not because of an especially long neck, but for the convenient position and good condition, measured $1.35 \times$ 
$0.60 \mathrm{~mm}$, with a neck of $0.458 \mathrm{~mm}$, slightly over one-third the length of the total body, excluding the spines in both measurements. C. longicollatus is diagnosed as having a neck one-third as long as the entire body.

The separation of $C$. variabilis from $C$. longicollatus is thus rather tenuous, and they are considered very closely related.

\section{Cryptophialus newmani, new species}

Figure 27

Diagnosis: Cryptophialus with operculum armed with two pairs of gnarled, haired protuberances bearing serrated spines and medial stout, toothed knobs. A row of about 15 very thin, hyaline, serrated teeth line the lateral edge of the operculum. The extremely thin lateral bar terminates in an area with a few heavy teeth.

Eтүмоцоgy: The species is named in honor of Dr. William A. Newman of the University of California at San Diego, a colleague and friend. It should be noted that an error of mine put the first species I named for him, Utinomia newmani, in synonymy with Weltneria hirsuta (q.v.). I trust that this species will be more permanent.

Distribution: About 115 specimens associated with Lithoglyptes wilsoni in Turbo lajonkairi from Wake Island, collected in July, or August, 1923, by D. Thaanum, from the Bernice P. Bishop Museum collection 66541, through the courtesy of Dr. Yoshio Kondo. Nine specimens were in Acropora digitifera (Dana) from near Coron, Palawan, Philippine Islands, from the collection of the National Museum of the Philippines, through the courtesy of Fernando Dayrit, identified by Professor Francisco Nemenzo of the University of the Philippines.

Type-material: Holotype: Female $1.34 \times 0.55 \mathrm{~mm}$, with a male of $0.37 \times 0.11 \mathrm{~mm}$, Bernice P. Bishop Museum B460. Paratypes: Aust, CA, Mex, Seto, SFSC, SIO, USNM, Vict. One paratype measured 1.20 $\times 0.72 \mathrm{~mm}$, with an aperture of $0.13 \mathrm{~mm}$ on a neck of $0.22 \mathrm{~mm}$. The figured specimen (fig. 1) measures $1.25 \times 0.55 \mathrm{~mm}$, with an aperture of $0.18 \mathrm{~mm}$ on a neck of $0.39 \mathrm{~mm}$. Additional material: Brit, Belg, BA, Dublin, Paris, UCT.

The main differentiating features of this species are to be found on the mantle. The differences in the opercular armament and lateral bar are pertinent, and separate this species from C. variabilis Stubbings and $C$. longicollatus Berndt.

The operculum tends to collect dirt and debris in the many serrated teeth and hairs. After cleaning and clearing by boiling in $\mathrm{KOH}$, 


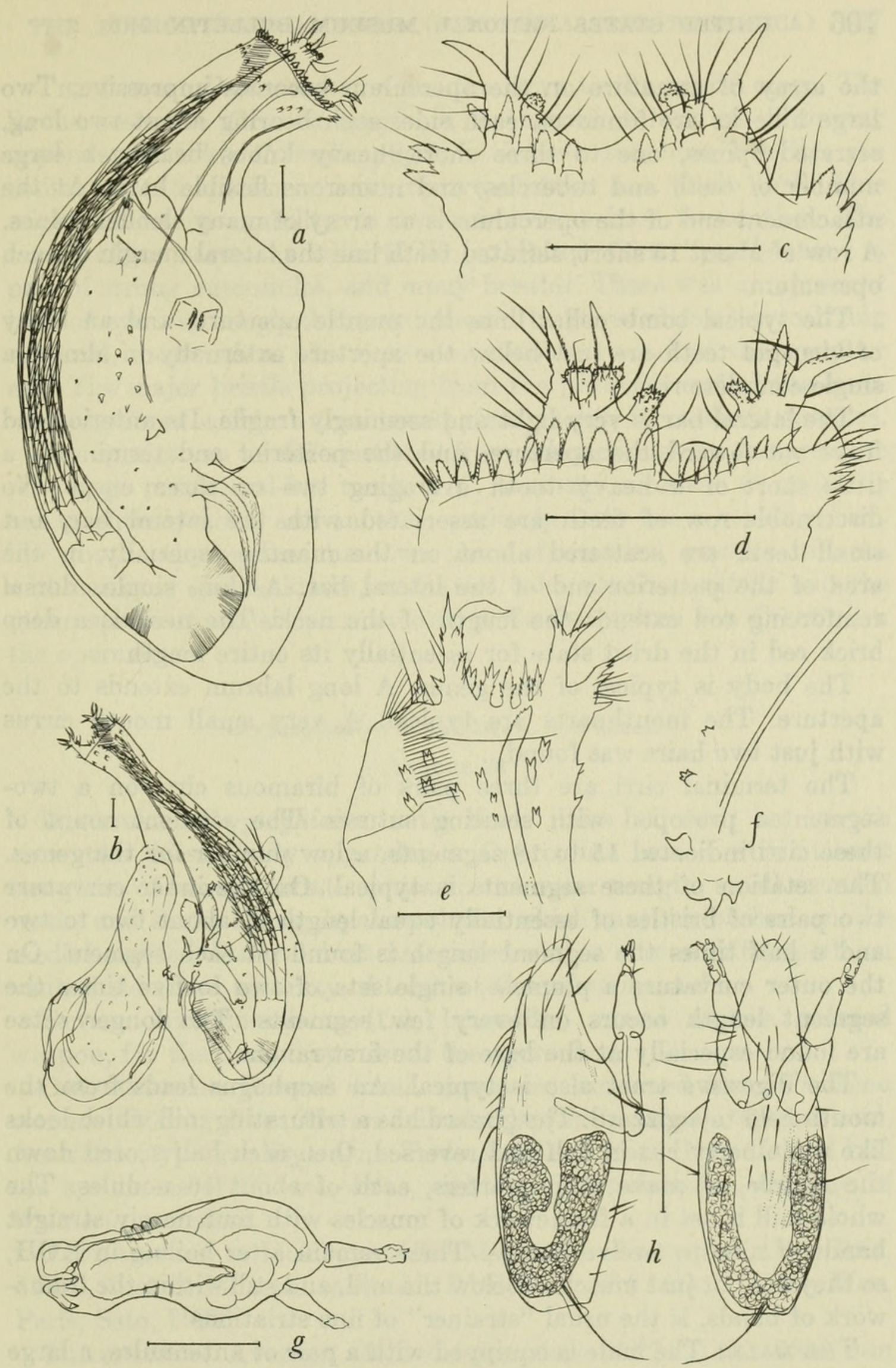

FigURE 27.-Cryptophialus newmani, new species: $a$, female, side view, from Turbo lajonkairi from Wake Island; $b$, female with males from Acropora digitifera from Palawan, Philippine Islands; $c$, opercular detail of a young specimen from Wake Island, row of serrated teeth on outside; $d$, opercular detail of a mature specimen from Wake Island; $e$, opercular detail of another specimen from Palawan, Philippine Islands; $f$, detail of lateral bar termination of specimen in $e ; g$, male of Wake Island specimen, with posterior teeth; $h$, lateral and ventral view of cyprid from Wake Island (specimen in $g$ ), lateral view shows only one antennule of pair. 
the array of armature on the operculum becomes impressive. Two large hillocks are found on each side, each bearing about two long, serrated spines, one to three short, heavy knobs bearing a large number of teeth and tubercles, and numerous flexible hairs. At the attachment end of the operculum is an array of many slender spines. A row of about 15 short, serrated teeth line the lateral margin of each operculum.

The typical comb collar lines the mantle aperture, and an array of bicuspid teeth are just below the aperture externally in almost a single complete ring.

The lateral bar is very light and seemingly fragile. Its anterior end frays out toward the aperture, and the posterior end terminates a little short of a heavy tooth averaging two or three cusps. No discernable row of teeth are associated with the lateral bar, but small teeth are scattered about on the mantle, especially in the area of the posterior end of the lateral bar. A thin, single, dorsal reinforcing rod extends the length of the neck. The neck is a deep brick red in the dried state for essentially its entire length.

The body is typical of the genus. A long labrum extends to the aperture. The mouthparts are typical. A very small mouth cirrus with just two hairs was found.

The terminal cirri are three pairs of biramous cirri on a twosegmented protopod with slanting sutures. The segment count of these cirri indicated 15 to 18 segments, a low number for the genus. The setation of these segments is typical. On the inner curvature two pairs of bristles of essentially equal length of about two to two and a half times the segment length is found on each segment. On the outer curvature a plumose, single seta of two to five times the segment length occurs on every few segments. The longer setae are found especially at the base of the first ramus.

The digestive tract also is typical. An esophagus leads from the mouth field to a gizzard. The gizzard has a triturating mill which looks like a mulberry cut in half and reversed, then each half scored down the middle, to make four quarters, each of about 16 nodules. The whole mill is set in a framework of muscles with four nearly straight bands of nine to twelve bumps. These remain after boiling in $\mathrm{KOH}$, so they are not just muscles. Below the mill, and still within the framework of bands, is the usual "strainer" of fine striations.

The male: The male is equipped with a pair of antennules, a large penis, and four chitinous teeth at the posterior end (fig. 27g). The body wall is slightly annulated in the midregion. The penis, after $\mathrm{KOH}$ treatment, does not show much annulation, but has what appears to be a chitinous tip. No naupliar eye or yellow organ was seen: 
The larva: $C$. newmani retains the larva to the cyprid stage. The larvae resemble $C$. melampygos in its apparent lack of swimming appendages. Like $C$. melampygos, it infects the host heavily. An estimated 115 specimens were recovered from one Turbo shell. This might reflect its inability to swim from one host to another. The larva, after treatment with $\mathrm{KOH}$, exhibited faint "peg plates," a pair of strong antennules, and many bristles. There was an apparent lack of eyes, although this point should be pursued further in living material, inasmuch as the male also apparently lacked the naupliar eye. The major bristle projecting from the posterior end of the larva was contained within a thin transparent sheath for a short distance.

The species can be differentiated from other species by the presence of a large postlateral-bar tooth in $C$. newmani, whereas $C$. variabilis has essentially none, and another species (p. 112) has a massive clawlike tooth. C. newmani has two pairs of massive, gnarled hillocks with serrated spines, knobs, and hairs, whereas $C$. variabilis and the other species have simpler and more slender spines set directly on the operculum.

\section{Cryptophialus lanceolatus, new species}

Figure 28

Diagnosis: Cryptophialus with three pairs of cirri; no mouth cirri; two dorsal body appendages. Operculum armed with at least two pairs of heavy pinnate spines on the outer margin, small serrated teeth, and several long, hyaline shafts which may be barbed on the medial surface. Lateral bars associated with a row of bifid teeth on ventral side, and an array of teeth at the posterior end.

EтүмоLogy: lanceolatus (L.), lance-like, armed with a pointed weapon, for the barbed spines on the operculum.

Distribution: Several dozen specimens examined from Tridacna maxima Röding from Heron Island, Capricorn Group, Queensland, Australia (type-locality). One Turbo speciosus from Heron Island had ten specimens of $C$. lanceolatus, eight of $C$. heterodontus, and two of Weltneria reticulata.

Type-material: Holotype: USNM 122620. Paratypes: Aust, Brit, SFSC, Vict. Additional material: BPB, Belg, BA, CA, Dublin, Mex, Paris, Seto, UCT.

Dimensions: Average of five specimens: $1.77 \times 0.93 \times 0.69 \mathrm{~mm}$ in length, dorsoventral width, and thickness, with an aperture 0.37 $\mathrm{mm}$ long. 




Figure 28.-Cryptophialus lanceolatus, new species, from Tridacna maxima from Heron Island, Australia: $a$, female side view; $b$, detail of opercular plates opened from the comb collar (carinal) end; $c, d$, detail of operculum, attachment (rostral) on left end, medial barbs (about 12 each) not included; $e-h$, opercular horizons of different specimens, with length in millimeters, attachment (rostral) on right: $e, 1.25 ; f, 1.40 ; g, 1.25 ; h, 1.15 ; i$, mouth field and long labrum; $j$, mandible; $k$, first maxilla; $l$, detail of portion of terminal cirrus; $m$, prominent tooth on mantle exterior; $n$, sketch of mature male, side view, showing curious "beak" on bottom, and recurved antennule on top; $o$, male, ventral view; $p$, sketch of cyprid larva and a detail of the "peg plates."

The mantle is not strongly muscular. The shape of the mantle is that of a bottle with a long, bent neck. The aperture is at the top end of the neck, and the attachment area is at the top of the widest flange on the dorsal side. The mantle aperture area is a brownish 
purple, which extends down the neck of the mantle almost to the attachment area, becoming streaked and lighter in the lower half of the neck.

The armature of the operculum is awesome. One minor and two major pairs of enormous, pinnately compound spines arise from the lateral edges, and a lesser pair of spiny processes serve as the dorsal end of the opercula (on the rostral, or attachment side). Although there is a lot of individual variation (figs. $28 \mathrm{c}-\mathrm{h}$ ), the basic pattern is the same. The spines are well over half as tall as the operculum is wide. The bases of the spines bear numerous smaller spines, set on collar-like heavier bases of their own. Two to five additional spines between the larger pair are also pinnately compound, with very fine hyaline teeth set on their margins. Long, flexible hairs are scattered over these spines.

Medial to the main spinal armature, six or more tall, barbed shafts arise like lances from the opercular surface (fig. 28b). These may be slightly curved, but are quite uniform in the width of the shaft. They are set on heavy bosses, but do not appear to articulate. They resemble commercial crochet hooks. On the ventral end of the mantle aperture (away from the attachment end) the typical comb collar infolds. This is a folded membrane or velum with even, fine crenulations which distally appear as a row of minute hairs.

The mantle along its two sides bears a pair of heavy lateral bars, plus a small reinforcing bar along the dorsal surface. These are reinforcing convolutions in the mantle chitin, and are typical. Heavy bifid teeth are deployed along the ventral side of the lateral bars, and a characteristic assemblage of teeth are distributed around the posterior end of the bar. This latter series consists of about eight simple teeth spread like an island chain in a wide arc, with a curvature opposite that of the lateral bar.

Another characteristic set of bifid teeth, numbering eight or more, face upward (anteriorly) around the neck just below the operculum. Other teeth are scattered over the surface of the mantle, especially in the ventral half. Some of these teeth can become very complex, with five-pointed teeth common, and a seven-pointed one seen (fig. $28 \mathrm{~m})$.

The attachment disk is not as heavy or horny as some other species, but the mantle definitely attaches to the burrow on the dorsal surface. No attachment knobs or orificial knobs are present.

The mouthparts are typical of the genus. A long labrum extends from the anterior mouth area into the mantle aperture. It is pointed, with many hairs along the lateral edges, and a few scattered shorter bristles on the ventral surface (fig. 28i). A pair of mandibles, with palps which seem to adhere to the labrum, and two pairs of maxillae complete the 
mouthparts. The mandibles are extremely light and delicate. They cannot be studied adequately by removing the mouthparts because of their delicacy and their position. Thus, they can best be seen in the $\mathrm{KOH}$-corroded whole animal (fig. 28j). The anterior cutting edge is serrated with numerous (about twelve) extremely fine teeth, three of which are slightly more prominent. These teeth form a reasonably straight line. Many light hairs are distributed along the ventral margin.

The first maxilla is typical of the genus: a long, relatively straight appendage with a tuft of long, heavy hairs at the e d (fig. 28k). There does not appear to be the pair of spines constituting the teeth of this maxilla, as is found in most other genera. The apodeme of the first maxilla is the typical long chitinous muscle-supporting rod bent at the end into what resembles a hockey stick.

The second maxilla is typical of the order: a pair of flat, hairy plates closing the posterior mouth field, with a hairy process extending anteriorly from the medial edge between the other mouthparts.

Extending dorsally and then posteriorly from the mouth is the esophagus, which leads into the gizzard, typical of the family. The gizzard is an apparatus equipped with muscles and a set of central teeth, followed by what appears to be a straining device. It is undoubtedly used to triturate the food. Its use notwithstanding, there often appears heavy particulate food material in the gut following the gizzard. The anus opens dorsally between the pairs of cirri.

On the dorsal surface of the thorax are two unpaired filamentary processes, similar to those of other members of the genus, and similar to structures found in the order Thoracica. They are long, tapered, annulated, flexible appendages set with a multitude of extremely short hairs. Inasmuch as one or both can be turned back along the thorax, they are sometimes difficult to observe clearly and hence can be missed.

The posterior portion of the thorax tapers to the point of attachment of the cirri. The dorsal surface is equipped with one prominent and one lesser V-shaped chitinous thickening which apparently reinforces the thorax. These areas bear especially prominent fine striations, which may extend across the entire thorax. These fine striations are typical of the order.

The mouth cirrus is missing completely. In the entire genus the mouth cirrus is reduced, with the greatest development exhibiting only small, unsegmented appendages bearing a few bristles. No such appendages can be seen in this species.

The cirri are restricted to the posterior end of the thorax, and consist of three pairs without a caudal appendage. The cirri are multisegmented and biramous, on a two-segmented protopod. The protopod bears a slanting articulation, with the distal segment much shorter 
than the proximal one. The segment counts of the cirri are as follows, for one specimen:

Terminal

cirrus:

1

2

3

Ramus:

anterior posterior

Segments:

16

20

$\begin{array}{cc}\text { anterior } & \text { posterior } \\ 22 & 24\end{array}$

anterior posterior

24

23

The segments bear two pairs of setae on the inner (ventral) curvature; with one unpaired seta on the outer curvature of segments up to five segments apart, although at the distal ends of the cirrus they are frequently on each segment. The paired setae on the inner curvature are plumose, with about ten very fine curled pinnae on the ventral surface. The setae are essentially of the same size, and have no basal hair arising from the segments between or in front of the setae. The unpaired seta on the outer curvature are faintly plumose.

The male: A few males have been found, attached to the female. Although care was taken to look, none were found in the burrow. It is not typical to find so few. Two rather poor specimens will be described at this point.

The first, believed to be a young specimen, was seen with antennules spread in such a way that he could not be turned without distortion (fig. 280). The paired antennules are typical. The little balls of darker tissue scattered throughout the body made the determination of eyes and yellow organs risky, and so no attempts will be made for this specimen. The antennules were not on long stalks. The body attenuated into a clear process posteriorly with a membranous covering, and was broadly rounded anteriorly. No surface ornamentation of any kind was seen. The most peculiar structure noted was a chitinous "beak," unpaired and centrally located ventrally. No function could be deduced for this structure, as it appeared not to be open at the tip. The specimen was rolled over without securing additional information, but its wrinkled condition precluded further illustration.

The second specimen was recovered from a female which had been boiled in $\mathrm{KOH}$, so much of the cellular detail was lost (fig. 28n). A definite penis is seen, a pair of antennules are on appreciable stalks, and a curious cylindrical projection of the mantle which could be related to the "beak" is shown.

The CYPRID: The female retains the embryo to the cyprid stage. The eggs and enclosed nauplii appear typical of the order, and the cyprid is typical of the genus. The carapace is ornamented with many individual hairs, and the plates forming the carapace are equipped with numerous spots or pegs arranged in rows which may appear quite regular. The size of the cyprid within the female is about $0.5 \times 0.2 \mathrm{~mm}$. 
It is clear that this species is closest associated with $C$. longicollatus Berndt. The main points of difference are as follows: Berndt's illustration (fig. 23) shows a much longer neck (up to one-third as long as entire animal), with two spines on a straight operculum. The teeth along the lateral bar he illustrates on the dorsal side, whereas in C. lanceolatus they are ventral. His species is up to $1.44 \mathrm{~mm}$ (of 45 to 50 specimens), whereas $C$. lanceolatus averages $1.77 \mathrm{~mm}$, and is up to $2.0 \mathrm{~mm}$ long. He does not describe a mouth cirrus, which $C$. lanceolatus lacks. The differences of host and locality are not considered significant. The barbed "lances" of $C$. lanceolatus are considered unique and should not have been overlooked by other workers.

The opercular spines and the serrated secondary teeth of $C$. lanceolatus are much like those of $C$. variabilis. The latter lacks the barbed shafts, however, and of course can be differentiated by the presence of mouth cirri and much heavier body musculature.

The Burrow: The burrow in cryptophialids is hard to describe, especially in shells overgrown with a variety of organisms, particularly algae. The interior of the burrow is essentially the same shape as the female animal, the major difference being that the attachment area is somewhat shallower than would be surmised, i.e., the neck can extend slightly out of the burrow.

The burrow aperture is nearly oval, about $0.4 \times 0.3 \mathrm{~mm}$, and of a shape depending to a large extent on the position within the shell and the associated organisms.

\section{Cryptophialus unguiculus, new species}

Figure 29

Diagnosis: Cryptophialus with long, hyaline shafts on medial surface of operculum not barbed. Lateral bar termination in heavy, compound tooth structure resembling a bear's claw.

Eтумоlogy: unguiculus (L.) : nail, claw, also talon or hoof, for the claw-shaped teeth at the posterior end of the lateral bar.

Distribution: Hundreds of specimens were found, dried, in the type-shell, and in Turbo marmoratus L. from Nitendi, or Santa Cruz Island; Turbo lajonkairi from Wake Island; and Turbo aperta Blainv. from Mokolea Rock and Manana, Oahu, Hawaii, and Necker Island. All specimens were closely associated with Lithoglyptes mitis, and are from the Bernice P. Bishop Museum collections.

Type-Material: Holotype: BPB B461. in Thais aperta from Necker Island. Paratypes: Aust, CA, Mex, Seto, SFSC, USNM, Vict. Additional material: Brit, Belg, BA, Dublin, Paris, UCT. 
Dimensions: Holotype $1.36 \times 0.52 \mathrm{~mm}$ in length and width, with aperture of $0.15 \mathrm{~mm}$ on a neck of $0.42 \mathrm{~mm}$. Seven paratype specimens from the type-host shell and averaged $1.40 \times 0.45 \mathrm{~mm}$, with an aperture of $0.176 \mathrm{~mm}$ on a neck of $0.45 \mathrm{~mm}$.

The distinguishing features of this species are found on the mantle. The operculum armament is almost as awesome as that of $C$. lanceolatus, except that the long, hyaline spines are not barbed.

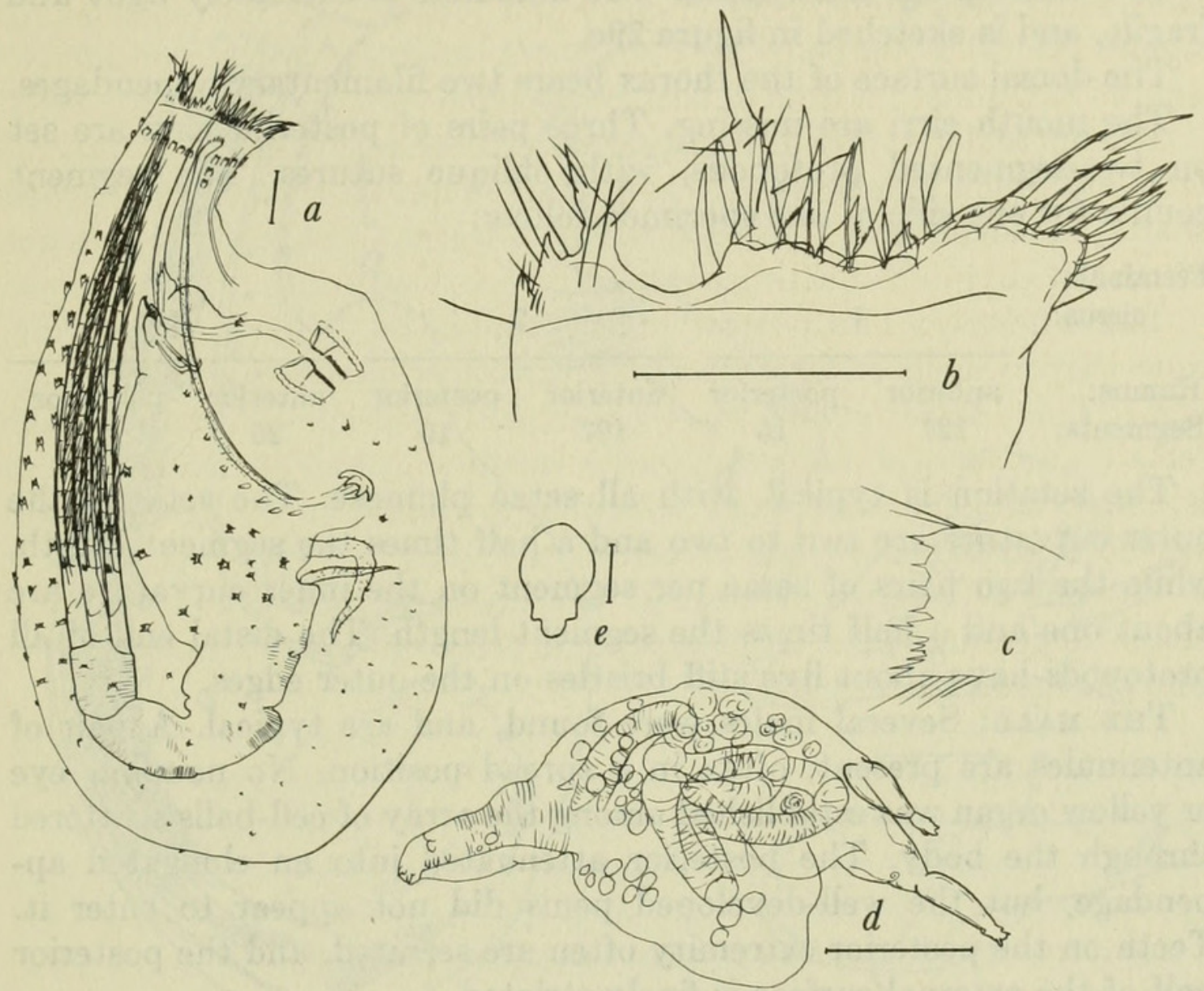

FigURE 29.-Cryptophialus unguiculus, new species: $a$, female, side view, from Thais aperta from Necker Island, Hawaii; $b$, opercular horizon, detail of $a$, left side, sequence from medial to lateral is medium spines, tall, haired spines, and short, serrated teeth; $c$, mandible of specimen from Turbo marmoratus from Santa Cruz Island; $d$, mature male from specimen in $c$; e, burrow aperture in Turbo lajonkairi from Wake Island.

On the outer edges of the operculum are two or three pairs of spines with smaller spines and many hairs attached. Between these major spines are hyaline teeth with strongly serrated edges. Medial to these spines and teeth are numerous long, hyaline spines which lack the barbs mentioned above.

The lateral bars terminate in a massive hillock with four to five teeth recurved anteriorly, giving the general appearance of a bear's claw. An occasional lighter "bear's claw" array of teeth has been 
found in $C$. cordylacis and $C$. heterodontus. These species can be separated by the appearance of the opercular armament.

The rest of the mantle is typical, but the teeth scattered around on the ventral outer surface appear somewhat heavier than the Australian species.

The attachment disk is light and diffuse, without an attachment knob or orificial knob.

The mouthparts are typical. The mandible is extremely light and fragile, and is sketched in figure $29 \mathrm{c}$.

The dorsal surface of the thorax bears two filamentary appendages.

The mouth cirri are missing. Three pairs of posterior cirri are set on two-segmented protopods, with oblique sutures. The segment counts for one side of one specimen follow:

Terminal

cirrus:

1

2

3

Ramus:

Segments:

\begin{tabular}{cc}
\hline anterior & posterior \\
$12 ?$ & 15
\end{tabular}

\begin{tabular}{cc} 
& \\
\hline anterior & posterior \\
$19 ?^{\circ}$ & 19
\end{tabular}

\begin{tabular}{cc}
\hline anterior & posterior \\
20 & 22
\end{tabular}

The setation is typical, with all setae plumose. The seta on the outer curvature are two to two and a half times the segment length, while the two pairs of setae per segment on the inner curvature are about one and a half times the segment length. The distal end of all protopods have about five stiff bristles on the outer edges.

The male: Several males were found, and are typical. A pair of antennules are present, often in a spread position. No naupliar eye or yellow organ was established among the array of cell-balls scattered through the body. The posterior attenuated into an elongated appendage, but the well-developed penis did not appear to enter it. Teeth on the posterior extremity often are serrated, and the posterior half of the external surface is finely striated.

\section{Cryptophialus cordylacis, new species}

Figure 30

D IAGNosis: Cryptophialus with aperture armed with three pairs of protuberances each equipped with many sharp-pointed spines. Lateral bars terminate in a horny ridge armed with claw-like teeth. Several heavy teeth with up to seven points are distributed ventrally on the mantle. Three pairs of terminal cirri are present.

Eтүмодоgy: Cordyl- (Gr.), a headdress, + acis (Gr.), a point, because of the pointed spines forming a "headdress." 


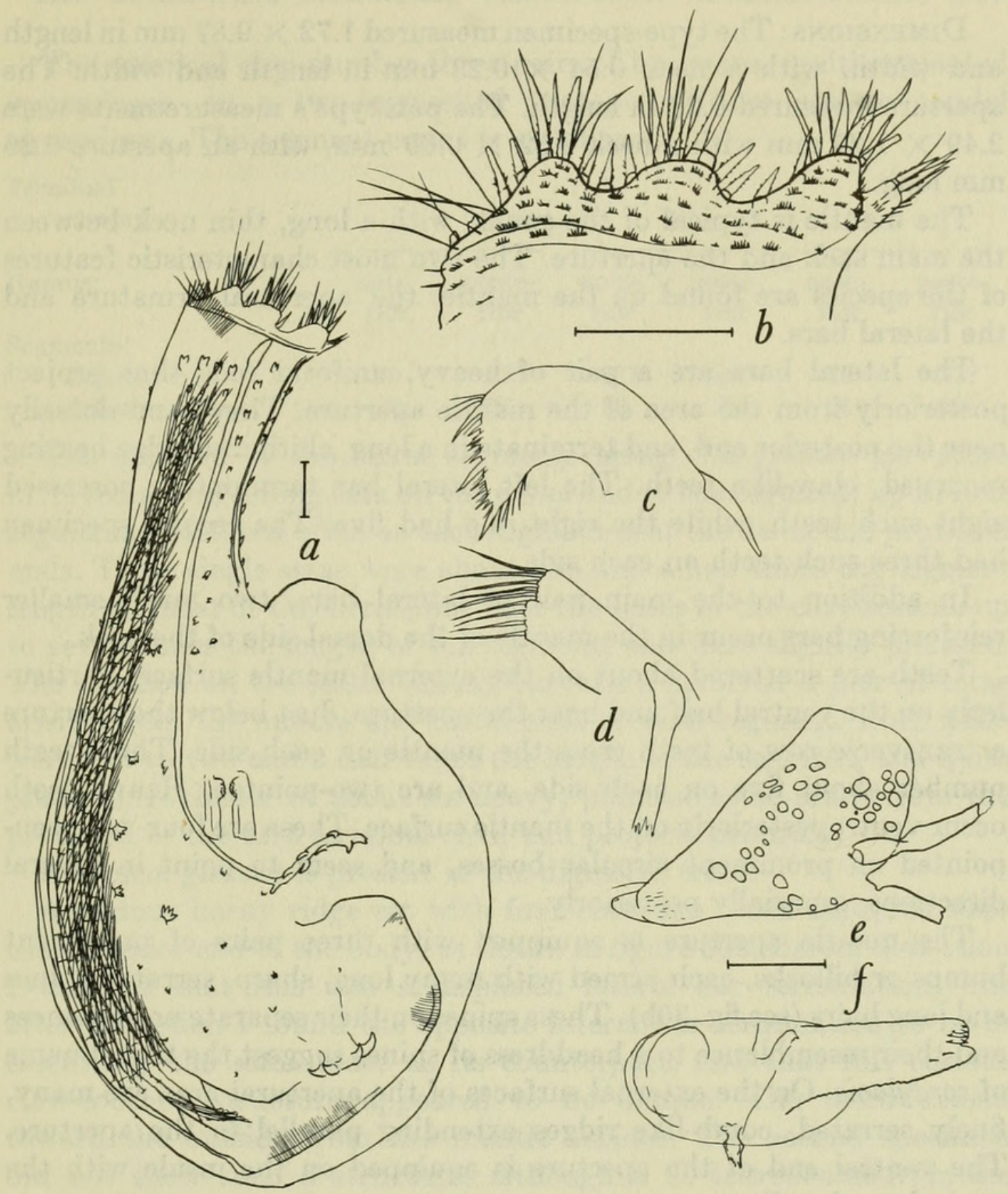

Figure 30.-Cryptophialus cordylacis, new species, from Distichopora nitida from the Marshall Islands: $a$, female side view; $b$, opercular detail of $a ; c$, mandible; $d$, first maxilla; $e$, young male; $f$, mature male, both males with damaged antennules.

Distribution: Two specimens obtained from the coral Distichopora nitida Verr. from the Marshall Islands; R. J. Ethridge, collector; from the Australian Museum G6234, courtesy of Dr. John Yaldwyn; in association with three specimens of Cryptophialus heterodontus. The specimens had been dried, and invaded by fungal mycelium. They were corroded in $\mathrm{KOH}$ and mounted in glycerin before measuring. The type was dissected and it and the secondary specimen remain in the author's collection at San Francisco State College. 
Dimensions: The type-specimen measured $1.72 \times 0.87 \mathrm{~mm}$ in length and width, with a neck $0.54 \times 0.23 \mathrm{~mm}$ in length and width. The aperture measured 0.28 in length. The paratype's measurements were $2.49 \times 1.29 \mathrm{~mm}$ with a neck $0.52 \times 0.60 \mathrm{~mm}$, with an aperture 0.26 mm long.

The mantle is typical of the genus, with a long, thin neck between the main sack and the aperture. The two most characteristic features of the species are found on the mantle: the apertural armature and the lateral bars.

The lateral bars are a pair of heavy, uniform rods that project posteriorly from the area of the mantle aperture. They bend dorsally near the posterior end, and terminate in a long, chitinized ridge bearing recurved, claw-like teeth. The left lateral bar termination possessed eight such teeth, while the right one had five. The second specimen had three such teeth on each side.

In addition to the main pair of lateral bars, two much smaller reinforcing bars occur in the mantle of the dorsal side of the neck.

Teeth are scattered about on the external mantle surface, particularly on the ventral half and near the aperture. Just below the aperture a transverse row of teeth cross the mantle on each side. These teeth number about five on each side, and are two-pointed. Heavy teeth occur ventroposteriorly on the mantle surface. These are four- to sevenpointed on prominent circular bosses, and seem to point in several directions, especially posteriorly.

The mantle aperture is equipped with three pairs of prominent bumps or hillocks, each armed with many long, sharp, serrated spines and long.hairs (see fig. 30b). These spines on their separate prominences and their resemblance to a headdress of spines suggest the trivial name of cordylacis. On the external surfaces of the apertural area are many, finely serrated, comb-like ridges extending parallel to the aperture. The ventral end of the aperture is equipped on the inside with the typical comb collar.

The fungal attack greatly harmed the appearance of the body itself. The mouthparts look typical: a long labrum, setose near the distal end; a mandible is present, along with mandibular palps; the first and second maxillae are typical of the genus. The mandible has delicate teeth, while the first maxilla possess hairs and an apodeme (fig. $30 \mathrm{c}, \mathrm{d}$ ).

The presence of mouth cirri could not be verified. Before dissection of the type there appeared to be a pair of small knobs in a typical position, but without bristles. After dissection no mouth cirri could be discerned. The paratype showed nothing. If present at all, they are extremely reduced. 
The terminal cirri number three pairs of biramous, multisegmented appendages, on a two-segmented protopod. There are no caudal appendages. The segment count is as follows:

Terminal

cirrus:

1

$\begin{array}{cc}\begin{array}{c}\text { ante- } \\ \text { rior }\end{array} & \begin{array}{c}\text { poste- } \\ \text { rior }\end{array}\end{array}$

2

\begin{tabular}{cc}
\hline $\begin{array}{c}\text { ante- } \\
\text { rior }\end{array}$ & $\begin{array}{c}\text { poste- } \\
\text { rior }\end{array}$ \\
& \\
$27 ?$ & 28 \\
18 & 23
\end{tabular}

3

$\begin{array}{cc}\text { ante- } & \text { poste- } \\ \text { rior } & \text { rior }\end{array}$

29

26
$27 ?$

29

The setation of the cirral segments along the greater curvature involved a single, long seta on the distal end of the segment, up to four segments apart, but often on each segment near the distal and proximal ends. These single setae were about two and a half times the segment length on most of the cirrus, but near the bases of the cirri became up to seven times the length of the segment, and were slightly plumose. The setation on the lesser (inner) curvature involved a pair of setae arising from the middle and distal ends of each segment. Both pairs were two to two and a half times the length of the segment, and quite plumose. A cluster of about six heavy, plumose setae arises from the protopod of the first terminal cirri, and projects inwardly.

A typical gizzard is present in the digestive tract.

A curious horny ridge set with four claw-like teeth appeared near the posterior end of the body, as shown in figure 30a. Before dissection I thought that this was a displaced lateral bar termination, but after dissection I found the opposite lateral bar termination to be in essentially the same place as its counterpart, and that this curious claw-toothed structure appeared to be unique. The teeth extend toward the outside from the mantle surface. The second specimen did not show such a structure, although a $C$. heterodontus from the same coral had one that appeared identical but was located farther forward on the dorsal surface. See $C$. unguiculus for a massive development of this feature.

\section{Australophialus, new genus}

Diagnosis: Cryptophialidae with four pairs of terminal cirri and one dorsal body process; mouth cirrus rudimentary.

Eтумоlogy: Austr- (L.) southern + phial- (Gr.) saucer or vial, named for their southern distribution.

Type-species: A. melampygos (Berndt), 1907b, page 288. 
Inasmuch as the rest of the order can be readily differentiated to family on the basis of the number of terminal cirri and the presence of the caudal appendage, it is reasonable that genera possessing a variation in the number of terminal cirri should be separated to reflect this most fundamental feature of the order.

\section{Australophialus melampygos (Berndt, 1907b)}

\section{Figure 31}

Cryptophialus melampygos Berndt, 1907b, page 288.

Diagnosis: Australophialus with opercular margin entire, not notched; opercular margin with distinct, short spines; in New Zealand shells.

Distribution: Abundant along the length of New Zealand, from North Auckland to Steward Island, on both east and west coasts, in many species of gastropods, pelecypods, chitons, and one record from the thoracican Elminius plicatus.

Type-material: Types unknown. Reference specimens in Otago Museum, Dunedin, New Zealand (A64.4), British Museum, SFSC, Seto, and USNM. Additional material to all of specimen deposition list (page 2), and bulk-labeled to a hundred museums.

Figure 31.-Australophialus melampygos (Berndt, 1907a), from Perna canaliculata from Portobello, New Zealand: $a$, female side view; $b$, detail of opercular horizon.

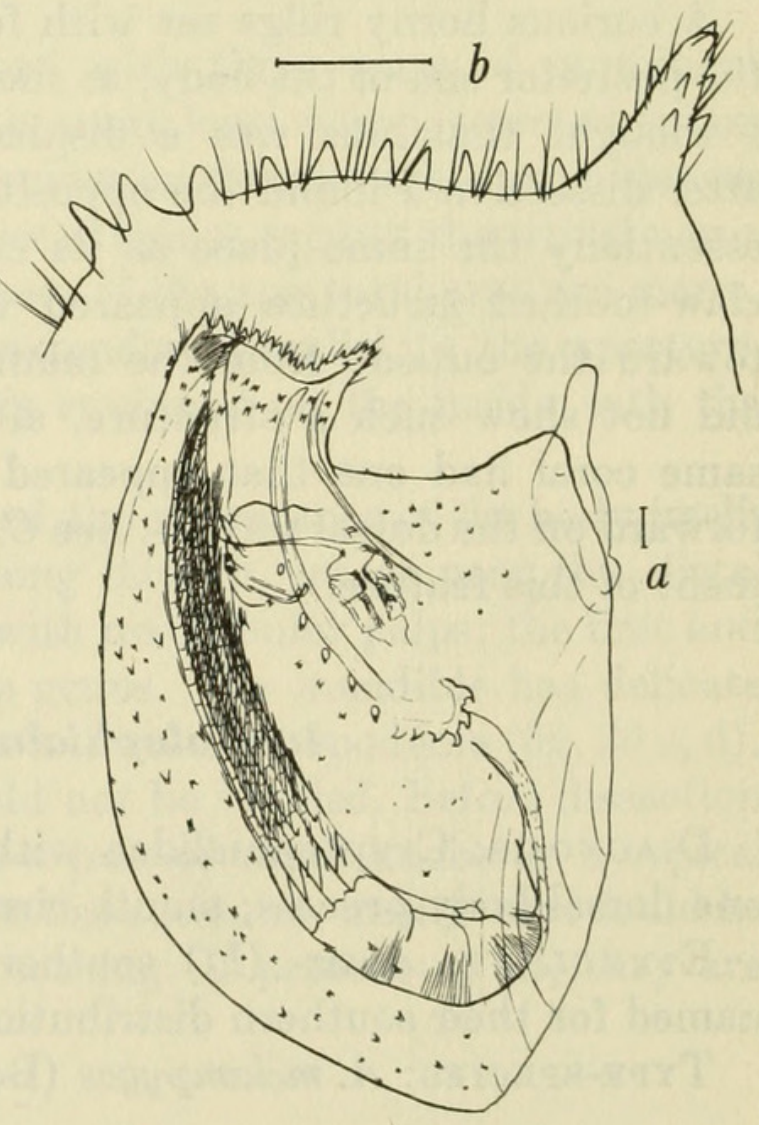


Segment counts for the left terminal cirri of two specimens follow:

Terminal

cirrus:

Ramus:

Segments:
1

\begin{tabular}{cc}
\hline $\begin{array}{c}\text { an- } \\
\text { terior }\end{array}$ & $\begin{array}{c}\text { pos- } \\
\text { terior }\end{array}$ \\
9 & 12 \\
9 & 13
\end{tabular}

2

\begin{tabular}{cc}
\hline an- & pos- \\
terior & terior \\
14 & 19 \\
17 & 19
\end{tabular}

3

\begin{tabular}{ccccc}
\hline $\begin{array}{c}\text { an- } \\
\text { terior }\end{array}$ & $\begin{array}{c}\text { pos- } \\
\text { terior }\end{array}$ & & $\begin{array}{c}\text { an- } \\
\text { terior }\end{array}$ & $\begin{array}{c}\text { pos- } \\
\text { terior }\end{array}$ \\
21 & 21 & & 19 & 20 \\
22 & 22 & & 23 & 23
\end{tabular}

This species has been examined recently by Batham and Tomlinson (1965), to which the reader is referred for details.

\section{Australophialus utinomii, new species}

\section{Figure 32}

Diagnosis: Australophialus with operculum with margin entire and in the shape of a little shield, with no prominent hooks, or spines, but fringed with numerous small, bifid teeth. Pointed lateral bars associated with numerous very small, simple teeth along its length.

Eтумоцоgт: Named for the eminent cirripedologist, Professor Huzio Utinomi, of the Seto Marine Biological Laboratories, Japan.

Distribution: Five complete specimens and two fragments from Dinoplax gigas, from Qolora, Cape Province, South Africa, from the collection of the University of Cape Town QQ.I.J. 20.5.39.

TyPe-material: Holotype: UCT, $1.15 \times 0.95 \mathrm{~mm}$ with aperture of $0.35 \mathrm{~mm}$ long. Paratypes: Brit, SFSC, USNM. Average size of four measurable specimens $1.29 \times 0.85 \mathrm{~mm}$ with aperture of $0.41 \mathrm{~mm}$.

The mantle is in the shape of a small bag, equipped with circular and longitudinal muscle bands, and studded with numerous fine teeth with one to four points. A well-developed adhesive attachment disk is present, but no orificial knob is present.

A pair of lateral bars reinforce the sides of the mantle, and are associated with three of four loose rows of very small spines projecting posteriorly on the ventral side and immediately external to the lateral bars. An internal reinforcing bar is found in the dorsal, apertural region.

The characteristic opercular plates fit close together and resemble a little shield. The margins are equipped with over a dozen bifid (rarely trifid) teeth each, plus numerous hairs, but are otherwise smooth and not notched or otherwise armed. The typical comb collar infolds from the ventral margin of the aperture.

The head is distinct from a separate crested fold immediately behind it. It is not markedly hairy or otherwise ornamented. 

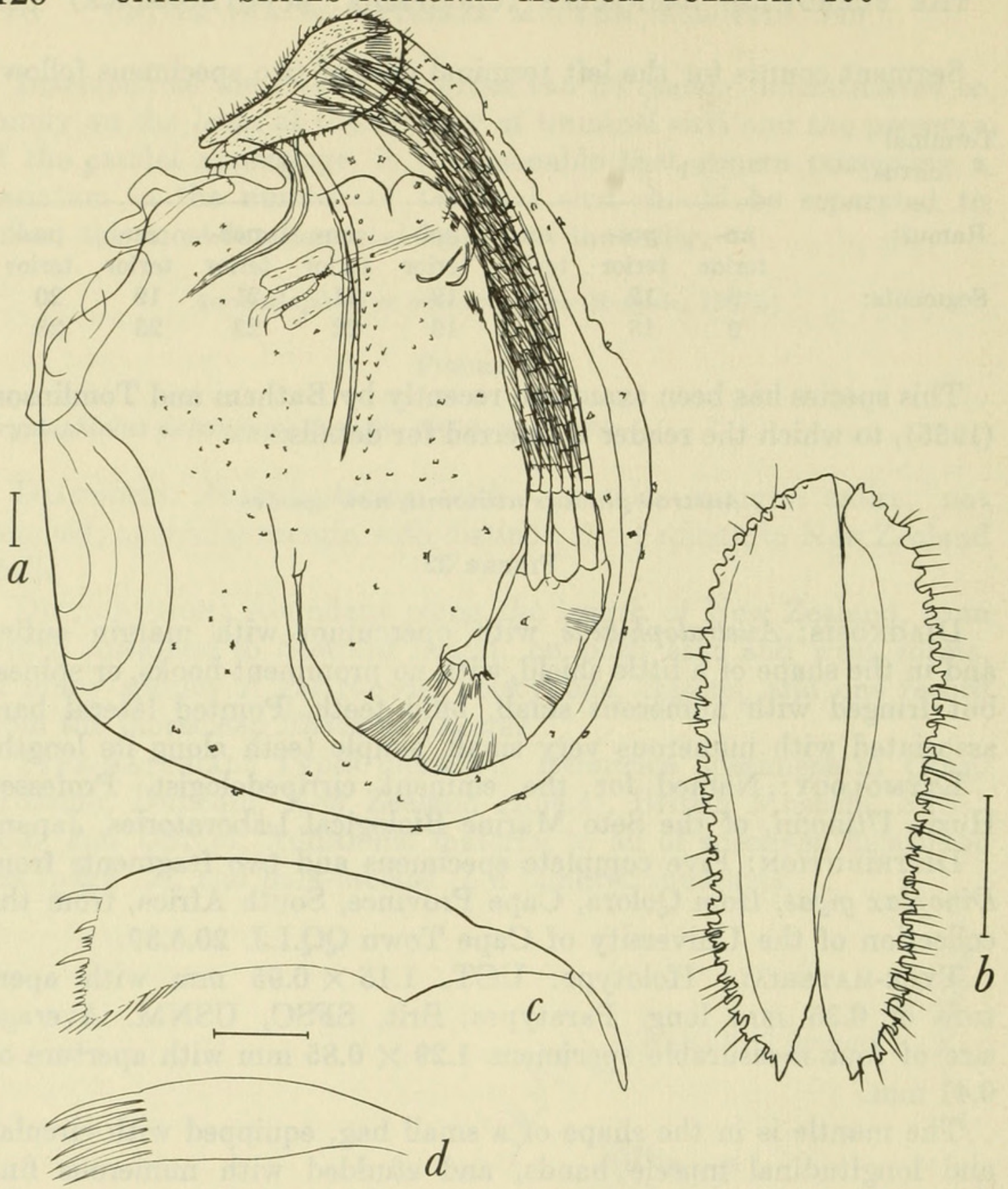

Figure 32.-Australophialus utinomii, new species, from Dinoplax gigas from Qolora, Cape Province, South Africa: $a$, female side view; $b$, surface view of operculum, rostral end down; $c$, mandible; $d$, first maxilla.

A large labrum extends from the mouth area to the aperture, is hairy at the distal tip, and is, perhaps, slightly larger than is typical of the genus.

The mouthparts are typical. A pair of mandibles with palps and two pairs of maxillae complete the set. The palps invariably are teased off with the labrum in this family, however. The mandibles are hyaline and very delicate. The teeth are extremely fine: two long, one medium, and about ten short ones could be seen, with numerous hairs along the medioposterior margin.

The first maxillae have many stiff bristles along the inner surface, 
and have a long apodeme. The second maxillae are typical of the order.

The esophagus leads dorsally to a gizzard typical of the family, with a toothed grinding mill anteriorly and what appears to be a fine strainer posteriorly.

A pair of small but obvious unsegmented, uniramous mouth cirri are found on the ventral thorax posterior to the mouth field.

A single dorsal body process was seen dorsal to the free portion of the thorax. Although it is possible that a second one escaped my notice in the two of the three specimens dissected which would show this feature clearly, I believe that a single process is all that is present. It is thin walled and wrinkled, but not hairy or scaly as in other species of the family.

The posterior thorax is striated superficially. It bears at the posterior extremity four pairs of biramous, multisegmented terminal cirri. The posterior pair is tucked between the others (depending on the angle of view) so that the superficial impression of three pairs is strong (fig. 32). The two-segmented protopod on each terminal cirrus is short, with the two segments of approximately equal length divided by a slanting suture. A small fringe of scaly hairs is found at the distal end of the protopods, extending over the bases of the rami.

The segment count for one specimen gave 5 and 13 for the anterior and posterior ramus of the first terminal cirrus, and 19 to 25 for each ramus of the others. Although no high degree of certainty could be obtained with the few specimens, the count seems comparable with other species in the family.

The setation of the terminal cirral segments is typical of the family. A pair of medial and distal setae, each about three times the segment length, arise from each segment along the inner curvature of each ramus, and a single seta about twice the segment length arises distally on the outer curvature, up to four segments apart. The inner curvature of the cirrus is wavy, in side view, with bosses for both the medial and distal setae.

No male was seen.

ReLATIONSHips: In proximity and anatomy this species is probably closest associated with Australophialus turbonis, of known species. It differs most noticeably in the opercular margin, which is not notched or indented in this species.

Australophialus turbonis (Barnard), 1925, page 5

Figure 33

Diagnosis: Australophialus with apertural margin bearing distinct notch at about one-third the distance from the rostral (attachment) end, margin lined with numerous short spines and hairs. 
Distribution: Found in Turbo sarmaticus from False Bay, Cape Province, South Africa. The species has been found in addition in Thais rudolphi from Umpangazi, Cape Vidal, North Natal Province; Burnupena cincta from Hermanus and Cape Hangklip, Cape Province; Burnupena limbosa from Paternoster and Yzerfontein, West Coast of Cape Province; thanks to the Lniversity of Capetown Zoology Department, and to Mrs. C. M. Connolly. It is often found associated in the same shell with Weltneria spinosa.

Type-material: No type-specimens.

In reply to inquiries about specimens of this species, Barnard wrote, "All the specimens reported on by me were returned to the Fisheries

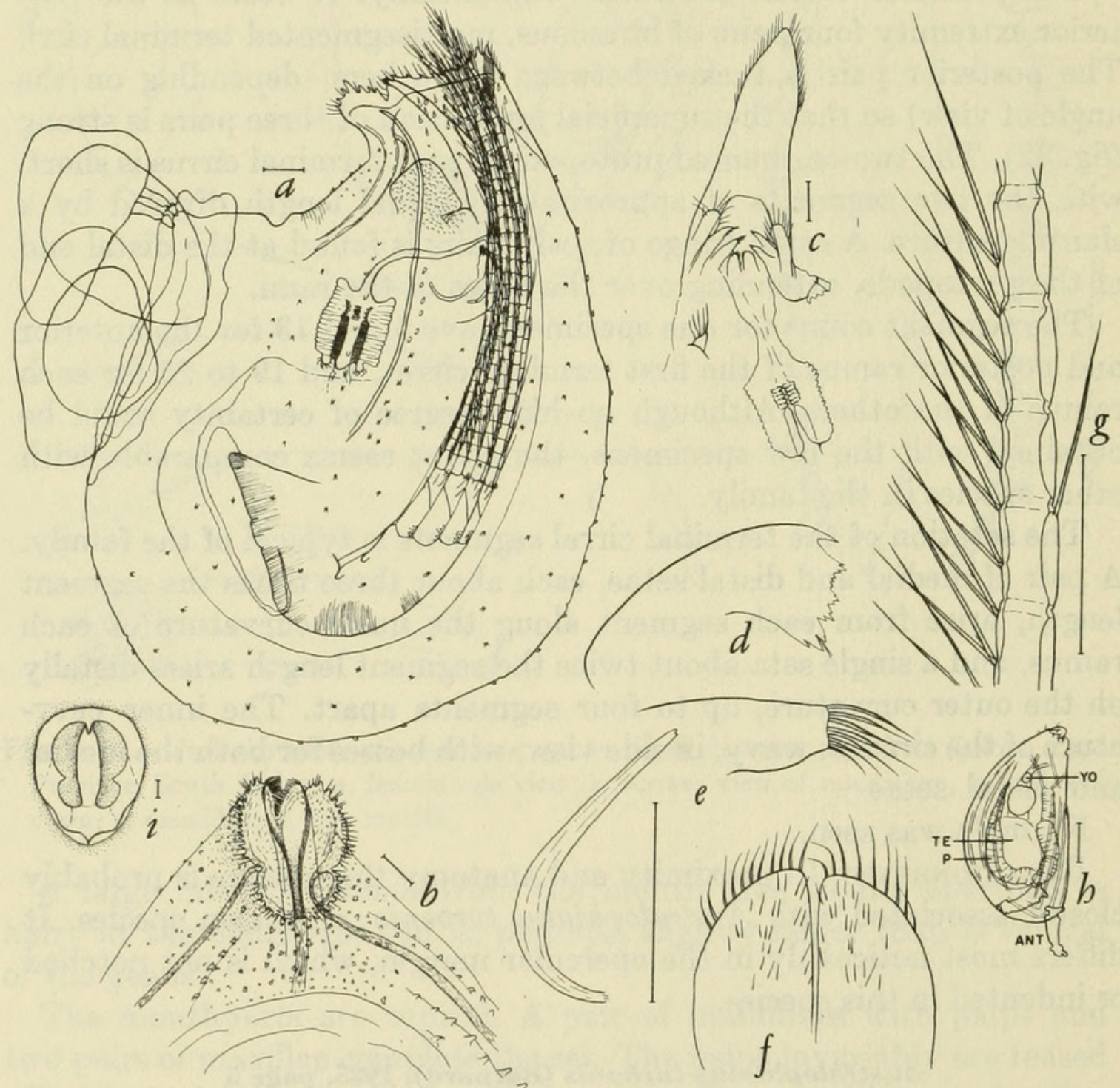

Figure 33.-Australophialus turbonis (Barnard, 1925), from Turbo sarmaticus, from False Bay, South Africa: $a$, female, side view, with attached males in outline; $b$, detail of opercular area, spread surface view; $c$, mouth field with labrum; $d$, mandible; $e$, first maxilla; $f$, second maxilla; $g$, detail of portion of terminal cirrus; $h$, mature male; $i$, burrow aperture, with shell surface and operculum stippled. 
Survey, but as its offices have changed more than once since 1925, and it never has had any proper building suitable for storage of specimens, I should imagine these particular specimens are lost." A letter from the Fisheries Survey confirmed that they were lost, and that no local workers have been able to locate the species since its description.

Reference specimens are deposited as follows. Principle reference specimen set: USNM 122624, from the type-host and locality, Turbo sarmaticus from False Bay, Cape Province, South Africa. Additional material: Aust, BPB, Brit, Belg, BA, CA, Dublin, Mex, Paris, Seto, SFSC, UCT, Vict.

Dimensions: The size of the female averages (of five specimens) $2.34 \mathrm{~mm}$ long $\times 1.47 \mathrm{~mm}$ wide $\times 1.25 \mathrm{~mm}$ thick, with an aperture length, measured straight across the body from both ends, of 0.43 $\mathrm{mm}$. The burrow aperture averages $0.33 \times 0.25 \mathrm{~mm}$ and is somewhat pear shaped, with a short point at the attached end. Hundreds of specimens were obtained, and dozens examined.

The lips of the mantle aperture are of the typical brick red color in life, and a light brown when preserved. Each side is split by a deep notch about one-third the distance from the dorsal end toward the attached surface. Relatively light teeth and hairs arm the edges of the apertural lips. An infolded velum bearing the convoluted lamellae extending into the uniformly haired comb collar is found at the ventral end of the aperture. Heavy reinforcing bars are present. One extends dorsally toward the attachment area from the dorsal end of the aperture, and a pair of lateral bars extend down each side of the mantle from the general area of the apertural notch. These lateral bars - much lighter and less well armed with teeth than is typical of the genus-do not terminate posteriorly in a hillock of teeth or spines. A row of teeth lies alongside the lateral bar, and another row frequently parallels the lateral bar, but at some distance from it. One specimen was found with two lateral bars on each side, and it was assumed that this specimen was approaching a molt stage. Several loose rows of single spines are found on the external mantle surface posterior to the aperture on the ventral two-thirds of the mantle.

The mantle is studded with small and uniformly spaced teeth, almost all of which are bifid, the exceptions being primarily the row of curved spines in a band around the periphery of the mantle in the saggital plane of the thorax.

The mantle musculature consists of transverse and longitudinal bands typical to the order.

The attachment area is obscured by layers of cemented exuviae forming the typical horny disk, upon which numerous males are usually found. 
No distinct orificial knob was seen, although a thickened and wrinkled area dorsal to the aperture could be homologous.

The head is rounded and scaly, without hairs or bristles. A large labrum extends from the mouth field to the aperture, as is typical for the genus. The mouthparts consist of the typical mandible with palp and two pairs of maxillae.

The mandible is delicate, with numerous extremely fine teeth that are easily broken in study. No bristles or hairs were seen. The palp is closely adpressed to the labrum in a typical manner and appearance. The first maxilla also is very weak, with no strong teeth, but numerous heavy bristles arising from a blunt end. The apodeme is long and curved, with the widening at the curve not as pronounced as the "keel" in some forms.

The second maxilla is typical.

A paired mouth cirrus is present, but is reduced to a pair of small, unsegmented processes bearing a few bristles.

There are four pairs of biramous terminal cirri and no caudal appendage. The terminal cirri are similar, with an oblique suture dividing the two segments of the protopod. The dorsal surface of the base of each terminal cirrus bears small granular knobs basally and a patch of small hairs distally.

The segment count for each cirrus follows:

\begin{tabular}{|c|c|c|c|c|c|c|c|c|}
\hline Cirrus: & $\begin{array}{c}2 \\
\text { terI }\end{array}$ & $\begin{array}{l}\text { inst } \\
\text { inal) }\end{array}$ & & & & & & \\
\hline Ramus: & $\begin{array}{l}\text { ante- } \\
\text { rior }\end{array}$ & $\begin{array}{l}\text { poste- } \\
\text { rior }\end{array}$ & $\begin{array}{l}\text { ante- } \\
\text { rior }\end{array}$ & $\begin{array}{l}\text { post- } \\
\text { rior }\end{array}$ & $\begin{array}{l}\text { ante- } \\
\text { rior }\end{array}$ & $\begin{array}{l}\text { poste- } \\
\text { rior }\end{array}$ & $\begin{array}{l}\text { ante- } \\
\text { rior }\end{array}$ & $\begin{array}{l}\text { poste- } \\
\text { rior }\end{array}$ \\
\hline Segments: & 13 & 18 & 22 & 25 & 25 & 29 & 25 & 25 \\
\hline
\end{tabular}

The number of any of these rami will vary about five segments between different specimens.

The setation on the terminal cirri involves a pair in the middle and distal ventral (lesser curvature) surface of each segment, and a single bristle on the distal dorsal surface of each second to fifth segment. The ventral setation is modified in that the pairs are equal, or nearly equal, in length, rather than the typical condition with the medial pair being much shorter than the distal pair.

From the dorsal surface of the thorax extends a single body process, probably homologous to the filamentary appendages of other barnacles. It is very thin skinned, and slightly lumpy, but not hairy or annulated.

The fine striations on the dorsal surface of the thorax are typical of the order, but the distribution is somewhat more restricted in area than is typical. 
The gizzard, characteristic of the family, is found at the end of the esophagus and before the stomach. It bears the usual muscular-supporting framework and the triturating teeth. The teeth are about five in number on each of the four grinding faces, set in a slightly convex manner when they are slightly apart, but can meet in a parallel plane when together. A series of what appear to be extremely fine sieves or other finely striated surfaces occupy the posterior portion of the gizzard, and the gizzard terminates posteriorly with knobby projections bearing what appears to be extremely fine hairs, or perhaps even cilia. Their function is unknown, and should be further studied in the living animal.

The male: The male is typical, $0.412 \times 0.225 \mathrm{~mm}$ in immature attached forms and $0.450 \times 0.275 \mathrm{~mm}$ in mature attached forms, with a pair of attaching antennules externally, and a long, coiled penis internally. The end distal to the antennules bears two or three teeth on the mantle surface which look like the boring teeth of the female mantle surface. There are an average of about twelve males per female, with a maximum number of seventeen counted on one female.

The nauplius is typical, with fine hairs distributed essentially as in Australophialus melampygos. The naupliar carapace bears numerous fine "pegs" over its surface, but the carapace does not appear to be differentiated into peg plates as in A. melampygos. Whether the nauplius is free-swimming or retained to the cyprid stage is not known.

\section{Suborder APYGOPHORA Berndt, 1907b, page 289}

Acrothoracica with 3 pairs of thoracic cirri, uniramous and fourjointed, the first two pairs possessing small prickly pads on second articulation; no caudal appendages; alimentary canal a sacculated system without an anus; brain and one ventral ganglion present; mandibular palp lacking or rudimentary without bristles.

\section{Family TRYPETESIDAE Krüger, 1940, page 454}

(=Alcippidae Hancock, 1849, Gerstaecker, 1866, page 532, Gruvel, 1905.)

Single family, with the characteristics of the suborder.

\section{Genus Trypetesa Norman 1903, p. 369}

(=Alcippe Hancock, 1849, page 313, non Alcippe Blyth, 1844, page 384,= Alcippoides Strand, 1928, page 40.)

Single genus, with the characteristics of the suborder. 
The shape of the burrow of barnacles of the genus Trypetesa is highly dependent upon thicknesses of the host shell, a lateral orientation being more pronounced in thinner shells.

$T$. lateralis, with a completely lateral orientation, is adapted to inhabit very thin Tegula shells. It is further modified by the presence of a unique external mantle flap, which penetrates to the outside surface of the shell, opposite the point of entry into the shell. The purpose of this second perforation in the shell is to maintain water currents, and is intimately associated with the presence of the males on the females. The external mantle flap is considered to be an adaptation to allow males to establish themselves underneath the laterally flattened females (see page 15).

The females of Trypetesa lampas are oriented perpendicularly to the surface of the host shell, necessitating a much deeper burrow than those of the females of $T$. lateralis, which are oriented parallel to the surface of the host shell. Measurements of the thickness of the host shells at the site of the burrows would be useful in determining the possible significance of this orientation.

$T$. habei and T. nassarioides are so variable in this characteristic that no attempt will be made to compare these species at this time.

Three shell fragments of Buccinum undatum from Plymouth, England, containing 23 specimens of T. lampas, and 10 shells of Tegula brunnea and Tegula funebralis from Moss Beach, California, with 10 specimens, were measured as close to the apertural slit as possible, perpendicular to the surface of the shell, with outside direct-reading micrometers. The average thicknesses, as given in table 2, are $2.19 \mathrm{~mm}$ for $T$. lampas and $0.98 \mathrm{~mm}$ for $T$. lateralis.

It is interesting to compare the shape of the burrow and orientation within the shell of $T$. lampas (fig. 34ab) and T. lateralis (fig. 26ab) with their respective shell thicknesses. T. lampas utilizes its full shell thickness much more completely than does T. lateralis. Burrows of the adult $T$. lampas females invariably leave a thin shell layer between the barnacles and the outside of the shell. T. lateralis females actually penetrate the outside surface of the shell with a minute hole from the external mantle flap, but the rest of the body lies well away from this surface.

It appears that the lateral orientation of $T$. lateralis is an adjustment mechanism to adapt to the much thinner shells of its host.

It is possible that the protuberant button or prickly pads on the distal end of the second segment of the first two pairs of terminal cirri 
TABLE 2.-Shell thicknesses at the site of Trypetesa burrows

Trypetesa lampas in Buccinum undatum shells

\begin{tabular}{|c|c|c|c|}
\hline Shell number & Barnacle number & Thickness* & Average \\
\hline & & 4. 12 & \\
\hline & 2 & 3. 42 & \\
\hline & 3 & 1. 72 & 2. 72 \\
\hline \multirow[t]{2}{*}{2} & $1-4$ & 2. 42 & \\
\hline & 5 & 1. 92 & \\
\hline \multirow[t]{3}{*}{3} & 1-8 (near aperture) & & 2. 12 \\
\hline & 9-15 (high in whorl) & & 1. 72 \\
\hline & & Average & 2. 19 \\
\hline
\end{tabular}

Trypetesa lateralis in Tegula funebralis shells

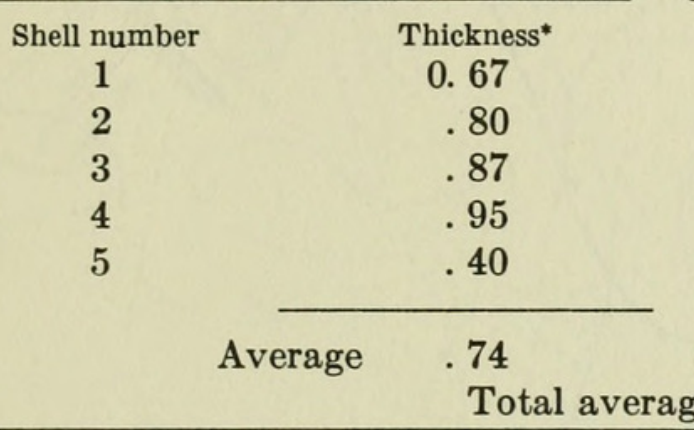

*Average of three readings over barnacle burrow, in millimeters.

represent one of the rami of the primitively biramous appendages. The two proximal segments of the cirrus would thus correspond to the standard protopod of the other species.

\section{Trypetesa lampas (Hancock, 1849)}

\section{Figure 34}

(=Alcippe lampas Hancock, 1849, page 314.) Alcippe lampas gigantea Berndt, $1907 \mathrm{~b}$, page 289 .

Diagnosis: Trypetesa with "capitulum" laterally compressed, perpendicular to surface of shell, with "disk" or ovigerous portion dorsoventrally compressed and parallel to surface of host shell; nauplius free-swimming; adult exceeding eight millimeters; bilaterally symmetrical; male possesses a well-developed penis; male attaches only to disk of female.

Distribution: Reported from the sublittoral of the northern Atlantic Ocean, North Sea, Mediterranean Sea, and the east coast of the United States, in gastropod shells occupied by hermit crabs. 
I would like to acknowledge the receipt of many specimens from Dr. H. G. Vevers, Marine Biological Laboratory, Plymouth, England, and one specimen from Dr. Ovar Nybelin, Göteborg Museum, Sweden.

Material: Specimens from Lunatia heros occupied by a hermit crab from Falmouth, Massachusetts, (courtesy of Victor Zullo), were sent to the following: Aust, BPB, Brit, Belg, BA, Dublin, Mex, Paris, Seto, SFSC, UCT, USNM, Vict.
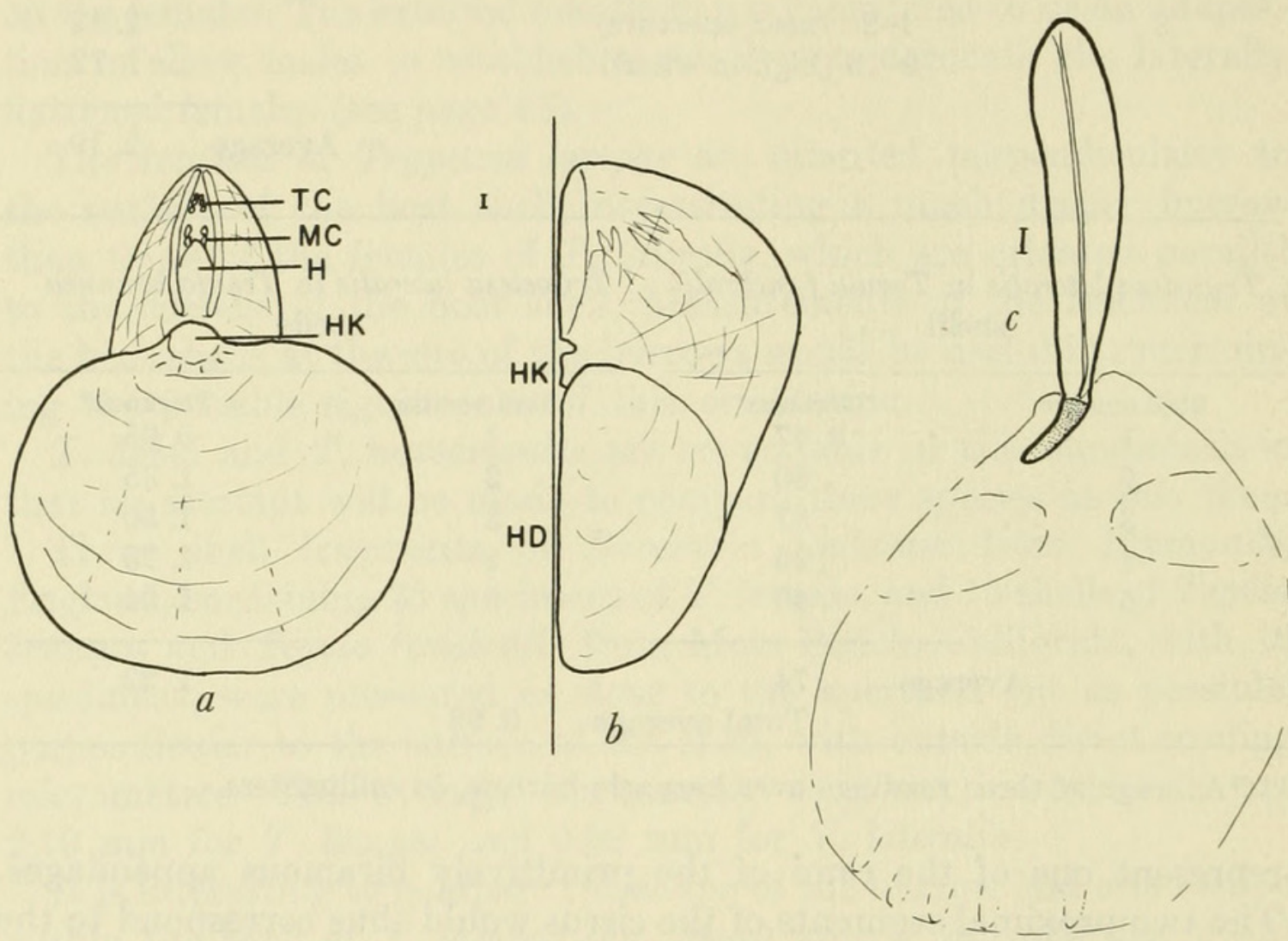

Figure 34.-Trypetesa lampas (Hancock, 1849), from Lunatia heros from Falmouth, Massachusetts: $a$, female viewed perpendicular to shell surface; $b$, viewed parallel to shell surface; $c$, female in burrow, surface view.

This species is oriented with the body at right angles to the surface of the shell in which it has burrowed. The horny disk underlies that portion of the shell directly opposed and in a straight line with the apertural slit in the shell. The animals are found in a variety of mollusk and barnacle shells, the original specimens being from Fusus antiquus and Buccinum undatum. They attain a size of about $11 \mathrm{~mm}$ in greatest diameter. Berndt (1907a) claims a subspecies which grows to be two and a half times as large, but the description is incomplete. T. lampas has pelagic nauplius, metanauplius, and cyprid stages, which have been studied by Kühnert (1934) and Genthe (1905). 


\section{Trypetesa caveata Tomlinson, 1963, page 164}

This is a fossil species, which is described with the other fossil species on page 141 .

\section{Trypetesa habei Utinomi, 1962, page 399}

\section{Figure 35}

Diagnosis: Trypetesa with orificial knob and two palps; aperture devoid of well-developed teeth or comb collar; shape of ovarian disk highly variable, but tending to extend posteriorly rather than to either side; male with penis sheath.

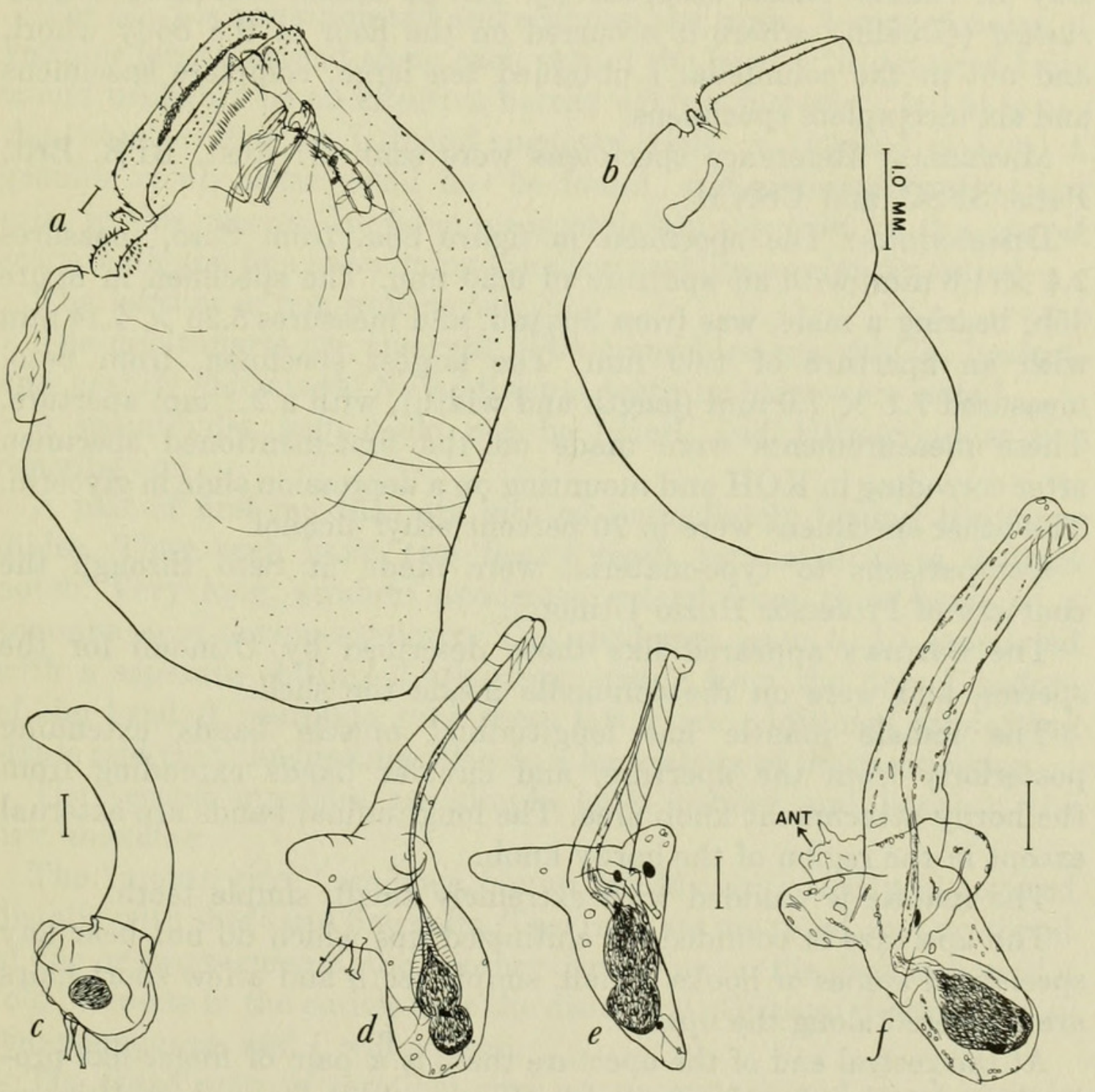

Figure 35.-Trypetesa habei Utinomi, 1962: a, female from Monilea from Seto, Japan; $b$, female from Susami Bay, showing position of male; $c$, male from female of $b ; d, e$, mature males from Tectus conus from Seto- $d$ shows antennules; $f$, mature male from Susami Bay, antennules broken off. 
Distribution: Utinomi described this species from material dredged from about 30 to 50 fathoms around the north coast of Amakusa Island and the entrance to Ariake Sea, western Kyushu, Japan. It occupied large-sized trochiform and naticid gastropod shells occupied by hermit crabs.

When at Seto Marine Biological Laboratories in the fall of 1963 , I collected locally many littoral hermit crabs in miscellaneous mediumsized gastropod shells. The following gastropod shells occupied by hermit crabs were collected littorally at Seto Point, near Sirahama, Wakayama-ken, Japan: Tectus (Rochia) conus (Gmelin), Chlorostoma (Omphalius) nigerrimum (Gmelin), and Monilea sp. These shells were occupied by Trypetesa habei. The cirriped also occurred at Susami Bay in similar shells occupied by hermit crabs, including Tegula rustica (Gmelin), where it occurred on the floor of the body whorl, and not in the columella. I obtained ten large, complete specimens and six incomplete specimens.

Material: Reference specimens were sent to: Aust, BPB, Brit, Paris, SFSC, and USNM.

Dimensions: The specimen in figure $35 \mathrm{a}$, from Seto, measures $2.4 \times 1.6 \mathrm{~mm}$, with an aperture of $0.80 \mathrm{~mm}$. The specimen in figure $35 \mathrm{~b}$, bearing a male, was from Susami, and measures $5.26 \times 4.14 \mathrm{~mm}$ with an aperture of $1.69 \mathrm{~mm}$. The largest specimen, from Seto, measured $7.1 \times 7.0 \mathrm{~mm}$ (length and width), with a $2.1 \mathrm{~mm}$ aperture. These measurements were made on the first-mentioned specimen after corroding in $\mathrm{KOH}$ and mounting on a depression slide in glycerin. The other specimens were in 70 percent ethyl alcohol.

Comparisons to type-material were made at Seto through the courtesy of Professor Huzio Utinomi.

The burrows appeared like those described by Utinomi for the species, and were on the columella inside the shell.

The female mantle has longitudinal muscle bands extending posteriorly from the aperture, and circular bands extending from the horny attachment knob area. The longitudinal bands are external except in the region of the horny knob.

The mantle is studded with extremely small, simple teeth.

The aperture is bounded by chitinized lips which do not bear any specialized spines or hooks. Small, simple teeth and a few short hairs are scattered along the lips.

At the rostral end of the aperture there is a pair of finger-like projections more or less in line with the apertural lips, which Utinomi calls "orificial palps." These may not be identical in size or shape, and are equipped with short, simple teeth. Between and behind (rostral to) these palps is a single orificial knob, also equipped with appreciable teeth. Behind this orificial knob is the large horny attachment knob, 
with many layers of cemented exuviae, where the female is attached to the burrow wall.

Within the lips of each side is a row of scaly teeth, which become thin in places along its length. This row of teeth presumably helps to prevent the intrusion of foreign matter or animals.

I could find no dorsoanterior mantle flap, as Utinomi describes, filled with egg masses. None of my specimens were gravid. Since the mantle flap of Trypetesa lateralis extends ventroanteriorly and is too solid to admit egg masses, the mantle flaps are not considered homologous or analogous. No lateral bar is present:

The body is small as compared with the size of the mantle sac in mature females. The segmentation appears to be of six segments as described by Utinomi.

The head is quite pointed and scaly on the apex. A row of hairs of variable length extend along each side of the head. This array of hairs would probably be an effective barrier against intrusion, but it is not the "comb collar" as Utinomi suggests (1964, p. 123 and p. 128). A genuine comb collar could not be found, and presumably does not exist in this species. Its function is probably assumed by the row of scaly teeth and fine hairs lining the apertural lips as already stated.

The labrum is not well developed.

The mouthparts are aberrant. The mandibles are simple, beaked, and heavily chitinized. No additional teeth or hairs were noted.

A mandibular palp could not be found, and Utinomi does not describe one.

A pair of first maxillae are located immediately behind the mandibles. They each have two heavy teeth separated by a distinct notch. Very long, straight apodemes extend from their bases to a common area dorsoposteriorly. The apodemes seem to be associated with a separate chitinized structure arising from the dorsal surface of the head. I postulate that these latter are additional reinforcing struts and that the first maxillae do a large share of the mastication.

The second maxillae are simple lobes behind and between the first maxillae.

The "mouth cirri," are long, plump, weakly chitinized, and covered distally with short and fine hairs. Two rami are mounted on a protopod of one or two segments, the number depending on the designation of a fold or crease in the cuticle near the distal end. Utinomi described it as one-segmented, and I will concur.

The three pairs of terminal cirri are uniramous and much shorter than acrothoracicans of other families. The first and third terminal cirri are approximately of equal length, and slightly shorter than the second pair. Each consists of four segments. The first two pairs of terminal cirri bear a protuberant "button" or "cushion" on the distal 
inner corner of the second segment. The size of this rugose button is greater on the second terminal cirrus, however.

Despite numerous females, no males were found on Utinomi's material. The larger female from Susami bore one mature male, which I removed intact. Three males were removed from the largest female from Seto. Additional males were observed in the $\mathrm{KOH}$ corroded, partial specimens from Seto, and up to four such remains were found on one female, on the exuviae around the horny knob.

The male is essentially like that of Trypetesa lampas. It occupies a deep pit on the right mantle exterior surface, although it could occupy either or both sides depending on which side were "up." Males are on the shallow side of the female (fig. 35bc). The male attaches by the usual antennules, to the outside mantle surface. The testes extend into a sac descending into the mantle pit, while the penis sheath extends forward toward the aperture. One male (fig. 35f) measures $0.90 \mathrm{~mm}$ long in toto, although only about $0.76 \mathrm{~mm}$ extends beyond the mantle surface. It is approximately $0.12 \mathrm{~mm}$ wide at the penis sheath. Bulbous projections at the level of the entrance into the mantle pit are of various widths (see fig. $35 \mathrm{~d}, \mathrm{e}$ ).

In removing the male from the female the antennules broke off. The cellular testicular area could be differentiated from the sperm storage vesicle. The testis is at the deepest portion of the lobe into the mantle pit, and is in close proximity to a black bean-shaped mass assumed to be the naupliar eye.

Projecting outwardly from the wavy mass of sperm is a penis sheath, although its length and structural detail could not be ascertained. The presence of an actual penis within the sheath of these specimens is doubted.

Numerous strands of small cells are scattered about within the cuticle of the male, some variously shaded yellowish or opaque. The distal end of the penis sheath bears internal reinforcing fibers, but no external teeth. The exterior of the male is smooth and not ornamented.

\section{Trypetesa lateralis Tomlinson, 1953, page 374}

\section{Figure 36}

Diagnosis: Trypetesa laterally compressed throughout; no freeswimming nauplius; adult does not exceed 5 millimeters; not bilaterally symmetrical in mantle structure (operculum on left side of mantle only); male without a penis; male attaches to disk of female or to the cavity wall near the external mantle flap.

Distribution: In snail shells occupied by hermit crabs, in littoral zone of central California. 


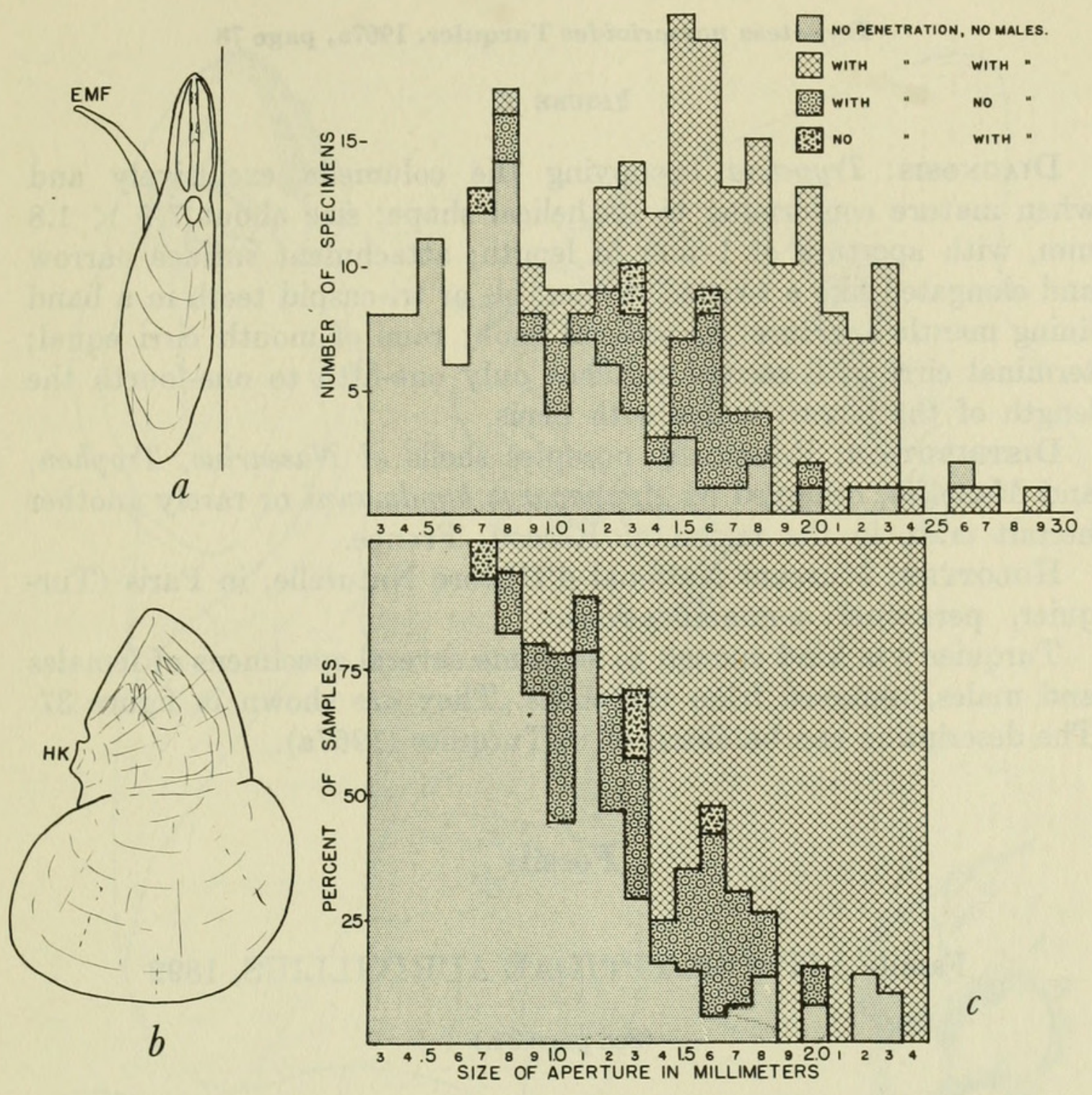

Figure 36.-Trypetesa lateralis Tomlinson, 1953, from Tegula shells from Moss Beach, California: $a$, female viewed parallel to shell surface, external mantle flap $(e, m, f)$ penetrates entirely through shell; $b$, viewed perpendicular to shell surface, horny knob $(h, k)$ evident; $c$, sizes and numbers of females with and without associated males.

Type-material: Holotype: USNM 93450. Paratypes: CA 9857; Allan Hancock Foundation, University of Southern California, Los Angeles; University of California Museum of Paleontology, Berkeley, Calif. 32960; Indian Zoology Society, Calcutta; Seto; University of Otago, New Zealand; Göteborg Museum, Sweden; Brit; University of Nancy, France; Plymouth Laboratory, England. Additional material: Aust, BPB, Belg, BA, Dublin, Mex, Paris, SFSC, UCT, Vict.

This species has been described in two papers (Tomlinson, 1953, 1955) and will not be repeated here. 
Trypetesa nassarioides Turquier, 1967 a, page 78

\section{FIGURE 37}

Diagnosis: Trypetesa occupying the columella exclusively and when mature conforming to its helical shape; size about $7.4 \times 1.8$ $\mathrm{mm}$, with aperture of $1 \mathrm{~mm}$ in length; attachment surface narrow and elongated like a twisted ribbon; bi- or tri-cuspid teeth in a band lining mantle aperture; no orificial knob; rami of mouth cirri equal; terminal cirri with second segment only one-fifth to one-fourth the length of the cirrus; males with penis.

Distribution: Principally occupies shells of Nassarius, Trophon, and Mangelia, occupied by Anapagurus hyndmanni or rarely another hermit crab, in the region of Roscoff, France.

Hоцотүре: Museum National d'Histore Naturelle, in Paris (Turquier, personnel communication).

Turquier was kind enough to send me several specimens of females and males, removed from the shells. They are shown in figure 37 . The description can be obtained in Turquier (1967a).

\section{Fossils}

Family LITHOGLYPTIDAE AURIVILLIUS, 1892

(See page 31.)

\section{Genus Simonizapfes Codez, 1957, page 704}

Diagnosis: Burrows long and narrow, maximum length of the burrow about four times the width.

TyPe-species: Simonizapfes elongata Codez, 1957, page 705.

\section{Sịmonizapfes elongata Codez, 1957, page 705}

Zapfella pattei Saint-Seine (1954, page 447) in part.

Diagnosis: Dimensions of the aperture about 1.0-2.3 $\times 0.3-0.6 \mathrm{~mm}$; maximum length and width of the burrow about $2.0-4.5 \times 0.5-1.1 \mathrm{~mm}$.

Distribution: Level, locality, and biotypes-this species is known from the Sinémurien to Portlandien inclusively; it is particularly abundant in the shells of belemnites and the Ostreidae, but exists also in other lamellibranchs, gastropods, corals, and crinoids, of Europe and India. 


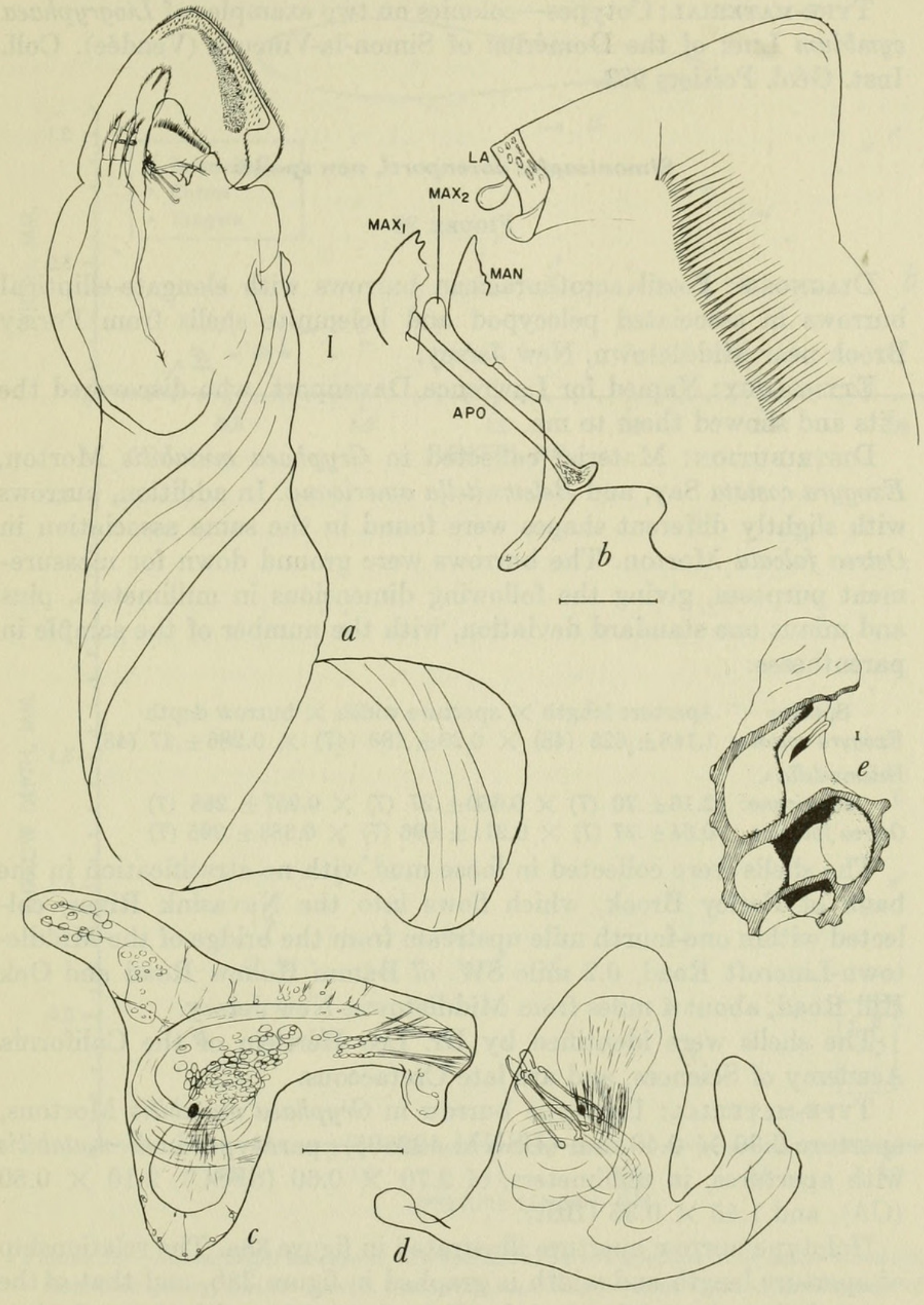

Figure 37.-Trypetesa nassarioides Turquier, 1967b, from his collection: $a$, female, side view of main body, left opercular lip notched; $b$, head and mouth field; $c, d$, males-the younger specimen in $d$ has retained the antennules, is less detailed, and is inverted in respect to $c ; e$, in situ in shell. 
Type-material: Cotypes-colonies on two examples of Liogryphaea cymbium Lmk of the Domérien of Simon-la-Vineuse (Vendée). Coll. Inst. Géol. Poitiers 983.

\section{Simonizapfes davenporti, new species}

Figure 38

Diagnosis: Fossil acrothoracican burrows with elongate-elliptical burrows in associated pelecypod and belemnite shells from Poricy Brook near Middletown, New Jersey.

EтyмоLogy: Named for Lawrence Davenport, who discovered the slits and showed them to me.

Distribution: Material collected in Gryphaea mutabilis Morton, Exogyra costata Say, and Belemnitella americana. In addition, burrows with slightly different shapes were found in the same association in Ostrea falcata Morton. The burrows were ground down for measurement purposes, giving the following dimensions in millimeters, plus and minus one standard deviation, with the number of the sample in parentheses:

Species Aperture length $\times$ aperture width $\times$ burrow depth

Exogyra costata: $1.148 \pm .625(48) \times 0.29 \pm .183(47) \times 0.286 \pm .17$

Belemnitella

americana: $\quad 2.16 \pm .70(7) \times 0.650 \pm .27(7) \times 0.957 \pm .268(7)$

Ostrea falcata: $\quad 0.64 \pm .37(7) \times 0.211 \pm .096(7) \times 0.683 \pm .295(7)$

The shells were collected in loose mud with no stratification in the bank of Poricy Brook, which flows into the Navasink River, collected within one-fourth mile upstream from the bridge of the Middletown-Lincroft Road, 0.2 mile SW. of Bamm Hollow Road and Oak Hill Road, about 4 miles from Middletown, New Jersey.

The shells were identified by Dr. Leo Hertlein of the California Academy of Sciences, and are late Cretaceous.

Type-Material: Holotype burrow in Gryphaea mutabilis Mortons, aperture $2.30 \times 0.40 \mathrm{~mm}$ (USNM 122605); paratypes in G. mutabilis with apertures, in millimeters, of $2.70 \times 0.60$ (SFSC), $2.10 \times 0.50$ (CA), and $1.45 \times 0.35$ (Brit).

Holotype burrow aperture illustrated in figure 38a. The relationship of aperture length and width is graphed in figure $38 \mathrm{~b}$, and that of the aperture length and burrow depth in figure $38 \mathrm{c}$, with datum points identified to the genera, and hence the species, listed above. 
THE BURROWING BARNACLES (CIRRIPEDIA: ACROTHORACICA) 137
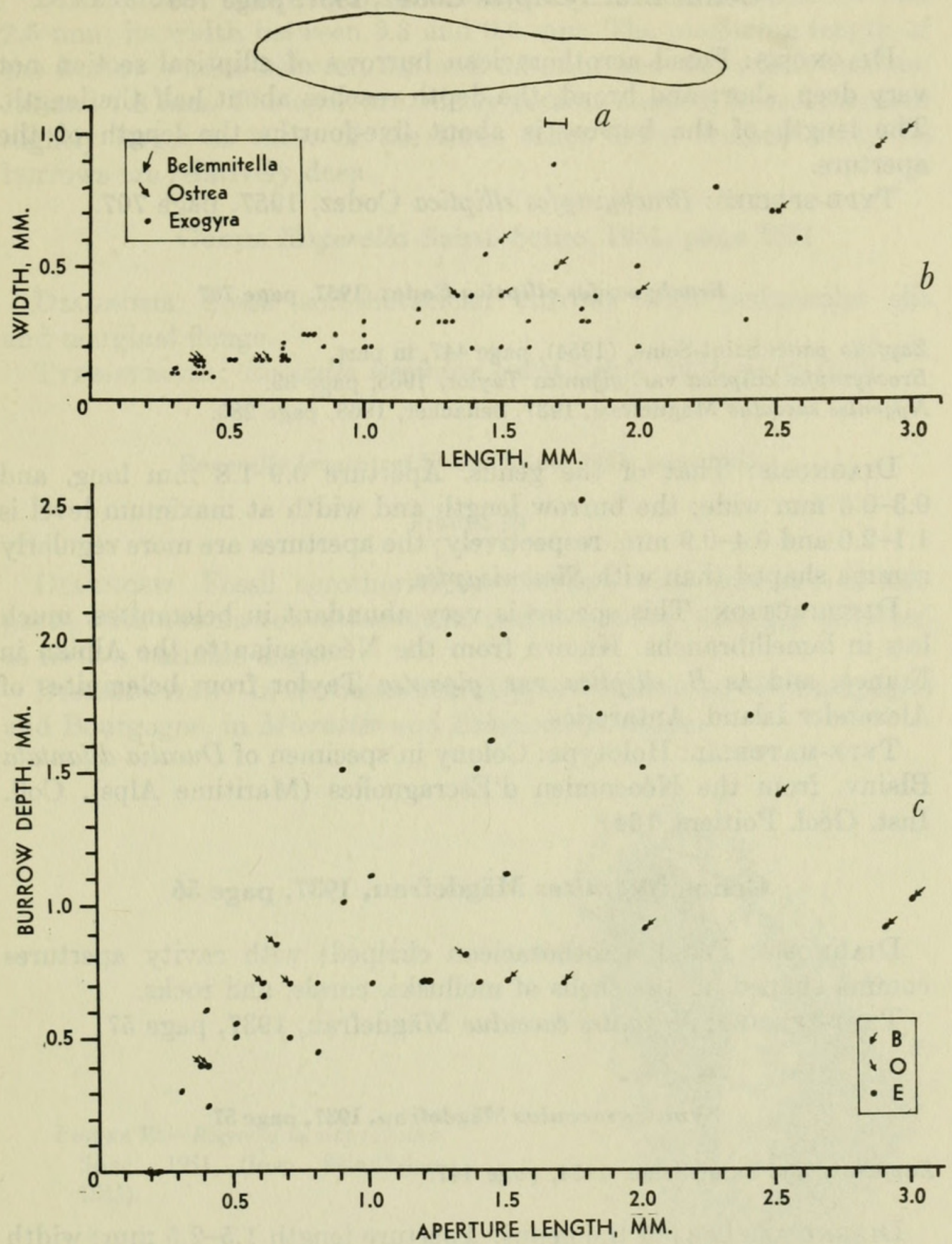

Figure 38. - Simonizapfes davenporti, new species: $a$, burrow aperture in Gryphaea mutabilis, from New Jersey, surface view; $b$, burrow aperture length versus width in three genera of shells; $c$, burrow aperture length versus burrow depth in three genera of shells. 


\section{Genus Brachyzapfes Codez, 1957, page 706}

Diagnosis: Fossil acrothoracican burrows of elliptical section not very deep, short and broad, the depth reaches about half the length. The length of the burrow is about five-fourths the length of the aperture.

Type-species: Brachyzapfes elliptica Codez, 1957, page 707.

\section{Brachyzapfes elliptica Codez, 1957, page 707}

Zapfella pattei Saint-Seine, (1954), page 447, in part.

Brachyzapfes elliptica var. gigantea Taylor, 1965, page 39.

Nygmites sacculus Mägdefrau, 1937. Seilacher, 1968, page 280.

Diagnosis: That of the genus. Aperture 0.9-1.8 mm long, and $0.3-0.5 \mathrm{~mm}$ wide; the burrow length and width at maximum level is 1.1-2.0 and $0.4-0.9 \mathrm{~mm}$, respectively; the apertures are more regularly comma shaped than with Simonizapfes.

Distribution: This species is very abundant in belemnites, much less in lamellibranchs. Knnown from the Néocomian to the Albian in France, and as B. elliptica var. gigantea Taylor from belemnites of Alexander Island, Antarctica.

Type-material: Holotype: Colony in specimen of Duvalia dilantata Blainv. from the Néocomien d'Escragnolles (Maritime Alps). Coll. Inst. Géol. Poitiers, 164.

\section{Genus Nygmites Mägdefrau, 1937, page 56}

Diagnosis: Fossil acrothoracican cirripeds with cavity apertures comma shaped, in the shells of mollusks, corals, and rocks.

TyPe-SPEcies: Nygmites sacculus Mägdefrau, 1937, page 57.

\section{Nymites sacculus Mägdefrau, 1937, page 57}

Zapfella pattei Saint-Seine, 1954, page 447.

Diagnosis: That of the genus. Aperture length $1.5-2.5 \mathrm{~mm}$; width 0.3-0.6 mm; maximum burrow length $2.2-3.6 \mathrm{~mm}$; burrow width $1.0-1.8 \mathrm{~mm}$.

Distribution: Found by Mägdefrau in Belemnites hastatus Mtf. from the Malm $\gamma$ of Wurtemberg, Germany. Saint-Seine describes it as abundant in gastropods and pelecypods, and in two Belemnites hastatus, through the Miocene and is rare in the Pliocene, of France, Algeria, Vienna Basin, and Korytnica, Poland (Radwański, 1964, page 61). 
Dimensions: The length of the aperture varies between 1.5 and $2.5 \mathrm{~mm}$; its width between 0.3 and $0.6 \mathrm{~mm}$. The maximum length of the burrow varies between 2.2 and $3.6 \mathrm{~mm}$ and the width between 1.0 and $1.8 \mathrm{~mm}$. The aperture, nicely comma shaped, is in dimension slightly larger to those of the three other forms studied here; the burrows are relatively deep.

\section{Genus Rogerella Saint-Seine, 1951, page 1051}

Diagnosis: Fossil acrothoracican burrows with peduncular slit and marginal flange.

TyPE-SPECIES: Rogerella lecointrei Saint-Seine, 1951, page 1051.

\section{Rogerella lecointrei Saint-Scine, 1951, page 1051}

\section{Figure 39}

Diagnosis: Fossil acrothoracican burrows with aperture in two parts, with the narrow attachment end sometimes strongly deflected to form a variable angle.

Distribution: In the Santonien (Upper Cretaceous) of Champagne and Bourgogne, in Micraster and Echinocorys. Rare.

Figure 39.-Rogerella lecointrei SaintSeine, 1951 (from Saint-Seine, 1955).

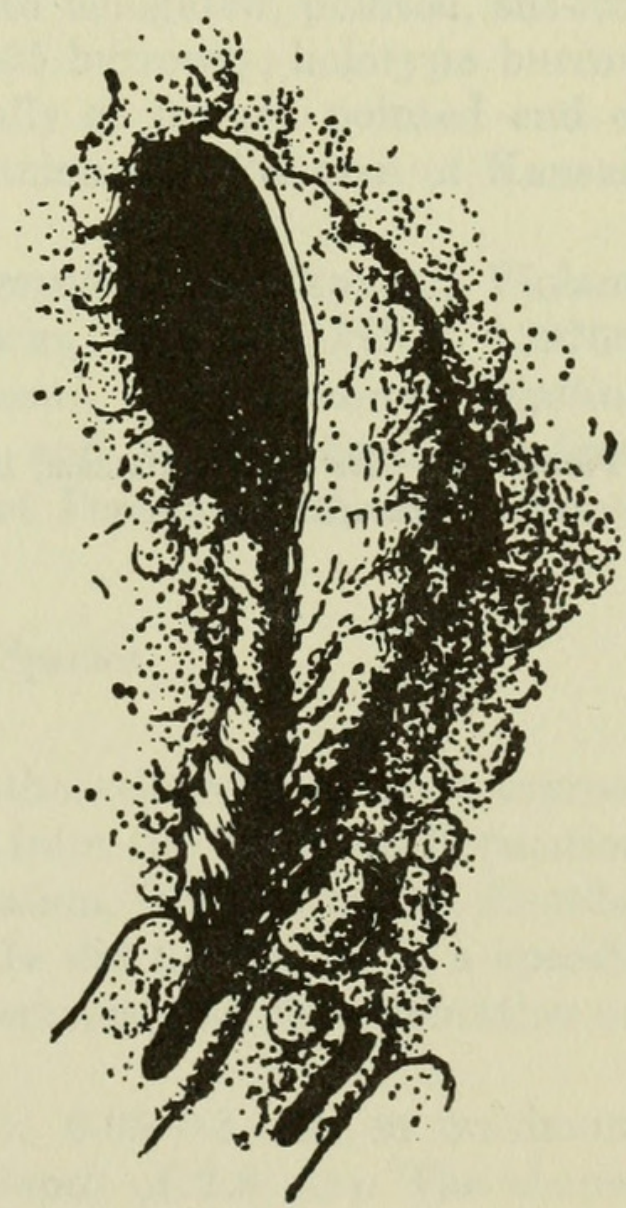


Dimensions: About $1.5 \times 0.5 \mathrm{~mm}$, not counting the thickness of the flange. Slit length reaches about $2.7 \mathrm{~mm}$, but may be much shorter. The flange which is usually present is thick, swollen, and of about $0.5 \mathrm{~mm}$ in maximum width.

\section{Rogerella mathieui Saint-Seine, 1955a, page 300}

Diagnosis: Fossil acrothoracican burrows with aperture straight or arched, widening regularly without two distinct parts. Flange thin, fragile, usually absent.

Distribution: It is found in echinoids of the middle Jurassic, invading lamellibranchs, belemnites, and corals in the Upper Cretaceous, persisting sporadically in the Miocene and Pliocene. AngloParisian basins.

Dimensions: Aperture 1-2 $\mathrm{mm} \times 0.3-0.8 \mathrm{~mm}$ in length and width; the burrow is $1.3-2.5$ and $0.6-1.1 \mathrm{~mm}$ in length and width. Burrow length may attain about $3 \mathrm{~mm}$ (var. elongata) without appreciable variation in width.

Figure 40.-Ibla idiotica Batham, 1945 (from Batham, 1945).

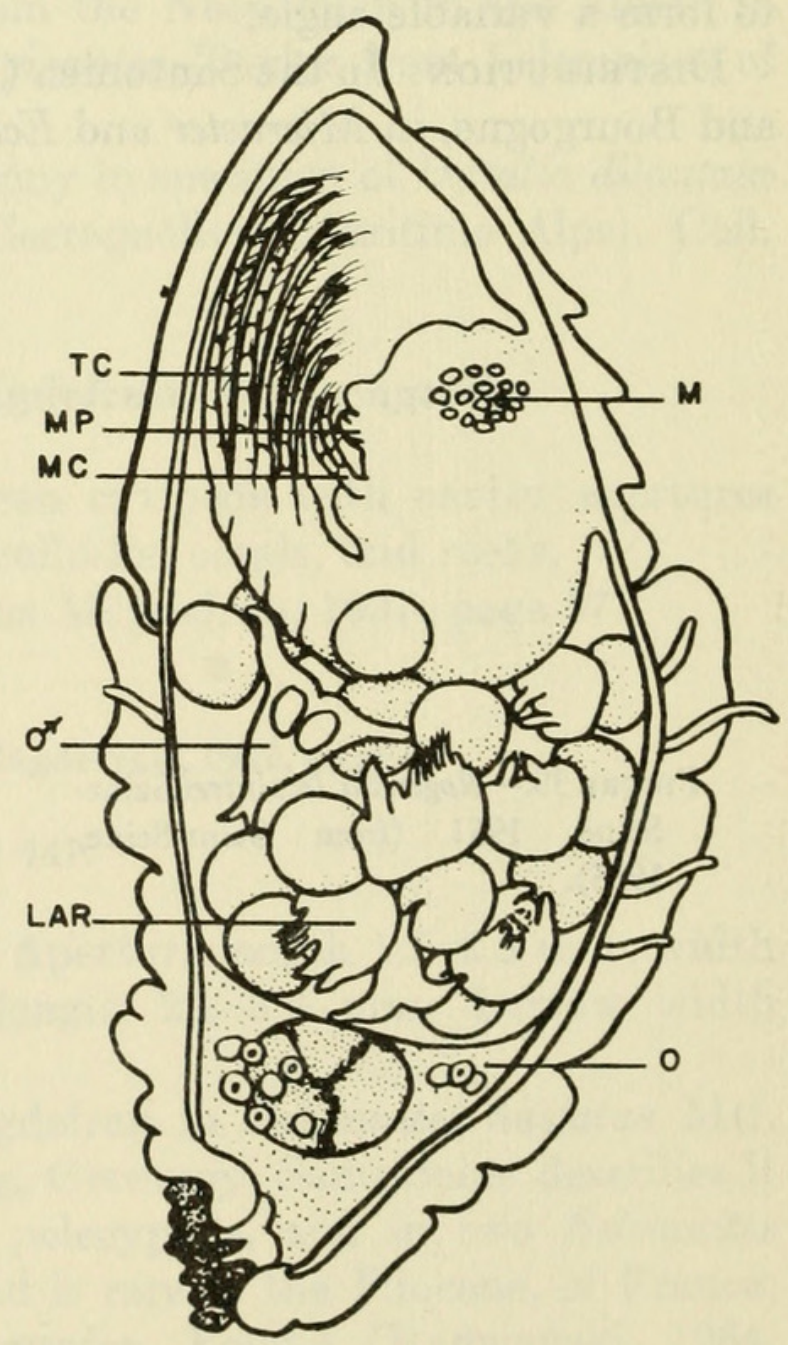




\section{Rogerella cragini Schlaudt and Young, 1960, page 903}

Diagnosis: Aperture of burrow $0.8-1.9$ and $0.3-0.7 \mathrm{~mm}$ in length and width, subelliptical, virgulate (comma shaped), sometimes hooked to the right, more often hooked to the left as viewed, with a peduncular slot or groove, joined to a widening opening at an angle varying with the location on the host shell; apertural flange rarely present; burrow slightly less than one-half as deep as it is long.

Distribution: In the gastropod Ceritella proctori (Cragin) from Edwards limestone (Middle Albian; Lower Cretaceous), Colorado River, Travis County, Texas. Other associated shells were not burrowed.

\section{Family TRYPETESIDAE KRÜGER, 1940, page 454}

Diagnosis: Burrow depth variable, burrow fan shaped, with peduncular slit. See also diagnosis on page 125.

\section{Genus Trypetesa Norman, 1903, page 369}

(See also description on page 125.)

\section{Trypetesa caveata Tomlinson, 1963a, page 164}

Diagnosis: Burrows fan shaped, with elongated, pointed, slit-like aperture $1.76 \times 0.6 \mathrm{~mm}$ (average of 205 burrows); holotype burrow $11.3 \times 5.0 \mathrm{~mm}$; burrow extends laterally or toward pointed end of aperture. In myalinids from Pennsylvanian and Permian of Kansas, Texas, and Oklahoma.

Type-material: Holotype in Septimyalina perattenuata, Vinland shale, Pennsylvanian, north of Baldwin, Kansas. USNM 139766. Other material from Orthomyalina slocomi, O. subquadrata, Myalina copei, M. pliopetina, M. glossodoidea, and Septimyalina orbiculata; from the Pennsylvanian and lowermost Permian of Kansas, Texas, and Oklahoma.

\section{Undescribed Fossil Species}

Ross (1965) described a fossil acrothoracican from an ectoproct bryozoan colony, possibly Holoporella, from the Tamiami Formation of the Upper Miocene near Monroe Station, Collier County, Florida, collected by Mrs. Susan R. Brooks. He did not assign it a specific name. There were no flanges on the apertures, and the orientation on the host shell appeared to be random.

The burrow apertures are $0.6-2.7 \times 0.09-0.3 \mathrm{~mm}$ in maximum length and width, with a maximum depth of $2.9 \mathrm{~mm}$. The shapes 
were elongate-elliptical, subrounded elliptical, arcuate-elliptical, elongate-elliptical with a slight constriction near the middle suggesting a figure 8 , subplanulate, and elongate-elliptical with an anterior flexure or "hook" due to the presence of a peduncular slit or groove.

Joysey (1959) described 17 burrows in the test of the echinoid Echinocorys from the Cretaceous Chalk of Culver Cliff, Isle of Wight, Great Britain, in association with 6 other kinds of burrows. The burrows have the general shape of a somewhat laterally compressed shoe, with the aperture of the burrow and shoe corresponding. The burrow is elongate oval in shape, almost slit-like. No dimensions or measurements are given. Measurements from the figures indicate a maximum burrow length and width of 2.1 and $0.83 \mathrm{~mm}$, respectively.

Schlaudt and Young (1960) describe a questionable acrothoracican from Permian fossils from the Glass Mountains of Trans-Pecos, Texas, on several species of brachiopods. Their apertures are elliptical, straight, with slight angulations at the loci of greatest curvature. They are $0.6-1.0$ and $0.3-0.5 \mathrm{~mm}$ in length and width of the burrows, respectively. The burrows completely penetrate the shell, which adds doubt as to their nature, although poor preservation could account for this feature.

Rodda and Fisher (1962) give an excellent account of what is probably several undescribed species of upper Paleozoic acrothoracican barnacles from Texas, as well as a useful review of previous work. The reader is referred to this paper for additional information. The only caveat is that the "anterior" end of the aperture, as used by paleontologists, refers to the anterior end of the attached larva, and is more the dorsal or rostral end of the mature barnacle. A good bibliography of articles with plates showing apparently acrothoracican burrows is included.

Zapfe (1936) describes some fossil burrows with acrothoracican characteristics resembling those described for Lithoglyptes indicus, in Pyrula cornuta of the Helvetian (Miocene) of Várpolata, and in Fasciolaria tarbelliana and Triton nodiferum from the Helvetian of Grund. These two localities are in the Mediterranean, where living $L$. indicus is completely absent. The dimensions of the burrows in the Fasciolaria shell are as follows: length of opening $3.5 \mathrm{~mm}$, greatest width $1.2 \mathrm{~mm}$, depth $5.3 \mathrm{~mm}$. These agree favorably with the measurements of Lithoglyptes indicus burrows, stated by Aurivillius as 4 $\mathrm{mm}$ long and $6 \mathrm{~mm}$ deep, but since so many acrothoracicans have these approximate dimensions, the identification must be regarded as nothing more than a guess at this time.

Through geological time, the acrothoracicans have apparently changed their major host types several times, each time infecting the thickest-shelled animals available. For example, they seem to be 
most readily found in heavy-shelled clams and brachiopods until the Mesozoic, when these shells became thinner. They then changed to ammonites and echinoids, and finally to gastropods as these heavyshelled forms became abundant in the Cenozoic.

It is quite certain that as more is known about the shapes of the burrows of these forms, more species will be described from the fossil record. Sponge and bryozoan burrows are common, and may be recognized by several distinct features. Sponge burrows usually perforate the shell, with small, round holes connecting larger spherical chambers. The burrows are often neither separate and distinct, nor with only a single aperture. Bryozoan colonies, being connected by stolons, usually have a branching pattern visible somewhere in the colony, and the individual burrows are connected by smaller holes formed by the stolons.

Acrothoracican burrows can be close enough to coalesce. I have found this condition in shells containing specimens of Cryptophialus melampygos, Berndtia purpurea, Trypetesa lampas, or $T$. lateralis. The usual situation, however, is for the individuals to have distinct, separate burrows, with a single aperture (except $T$. lateralis, which has the second minute opening of the external mantle flap). They are frequently grouped together, especially around the umbo or beak of a bivalve, where the periostracum has been abraded. The position and orientation of burrows on the shell may indicate swimming habits of such forms as belemnites (Seilacher, 1968).

\section{Distribution}

As indicated by the map of world distribution (fig. 41), the order Acrothoracia is cosmopolitan.

The species with the widest known range are Lithoglyptes spinatus and Kochlorine hamata. The former is found scattered through the Pacific Ocean, in the Caribbean, the Indian Ocean, and in the Red Sea. K. hamata is found on the eastern and western Pacific, and the Indian Ocean, and is the only species in the Mediterranean.

The most restricted distribution seems to be that of Australophialus melampygos, found only in New Zealand. It has a larva which does not swim.

Other generalities can be drawn as follows: Weltneria is in the Indo-Western Pacific. Lithoglyptes is a complex genus with wide distribution of imperfectly differentiated species. All species should be expected to have appreciable distributions when fully known. Kochlorine is widely represented by Kochlorine hamata. K. floridana appears to be in Madagascar (Malagasy Republic) in addition to 


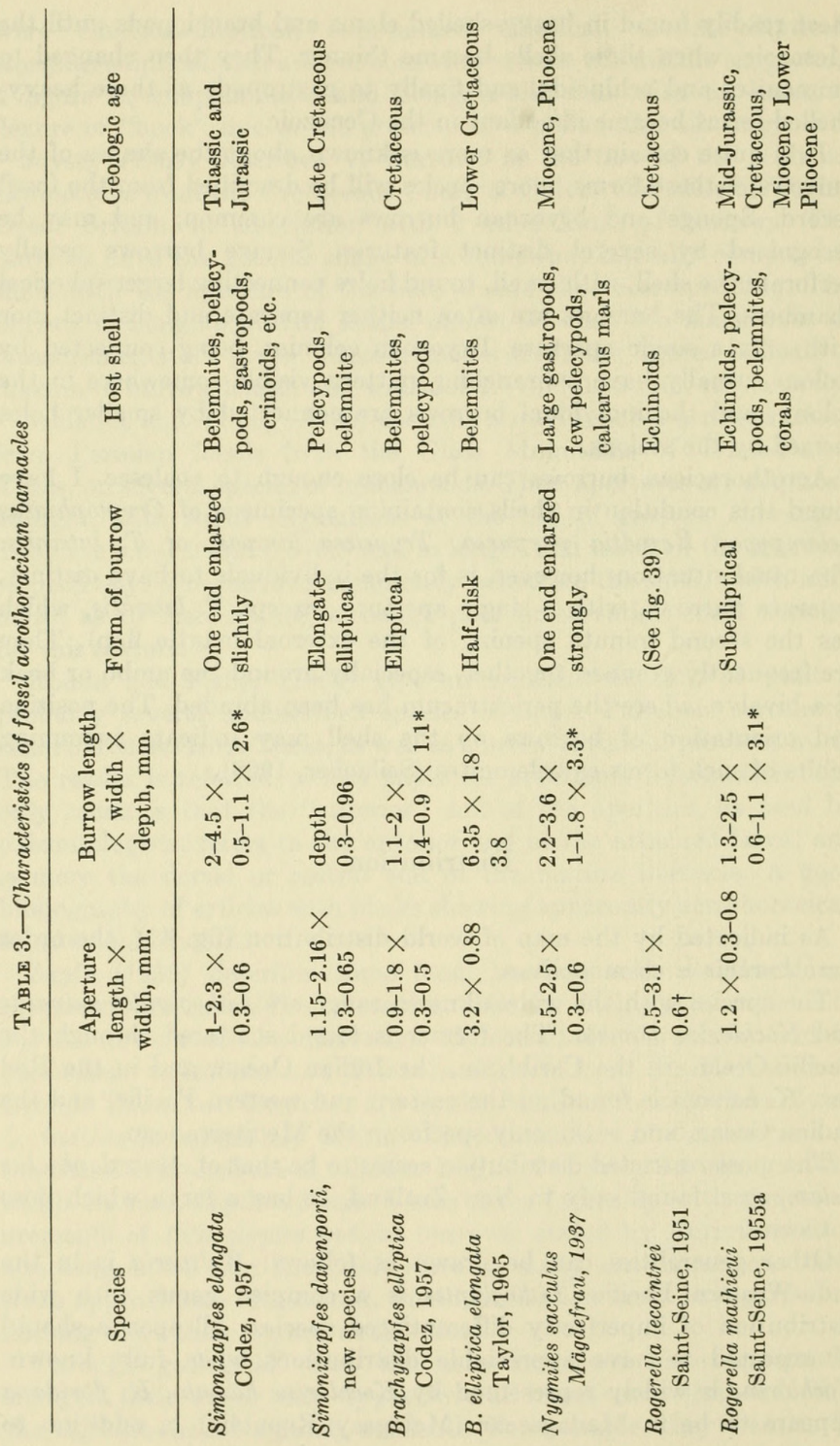


THE BURROWING BARNACLES (CIRRIPEDIA: ACROTHORACICA) 145
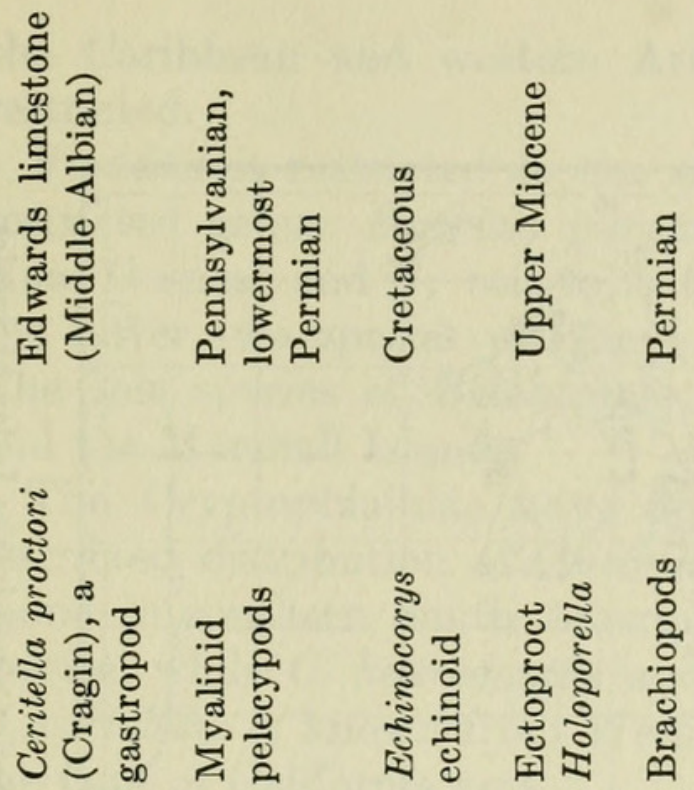

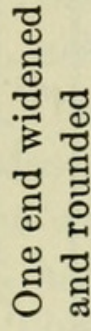

$\stackrel{\circ}{\circ}$

$\dot{0}$

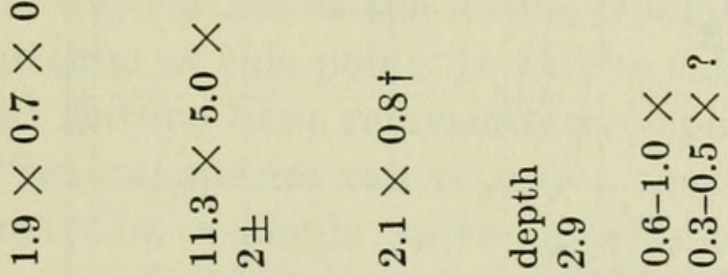

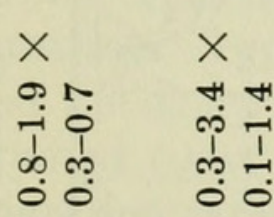

\&

ธิ๊

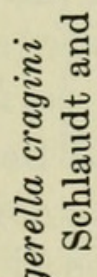
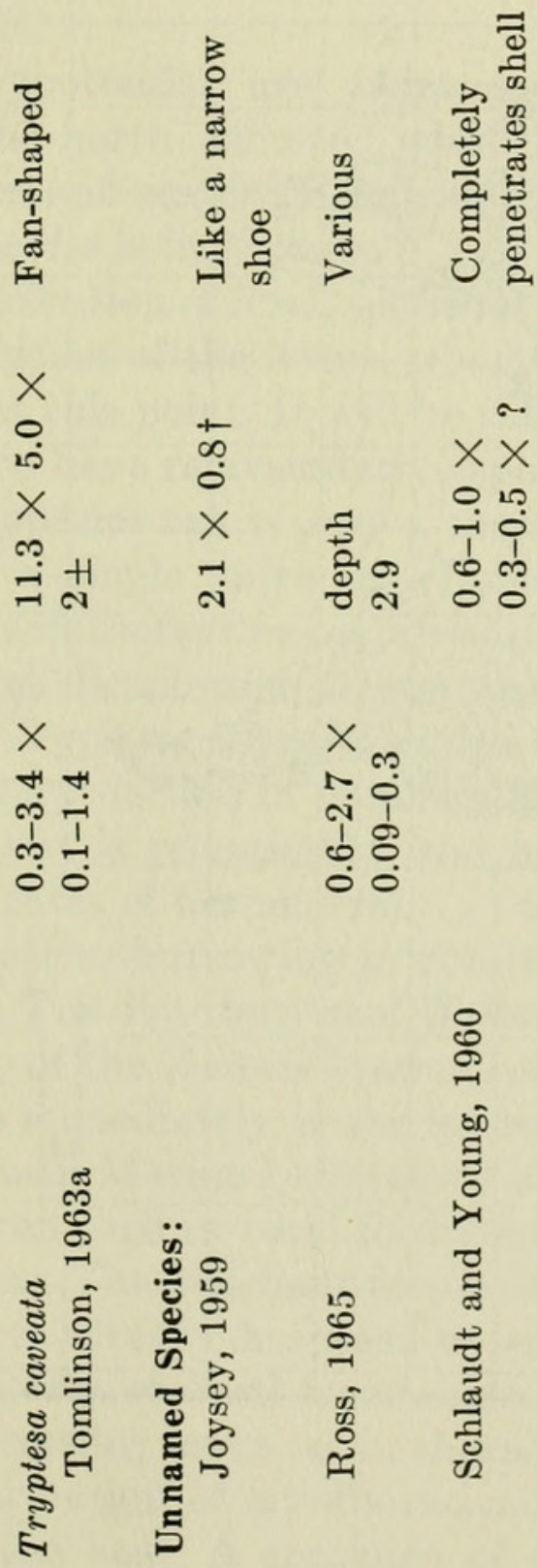

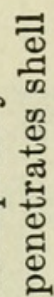

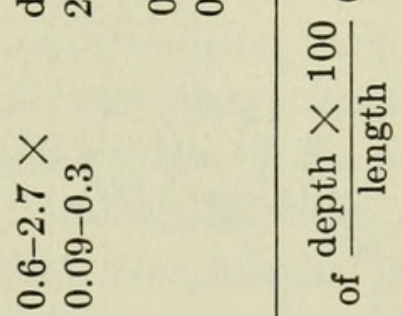

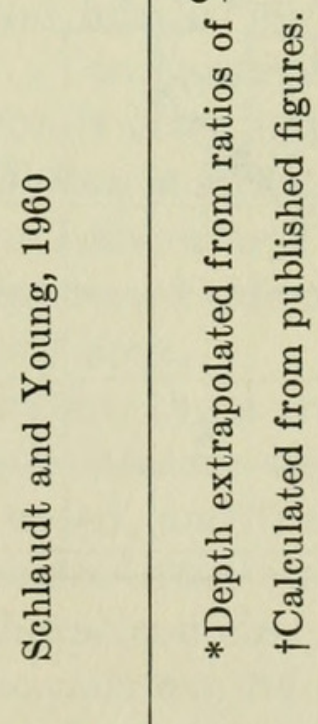




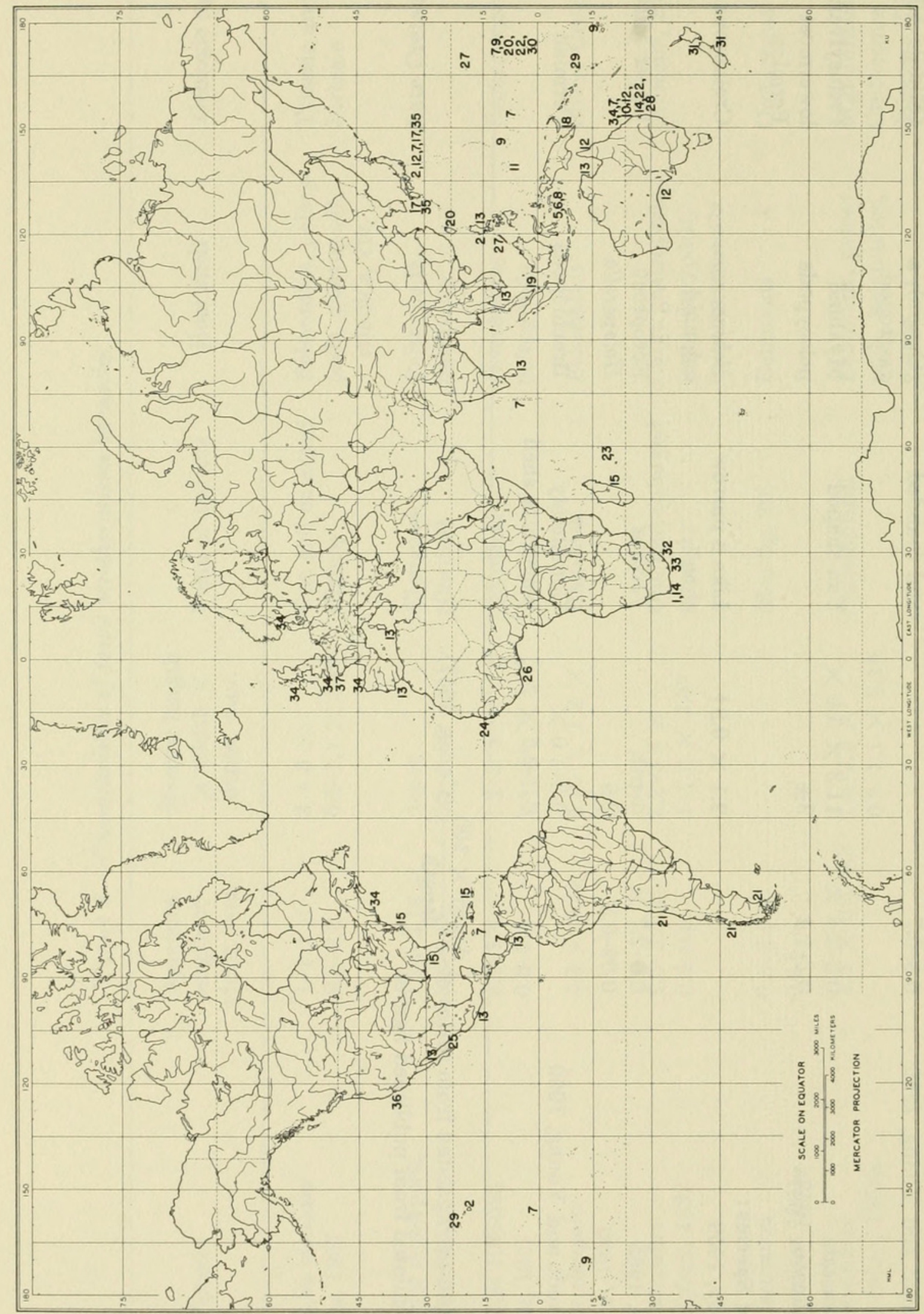

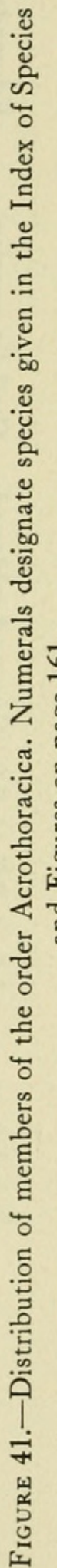


the Caribbean and western Atlantic, but other species are more restricted.

Berndtia is restricted to the western Pacific, making it the most restricted genus. Berndtia purpurea is Japanese, $B$. fossata is from New Guinea, and $B$. nodosa is from Singapore. It is expected that the latter two species will have a larger range when fully known. The sole species of Balanodytes, B. taiwanus, is found on Taiwan and the Marshall Islands.

The Cryptophialidae have been discussed above regarding the restricted distribution of Australophialus melampygos. C. minutus is found in southern South America, C. cordylacis is a central Pacific species, while $C$. heterodontus and $C$. lanceolatus extend to Australia. C. variabilis is known from West Africa, and $C$. wainwrighti is from the Gulf of California area.

Australophialus turbonus is known only from South Africa, as is A. utinomii.

The Trypetesidae are widespread. Trypetesa lampas is on both sides of the north Atlantic, while T. habei and T. lateralis occur in the western and eastern Pacific, in Japan and California, respectively. T. nassarioides is in France.

The distribution of fossil species is largely a matter of the recognition and description of the forms, which is so incomplete as not to occupy our time at this point. It will be sufficient to say that North America and Europe have representative species.

Several species can occupy a single shell or coral. On Heron Island, Australia, a single valve of Tridacna maxima Röding yielded four species of acrothoracicans representing three genera.

The local distribution of acrothoracican species can be most interesting. Trypetesa lateralis prefers shells of the exposed open coast, and the sharp decline in numbers in shells a short distance from the exposed coast is remarkable, and has led to speculation on the low migration rates of hermit crabs. (Tomlinson, 1960b)

Those species burrowing in corals of ten have limited areas of concentration. The distribution of Weltneria hirsuta on the reef at Coconut Island, site of the Hawaii Marine Laboratory, is heavily concentrated in the area immediately to the landward side of the channel traversed by the Hawaii Marine Laboratory boat.

On a given shell or coral formation there are markedly nonrandom distributions. The penchant for the heavier areas of the shells without periostracum already has been noted, and they prefer in general the dead basal area of coral formations. Often striations in the shell will orient the settling larva, as in thoracican cirripeds.

The distribution of acrothoracicans can be remarkably nonspecific regarding the host. A specimen of coral with a Spondylus attached 
was attacked by barnacles which have since been scoured out, but which appear to be a single species. The array of specimens burrowed along the lower side of the coral and the Spondylus in undiminished numbers. Frequently a local species will attack any heavy shell or coral available.

A great deal of work remains to be done on the nature of the mechanisms influencing the micro- and macro-distribution of these animals.

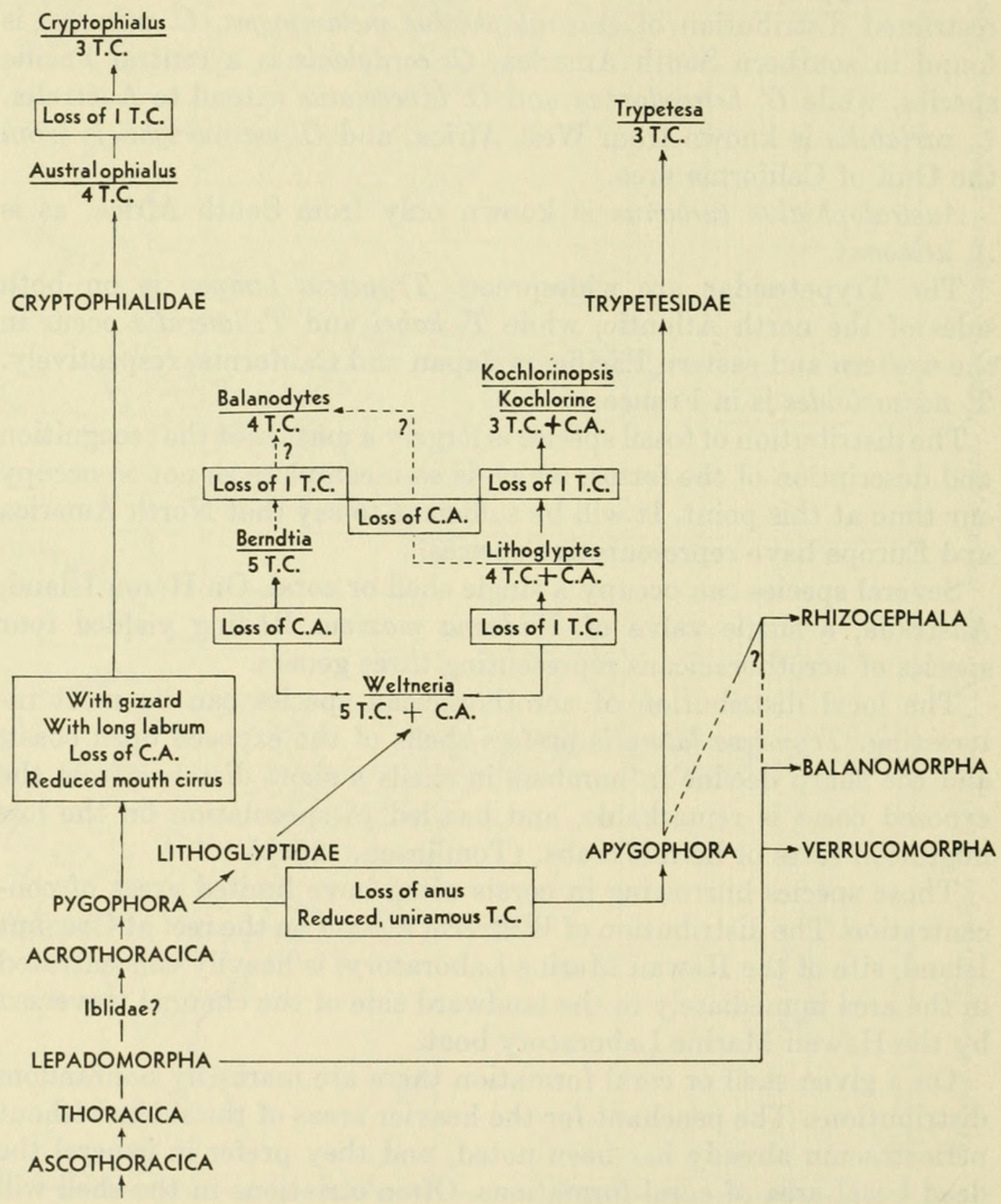

Figure 42.-Phylogenetic diagram showing possible relationships of the genera within the order Acrothoracica, and the orders within the subclass Cirripedia. C.A. = caudal appendages, paired; T.C. $=$ terminal cirri, number of pairs. 


\section{Key to the Order Acrothoracica}

1a. With an anus, terminal cirri biramous, caudal appendage may be present (Suborder Pygophora) . . . . . . . . . . . . . . . . . . . . . 2

1b. Without an anus or caudal appendage, terminal cirri uniramous (Suborder Apygophora, Family Trypetesidae, Genus Trypetesa) . . . . . . . 32

2a. Alimentary canal without gut teeth (gizzard), mouth cirri well developed, labrum of approximately the same size as the rest of well-developed mouthparts, burrow aperture in shell a tapered slit like a typed apostrophe (Family Lithoglyptidae)

2b. Alimentary canal with gut teeth (gizzard), mouth cirri atrophied or absent, large attenuated labrum present, mouthparts relatively weak, burrow aperture in shell very small and short, almost round. (Family Cryptophialidae). 4

3. Excluding mouth cirri, terminal cirri number in pairs:

5 plus caudal appendage. . . . . . . . . . . . Weltneria, 16

5 without caudal appendage . . . . . . . . . . . Berndtia, 19

4 plus caudal appendage . . . . . . . . . . . Lithoglyptes, 21

4 without caudal appendage. . . . . . . Balanodytes taiwanus

3 plus caudal appendage . . . . Kochlorine, Kochlorinopsis, 28

4a. With 4 pairs of terminal cirri, 1 dorsal body process . . Australophialus, 5

4b. With 3 pairs of terminal cirri, 2 dorsal body processes . Cryptophialus, 7

5a. Opercular margin entire, not notched . . . . . . . . . . . . . . . 6

5b. Opercular margin with distinct notch at $1 / 3$ length from attachment end

Australophialus turbonis

6a. Margin with distinct short spines: New Zealand only . . A. melampygos

6b. Margin with small, bifid teeth; South Africa . . . . . . . A. utinomii

7a. Operculum with 2-6 spines about half as long as apertural length . . . 8

7b. Operculum with hillocks less than $1 / 3$ as high as apertural length, bearing

nıany teeth or thin straight spines. . . . . . . . . . . . . . 13

8a. Teeth between spines serrated . . . . . . . . . . . . . . . . . . 9

8b. No teeth between spines, or if present, not serrated . . . . . . . . . 12

9a. Spines heavily toothed, with miniature barbed spines between main spines

Cryptophialus lanceolatus

9b. Spines sparsely toothed, without barbed miniature spines between main spines . . . . . . . . . . . . . . . . . . . 10

10a. With 2 pairs of distinct, haired spines on operculum . . . . . . . . . 11

10b. With 2 gnarled hillocks bearing serrated spines, knobs, and hairs

C. newmani

11a. Lateral bar terminates in area with heavy recurved teeth resembling a claw

C. unguiculus

11b. Lateral bar without terminal array of teeth . . . . . . . . C. variabilis

12a. Circlet of teeth distributed around posterior end of left lateral bar, apertural spines heavy (about 3 times as long as wide) . . . . . . C. coronatus

12b. Lateral bars pointed posteriorly, without circlet of teeth, apertural spines light, about 5 times as long as wide . . . . . . . C. longicollatus

13a. Operculum armed with bunches of thin, straight spines . . C. cordylacis

13b. Operculum armed with teeth, which are conical or curved . . . . . 14

14a. Opercular teeth essentially uniform and conical in shape . . . . . . . 15

14b. Operculum with low, conical, toothed hillocks and curved, bifid, blunt teeth

C. wainwrighti 
15a. Opercular teeth becoming progressively larger toward dorsal or attachment end

C. heterodontus

15b. Opercular teeth of various size, but variously distributed on low hillocks

C. minutus

16a. Apex of operculum with well-developed spine or hook on each side . 17

16b. Apex of operculum without such strong spines or hooks . . . . . . . 18

17a. Apex with straight spine, with 12 or more long hyaline spines of approximately equal length along operculum . . . . . . . . . . W. aapta

17b. Apex with curved hooks, a pair of weak irregular lateral bars present

Weltneria spinosa

18a. Operculum with many small spines and hairs . . . . . . . . W. hirsuta

18b. Operculum ornamented with many small bifid and crenulated teeth, a reticulated pattern medially and rows of fine dots laterally . W. reticulata

19a. Operculum studded over outer surfaces with numerous blunt, heavy, nodular teeth, margins with over 30 simple teeth .

Berndtia nodosa

19b. Operculum superficially smooth, except for many small marginal teeth . 20

20a. Marginal teeth simple .............. B. purpurea

20b. Marginal teeth serrated into 3-5 points arranged in an arc . . B. fossata

21a. With a pair of strong spines or hooks at the apical end of the operculum . 22

21b. Without such paired apical spines or hooks . . . . . . . . . . . . . 25

22a. Apical projections are hooked, or with strong spur-like teeth on spine to make it appear hooked . . . . . . . . . . . . . . . . . . . . 23

22b. Apical projections not hooked . . . . . . . . . . . . . . . . . . 24

23a. Projection itself is uniformly and strongly hooked. Lithoglyptes spinatus

23b. Spur-like tooth on projection may give hooked appearance . . . . . . 27

24a. Projections long, bristle-bearing 2 pairs of processes or operculum . . . 26

24b. Projections shorter, with bifid teeth and few short hairs . . . . L. mitis

25a. Hooks or spines present, not paired apically . . . . L. scamborachis

25b. No hooks or spines present . . . . . . . . . . . . . . . . L. indicus

26a. Both pairs of processes conical, erect . . . . . . . . L bicornis

26b. Pair toward attachment end strongly hooked. . . . . . . . L. ampulla

27a. Spur-like tooth common, most prominent teeth on operculum, large, simple, strong lateral bar . . . . . . . . . . . . . . L habei

$27 \mathrm{~b}$. Spine rarely spurred, most prominent teeth on operculum bifid, lateral bar absent . . . . . . . . . . . . . . . . . . L. wilsoni

28a. With paired anterior opercular processes . . . . . . . . . . . . . . 29

28b. Operculum merely pointed anteriorly . . . . . . . . . . . . . . . 30

29a. One posterior hook on operculum . . . . . . . Kochlorine hamata

29b. No posterior hooks, opercular margin with large anchor-shaped teeth

K. anchorella

30a. With two posterior hooks on operculum

K. bihamata

$30 \mathrm{~b}$. With no posterior hooks on operculum . 31

31a. Lateral bar and retractor pallii rostralis present .

K. floridana

31 b. Lateral bar and retractor pallii rostralis absent

Kochlorinopsis discoporellae

32a. Ovarian disk tending to extend posteriorly rather than to either side . . 33

32b. Ovarian disk extending to right side of slit in shell . . Trypetesa lateralis

33a. Attachment area oval, not twisted

33b. Attachment area elongated, twisted spirally . . . . . T. nassarioides

34a. With well-developed comb collar inside mantle aperture . . . T. lampas

34b. Without comb collar. . . . . . . . . . . . . . . . . T. habei 


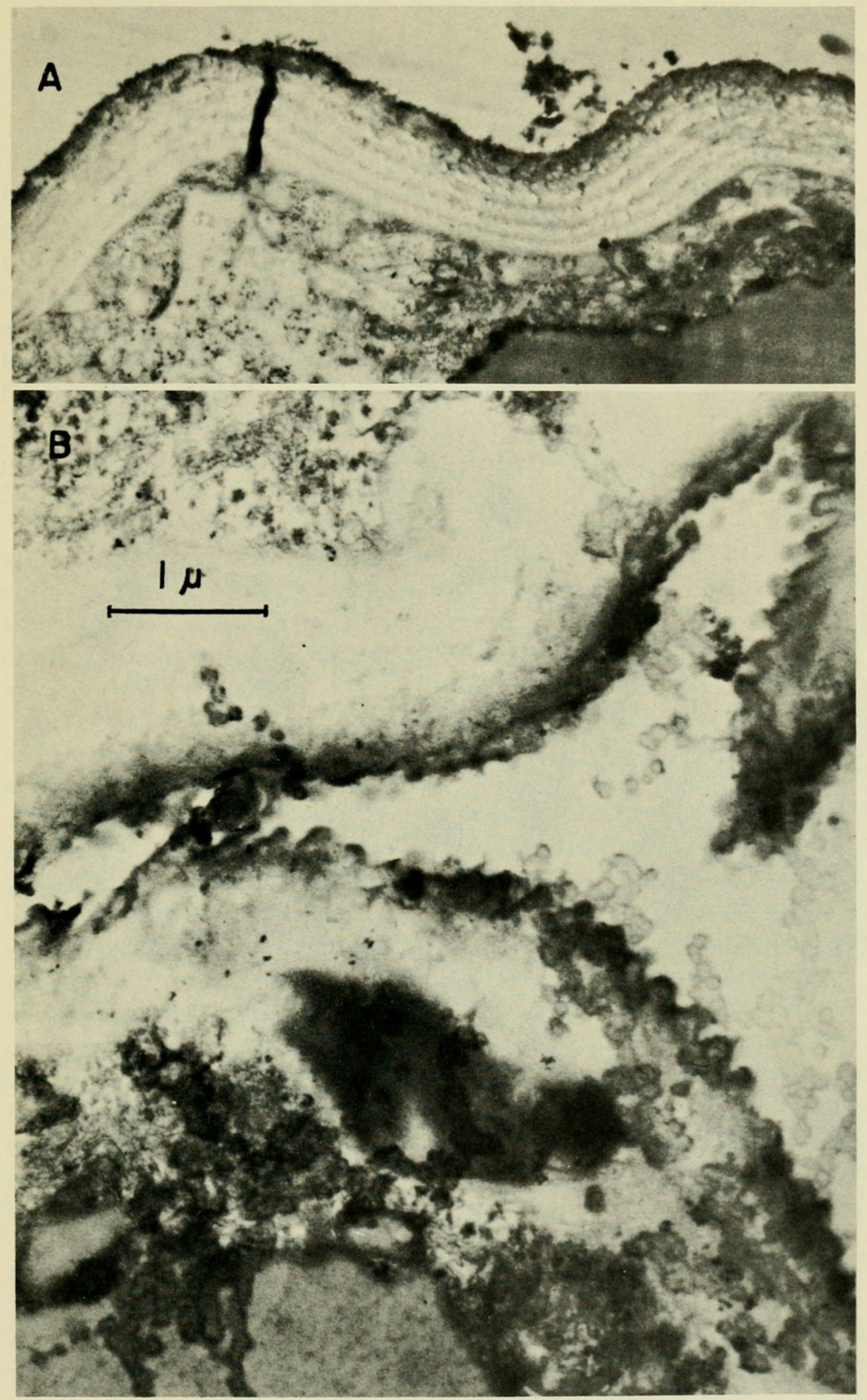

Figure 43.-Electron micrographs of Trypetesa lateralis male cuticle, 20,800x. $A$, region showing smooth, laminar cuticle; $B$, region showing rugose, peg-like surface. 


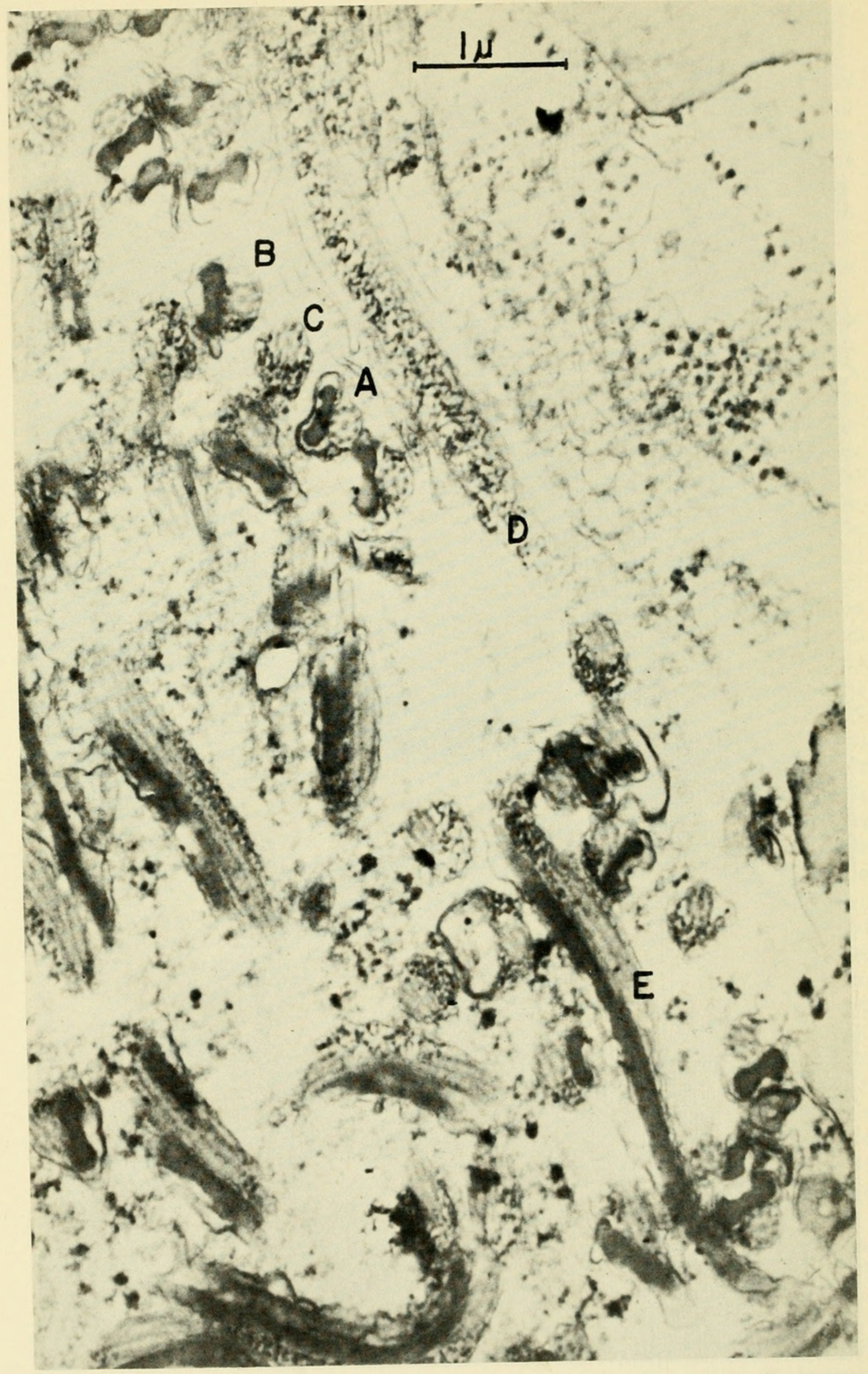

Figure 44.-Electron micrograph of $T$. lateralis male, showing sperm, 20,800x. $A-C$, cross sections corresponding to position in diagram in figure $45 ; D-E$, longitudinal sections of sperm through granular and dense areas corresponding to diagram in figure 45 . 


\section{Phylogeny}

The multiplicity of families in the order Acrothoracica appears to be a result of emphasis on different features which appeared at the time to be of major importance. I have retained these families up to the present writing for two reasons: they could be very nicely differentiated by the number of terminal cirri and caudal appendages, and I was optimistic that many new species of acrothoracicans would be found and new genera would be erected. For this reason, I erected the new family Utinomiidae. My hopes regarding the many new species seems to have been well founded, but these species have fit nicely into existing genera, and it now appears that the order is "top heavy" with families, most of which are monotypic.

I believe that we would be putting the systematics of the order in more realistic terms if we rejected most of these families, and retained only the three major extant groups represented by the Cryptophialidae, the Trypetesidae, and the Lithoglyptidae, the latter incorporating the old families Berndtiidae, Balanodytidae, Kochlorinidae, Utinomiidae, and Chytraeidae.

It is likely that the members of the fossil form-families Zapfellidae and Rogerellidae also would fit into the family Lithoglyptidae if the animals themselves were known.

Although there remains little need for the suborders Pygophora and Apygophora, when there are only three extant families to incorporate within them, they can be retained without problems. It seems obvious that the Trypetesidae, the sole family of the Apygophora, is more specialized and divergent than the two families in the Pygophora.

There are several clear trends in the order Acrothoracica, primarily in the direction of reduction of appendages and a simplification of organ systems. One specialization is in the loss of thoracic and caudal appendages, with a change from biramous to uniramous condition in the suborder Apygophora. The grouping of the thoracic cirri onto the end of the thorax seems to necessitate the adaptation of the first pair of cirri toward removal of food from these closely associated thoracic appendages. The members of this pair are called the "mouth cirri."

In thoracican barnacles the cirri are spaced far enough apart so that they move in relation to each other as the thorax is flexed and extended in a feeding motion. Thus food is passed along to the progressively smaller cirri near the mouth, to be seized by the mouthparts and ingested. The acrothoracicans, on the other hand, have most of their cirri bunched at the terminal end of the thorax, and hence movement in relation to one another is impossible, and food material cannot be transferred from one pair of cirri to another. They would, therefore, 
need a secondary pair of cirri near the mouth to remove the food material and transport it to the mouth. The intermediate step between typical thoracicans and the acrothoracicans is exemplified by the genus Ibla Leech 1825, which shows a slight separation between the first pair of cirri and the remaining pairs. Ibla also has reduced plates, a dioecious sexual condition with dwarfed males, and the placement of the adductor muscle posterior to the esophagus (fig. 40).

The most primitive family of the order Acrothoracica is the family Lithoglyptidae. The members of the genus Weltneria resemble the thoracicans in having biramous cirri, a mandibular palp, an anus, and two ventral ganglia, as well as the largest number of cirri (six
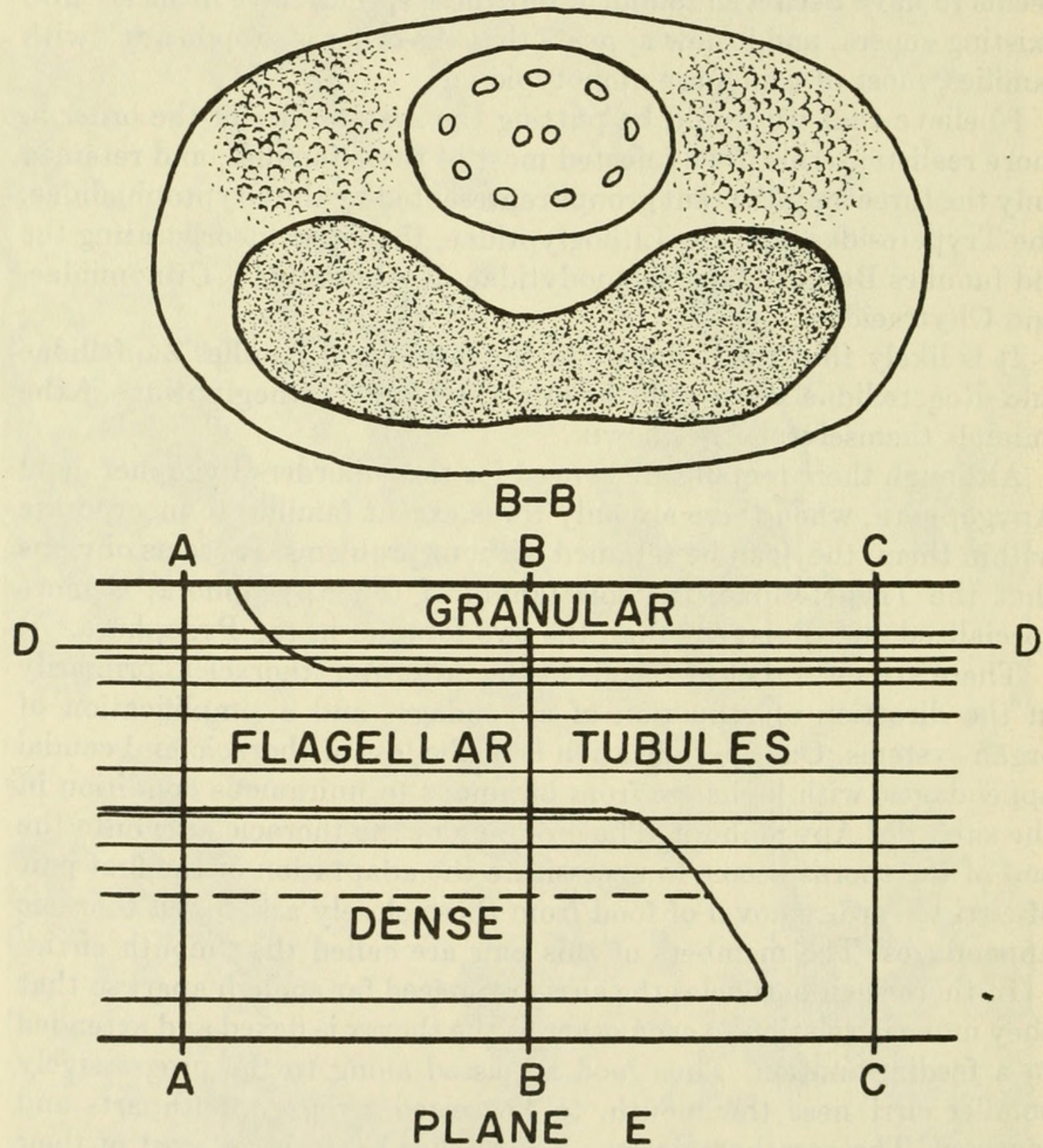

FIGURE 45.-Diagram of cross section and longitudinal section of sperm of T. lateralis. Letters correspond to cross section planes in figure 44 . The longitudinal diagram is in plane $E$ of figure 44 . 
pairs, as in the thoracicans), plus the caudal appendages. The number of pairs of biramous cirri are lost progressively in the genera Lithoglyptes (five pairs total) and Kochlorine (four pairs total) while a parallel series of genera without caudal appendages include Berndtia (six pairs total), and Balanodytes (five pairs total). There is no known genus with four pairs of biramous cirri without caudal appendages. I predict that such a genus will be found. The derivation of Balanodytes from Berndtia through the loss of a terminal cirrus is only a little more likely than deriving Balanodytes from Lithoglyptes through the loss of the caudal appendages. The latter is quite possible, however.

The Cryptophialidae have the mouth cirri reduced to mere vestiges, and a reduced number of cirri. They have a unique gizzard.

The Trypetesidae represent a marked divergence from the above families. They have uniramous cirri, no anus, and only one ventral ganglion. Their reduced appendages and lack of an anus leads to modified methods of feeding. Trypetesa lateralis males also lack a penis.

The marked reduction in cirrus number, nervous structure, and development of the male are seen to an even greater degree in the order Rhizocephala, and a possible close relationship is to be considered. 



\section{Literature Cited}

Aurivillius, C. W.S.

1892. Neue Cirripeden aus dem Atlantischen, Indischen und Stillen Ocean. Öf versigt af Kongl. Vet. Akad. Förh., Stockholm., vol. 49, no. 3, pp. 133-134.

1894. Studien über Cirripeden. K. Svenska Vetenskaps Akademien. Handl., Stockholm, ser. 4, vol. 26, no. 7, pp. 1-107.

Barnard, K. H.

1924. Contributions to the Crustacean fauna of South Africa. Ann. South African Museum, vol. 20, pt. 1, pp. 1-103.

1925. Report on a collection of Cirripedia (barnacles) from South African waters. Fish. Mar. Biol. Surv., Capetown, Rep. no. 4.

BARNes, H.

1962. The composition of the seminal plasma of Balanus balanus. Journ. Exp. Biol., vol. 39, pp. 345-351.

Bassindale, R.

1961. On the marine fauna of Ghana. Proc. Zool. Soc., London, vol. 137, no. 4 pp. $481-510$.

Batham, Elizabeth J.

1945. Description of female, male and larval forms of a tiny stalked barnacle, Ibla idiotica n. sp. Transactions Royal Soc. New Zealand, vol. 75, no. 3 , pp. $347-356$, pls. $26-28$.

Batham, E. J., and Tomlinson, J. T.

1965. On Cryptophialus melampygos Berndt, a small boring barnacle of the Order Acrothoracica abundant in some New Zealand molluses. Trans.

BERNDT, W. Roy. Soc. New Zealand, Zool., vol. 7, no. 9, pp. 141-154, 23 figs., 1 pl.

1903a. Zur Biologie und Anatomie von Alcippe lampas Hancock. Zeitschr. wissensch. Zool., vol. 74, pp. 396-457, pls. 19-22.

1903b. Die Anatomie von Cryptophialus striatus Berndt. Gesellsch. naturfor. Freunde, Berlin, Sitzungsber., vol. 1903, no. 10, pp. 436-444.

1907a. Studien an bohrenden Cirripedien (Ordnung Acrothoracica Gruvel, Abdominalia Darwin). I Teil: Die Cryptophialidae. Arch. Biontol., vol. 1, pp. 167-210.

1907b. Über das System der Acrothoracica. Arch. Naturg., Jahrg., vol. 73,

Blyth, Edward. no. 1 , pp. 287-289.

1844. Mr. Blyth's monthly report for December meeting, 1842. Appendix to Mr. Blyth's report. Journ. Asiatic Soc. Bengal, vol. 13, p. 384.

Boekschoten, G. J.

1966. Shell borings of sessile epibiontic organisms as palaeoecological guides (with examples from the Dutch coast). Palaeogeography,

BROCH, H. Palaeoclimatology, Palaeoecology, vol. 2, pp. 333-379.

1927. Cirripedia. Kükenthal's Handb. Zool., Berlin und Leipzig, W. De Gruyer and Co., vol. 3.

1931. Papers from Dr. Th. Mortensen's Pacific Expedition 1914-1916. LVI. Indomalayan Cirripedia. Vidensk. Medd. Dansk naturh. Foren., Bd. 91, pp. 1-146. 


\section{Burmeister, H.}

1834. Beiträge zur Naturgeschichte der Rankenfüsser. Berlin, G. Reimer. Calman, William T.

1909. Crustacea. Lankester's treatise on zoology. pt. 7, 3d fasc. London, A. and C. Black.

Charniaux-Cotton, Hélène.

1960. Sex determination. In Talbot H. Waterman, The physiology of Codez, Jean. Crustacea, vol. 1. Academic Press, New York and London, 670 pp.

1957. Études de Cirripèdes acrothoraciques fossiles: Diplôme d' Études supérieures, Poitiers. (not seen)

Codez, J. and de Saint-Seine, R.

1957. Révision des cirripèdes acrothoraciques fossiles. Bull. Soc. géol., France, ser. 6, vol. 7, pp. 699-719, pls. 37-39,

Collier, Albert; Ray, Sammy; and Wilson, W. B.

1956. Some effects of specific organic compounds on marine organisms. Science, vol. 124, pp. 220.

\section{Darwin, Charles.}

1854. A monograph on the sub-class Cirripedia. vol. 2., the Balanidae, the Verrucidae, etc. London, The Ray Society.

Genthe, K. W.

1905. Some notes on Alcippe lampas (Hanc.) and its occurrence on the American Atlantic shore. Zool. Jahrb., Abt. Anat., vol. 21, pp. 181-200.

Gerstaecker, A.

$1866-$

1879. Arthropoda. Bronn's Klassen und Ordnungen. Leipzig und HeidelGreen, James. berg, C. F. Winter, vol. 5, pp. 406-589.

1961. A biology of Crustacea. Quadrangle Books, Inc., Chicago. $180 \mathrm{pp}$. Gruvel, A.

1905. Monographie des Cirrhipèdes our Thécostracés. Paris, Masson and Cie. 472 pp.

HANCOCK, A.

1849. Notice of the occurrence on the British coast of a burrowing barnacle belonging to a new order of the class Cirripedia. Ann. Mag. Nat. Hist., vol. 4, no. 2, pp. 305-314, pls. 8-9.

Hardin, Garrett.

1960. The competitive exclusion principle. Science, vol. 131, pp. 12921297. $c f$. Science, vol. 132 , pp. 348-349; vol. 132 , pp. 1674-1676.

Henry, D. P., and McLaughlin, P.

1965. Unique occurrence of complemental males in a sessile barnacle. Nature, vol. 207, no. 5001, p. 1107.

Hiro, F.

1937. Occurrence of an acrothoracican barnacle in Japan. DobutsugakuZasshi (Zool. Mag.), vol. 49, pp. 135-136. (In Japanese.)

[Note: Hiro, F., later became Utinomi, H.]

Ноек, P. P. C.

1883. Report on the Cirripedia collected by H.M.S. Challenger, during the years 1873-1876. Systematic Part, Challenger Expedition, Report on Scientific Results, Zoology, vol. 8, no. 3, pp. 1-168. 
Joysey, K. A.

1959. Probable Cirripede, Phoronid, and Echiuroid burrows within a cretaceous echinoid test. Paleontology, vol. 1, no. 4, pp. 397-400.

KR ÜGER, P. pl. 70 .

1940. Cirripedia. Bronn's Klassen und Ordnungen d. Tierreichs. Leipzig, Akademische Verlags gesellschaft m.b.H., Bd. 5, Abt. 1, Buch 3, Teil III.

KüHNERT, L.

1934. Beitrag zur Entwicklungsgeschichte von Alcippe lampas Hancock.

Z. Morph. Ökol, vol. 29, pp. 45-78.

Leech, William.

1825. A tabular view of the genera composing the Class Cirripedes, with descriptions of the species of Otion, Cineras, and Clyptra. Zool. Journ., vol. 2, no. 6, pp. 208-215.

MäGdefrau, KarL.

1937. Lebensspuren fossiler "Bohr"-Organismen. Beitr. Naturk. Forsch. S.W.-Deutschland, vol. 2, pp. 53-67, pls. 4-6.

Murray, James A. H.

1893. A new English dictionary on historical principles. Vol. II, c.p.t. 1. C-COMM. Oxford.

Newell, N. B.

1942. Late Paleozoic pelecypods: Mytilacea. Kansas Geol. Surv., vol. 10, no. 2 , pp. $1-115,15$ pls.

Nilsson-Cantell, C. A.

1921. Cirripeden-Studien. Zool. Bidr. Uppsala. vol. 7, pp. 98-99, 120-126. Noll, F. C.

1872a. Mittheilung von Dr. F. C. Noll. Bericht über die Senckenbergische naturf. Gesellsch., 1871-1872, vol. 3, pp. 21-26.

1872 b. Kochlorine hamata N., ein bohrender Cirripede. Bericht über die Senckenbergische naturf. Gesellsch., vol. 4, pp. 50-58.

1875. Kochlorine hamata N., ein bohrendes Cirriped. Zeitschr. wissens. Zool. Anz., vol. 25, pp. 114-128, pl. 6.

1883. Kochlorine bihamata, zur Verbreitung von Kochlorine. Zool. Anz., vol. 6 , pp. $471-472$.

Norman, A. M.

1903. New generic names for some Entomostraca and Cirripedia. Ann. Nat. Hist., vol. 11 , no. 7 , pp. 367-369.

Nussbaum, M.

1890. Anatomische Studien an Californischen Cirripedien. 97 pp. 12 pls. Max Cohen \& Sohn (Fr. Cohen), Bonn.

Radwakski, A.

1964. Boring animals in Miocene littoral environments of Southern Poland. Bulletin De L'Académie Polonaise Des Sciences. Série des sci. géol. et géogr, vol. XII, no. 1, pp. 57-62, pls. 1-6 (especially p. 61 and pl. 6).

Rodda, P. U., and Fisher, W. L.

1962. Upper Paleozoic acrothoracic barnacles from Texas. The Texas Journ.

Ross, Arnold. Sci. vol. XIV, no. 4, pp. 460-479.

1965. Acrothoracican barnacle burrows from the Florida Miocene. Crustaceana, vol. 9, no. 3, pp. 317-318, pl. 23. 


\section{Saint-Seine, Roseline De.}

1951. Un Cirripède acrothoracique du Crètacè: Rogerella lecointrei, n.g., n.sp. C.R. Acad. Sci., Paris, vol. 233, no. 18, pp. 1051-1053.

1954. Existence de Cirripèdes acrothoraciques dès le Lias: Zapfella pattei, nov. gen., nov. sp. Bull. Soc. Géol. France, 6th series, vol. 4, no. 4/6, pp. 447-451.

1955a. Les Cirripèdes acrothoraciques Echinocoles. Bull. Soc. Géol. France, 6th series, vol. 5, no. 4/6, pp. 299-303, 2 pls. 16-17.

1955b. Présence de Cirripédes acrothoraciques dans le Jurassique supérieur de l'Ouest. Compt. Rend. Soc. Géol. France, vol. 1955, no. 7/8, pp. 131-132.

1956. Existence d'une fente pédonculaire chez l'Acrothoracique Rogerella mathieui Saint-Seine. C.R. somm. Soc. Géologique France, no. 6, séance du 19 mars 1956, p. 78.

SchlaudT, C. M., and Young, K.

1960. Acrothoracic barnacles from the Texas Permian and Cretaceous. Journ. Paleo., vol. 34, no. 5, pp. 903-907, pls. 119-120, 3 text-figs.

Seilacher, Adolf.

1968. Swimming habits of Belemnites-recorded by boring barnacles. Palaeogeography, Palaeoclimatology, Palaeoecology, vol. 4, no. 4, pp. 279-285.

In press. Paleoecology of boring barnacles. American Zoologist.

SмIтн, R. I.

1960. Review of "The Physiology of Crustacea," volume 1. Talbot H. Waterman, Ed. Academic Press, N.Y., in Science, vol. 132, pp. 888889.

Stebbing, T. R. R.

1910. General catalogue of South African Crustacea. Ann. South African Mus., vol. 6, pt. 4, pp. 575-576, pls. 15-22.

Stephensen, K.

1938. Cirripedia. The Zoology of Iceland, vol. 3, pp. 30-31. Strand, E.

1928. Miscellanea nomenclatorica zoologica et palaeontologica, I-II. Arch. Naturg., vol. $92 \mathrm{~A}$, no. 8 , pp. 40-41.

Stubbings, H. G.

1961. Cirripedia: Campagne de la Calypso dans le Golfe de Guinée et aux îles Principe, São Tomé, Annobon (1956). Ann. Inst. Océan., vol. 39, pp. 179-192.

1964. Cirripedia from the Congo Estuary and adjacent coasts in the Musée Royal de l'Afrique Centrale, Tervuren, Belgium. Rev. Zool. Bot. Afrique, vol. 69, pp. 327-347.

1967. The cirriped fauna of tropical West Africa. Bull. Brit. Mus. (Nat. Hist.), Zool., vol. 15, no. 6, pp. 227-319, plate 1 (esp. pp. 301-306 and pl. 1.).

TAYLOR, BRIAN J.

1965. Aptian cirripedes from Alexander Island. Brit. Antarctic Surv. Bull., no. 7, pp. 37-42.

Tomuinson, J. T.

1953. A burrowing barnacle of the genus Trypetesa (Order Acrothoracica). Journ. Washington Acad. Sci., vol. 43, no. 11, pp. 373-381.

1955. The morphology of an acrothoracican barnacle Trypetesa lateralis. Journ. Morphol., vol. 96, no. 1, pp. 97-114, pls. 1-4. 
1960a. Cryptophialus coronatus, a new species of acrothoracican barnacle from Dakar. Bull. de l'Institut Francais d'Afrique Noire, vol. 22A, no. 2 , pp. 402-410.

1960b. Low hermit crab migration rates. The Veliger, vol. 2, no. 3, p. 61.

1963a. Acrothoracican barnacles in Paleozoic myalinids. Journ. Paleo., vol. 37 , no. 1 , pp. 164-166, pl. 23.

1963b. Lithoglyptes hirsutus (Cirripedia: Acrothoracica), a new burrowing barnacle from Hawaii. Pacific Sci., vol. XVII, no. 3, pp. 299-301.

1963c. Two new acrothoracican cirripeds from Japan. Publ. Seto Mar. Biol. Lab., vol. XI, no. 2, pp. 263-280.

1966. The advantages of hermaphroditism and parthenogenesis. J. Theoret. Biol., vol. 11, pp. 54-58.

1967. Berndtia nodosa sp. nov. (Cirripedia, Acrothoracica) a new burrowing barnacle from Singapore. Bull. Nat. Mus. Singapore, no. 33, part 15, pp. 101-105.

In press. Shell-burrowing barnacles. American Zoologist.

Tombinson, J. T., and Newman, Wm. A.

1960. Lithoglyptes spinatus, a burrowing barnacle from Jamaica. Proc. U.S.N.M., vol. 112 , no. 3445 , pp. 517-526.

TURQUIER, Yves.

1967a. Description d'un nouveau Trypetesa Norman (Alcippe Hancock), Cirripède Acrothoracique des côtes françaises de la Manche. Cahiers De Biologie Marine, tome VIII, pp. 75-87.

1967b. Le dèveloppement larvaire de Trypetesa nassarioides Turquier, cirripède acrothoracique. Arch. de zool. exp. et gén., vol. 108, no. 1 , pp. 33-47.

1967c. L'embryogenèse de Trypetesa nassarioides Turquier (cirripède, acrothoracique) Ses rapports avec celle des autres cirripèdes. Arch. de zool. exp. et gén., vol. 108, no. 1, pp. 111-137.

1968. Recherches sur la biologie des Cirripèdes Acrothoraciques. I. L'anhydrase carbonique et le mécanisme de perforation du substrat per Trypetesa nassarioides Turquier. Arch. de zool. exp. et gén., vol. 109, no. 1, pp. 113-122.

Utinomi, H.

1950a. A new remarkable coral-boring acrothoracican cirriped. Mem. Coll. Sci., Univ. Kyoto, ser. B. vol. 19, no. 3, art. 18, pp. 83-89.

1950b. On another form of Acrothoracica, newly found from Formosa. Mem. Coll. Sci., Univ. Kyoto., ser. B. vol. 19, no. 3, art. 19, pp. 91-96.

1950c. General account of Acrothoracica. In Prof. Nakamura's "Some problems of Modern Biology." (In Japanese), Kyoto.

1957. Studies on the Cirripedia Acrothoracica. I. Biology and External Morphology of the Female of Berndtia purpurea Utinomi. Publ. Seto Mar. Biol. Lab., vol. VI, no. 1, pp. 1-26, 2 pls.

1960. Studies on the Cirripedia Acrothoracica. II. Internal Anatomy of the Female of Berndtia purpurea Utinomi. Publ. Seto Mar. Biol. Lab. vol. VIII, no. 2, pp. 223-279, pls. 31-33.

1961. Studies on the Cirripedia Acrothoracica. III. Development of the Female and Male of Berndtia purpurea Utinomi. Publ. Seto Mar. Biol. Lab., vol. IX, no. 2, pp. 413-446.

1962. Occurrence of a Trypetesa in Japan. (In Japanese) Zool. Mag. (Dobutsugaku Zasshi), vol. 71, no. 1-12, pp. 399. 
1963. Studies on the Cirripedia Acrothoracica. IV, Morphology of the female of Balanodytes taiwanus Utinomi. Publ. Seto Mar. Biol. Lab., vol. XI, no. 1, pp. 57-73, pl. 1 .

1964. Studies on the Cirripedia Acrothoracica. V, Morphology of Trypetesa habei Utinomi. Publ. Seto Mar. Biol. Lab., vol. XII, no. 2, pp. 117132 pls. 2,3,4.

1967. Re-examination of Lithoglyptes indicus sensu Broch (Cirripedia, Acrothoracica). Crustaceana, vol. 12, part 3, p. 320.

UTinomi, H., and KIKUCHI, T.

1966. Fauna and flora of the sea around the Amakusa Marine Biological Laboratory, Part VI. Cirriped Crustacea. Amakusa Mar. Biol. Lab., Kyushu University.

Wells, H. W., and Tombinson, J. T.

1966. A new burrowing barnacle from the Western Atlantic. Quarterly Journ. Florida Acad. Sci., vol. 29, no. 1, pp. 27-37.

WELTNER, W.

1897. Verzeichnis der bisher beschriebenen recenten Cirripedienarten. Archiv. für Naturg., Berlin, vol. 63, pp. 227-280.

Yanagimachi, Ryuzo.

1961a. Studies on the sexual organization of the Rhizocephala. III. The mode of sex-determination of Peltogasterella. Biol. Bull., vol. 120, no. 2, pp. 272-283.

1961b. The life-cycle of Peltogasterella (Cirripedia Rhizocephala). Crustaceana, vol. 2 , no. 3, pp. 183-186.

Yanagimachi, Ryuzo, and Fujimaki, Noboru.

1967. Studies on the sexual organization of the Rhizocephala. IV. On the nature of the "testis" of Thompsonia. Annotationes Zoologicae Japonenses, vol. 40, no. 2, pp. 98-104.

ZAPFE, $\mathrm{H}$.

1936. Spuren bohrender Cirripedier in Gastropoden-Gehäusen des Miozäns.

Senckenbergiana, vol. 18, pp. 130-134. 


\section{$2 \mathrm{BHL}$ Biodiversity Heritage Library}

Tomlinson, Jack T. 1969. "The burrowing barnacles (Cirripedia, order Acrothoracica)." Bulletin 296, 1-162.

View This Item Online: https://www.biodiversitylibrary.org/item/33341

Permalink: https://www.biodiversitylibrary.org/partpdf/70807

\section{Holding Institution}

Smithsonian Libraries

\section{Sponsored by}

Smithsonian

\section{Copyright \& Reuse}

Copyright Status: NOT_IN_COPYRIGHT

This document was created from content at the Biodiversity Heritage Library, the world's largest open access digital library for biodiversity literature and archives. Visit BHL at https://www.biodiversitylibrary.org. 